UNIVERSIDADE DE SÃO PAULO

FACULDADE DE ECONOMIA, ADMINISTRAÇÃO E CONTABILIDADE DEPARTAMENTO DE ECONOMIA PROGRAMA DE PÓS-GRADUAÇÃO EM ECONOMIA

A ARMADILHA DO SUBDESENVOLVIMENTO: UMA DISCUSSÃO DO PERÍODO DESENVOLVIMENTISTA BRASILEIRO SOB A ÓTICA DA ABORDAGEM DA COMPLEXIDADE

Fernanda Graziella Cardoso

Orientador: Prof. Dr. Gilberto Tadeu Lima

SÃO PAULO 
Prof. Dr. João Grandino Rodas

Reitor da Universidade de São Paulo

Prof. Dr. Reinaldo Guerreiro

Diretor da Faculdade de Economia, Administração e Contabilidade

Prof $^{a}$. Dra ${ }^{\mathrm{a}}$. Elizabeth Maria Mercier Querido Farina

Chefe do Departamento de Economia

Prof. Dr. Pedro Garcia Duarte

Coordenador do Programa de Pós-Graduação em Economia 


\section{A ARMADILHA DO SUBDESENVOLVIMENTO: UMA DISCUSSÃO DO PERÍODO DESENVOLVIMENTISTA BRASILEIRO SOB A ÓTICA DA ABORDAGEM DA COMPLEXIDADE}

Tese apresentada ao Programa de PósGraduação em Economia da Faculdade de Economia, Administração e Contabilidade da Universidade de São Paulo, para obtenção do título de Doutor em Ciências.

Orientador: Prof. Dr. Gilberto Tadeu Lima

\section{Versão Corrigida}

(versão original disponível na Faculdade de Economia, Administração e Contabilidade)

\section{SÃO PAULO}


FICHA CATALOGRÁFICA

Elaborada pela Seção de Processamento Técnico do SBD/FEA/USP

Cardoso, Fernanda Graziella

A armadilha do subdesenvolvimento: uma discussão do período desenvolvimentista brasileiro sob a ótica da Abordagem da Complexidade / Fernanda Graziella Cardoso. -- São Paulo, 2012.

$250 \mathrm{p}$.

Tese (Doutorado) - Universidade de São Paulo, 2012.

Orientador: Gilberto Tadeu de Lima.

1. Desenvolvimento econômico 2. Subdesenvolvimento 3. Complexidade

I. Universidade de São Paulo. Faculdade de Economia, Administração e Contabilidade II. Título.

$\mathrm{CDD}-338.9$ 
Aos professores que participaram da minha formação escolar e acadêmica, e aos meus futuros alunos. 


\section{AGRADECIMENTOS}

Agradeço ao Cnpq e à FAPESP por terem me financiado por boa parte do período.

Agradeço a todos os funcionários que compõem a FEA-USP, cuja boa convivência por tantos anos no local onde trilhei a maior parte da minha trajetória acadêmica, foi fundamental para a formação de um adequado ambiente de trabalho.

Agradeço aos amigos de pós-graduação, em especial: a Ana Giuberti e Marisa Amaral, amigas que foram para mim fonte constante de conhecimento e de alegrias; a Cristina Reis e Gustavo Barros, por suas contribuições diretas e indiretas para a composição dessa tese; e à memória da querida Veridiana Ramos Carvalho, com quem tive o privilégio de conviver por poucos anos, suficientes para lhe dedicar minha eterna admiração.

Agradeço aos professores José Flávio Motta, Renato Perim Colistete e José Francisco Lima Gonçalves por terem me concedido a oportunidade de atuar como monitora de suas disciplinas, e por terem feito da monitoria uma experiência enriquecedora, concedendo-me ampla liberdade de atuação.

Agradeço aos professores que participaram de minha banca de qualificação, o professor Eleutério Fernando da Silva Prado e novamente o professor Renato Perim Colistete. As sugestões e críticas apresentadas foram fundamentais para a trajetória da pesquisa.

Agradeço aos meus colegas da Câmara Municipal de São Paulo, em especial ao meu chefe Gilberto Hashimoto e à minha supervisora Regina Kimachi, sem cujo suporte a consecução desse trabalho teria sido muito dificultada.

Agradeço aos meus demais amigos e familiares, que entenderam a minha ausência e indisponibilidade quase constante no período de elaboração dessa tese. Em especial, agradeço ao meu pai Antonio, à minha mãe Graciete e à minha prima Arley, pelo amor e carinho; e aos meus queridos Alexandre Henrique Cardoso e Renata Rodrigues Gimenez, pela presença, apoio e paciência constantes.

Por fim, agradeço ao meu orientador Gilberto Tadeu Lima, a quem sempre me faltarão palavras para agradecer por tudo o que significou e significa na minha trajetória acadêmica, desde a minha graduação. No que se refere a esse trabalho, agradeço especialmente pelo seu apoio constante, pelos seus incentivos e pela confiança a mim dispensada. 
"Para evitar esse dilema entre atitudes antisociais, conscientes ou inconscientes, de parte dos economistas com responsabilidade na política econômica, é mister que alcancemos um mais alto grau de independência no plano das formulações teóricas. É necessário que realizemos um esforço continuado no sentido de enriquecer e vivificar as teorias econômicas que nos chegam e mesmo no reformulá-las, toda vez que as hipóteses convencionais não possuam o poder explicativo necessário para abarcar a realidade sobre a qual devemos atuar." Celso Furtado 


\section{RESUMO}

Essa tese apresenta como investigação norteadora porque o Brasil, mesmo tendo avançado em sua matriz industrial e alcançado altas taxas de crescimento no período 1930-1980, não conseguiu escapar da armadilha do subdesenvolvimento econômico. Para tentar vislumbrar alguns caminhos que potencialmente alargariam a discussão e compreensão do tema, recorrese à perspectiva da Abordagem da Complexidade, combinada com a retomada das discussões teóricas promovidas por alguns dos autores conhecidos como pioneiros do desenvolvimento econômico. Desse modo, a novidade proposta por essa tese reside na perspectiva pela qual se discute o tema, e não ao tema propriamente dito, que foi e vem sendo amplamente discutido pela literatura. $\mathrm{O}$ objetivo é a realização de algumas discussões e ilações teóricas relativas à experiência brasileira no período, tendo sempre em mente a Abordagem da Complexidade e sua potencial contribuição para o alargamento do escopo de compreensão do tema. 


\begin{abstract}
This thesis presents as main question why Brazil, even having developed its industrial park and having achieved high rates of growth between 1930 and 1980, was unable to escape from the trap of economic underdevelopment. In order to list some ways that could potentially enrich the thinking and the understanding of the question, this inquiry is based on the perspective of Complexity thinking combined with the resumption of theoretical contributions of some authors known as economic development pioneers. Thus, the core of this thesis lies in the perspective by which accomplishes the theme discussion, not in the theme itself, which was and is being widely discussed by the literature. The aim is the achievement of some theoretical considerations and discussions about Brazilian experience in the period, always keeping in mind the Complexity thinking and its potential contribution to broaden the theme comprehension.
\end{abstract}




\section{SUMÁRIO}

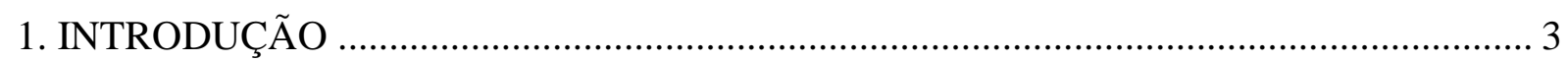

PARTE I: DISCUSSÕES TEÓRICAS E METODOLÓGICAS

2. DESENVOLVIMENTO E COMPLEXIDADE ..................................................... 13

2.1. Desenvolvimento Econômico: delimitação temática e definiçãa .................................................. 13

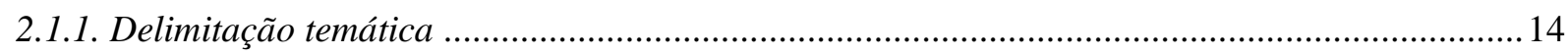

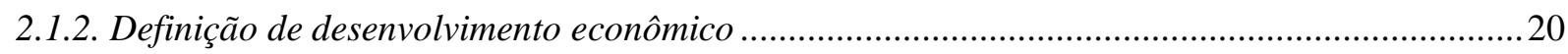

2.2. Algumas implicações da Abordagem da Complexidade à discussão do tema Desenvolvimento

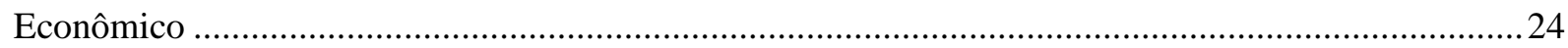

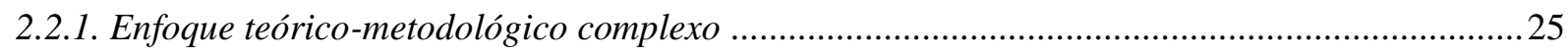

2.2.2. Algumas implicações da Abordagem da Complexidade à discussão de desenvolvimento ........... 34

2.2.3. Alguns caminhos abertos pela Abordagem da Complexidade para a discussão da emergência e

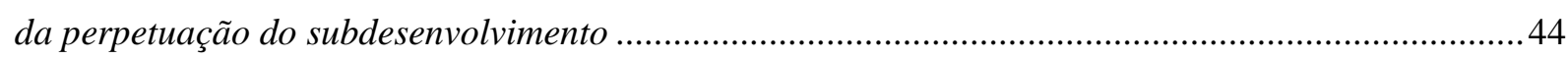

3. OS PIONEIROS DO DESENVOLVIMENTO ECONÔMICO I: UM OLHAR SOBRE O

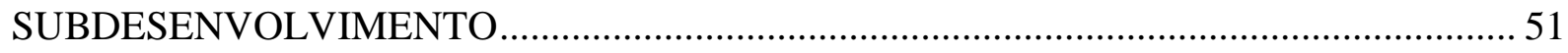

3.1. Paul Narcyz Rosenstein-Rodan: a Teoria do Grande Impulso ...................................................52

3.2. Hans Wolfgang Singer: tese Singer-Prebisch e a distribuição desigual de ganhos entre as nações

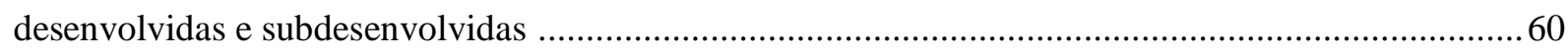

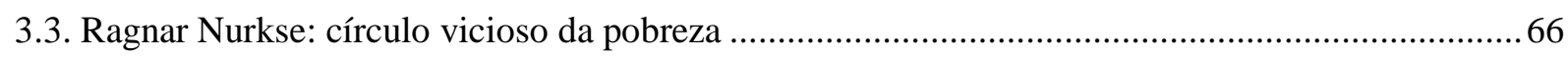

3.4. William Arthur Lewis: oferta ilimitada de mão-de-obra e dualidade estrutural.............................. 73

3.5. Albert Otto Hirschman: efeitos de encadeamento para frente e para trás e o caráter desequilibrado

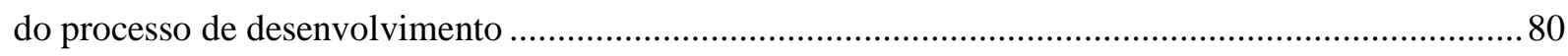

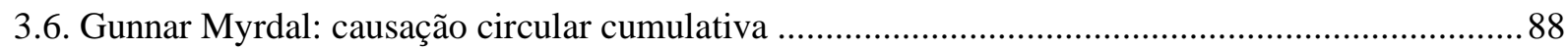

3.7. Michal Kalecki: problemas cruciais do subdesenvolvimento ......................................................94

4. OS PIONEIROS DO DESENVOLVIMENTO ECONÔMICO II: A CONTRIBUIÇÃO

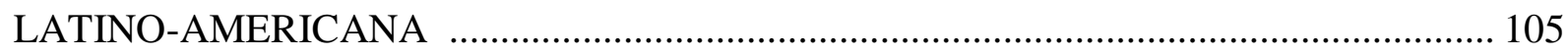

4.1. Raúl Prebisch: tese Singer-Prebisch e a dinâmica centro-periferia 
4.2. Celso Furtado: o capitalismo periférico

PARTE II: A EMERGÊNCIA DO SUBDESENVOLVIMENTO ECONÔMICO BRASILEIRO: DISCUTINDO O PERÍODO DESENVOLVIMENTISTA SOB A ÓTICA DA ABORDAGEM DA COMPLEXIDADE

\section{A COMPLEXIDADE EM CELSO FURTADO: DISCUSSÕES SOBRE O CASO}

BRASILEIRO

5.1. A complexidade do evolver histórico: algumas considerações sobre o papel dos historiadores ..138

5.2. Um breve panorama da historiografia econômica brasileira 142

5.3. A perspectiva complexa de Furtado sobre o caso brasileiro 147

5.3.1. Do período colonial até 1930: breves considerações sobre as raízes da formação econômica e social brasileira 149

5.3.2. De 1930 a 1945: a internalização do centro dinâmico e a industrialização não intencionada 157

5.3.3. Do pós-guerra à década de 1950: consolidação da base industrial. 161

5.3.4. Década de 1960: crise, golpe, reestruturação e milagre 170

5.3.5. Década de 1970: o Brasil pós-milagre, II PND e a crise da dívida 181

6. SUBDESENVOLVIMENTO ECONÔMICO BRASILEIRO NO PERÍODO 1930-1980: UMA DISCUSSÃO BASEADA NA ABORDAGEM DA COMPLEXIDADE 189

6.1. O retorno dos pioneiros: discutindo alguns aspectos da emergência e da perpetuação do subdesenvolvimento econômico brasileiro no período 1930-1980 190

6.2. Alguns caminhos abertos pela Abordagem da Complexidade para a discussão da emergência e da perpetuação do subdesenvolvimento econômico brasileiro no período 1930-1980 .228 


\section{INTRODUÇÃO}

Desde sua composição, o sistema econômico-político mundial sempre foi caracterizado por um ordenamento, em termos de riqueza acumulada e de desenvolvimento econômico, relativamente bem definido: por um lado, o grupo composto por algumas poucas nações líderes e, por outro, um grande grupo (bastante heterogêneo) de nações seguidoras. A origem remonta à constituição dos primeiros Estados europeus no século $\mathrm{XV}$, e a subsequente expansão do seu sistema de organização para o Novo Mundo. Em princípio, essa hierarquia a qual já foi denominada pela literatura de variadas formas, como Norte e Sul, primeiro e terceiro mundos, centro e periferia, países avançados e atrasados, países desenvolvidos e subdesenvolvidos, países desenvolvidos e em desenvolvimento - era mais explícita, sob a forma direta de dominação econômica, territorial e militar das metrópoles sobre suas colônias.

Posteriormente, acompanhando a própria evolução do sistema capitalista - em especial, após a Revolução Industrial -, a reprodução da hierarquia se mostrou em novos termos: sob a égide do liberalismo econômico e da teoria das vantagens comparativas, as nações que então lideravam o processo acumulativo se valeram dos benefícios da divisão internacional do trabalho, deixando a cargo das antigas colônias a produção de matériasprimas e insumos básicos. Viram nesses territórios também potenciais mercados consumidores e receptores de capitais já ociosos no Velho Mundo.

Principalmente após a crise de 1929, parte dessas antigas colônias se deu conta de que as possibilidades de sustentação do crescimento do modelo primário-exportador haviam se esgotado. Delimitando essa generalização especialmente ao contexto latino-americano, observou-se um movimento de inflexão ${ }^{1}$ relativamente às políticas econômicas que até então vinham sendo adotadas: algumas das economias latino-americanas se voltaram para dentro e elegeram a modernização e o desenvolvimento industrial como saída e necessidade estratégica primordial. Até a década de 1970, sob o processo substitutivo de importações, boa parte dos latino-americanos - dentre eles, o Brasil - avançou consideravelmente no desenvolvimento da sua matriz industrial e alcançou bons resultados em termos de crescimento econômico.

No entanto, o relativo sucesso desse modelo de desenvolvimento também acabaria ${ }^{2}$.

\footnotetext{
${ }^{1}$ A natureza, o grau e as consequências para o Brasil dessa mudança de atuação constitui objeto de análise do presente trabalho. Essa delimitação e conceituação de ponto de inflexão se encontram explicadas em Furtado (1954a, 1959) e são discutidas no capítulo 5.

${ }^{2}$ A discussão dos motivos, no caso brasileiro, é realizada nos capítulos 5 e 6.
} 
Com uma nova crise econômica de alcance mundial no fim da década de 1970, em decorrência especialmente dos dois choques do petróleo e do aumento dos juros do dólar, aquela que talvez fosse a maior fragilidade das economias que estavam mais mal colocadas na hierarquia da acumulação e do desenvolvimento, a dependência de recursos financeiros externos, veio à tona na forma de uma enorme dívida externa, impagável para boa parte dos países, incluindo o Brasil.

Adentramos a década de $1980^{3}$, a partir da qual pode ser indicado um segundo ponto de inflexão na postura dos países que não haviam alcançado a condição de desenvolvimento econômico: o Estado, que até então agia ativamente na condução de políticas econômicas de outras naturezas que não somente a monetária, passa a perder seu espaço para a suposta eficiência privada. Retornamos ao liberalismo econômico do século XIX, agora sob a alcunha de neoliberalismo, ${ }^{4}$ e as políticas de orientação desenvolvimentista ${ }^{5}$ foram engavetadas.

Consigo, as políticas neoliberais traziam a promessa de que, no fim, as diferenças de padrão de vida entre os países seriam, ao menos, amenizadas. Para tal, só seria necessário retirar todos os entraves e obstáculos que impediam o bom funcionamento dos mecanismos de mercado, os quais, por pressuposto, seriam altamente eficientes. Se a receita fosse seguida à risca, a hierarquia característica do sistema econômico-político mundial seria substituída pela convergência: todas as nações, ao se integrarem devidamente ao sistema capitalista mundial, tenderiam a obter o mesmo padrão de vida dos países que já haviam alcançado a condição de desenvolvidos.

Partindo da ideia de que para ao menos haver chance de uma estratégia de desenvolvimento ser bem-sucedida, as especificidades econômicas, sociais e culturais dos

\footnotetext{
${ }^{3}$ As décadas de 1980, 1990 e os anos 2000 não são objeto de análise dessa tese. Logo, o chamado neodesenvolvimentismo, no qual estão incluídos autores como Ha-Joon Chang, não são objeto de investigação do presente trabalho, mas sim fontes potenciais de insights que se coadunem com o objetivo de discutir o subdesenvolvimento sob a ótica da Abordagem da Complexidade.

${ }^{4}$ Prado (2009) observa que a visão neoliberal de Estado não corresponderia à visão de Estado Mínimo, e sim de Estado Pró-Ativo. Sob o neoliberalismo, "[...] o Estado deve fomentar o livre-mercado combatendo todos os entraves que se apresentem ao seu desenvolvimento, pois vem a ser a herança mais valiosa da época moderna." (PRADO, 2009, p. 154).

${ }^{5}$ Consideram-se aqui como aquelas políticas que privilegiam o desenvolvimento interno da matriz produtiva naquele contexto, especialmente a industrial - e/ou das atividades com grande capacidade indutiva e multiplicadora interna da renda, que geram efeitos de encadeamento (HIRSCHMAN, 1958) e retroalimentação por outros setores e atividades, provocando transformações por toda a economia, no sentido de aumentar a sua autossuficiência produtiva e, por conseguinte, de diminuir a sua dependência com relação aos bens importados. É interessante notar, conforme ficará mais claro quando da discussão dos pioneiros do desenvolvimento econômico nos capítulos 3 e 4, que os efeitos de encadeamento remetem a uma propriedade típica da Abordagem da Complexidade, o que inclusive justifica, em boa medida, a escolha desses autores para compor a base teórica do presente trabalho. No entanto, dessa observação não se deriva necessariamente que as políticas econômicas de cunho desenvolvimentista sejam as mais adequadas ou as únicas derivadas a partir de uma perspectiva baseada na Abordagem da Complexidade, tratando-se essa de uma questão a ser aqui abordada.
} 
países onde são implementadas devem ser levadas em conta, essa tese se debruça especificamente sobre o caso brasileiro, tendo como foco o período que se estende desde o início década de 1930 - o marco do primeiro ponto de inflexão supracitado - até o início da década de 1980 - o marco do segundo ponto de inflexão exposto acima -, período, que, para parte da literatura, se caracteriza pelo processo substitutivo de importações e por políticas de cunho desenvolvimentista, com ampla e importante atuação do Estado brasileiro, como planejador e agente econômico propriamente dito.

Para a realização dessa investigação, recorre-se, em todo o trabalho, à ótica teórica e metodológica da Abordagem da Complexidade. Considera-se que uma compreensão e um tratamento teórico adequado do caráter dinâmico, complexo e adaptativo do sistema econômico podem ser promissores à sugestão de caminhos para a elaboração de políticas de crescimento e desenvolvimento eficazes; ademais, para promovê-las, far-se-ia necessário entender as especificidades da formação econômica e social da nação em que se pretende aplicá-las, sendo as próprias nações sistemas adaptativos complexos. São duas frentes de críticas aparentemente distintas, porém ambas seriam contempláveis pelo arcabouço teórico da Abordagem da Complexidade, e sua combinação mostrar-se-ia potencialmente frutífera para o avanço da compreensão de casos específicos, tal como o caso de subdesenvolvimento econômico brasileiro, no período 1930-1980.

O desenvolvimento, bem como o não desenvolvimento ou o subdesenvolvimento, resulta da composição e conjugação de diversos fatores e elementos, que vão desde o nível decisório dos agentes que compõem determinada economia, até o sistema político-econômico mundial propriamente dito, perpassando ainda questões institucionais, sociais, culturais, políticas, ambientais e tecnológicas. É um fenômeno (ou processo) complexo, cuja compreensão global, necessariamente, extrapola o escopo da Economia. Porém, mesmo se restringindo à discussão do tema ao escopo econômico - tratando-se, portanto, de uma discussão por natureza incompleta -, o tema requer um aporte teórico-metodológico que permita lidar com a riqueza de elementos e propriedades que lhe envolvem.

Retomando a discussão que realizei em minha dissertação de mestrado, sugere-se que esse aporte teórico-metodológico deveria satisfazer, em alguma medida, ao menos as seguintes características: (i) uma microfundamentação adequada a sistemas complexos; (ii) mecanismos que fundamentem a interação entre os agentes; (iii) mecanismos que expliquem como transcorre a passagem do que ocorre no campo "micro" para o que ocorre no campo "macro"; (iv) mecanismos que expliquem as relações de feedback entre a micro e a macroeconomia; e que possua, portanto, (v) um enfoque dinâmico, não-linear e não- 
determinista. $^{6}$ Naquele contexto, o objetivo era elencar alguns elementos teóricos para a integração analítica da micro e da macroeconomia a partir da investigação de alguns autores ${ }^{7}$ e da própria literatura da Abordagem da Complexidade, sendo que a contribuição selecionada desses autores também se mostrava compatível com a perspectiva da Abordagem da Complexidade aplicada à Economia.

No atual trabalho, estende-se essa consideração mais geral da Abordagem da Complexidade a respeito do funcionamento do sistema econômico à discussão da temática do Desenvolvimento Econômico. Para tal, mostram-se interessantes outras considerações teóricas além daquelas relacionadas à Abordagem da Complexidade ou à integração analítica da micro e da macroeconomia, para a identificação das quais parece agregar a investigação da contribuição dos pioneiros do desenvolvimento econômico, sendo os escolhidos para compor a base teórica dessa tese: Albert Hirschman, Arthur Lewis, Celso Furtado, Gunnar Myrdal, Hans Singer, Michal Kalecki, Paul Rosenstein-Rodan, Ragnar Nurkse e Raúl Prebisch. ${ }^{8}$ Esses autores, além de outros, compuseram a base teórica do que passou a ser denominada, no pós II Guerra Mundial, de Economia do Desenvolvimento.

Assim como fez originalmente Foley (2003) com os economistas clássicos, a construção de alguns paralelos teóricos entre os pioneiros do desenvolvimento e a Abordagem da Complexidade é um exercício anacrônico, na medida em que esses autores escreveram antes da emergência do que recentemente se define como Abordagem da Complexidade. Mas é justamente por isso que esse exercício teórico se mostra interessante, pois, a busca por paralelos com a Abordagem da Complexidade de autores de períodos anteriores à consolidação dela permite o resgate de contribuições teóricas que, ao destoarem da abordagem mais convencional de economia, pautada no paradigma neoclássico, encontravamse, em alguma medida, sem um aparato metodológico condizente.

Os nove pioneiros do desenvolvimento econômico a serem aqui tratados fornecem contribuições teóricas que permitem a satisfação, em determinados sentidos, dos requisitos metodológicos (i) a (v) listados anteriormente. Partindo dessa consideração, segue-se que a pesquisa dos pioneiros do desenvolvimento econômico norteia-se tanto pelo que eles trazem de contribuições teóricas compatíveis à ótica da Abordagem da Complexidade - e, por conseguinte, da consideração do desenvolvimento e do subdesenvolvimento econômicos

\footnotetext{
${ }^{6}$ Cardoso (2008, p. 105).

${ }^{7}$ Herbert Simon, John Maynard Keynes, Michal Kalecki e Joseph Schumpeter.

${ }^{8}$ Raúl Prebisch e Celso Furtado, no que concerne à discussão do subdesenvolvimento latino-americano, são objeto específico do capítulo 4, e os demais pioneiros, em sua abordagem mais geral de subdesenvolvimento, do capítulo 3. No que se refere à discussão do caso brasileiro, Furtado é retomado no capítulo 5.
} 
como fenômenos complexos, sujeitos a diversos mecanismos de retroalimentação, de origem e caráter externos e internos ${ }^{9}$-, quanto do tratamento específico dispensado às nações subdesenvolvidas em geral.

Comum a esses pioneiros do desenvolvimento econômico é a rejeição, em alguma medida, da estrutura teórica micro e macroeconômica convencional e também dos modelos de crescimento neoclássico - que atribuem um caráter neutro e praticamente automático ao processo de desenvolvimento - e da teoria clássica do comércio - que pode ser resumida pela teoria das vantagens comparativas -, os quais não seriam eficazes, em termos da promoção do desenvolvimento, ao contexto diferenciado dos países subdesenvolvidos. Pelo contrário, o comércio internacional livre poderia trazer problemas para os países menos desenvolvidos, a desigualdade entre as nações do mundo seria crescente ao longo do tempo e grande parte da responsabilidade pelo aumento do hiato de renda entre as nações mais ricas e as nações mais pobres seria devida justamente às interações internacionais. A princípio, deriva-se desses autores que haveria uma tendência sistêmica à perpetuação das desigualdades entre as nações, tendência que fundamentam recorrendo a algumas das especificidades das nações subdesenvolvidas. Especificidades essas que, de algum modo, ajudaram a manter essas nações presas na armadilha do subdesenvolvimento.

Dentre os pioneiros escolhidos para compor o corpo teórico dessa tese, Celso Furtado, além de discutir o caso latino-americano, investigou profundamente o caso brasileiro, e por isso desempenha nesse trabalho um papel que vai além de compor parte da base teórica. A obra de Furtado representa uma fonte, além de analítica, historiográfica, bastante pertinente. ${ }^{10}$

Retomando o conceito de desenvolvimento derivado a partir de Schumpeter (1912), emerge o seguinte questionamento: pode-se afirmar que houve de fato um processo de desenvolvimento econômico brasileiro? Se se admite a diferenciação de caráter entre desenvolvimento e subdesenvolvimento, não parece de fato nada razoável afirmar que o Brasil teria passado por um processo de desenvolvimento. Obviamente ocorreram mudanças importantes no período 1930-1980. Entretanto, por que essas mudanças não teriam sido suficientes para libertar o Brasil definitivamente do estigma de (eterno) país do futuro?

É interessante já ressaltar que há aparentemente um processo de perpetuação e

\footnotetext{
${ }^{9}$ Ou de caráter nacional ou internacional. Essa observação é importante, pois há que se considerar a composição analítica de fatores internos e externos, igualmente cruciais para a determinação da dinâmica dos sistemas econômicos nacionais. Esse tema foi por mim desenvolvido em coautoria, em trabalho de pesquisa anterior, e é aqui retomado. Vide Reis e Cardoso (2009a, 2009b e 2010).

${ }^{10}$ A discussão da análise Furtadiana do caso brasileiro é objeto do capítulo 5. Vale notar, desde já, que não se pretende aqui defender a abordagem Furtadiana como a mais ou menos adequada, tampouco adentrar profundamente o vasto campo de discussão do pensamento historiográfico brasileiro.
} 
retroalimentação dos mecanismos de desigualdade: começando pelo nível internacional (centro e periferia), passando ao regional, ao de classes (distribuição de riqueza e distribuição funcional da renda) e ao intra-classes (distribuição pessoal da renda). Em alguma medida, dessa relação cumulativa perversa poder-se-ia derivar parte da explicação para a manutenção do resultado do subdesenvolvimento. A pergunta central que então permanece é: por que, afinal, o Brasil não conseguiu, entre 1930 e 1980, romper definitivamente com o subdesenvolvimento?

Essa tese, de caráter estritamente teórico, objetiva, por meio da atuação crítica em duas frentes - teoria e história -, sob a ótica da Abordagem da Complexidade e recorrendo a alguns autores pioneiros da Economia do Desenvolvimento, contribuir, em alguma medida, à discussão do processo que resultou e fez persistir o subdesenvolvimento econômico brasileiro no período 1930-1980. Pretende-se que, com base numa investigação combinada de metodologia, teoria econômica e de historiografia do Brasil, surjam alguns discussões elucidativas que possibilitem expandir o horizonte de compreensão de alguns aspectos e especificidades do caso brasileiro.

A novidade proposta por essa tese, por conseguinte, refere-se à perspectiva a partir da qual se realiza a investigação e discussão do tema, e não ao tema propriamente dito, o qual foi e vem sendo amplamente debatido pela literatura de história econômica e economia brasileira. ${ }^{11}$ Vale ressaltar, igualmente, que não se pretende resolver controvérsias relativas ao tema ou promover uma síntese geral das diversas contribuições teóricas discutidas, tampouco indicar novas interpretações gerais. O objetivo, bem mais modesto, é a realização de algumas discussões e ilações teóricas relativas à experiência brasileira no período, tendo sempre em mente a Abordagem da Complexidade e sua potencial contribuição para o alargamento do escopo de compreensão do tema.

Além dessa introdução e das considerações finais, essa tese se divide em duas partes e em mais cinco capítulos. Na Parte I, dividida em três capítulos, a partir de revisão bibliográfica pertinente, pretende-se desenrolar a discussão teórico-metodológica relativa ao tema geral Desenvolvimento Econômico e Complexidade. No capítulo 2, busca-se explicitar e discutir alguns dos caminhos e implicações que Abordagem da Complexidade traz à compreensão do tema desenvolvimento econômico, tendo em vista o especial interesse na investigação da emergência e perpetuação do subdesenvolvimento, assunto a ser discutido nos dois capítulos subsequentes. No capítulo 3, recorrendo a alguns pioneiros do desenvolvimento

\footnotetext{
${ }^{11}$ Alguns dos autores que se debruçaram sobre o tema compõem a literatura dos capítulos da Parte II.
} 
econômico - Rosenstein-Rodan, Singer, Nurkse, Lewis, Hirschman, Myrdal e Kalecki -, que discutiram o subdesenvolvimento sob uma perspectiva teórica mais geral, e no capítulo 4, que direciona a discussão de subdesenvolvimento à América Latina - com base em Prebisch e Furtado -, são elencadas algumas das contribuições teóricas desses autores que se mostram compatíveis e convergentes com a Abordagem da Complexidade.

Na Parte II, dividida em dois capítulos, o intuito é aplicar a discussão teóricometodológica desenvolvida na Parte I à investigação do caso brasileiro, no período 19301980. No capítulo 5, recorre-se à ótica de Furtado para discutir o período, buscando novamente conceder destaque a alguns elementos teóricos compatíveis e convergentes com a Abordagem da Complexidade, mantendo a linha discursiva dos capítulos anteriores. No capítulo 6, constrói-se novamente uma narrativa, destacando especialmente os planos do governo elaborados no período, e retomam-se algumas das contribuições teóricas dos pioneiros do desenvolvimento discutidos nos capítulos anteriores, buscando-se analisar, com base na Abordagem da Complexidade, alguns dos aspectos considerados relevantes para entender porque não teria o Brasil escapado da armadilha do subdesenvolvimento no seu período desenvolvimentista. 
PARTE I: DISCUSSÕES TEÓRICAS E METODOLÓGICAS 


\section{DESENVOLVIMENTO E COMPLEXIDADE}

Mesmo partindo de uma delimitação mais restrita de desenvolvimento, enfatizando apenas o que seriam considerações concernentes ao escopo da Teoria Econômica, o desenvolvimento é, necessariamente, por sua natureza, multidisciplinar, um tema que engloba uma grande quantidade de dimensões e variáveis relevantes, as quais, se não levadas devidamente em conta, podem implicar uma compreensão não apenas incompleta do fenômeno, mas principalmente distorcida.

Nesse capítulo, subdividido em duas seções, discute-se como, e por meio de alguns caminhos, a Abordagem da Complexidade pode contribuir, ainda que parcialmente, para o aprofundamento da discussão da temática de Desenvolvimento Econômico. Na seção 2.1, dividida em duas subseções, realiza-se uma breve retomada histórica da delimitação do tema desenvolvimento - subseção 2.1.1 -, bem como se indica o conceito de desenvolvimento no qual se pauta essa tese - subseção 2.1.2. Na seção 2.2, dividida em três subseções, com base em alguns autores que já discutiram o desenvolvimento sob uma perspectiva complexa, levantam-se discussões teóricas de interesse, além da sugestão de outras novas. Na subseção 2.2.1 apresentam-se conceitos e discussões teóricas gerais da Abordagem da Complexidade, mas já direcionadas ao tema desenvolvimento. Na subseção 2.2.2, parte-se para a discussão do desenvolvimento a partir de autores que discutiram explicitamente o tema com base na Abordagem da Complexidade. E, na subseção 2.2.3, indicam-se alguns caminhos pelos quais a Abordagem da Complexidade pode contribuir para a compreensão da emergência e da perpetuação do subdesenvolvimento econômico.

As questões teórico-metodológicas elencadas e iniciadas no presente capítulo permeiam o decorrer de todo o trabalho, funcionando como guia tanto para a revisão de literatura dos pioneiros do desenvolvimento econômico, realizada nos capítulos 3 e 4, quanto para a discussão do caso brasileiro de perpetuação do subdesenvolvimento no período 19301980, realizada nos capítulos 5 e 6.

\subsection{Desenvolvimento Econômico: delimitação temática e definição}

Nessa seção, dividida em duas subseções, inicia-se realizando uma breve retomada da 
história do desenvolvimento econômico enquanto tema específico da Economia - subseção 2.1.1. Na subseção 2.1.2, com base em Schumpeter (1912), define-se o conceito de desenvolvimento econômico do qual parte esse trabalho, ainda sem incorporar explicitamente a perspectiva da Abordagem da Complexidade. No entanto, por conta dos diversos paralelos possíveis entre a abordagem Schumpeteriana e a Abordagem da Complexidade, ${ }^{12}$ algumas discussões eventualmente são já elencadas.

\subsubsection{Delimitação temática}

Antes de passar à exposição de fatos que levaram à delimitação temática do Desenvolvimento Econômico dentro da Ciência Econômica, vale tecer algumas considerações sobre essa própria separação, ainda persistente, entre Teoria Econômica e Economia do Desenvolvimento. Se para o bem ou para o mal, é algo que necessita de prolongada discussão ${ }^{13}$. Conforme Patnaik (2005):

Quando eu era um estudante nos anos 60, nós costumávamos pensar a Economia como dividida basicamente em dois segmentos: por um lado, estava a 'Teoria Econômica' e, por outro, estava uma mistura de História Econômica, 'Economia Indiana' e 'Desenvolvimento Econômico'. ${ }^{14}$ (PATNAIK, 2005, p. 1).

Seria essa dicotomia, entre o que é Teoria Econômica e o que é Economia do Desenvolvimento, justificável? Ou, mais do que isso, seria essa separação frutífera do ponto de vista da discussão do processo de desenvolvimento? Como bem destaca Patnaik, a justificativa para essa dicotomia a que correntemente se recorre seria a natureza institucional distinta das economias desenvolvidas e das economias subdesenvolvidas.

Conforme discutido adiante, no pós II Guerra Mundial, com a emergência das teorias do desenvolvimento, passou-se a assimilar as teorias do crescimento à discussão das nações desenvolvidas e as teorias do desenvolvimento à discussão das nações subdesenvolvidas ou em desenvolvimento. Implícita a essa distinção estaria uma perspectiva de que, se aprovadas na lição da Economia do Desenvolvimento, as ex-nações não desenvolvidas poderiam finalmente se valer da Teoria Econômica e de seus ótimos princípios, em sua forma mais tradicional. Outro problema que aqui se mostra é que, ao colocar o estado de desenvolvimento

\footnotetext{
${ }^{12}$ Vide, por exemplo, Cardoso (op. cit.), em que a autora realiza um exercício teórico comparativo entre as duas abordagens referidas.

13 Essa discussão é objeto da seção 2.2 deste capítulo, referente às contribuições da Abordagem da Complexidade à discussão da temática do desenvolvimento econômico.

14 "When I was a student in the 1960s, we thought of economics as basically divide into two segments: there was 'economic theory' on the one side, and there was a whole mishmash of economic history, 'Indian economics' and 'development economics' on the other."
} 
das nações avançadas como foco, se corre o risco de concentrar esforços no estudo de suas instituições e condições particulares, em detrimento da investigação das especificidades das próprias nações não desenvolvidas.

Tal como concebida, a Teoria Econômica convencional não comporta adequadamente a explicação de fenômenos complexos, como os processos relacionados ao desenvolvimento econômico. ${ }^{15}$ Provavelmente, por conta dessa inadequação teórico-metodológica da abordagem convencional é que uma linha temática, fora do núcleo teórico do mainstream, foi formada para discutir especificamente os casos de persistência de subdesenvolvimento. ${ }^{16}$

Feita essa breve discussão teórica, a ser retomada adiante, passemos à função da presente subseção, que é realizar um breve relato dos fatos históricos relacionados à formação da chamada Economia do Desenvolvimento, bem como às mudanças de perspectiva pelas quais passou nas primeiras décadas do pós II Guerra Mundial.

Relacionado aos objetivos bélicos e aos planos do pós-guerra, ao fracasso econômico liberal dos anos 20 e 30 e ao próprio contexto da Guerra Fria, o desenvolvimento econômico, como interesse principal de governos ocidentais, de economistas e da opinião pública em geral, ganhou forma e força durante a II Guerra Mundial. Segundo Fiori (1999), a partir de então, e até a década de 1970, a chamada "geocultura do desenvolvimento" ${ }^{17}$ se transformou em fenômeno universal, levando à formação e à consolidação do que o autor denomina de hegemonia desenvolvimentista. Nas palavras do autor:

Entre 1945 e 1973, a época dourada do crescimento capitalista e socialista mundiais fez pensar que chegara a hora de realização não só do projeto de autodeterminação dos povos, mas também das profecias econômicas dos clássicos, mesmo quando tivessem sido perseguidas por meio das políticas propostas pelo heterodoxo Friedrich List, implementadas pelos Estados desenvolvimentistas que se multiplicaram e se legitimaram através de todo o mundo depois da II Guerra Mundial. (FIORI, 1999, p. 23).

Como bem observa Chang (2001, p. 1), "O fim da II Guerra Mundial testemunhou a rejeição geral da doutrina do laissez-faire, que falhou de maneira espetacular no período entre guerras." ${ }^{18}$ Como consequência, abriu-se espaço para diversas teorias econômicas de cunho intervencionista, decorrentes, em larga medida, da própria Revolução Keynesiana, que, assim como a teoria do desenvolvimento econômico desenvolvida por Schumpeter, tiveram importante participação na formação e consolidação da Economia do Desenvolvimento. Essas

\footnotetext{
${ }^{15}$ Discussão a ser desenvolvida também na seção 2.2.

${ }^{16}$ No entanto, vale observar que, do ponto de vista de teoria econômica pura, os pioneiros do desenvolvimento econômico e a Economia do Desenvolvimento então estabelecida no pós II Guerra Mundial não apresentaram grandes inovações, embora tenham incorporado, em alguma medida, elementos teóricos Keynesianos e Schumpeterianos às suas análises.

${ }^{17}$ Vide Wallerstein (1974).

18 "The end of the Second World War witnessed the worldwide rejection of the laissez faire doctrine, which had failed so spectacularly during the interwar period."
} 
teorias intervencionistas identificaram uma série de falhas de mercado indicando, em linhas gerais, que um envolvimento ativo do Estado se fazia necessário para sustentar ou alcançar o desenvolvimento.

Conforme observação de Arndt (1987), o artigo de Paul Rosenstein-Rodan, publicado em 1943 no The Economic Journal, "Problemas de Industrialização da Europa Oriental e SulOriental", pode ser considerado como o trabalho inaugural da moderna Economia do Desenvolvimento. De acordo com Hirschman (1981), a Economia do Desenvolvimento inclui o pensamento dos autores anglo-saxões - Paul Rosenstein-Rodan, Hans Singer, Ragnar Nurkse, Arthur Lewis, Albert Hirschman e Gunnar Myrdal, dentre outros - e dos estruturalistas latino-americanos da CEPAL - Raúl Prebisch e Celso Furtado, dentre outros. Esses autores também passaram a ser denominados convencionalmente pela literatura como pioneiros do desenvolvimento econômico. ${ }^{19}$ Sobre a Economia do Desenvolvimento, diz retrospectivamente o autor:

[...] a economia do desenvolvimento inicia-se como a ponta de lança de um esforço para se alcançar a completa superação do atraso. Hoje ficou claro que isto não pode ser feito somente através da economia. É por esta razão que o declínio da economia do desenvolvimento não pode ser totalmente revertido [...] ${ }^{20}$ (HIRSCHMAN, 1981, p. 23).

A partir da década 1950, e na maior parte das próximas duas décadas, a interpretação de que o desenvolvimento econômico poderia ser definido como crescimento econômico sustentado - e que, conforme Myrdal (1957), como consequência, o padrão de vida dos mais pobres (ou da maioria da população) seria melhorado -, dominou a literatura desenvolvimentista. Interessante notar que o termo crescimento econômico era utilizado no caso dos países ricos, e que o termo desenvolvimento econômico o era no caso dos países pobres, mesmo que, ao fim e ao cabo, significassem o mesmo: a promoção e sustentação do incremento da renda per capita. Prova dessa correspondência entre crescimento e

\footnotetext{
${ }^{19}$ Vale ressaltar que os autores que ficaram conhecidos como pioneiros do desenvolvimento no pós II Guerra Mundial, compondo a base da Economia do Desenvolvimento, também sofreram influência teórica de outros autores que também trataram do tema desenvolvimento, porém no contexto de nações (centrais) que se industrializaram tardiamente. Dentre esses "pioneiros dos pioneiros" estão, por exemplo, Alexander Hamilton (1791) e Friedrich List (1856), que fundamentaram o argumento da indústria nascente. Outro autor que merece menção é Alexander Gerschenkron (1962), por conta da sua discussão de industrialização tardia, embora estivesse restrita ao contexto europeu. Conforme explicitado nos capítulos 3 e 4, os conceitos de indústria nascente e de industrialização tardia são assuntos bastante recorrentes nas abordagens dos pioneiros tratados por essa tese. Por fim, outro autor que merece menção especial, e que inclusive é brevemente discutido na subseção seguinte, é Schumpeter (1912), cuja teoria do desenvolvimento também foi pensada no contexto das nações centrais, porém apresenta delimitações teóricas importantes, relacionadas especialmente ao caráter inerentemente dinâmico e de mudança revolucionária atribuídas ao desenvolvimento econômico. Delimitações que inclusive compõem o conceito de desenvolvimento no qual se baseia essa tese, conforme discutido na próxima subseção.

20 "[...] development economics started out as the spearhead of an effort that was to bring all-around emancipation from backwardness. If that effort is to fulfill its promise, the challenge posed by dismal politics must be met rather than avoided or evaded. By now it has become quite clear that this cannot be done by economics alone. It is for this reason that the decline of development economics cannot be fully reversed [...]".
} 
desenvolvimento seria, segundo destaca Arndt, o título do livro de Arthur Lewis, que pretendia ser um livro abrangente sobre desenvolvimento econômico, mas intitulado como “The Theory of Economic Growth”, de 1955. ${ }^{21}$

Mesmo que não se considerasse a renda per capita como uma medida fidedigna do padrão de vida, encarava-se o crescimento real do produto interno bruto (PIB) como uma condição necessária, embora não suficiente, do desenvolvimento econômico. No Ocidente, a tendência que se configurou em assimilar desenvolvimento com crescimento pareceu ser consequência, em boa medida, do fato de que, no pós II Guerra Mundial, a grande preocupação dos países desenvolvidos - e de seus teóricos - era o próprio crescimento econômico de seus países. O aporte teórico para se discutir desenvolvimento nos países pobres era, portanto, ainda derivado, de alguma forma, daquele desenvolvido para analisar o crescimento econômico nos países avançados. O que se trata de uma escolha teórica com problemas, dadas as diferenças de especificidades entre esses dois grupos de países, as quais, por si só, implicariam a necessidade de aportes teóricos, e de estratégias que deles derivariam, distintos.

Entretanto, Fiori observa que a fragilidade da Economia do Desenvolvimento não estaria restrita apenas ao seu economicismo. Segundo o próprio pioneiro Hirschman, mesmo no restrito escopo da Economia, o debate entre os pioneiros fora inconcluso. Sobre esse ponto, sintetiza Fiori:

Se todos os teóricos do desenvolvimento compartilharam a necessidade de uma teoria específica para as economias dos países atrasados, nunca estiveram de acordo sobre as vantagens comparativas no comércio internacional, nem tampouco sobre a identificação e hierarquização dos "fatores internos" que poderiam ser os grandes obstáculos ou estímulos ao desenvolvimento das economias atrasadas. E se todos compartilharam igualmente a defesa do intervencionismo estatal, jamais estiveram de acordo sobre a natureza hierárquica e competitiva da ordem política e econômica internacional. (FIORI, 1999, p. 25).

Porém, apesar de seu economicismo, não há como não reconhecer que a Economia do Desenvolvimento, por meio de seus representantes, acabou incorporando discussões históricas, políticas e sociológicas. Embora, segundo Fiori, essas considerações tenham sido mais impactantes nas definições de estratégias e políticas de desenvolvimento do que propriamente no ferramental analítico da teoria que as baseavam. ${ }^{22}$

Havia também uma tendência a se associar necessariamente desenvolvimento econômico com industrialização, como se fossem sinônimos. A vulnerabilidade das nações

\footnotetext{
${ }^{21}$ Interessante notar que a tradução em Português do livro de Lewis é Teoria do Desenvolvimento Econômico, o que seria um possível reflexo da não distinção, ainda não muito clara, entre crescimento e desenvolvimento.

22 Essa observação é importante pois, conforme será discutido nas próximas seções, a Abordagem da Complexidade fornece interessantes elementos teóricos para a discussão do processo de desenvolvimento e de subdesenvolvimento.
} 
primário-exportadoras durante a Grande Depressão e a II Guerra Mundial, especialmente na América Latina, teria implicado a demanda por industrialização como meio para a diversificação econômica. A industrialização, por seu turno, requeria acumulação de capital fixo. A ênfase na formação de capital estava ainda imbuída num amplo espectro ideológico, presente em quase toda a discussão a respeito de desenvolvimento econômico, de que o desenvolvimento não poderia ser deixado a cabo das forças de mercado, mas sim, que deveria ser objeto de planejamento.

Da identificação da necessidade de planejamento para o apontamento da importância da participação crucial do Estado nesse processo, como bem observa Arndt, foi apenas um passo. E os fundamentos intelectuais para essa defesa da intervenção governamental já estariam presentes no próprio artigo inaugural citado de Rosenstein-Rodan. Ainda no decorrer dos anos 1950, outros pioneiros, tais como Prebisch, Singer, Nurkse, Lewis, Myrdal e Hirschman, teriam ajudado a disseminar essa ideia de necessidade de intervenção estatal para a consecução das estratégias de desenvolvimento.

No que se refere à ênfase do comércio como motor do crescimento, é interessante notar que, durante a primeira década do pós-guerra, a literatura sobre desenvolvimento econômico das nações menos desenvolvidas era dominada por críticas ao livre comércio ou à validade da teoria das vantagens comparativas. Por exemplo, Prebisch $(1949,1952)$ na América Latina e Myrdal (1957) na Europa, argumentaram, em linhas gerais, que a teoria do livre comércio era inaplicável no contexto dos países menos desenvolvidos, pois, ao invés de resolverem seus problemas relativos a estrangulamentos internos e externos, os intensificavam. Como principal inferência de política para os países subdesenvolvidos, destacou-se a necessidade de rápida industrialização baseada na substituição de importações. A argumentação em prol da indústria nascente também pode ser encontrada, por exemplo, na obra de Lewis, Hirschman e de Furtado.

Entretanto, ainda durante os anos 1950, passou-se a contestar se o comércio internacional poderia, em alguma medida, e a depender de políticas complementares, desempenhar um papel positivo no desenvolvimento econômico. Essa discussão teria derivado, segundo Arndt, de três influências: a preocupação a respeito da lacuna existente de comércio externo dos países em desenvolvimento, o crescente desencantamento com a estratégia de substituição de importações e os esforços soviéticos em neutralizar o papel do GATT, reforçados pela crescente importância político-estratégica do Terceiro Mundo. Como conseqüência, ocorreu a primeira Conferência das Nações Unidas sobre Comércio e Desenvolvimento - UNCTAD I - em 1964, declamando o comércio internacional como o 
instrumento primário do desenvolvimento econômico.

Nesse contexto, insere-se o relatório elaborado por Prebisch, como secretário-geral da UNCTAD, em 1964, intitulado "Por uma Nova Política Comercial para o Desenvolvimento", ${ }^{3}$ cuja principal inovação, em termos de sugestão de política de desenvolvimento, foi uma nova ênfase concedida à necessidade dos países em desenvolvimento passarem a exportar também bens manufaturados, tanto para outras nações em desenvolvimento, quanto para as nações desenvolvidas. Porém, a efetivação dessa política pressupunha, ao menos em seu início, acordos de cooperação internacional. Por isso, tratavase de uma sugestão ainda muito distante da liberalização geral do comércio. Nos países do Norte, as discussões circulavam em torno das negociações multilaterais de tarifas. Entretanto, as diferenças entre as perspectivas e prioridades das nações do Norte e do Sul teriam prejudicado o diálogo entre as duas partes, impedindo a formação de um consenso a partir da UNCTAD I.

Sobre a década de 1960, Fiori faz uma importante observação. Apesar das Nações Unidas e o governo estadunidense terem declarado essa como a "década do desenvolvimento", na América Latina já se multiplicavam os sinais de esgotamento e as críticas à estratégia da industrialização baseada na substituição de importações ${ }^{24}$. No âmbito dos intelectuais, iniciou-se um período de marcado pessimismo relativamente, não somente à viabilidade dos projetos de industrialização e modernização, mas inclusive se seria possível que as economias atrasadas atingissem o desenvolvimento. Nesse contexto, emergiram as teorias da dependência, ${ }^{25}$ dentro e fora da tradição estruturalista.

Também nos anos 1960, especificamente em meados da década, de acordo com Arndt, teria ocorrido uma mudança profunda na opinião pública e acadêmica sobre os objetivos do desenvolvimento, incorporando o que pode ser chamado genericamente de objetivos sociais, tais como adequadas condições de saúde, educação e nutrição. E não se tratou apenas de acrescentar os objetivos sociais aos econômicos, mas inclusive de colocar em questão se determinados tipos de crescimento, ao invés de resolver problemas políticos e sociais poderiam na verdade ocasioná-los. Conforme afirma Higgins (1980):

[...] a rejeição do crescimento da renda nacional como o único objetivo do plano de desenvolvimento [...] mostrou a necessidade de planejar direta e simultaneamente todos os objetivos do desenvolvimento com total conhecimento das interações e retroalimentações entre

\footnotetext{
${ }^{23}$ Trechos selecionados desse relatório (PREBISCH, 1964) serão discutidos no capítulo 4, na seção 4.1.

${ }^{24}$ Vide Tavares (1972), cujos argumentos são retomados no capítulo 6.

${ }^{25}$ As discussões e autores relacionados à teoria da dependência, apesar de sua importância, não são objeto de investigação do presente trabalho, que restringe seu escopo à discussão de subdesenvolvimento que emerge no imediato pós II Guerra Mundial e que originou a Economia do Desenvolvimento.
} 
eles. ${ }^{26}$ (HIGGINS, 1980, p. 26).

Em outras palavras, e adaptando a observação de Higgins ao contexto dessa tese, pautada na perspectiva da Abordagem da Complexidade, na medida em que aumente o escopo de discussão do tema, e quanto mais elementos explicativos forem incorporados à discussão, maior é o grau potencial de compreensão dos processos que envolvem o desenvolvimento e o subdesenvolvimento. Apesar dos diversos problemas, tais como o excesso de economicismo ou a manutenção de alguns elementos teóricos clássicos, os pioneiros foram críticos à teoria econômica convencional e, por meio de suas teorias, enriqueceram a discussão sobre os elementos que envolvem os processos de desenvolvimento e de subdesenvolvimento econômicos.

Como ficará mais claro nos capítulos subsequentes, quando da discussão da contribuição dos nove pioneiros selecionados, mostram-se especialmente promissoras e importantes as considerações e discussões dos mecanismos de retroalimentação - podendo estar relacionados a fatores estruturais, sociais, culturais ou institucionais - que condicionam e perpetuam os círculos viciosos ou nós que precisam ser enfrentados pelas nações não desenvolvidas para superarem o subdesenvolvimento.

Realizado um breve panorama da delimitação e evolução temática do Desenvolvimento Econômico no pós II Guerra Mundial, faz-se agora necessário especificar a definição de desenvolvimento econômico da qual se pretende partir, antes de passarmos à seção seguinte, que começa a incorporar algumas implicações teóricas da Abordagem da Complexidade à discussão da temática do Desenvolvimento Econômico.

\subsubsection{Definição de desenvolvimento econômico}

Tendo a Teoria do Desenvolvimento Econômico (TDE) de Schumpeter como referência principal, considera-se que o desenvolvimento econômico possui um caráter de mudança revolucionária ${ }^{27}$ e por isso não passível de tratamento adequado pela análise estática.

\footnotetext{
${ }^{26}$ " [...] a rejection of growth of national income as the sole objective of development planning [...] It stressed the need to plan directly and simultaneously for all objectives of development with full cognizance of interactions and feedbacks among them."

${ }^{27}$ Nesse sentido de mudança revolucionária, vale reproduzir as palavras de Georgescu-Roegen (1979, p. 4): “[...] o sistema econômico muda continuamente em termos qualitativos. Usando uma variação de um dos ensinamentos característicos de Joseph Schumpeter, basta lembrarmo-nos de que não continuamos produzindo uma carruagem-correio após outra, para sempre. Passamos de viagens em carruagens para viagens em trens, de automóveis, de aviões e, possivelmente, de foguetes." Na subseção 2.2.1, veremos como essa definição de mudança revolucionária se assemelha à noção de equilíbrio pontuado da Abordagem da Complexidade.
} 
Sob a ótica Schumpeteriana, o desenvolvimento econômico é um processo que envolve, obrigatoriamente, uma grande inflexão ou ruptura da economia, que cria e alimenta incertezas $^{28}$. Ao final do processo, a economia deve, necessariamente, estar melhor do que antes, sendo esse um processo de mudança necessariamente qualitativa, embora envolva também, em geral, mudanças quantitativas. Essa indicação de necessidade de mudança qualitativa é crucial, na medida em que se coaduna com uma perspectiva mais abrangente do processo de desenvolvimento, e com as transformações que envolve, extrapolando considerações relativas somente ao crescimento, em linha com a observação de Higgins citada ao final da subseção 2.1.1.

Outra delimitação teórica fundamental derivada de Schumpeter é o aspecto endógeno do desenvolvimento, embora, obviamente, envolva a interação de fatores internos e externos. Nas palavras do próprio autor, "Entenderemos por "desenvolvimento", portanto, apenas as mudanças da vida econômica que não lhe foram impostas de fora, mas que surjam de dentro, por sua própria iniciativa." 29 (SCHUMPETER, 1912, p. 47). Do autor, pode-se derivar também o caráter necessariamente cumulativo do processo de desenvolvimento, pois "Todo processo concreto de desenvolvimento repousa sobre o desenvolvimento precedente" (Ibid., p. 47), não se tratando, portanto, de um resultado natural ou espontâneo. Por conta das características expostas - o desenvolvimento envolve transformações qualitativas, resulta de mecanismos endógenos e está sujeito a processos cumulativos -, nas palavras do autor:

O desenvolvimento, no sentido em que o tomamos, é um fenômeno distinto, inteiramente estranho ao que pode ser observado no fluxo circular ou na tendência para o equilíbrio, que altera e desloca para sempre o estado de equilíbrio previamente existente. (Ibid., p. 47).

Assim, para Schumpeter, a análise estática seria incapaz de predizer as consequências das mudanças no sistema econômico, de explicar a ocorrência de revoluções produtivas, bem como dos fenômenos que a acompanham, questões fundamentais para a compreensão do processo de desenvolvimento.

Tendo essa definição Schumpeteriana de desenvolvimento como base, e em linha com os pioneiros do desenvolvimento econômico a serem discutidos nos capítulos subsequentes, considera-se nessa tese como processo de desenvolvimento econômico a ocorrência de mudanças na estrutura produtiva de determinada economia, relacionadas especialmente a incrementos na produtividade do trabalho, que desencadeiem mudanças qualitativas

\footnotetext{
28 Nas palavras de Schumpeter, "Enquanto no fluxo circular habitual todo indivíduo pode agir pronta e racionalmente [...] ele não pode simplesmente fazer isso quando se defronta com uma nova tarefa." (SCHUMPETER, 1912, p. 57).

${ }^{29}$ Essa observação, conforme ficará mais claro quando da discussão da Abordagem da Complexidade na seção 2.2, é crucial para a formação de uma perspectiva de desenvolvimento pautada na abordagem citada.
} 
determinadas, quais sejam, relativas principalmente a melhoras não apenas absolutas, mas especialmente relativas, nas condições de vida da maior parte da população, ou ainda mais especificamente, daqueles relativamente mais pobres. Em outras palavras, o processo de desenvolvimento econômico seria efetivo quando, como resultado de mudanças na estrutura produtiva e de incrementos de produtividade, fosse observada uma diminuição significativa na desigualdade distributiva de renda e riqueza, impactando positivamente especialmente sobre o nível de vida dos relativamente mais pobres, garantindo-lhes ao menos condições mínimas de subsistência. ${ }^{30}$

De maneira reflexa, seria então possível definir subdesenvolvimento econômico a partir: (i) do não acontecimento da mudança produtiva que permitisse um incremento significativo na produtividade do trabalho; ou (ii) mesmo que tal mudança tivesse ocorrido e que tivesse incrementado a produtividade do trabalho, da não observação da melhoria relativa das condições de vida da maior parte da população, especialmente dos mais pobres, e, como consequência, da diminuição da desigualdade.

No primeiro caso (i), é de fundamental importância a discussão do processo de inovação e de geração autônoma de progresso tecnológico. Conforme argumentam os Neoschumpeterianos Freeman e Soete (1997), o processo de difusão de inovações seria uma fonte explicativa interessante para entender as distintas performances de crescimento e desenvolvimento econômico dos países, pois:

O desenvolvimento não se refere aos êxitos e produção individuais, mas à capacidade de estabelecer sistemas tecnológicos inter-relacionados em evolução, que gerem sinergias para processos de crescimento autossustentados. ${ }^{31}$ (FREEMAN e SOETE, 1997, p. 361).

Embora não se pretenda aqui abarcar a discussão de inovação e progresso tecnológico no que se refere à sua geração propriamente dita, serão discutidos, nos capítulos pertinentes, os seus efeitos dinâmicos sobre o processo de desenvolvimento sob a perspectiva dos pioneiros que se debruçaram sobre esse tema.

No segundo caso (ii), constituem-se como variáveis analíticas centrais - porém, não únicas - àquelas relacionadas à mensuração da desigualdade, especialmente a distribuição funcional da renda e a distribuição de riqueza. Conforme também discutido em capítulos

\footnotetext{
30 Trata-se de uma definição qualitativa de desenvolvimento econômico, embora faça referência a aspectos quantitativos. Nesse sentido, vale ressaltar que a pretensão do presente trabalho se restringe à reflexão de alguns dos aspectos teóricos relativos ao desenvolvimento e subdesenvolvimento econômicos, não se recorrendo, e muito menos desenvolvendo, a quaisquer empirias. No entanto, a delimitação do conceito de desenvolvimento econômico mostrou-se pertinente a fim de balizar, em alguma medida, as discussões sobre o tema a serem realizadas nos capítulos subsequentes.

31 "Development is not about individual product and successes but about the capacity to establish interrelated technology systems in evolution, which generate synergies for self-sustained growth processes."
} 
pertinentes, muitos dos pioneiros atentaram para a importância dinâmica do grau de desigualdade de distribuição de renda e riqueza na perpetuação dos círculos viciosos característicos do subdesenvolvimento.

Mostra-se ainda importante notar que a TDE de Schumpeter foi desenvolvida a partir do contexto dos países centrais (ou já desenvolvidos). Nesses países, as mudanças revolucionárias já ocorreram no contexto do desenvolvimento: partia-se de uma situação inicial em adequadas condições de avanço e modernidade para resultar em outra ainda mais avançada e moderna. Já no contexto do subdesenvolvimento, a ruptura necessária para atingir como resultado final uma economia desenvolvida envolveria uma transformação de natureza mais profunda e, por isso, necessariamente brusca. Essa é justamente a questão central dos pioneiros do desenvolvimento econômico: como transformar a velha ordem (subdesenvolvimento) numa nova ordem (desenvolvimento)?

Dessa observação mais geral, decorrem os seguintes questionamentos mais específicos: como transformar um processo de crescimento sustentado, tal como o desempenhado pelo Brasil entre 1930 e 1980, num processo real de desenvolvimento? Quais variáveis (políticas, instituições, dotações, etc.) deveriam ser alteradas para que se observasse tal resultado? Além disso, estariam essas variáveis no escopo da Ciência Econômica? E, por fim, até que ponto, e em que grau de abrangência, pode a Economia tratar do tema, implicando políticas específicas para tal?

Esses questionamentos, em determinados aspectos e dimensões, serão abordados ao longo dessa tese. A discussão será permeada por questões teóricas e metodológicas, e adquirirá diferentes destaques a depender do contexto e escopo de discussão. Na próxima seção desse capítulo, a discussão é abordada predominantemente ainda sob um ponto de vista teórico-metodológico; no capítulo 3, passa-se ao escopo teórico geral da condição de subdesenvolvimento; no capítulo 4, volta-se ao contexto teórico da América Latina; e nos capítulos 5 e 6 , o foco está sobre o Brasil.

Vale destacar desde já que nem todas as variáveis de interesse ao tema estão no escopo da Economia, o que, na verdade, é algo esperado, em virtude da própria noção de que o desenvolvimento (ou a ausência dele) é resultado de elementos de diversas naturezas, objetos de outras ciências. Entretanto, muitas dessas variáveis estariam no escopo da Economia, como os mecanismos que implicam a distribuição de renda e riqueza ou a natureza, a origem e o direcionamento dos recursos que financiam o processo produtivo e as inovações tecnológicas. Essas variáveis, portanto, podem e devem ser objeto de políticas econômicas que visem o desenvolvimento econômico, especialmente no contexto das nações subdesenvolvidas. Pois, 
nesses casos, a mudança a ser empreendida para se configurar um processo de desenvolvimento deve ser profunda o suficiente para retirar essas nações dos círculos viciosos e/ou das causações cumulativas que compõem a armadilha do subdesenvolvimento. Mudanças marginais ou com baixo poder de transformação e propagação, apesar de poderem implicar alterações qualitativas, não seriam suficientemente fortes para romper a barreira do subdesenvolvimento. É como mudar para continuar o mesmo, o que seria suficiente no contexto do desenvolvimento. Já no contexto do subdesenvolvimento, a questão é como se transformar numa economia madura, superando aquela condição definitivamente.

$\mathrm{Na}$ próxima seção, discutem-se algumas possíveis implicações da Abordagem da Complexidade à discussão do tema mais geral Desenvolvimento Econômico. Essas considerações podem potencialmente auxiliar no aprofundamento da compreensão dos processos que desencadeiam o desenvolvimento e perpetuam o subdesenvolvimento, bem como o hiato de desigualdade resultante entre as nações, e em que medida esses resultados estariam interligados.

\subsection{Algumas implicações da Abordagem da Complexidade à discussão do tema Desenvolvimento Econômico}

Por meio da contribuição de alguns autores que se debruçaram especificamente sobre a questão da geração de riqueza e desenvolvimento sob uma perspectiva complexa, a presente seção, dividida em três subseções, buscará elencar algumas implicações pertinentes ao tema Desenvolvimento Econômico, bem como sugerir direcionamentos ao encaminhamento da discussão a ser aprofundada no decorrer do presente trabalho. Importante ressaltar desde já que não se pretende realizar aqui uma discussão da já vasta literatura relacionada à Abordagem da Complexidade, aplicada em diversas áreas de pesquisa dentro da Economia, nem discutir as suas diferentes concepções ${ }^{32}$. O objetivo dessa seção é, já sob a ótica da Abordagem da Complexidade, ${ }^{33}$ realizar um levantamento de elementos analíticos, discutidos

\footnotetext{
32 Como destaca Prado (2009, p. 14), “[...] não há unanimidade na formulação da concepção de sistema complexo. Ao contrário, pode-se dizer mesmo que coexistem muitas teses díspares sobre a questão de como definir esse objeto que se mostra com contornos imprecisos." Ademais, vale observar que a Abordagem da Complexidade não pretende somente ser uma área temática de pesquisa, mas sim um novo paradigma, na medida em que fornece uma nova ótica, por meio de seu arcabouço metodológico e teórico diferenciado.

33 A linha teórica aqui adotada enquadra-se primordialmente na chamada "Complexidade de Santa Fé", que envolve o foco na interação de agentes heterogêneos e das propriedades que dela emergem. Conforme Arthur, Durlauf e Lane (1997), são características comuns aos sistemas complexos: sistemas compostos por agentes
} 
por alguns autores, que se mostram especialmente promissores à discussão específica de subdesenvolvimento.

Inicia-se a discussão com um corte teórico-metodológico mais geral na subseção 2.2.1, destacando alguns dos diferenciados ferramentais analíticos e teóricos da Abordagem da Complexidade que, relativamente aos tratamentos teóricos mais tradicionais, se mostrariam potencialmente mais profícuos à discussão do desenvolvimento. Na subseção 2.2.2, indicamse algumas implicações possíveis da Abordagem da Complexidade à reflexão sobre o desenvolvimento buscando, dentro outras questões, abordar, ainda que superficialmente, a questão do papel do Estado. Já na subseção 2.2.3, são elencadas certas questões específicas ao subdesenvolvimento, especialmente àquelas relativas à perpetuação das desigualdades em diversos níveis de agregação.

\subsubsection{Enfoque teórico-metodológico complexo}

Antes de passar à discussão propriamente dita dos elementos analíticos abarcados pela literatura da Abordagem da Complexidade considerados pertinentes à discussão do tema Desenvolvimento Econômico, vale retomar uma discussão aventada na subseção 2.1.1, a respeito da dicotomia entre Teoria Econômica e Economia do Desenvolvimento. Segundo Patnaik:

O resultado dessa dicotomia, tão cultivada pelo 'mainstream' da Economia, é o empobrecimento tanto da 'Teoria Econômica' quanto da 'Economia do Desenvolvimento'. Em outras palavras, ela não apenas prejudica a compreensão dos problemas do desenvolvimento; ela faz com que a própria Teoria Econômica torne-se, em larga medida, irrelevante. ${ }^{34}$ (PATNAIK, 2005, p. 3).

Como exemplos desse citado empobrecimento teórico, Patnaik indica a teoria do crescimento neoclássica e a teoria do comércio internacional. Levando em consideração o entendimento teórico do funcionamento do sistema capitalista mundial e, especialmente, da condição de subdesenvolvimento econômico, essas teorias não seriam nem profícuas, nem adequadas. Como bem destaca o autor, "Economias subdesenvolvidas não são meras

\footnotetext{
idiossincráticos com potencial de aprendizado e adaptação; ocorrem interações entre os componentes do sistema que são coordenadas por normas, instituições e organizações endógenas, não havendo nenhum mecanismo global de controle; tais sistemas apresentam mecanismos de auto-organização e estruturas emergentes que resultam tanto da agregação quanto da interação de suas partes; o novo emerge recorrentemente; e sua dinâmica se desenrola fora do equilíbrio. Segundo Rosser Jr. (2009, p. 3), "Esse nível mais baixo de complexidade pode ser visto como o cavalo de batalha e o foco central de grande parte da pesquisa em complexidade que já foi feita e continua a ser feita." Na versão original: "This lowest level of complexity can be viewed as the central workhorse and focus of much of complexity research that has gone on and continues to go on."

34 "The result of this dichotomy, which 'mainstream' economics so assiduously cultivates, is to impoverish both 'economic theory' and 'development economics'. In other words, it does not merely detract from an understanding of the problems of development; it makes the so called economic theory itself largely irrelevant."
} 
retardatárias esperando se equiparar às nações desenvolvidas." 35 (Ibid., p. 6).

O desenvolvimento de algumas nações parece estar organicamente interligado com o subdesenvolvimento de outras, o que, por sua vez, não significa que apenas os fatores externos aos sistemas econômicos nacionais exercem influência determinante. Relembrando citação de Schumpeter, o desenvolvimento é um processo que, necessariamente, deve ser endogenamente criado. Além disso, as economias nacionais não são sistemas isolados, e sim partes componentes de um sistema global, o sistema político-econômico mundial. Ademais, cada nação passou por um processo de consolidação socioeconômica particular, sendo, cada uma delas, um sistema próprio. Por isso também a necessidade de atentar para as diferenças entre as nações, o que só é possível por meio da investigação das especificidades históricas de cada nação e, por conseguinte, da consideração explícita de que as nações são heterogêneas.

A teoria convencional não comportaria a consideração dessas características, a começar por um de seus pressupostos fundadores, e de especial interesse aqui, o de "agente representativo". Segundo Kirman (2009), a recorrência ao agente representativo, que habilita passar do comportamento no nível micro para o comportamento agregado, é puramente ad hoc e nenhuma restrição razoável nas características individuais garante que o agregado satisfaça as hipóteses feitas sobre os indivíduos. Dito isso, duas opções são colocadas: continuar a tentar derivar o comportamento agregado a partir unicamente do indivíduo racional padrão ou aceitar que a diferença entre o comportamento individual e o comportamento agregado é fundamental, o que implicaria a necessidade de construção de modelos que considerassem explicitamente essa diferença. Habilitada à segunda opção, a Abordagem da Complexidade tem como foco o estudo das interações de agentes heterogêneos, das quais resultam propriedades emergentes, cuja compreensão é crucial para o entendimento da dinâmica de funcionamento dos sistemas investigados. Observação pertinente no âmbito da discussão do tema Desenvolvimento Econômico, especialmente no contexto do subdesenvolvimento, com nações apresentando diferentes graus de desenvolvimento econômico, compondo um grupo de países bastante heterogêneo e resultando numa dinâmica de sistema político-econômico mundial deveras complexa.

Para lidar com o dinâmico, complexo e adaptativo sistema econômico mundial, de cujo funcionamento resulta nações em condição de desenvolvimento e nações em condição de recorrente subdesenvolvimento, os seguintes requisitos teóricos são considerados importantes: (i) uma microfundamentação adequada a sistemas complexos; (ii) mecanismos que

\footnotetext{
35 "Underdeveloped economies are not mere laggards waiting to catch up with developed countries."
} 
fundamentem a interação entre os agentes; (iii) mecanismos que expliquem como transcorre a passagem do que ocorre no campo "micro" para o que ocorre no campo "macro"; (iv) mecanismos que expliquem as relações de retroalimentação entre a micro e a macroeconomia; e que possua, portanto, (v) um enfoque dinâmico, não-linear e não-determinista. ${ }^{36}$

Tendo em mente essas considerações, passemos à discussão da contribuição de alguns autores à problemática do Desenvolvimento Econômico, lembrando que, contrariamente aos pioneiros, os autores cujas contribuições são apresentadas e discutidas em seguida nesse capítulo estão explicitamente partindo de uma perspectiva pautada pela Abordagem da Complexidade. Nessa subseção, abordam-se elementos teóricos mais gerais, porém importantes para as discussões a serem realizadas nas duas subseções seguintes.

Discorrendo a respeito do papel das hipóteses na construção de uma teoria, Beinhocker (2006) aponta duas condições principais para sua validade: as hipóteses devem ser apropriadas ao propósito do modelo e elas não devem afetar as respostas que o modelo fornece àquele propósito. No caso da Economia Tradicional, nas palavras do autor:

[...] a partir de Walras e Jevons, os economistas começaram arbitrariamente a fazer hipóteses sobre racionalidade perfeita, leiloeiros como deuses, e assim por diante, com o único propósito de fazer a matemática do equilíbrio funcionar. ${ }^{37}$ (BEINHOCKER, 2006, p. 50).

A limitação analítica do método pautado por análises de equilíbrio teria forçado os seus modelos derivados a retirarem do seu escopo de análise muitas questões interessantes e fundamentais, relacionadas ao funcionamento do sistema econômico, tratando-as como exógenas. Assim, apesar dos esforços dos economistas do mainstream em adicionar certa dose de realismo por meio do relaxamento de algumas hipóteses - por exemplo, modelos com racionalidade limitada, informação imperfeita, dinâmica, endogeneização de novas variáveis não há um modelo que supere todas essas hipóteses de uma só vez pois, para tal, deveria, em primeiro lugar, abandonar a ideia de que a economia é um sistema em equilíbrio.

Ao longo da segunda metade do século $\mathrm{XX}$, enquanto os economistas vinculados à linha teórica do mainstream continuaram tratando a economia como um sistema em equilíbrio, tal como lhes legara Walras, biólogos, químicos e físicos passaram a discutir e a investigar sistemas dinâmicos, complexos e que funcionavam longe do equilíbrio. Já no início dos anos 1970, cientistas dessas diversas áreas começaram a definir esses sistemas como sistemas complexos simplesmente, querendo implicar, com essa definição, sistemas com

\footnotetext{
${ }^{36}$ Condições discutidas com mais detalhes em Cardoso (op. cit.). No escopo do presente trabalho, parte-se delas como requisitos a serem cumpridos, em alguma medida, pelos elementos teóricos extraídos dos autores discutidos nos próximos capítulos.

37 "[...] beginning with Walras and Jevons, economists began arbitrarily making up assumptions about perfect rationality, godlike auctioneers, and so on, with the sole purpose of making the equilibrium math work."
} 
elementos heterogêneos que interagem dinamicamente, resultando na emergência de padrões macro de comportamento. Especialmente a partir da década de 1980, a Abordagem da Complexidade passou a ser aplicada à Economia.

Importante notar que, conforme assinala Arthur (2009), o tratamento teórico da economia como um sistema complexo e adaptativo possui uma complicação adicional: diferentemente das ciências naturais, os elementos econômicos - os agentes humanos - agem e reagem com base em estratégias e previsões, buscando levar em consideração os efeitos de um comportamento ou decisão que venham a adotar. Além disso, vale acrescentar que, como os agentes econômicos possuem racionalidade limitada ${ }^{38}$ e o sistema está sujeito à incerteza forte, em seu sentido Knigthiano ou Keynesiano, a interação dinâmica entre esses agentes é uma fonte endógena adicional (e infinita) de incerteza.

Assim, sendo a economia altamente complexa e inexistindo um mecanismo global de controle, como pode o sistema econômico funcionar de forma auto-organizada? É justamente na investigação dos padrões macro que emergem dessa interação dinâmica entre agentes que pode contribuir a Abordagem da Complexidade ao avanço científico da Economia. Note-se que, sob essa perspectiva, ao invés de perseguir um determinado resultado - na abordagem convencional, o de equilíbrio -, o foco investigativo está no processo que gera os resultados, que podem ser infinitos. Por isso o maior potencial explicativo da Abordagem da Complexidade.

Como bem observa Beinhocker, ainda sobre o conceito de equilíbrio, quando Walras o emprestou da Física, essa ciência só considerava a $1^{\text {a }}$ Lei da Termodinâmica ( $1^{\mathrm{a}}$ L. T.), desenvolvida na primeira metade do século XIX. Segundo essa lei, a energia não é nem criada nem destruída, por isso também é conhecida como Princípio da Conservação de Energia. Desse princípio decorre a seguinte propriedade, relativa ao equilíbrio sistêmico: se a energia total em um sistema é fixa - ou conservada -, está garantido que o sistema alcançará o equilíbrio. Desse modo, tendo a fixação ou a conservação como condições, não é à toa que os economistas marginalistas recorrem tanto ao termo ceteris paribus em suas explicações. Além disso, a noção econômica convencional de equilíbrio do sistema requer que cada elemento constituinte esteja, ele mesmo, em equilíbrio.

\footnotetext{
${ }^{38}$ De acordo com Simon (1955), os agentes não são capazes de calcular os diversos pay-offs que decorrem de uma decisão, tanto por conta de suas insuficiências de informação, quanto de sua limitada capacidade cognitiva. Além disso, segundo Simon (1979), a presença de incerteza impossibilita que um comportamento seja substantivamente racional.
} 
Já a $2^{\mathrm{a}}$ Lei da Termodinâmica $\left(2^{\mathrm{a}}\right.$ L. T.), ${ }^{39}$ ignorada pelos marginalistas, define que a entropia, uma medida de desordem ou aleatoriedade sistêmica, é sempre crescente. Pela $2^{\mathrm{a}} \mathrm{L}$. T., o universo como um todo está inevitavelmente se alternando entre um estado de ordem e outro de desordem. Ou seja, ao longo do tempo, toda a ordem, estrutura e padrão no universo se rompem, decaem ou se dissipam. ${ }^{40}$ Importante notar que a entropia é que dá ao tempo a sua direção, levando a implicações fundamentalmente distintas da $1^{a}$ L. T. Segundo Beinhocker, "Sem entropia e a inevitável alternância entre ordem e desordem, não haveria como definir o que é passado, presente ou futuro. Desde sua descoberta, a entropia se tornou um conceito central à maneira como os físicos enxergam o universo." ${ }^{41}$ (BEINHOCKER, op. cit., p. 68).

Desse modo, aplicar a $2^{\mathrm{a}}$ L. T. à análise econômica, de partida, já invalidaria a manutenção da estrutura teórica equilibrista, pois a condição ceteris paribus não mais necessariamente verificar-se-ia. Sem contar o caráter dinâmico, mutável e temporalmente definido do processo de dissipação e incremento de entropia, que torna a análise estática desinteressante do ponto de vista explicativo. Segundo Foley (2003, p. 13), “A tradicional concepção Walrasiana de equilíbrio econômico possui entropia zero: é completamente ordenada no nível micro." 42

Outros conceitos físicos importantes, também não considerados pelos marginalistas, são os de sistemas termodinâmicos abertos e fechados. Vejamos a definição de cada um desses conceitos.

Sistema termodinâmico é qualquer conjunto definido de espaço, matéria, energia ou informação. Sobre o mesmo conceito, importante notar que o sistema termodinâmico é dito em equilíbrio se o seu nível macro tender a se auto-reproduzir, mesmo se o nível micro estiver em constante mudança ou desordem. Embora o conceito de equilíbrio termodinâmico guarde

\footnotetext{
${ }^{39}$ Sobre as implicações da $2^{\text {a }}$ L.T. à Economia, imprescindível destacar a contribuição original de Nicholas Georgescu-Roegen (1971), considerado como um dos "pais" da Abordagem da Complexidade, inclusive da sua aplicação à Economia. Interessante notar ainda a influência intelectual de Schumpeter sobre Georgescu: "Schumpeter teve influência crucial na carreira de Georgescu e foi quem o transformou em um economista. Os dois anos (1934 a 1936) de convívio em Harvard foram de atividade intelectual intensa e fundamentais para reforçar a sua convicção de que os processos históricos são únicos e impossíveis de serem descritos por uma fórmula matemática." (CECHIN, 2010, p. 47).

${ }^{40}$ Interessante notar a semelhança com Marx e Engels (1848), em o Manifesto Comunista - "Todas as relações firmes, sólidas, com sua série de preconceitos e opiniões antigas e veneráveis foram varridas, todas as novas tornaram-se antiquadas antes que pudessem ossificar. Tudo o que é sólido derrete-se no ar" (MARX e ENGELS, 1848, p.14) - e o conceito de destruição criativa de Schumpeter (1943) - "[...] que incessantemente revoluciona a estrutura econômica a partir de dentro, incessantemente destruindo a velha, incessantemente criando uma nova. Esse processo de Destruição Criativa é o fato essencial acerca do capitalismo" (SCHUMPETER, 1943, p.113).

41 "Without entropy and the inevitable drift from order to disorder, there would be no way to tell what was the past, present, or future. Since its discovery, entropy has become a central concept in the way physicists view the universe."

42 "The traditional Walrasian conception of economic equilibrium has zero entropy: it is completely orderly at the micro-level."
} 
semelhanças com o conceito de auto-organização - propriedade emergente dos sistemas complexos -, a ordem macro do sistema termodinâmico reflete, na verdade, a sua total falta de ordenação no nível micro, situação que não necessariamente se verifica no caso dos sistemas complexos, tal como a economia. ${ }^{43}$

Sistema fechado é aquele que não apresenta qualquer interação ou comunicação com outro sistema. Nesse, a energia pode ser convertida em diferentes formas, mas a quantidade total é constante, de acordo com a $1^{\mathrm{a}} \mathrm{L}$. T. Já pela $2^{\mathrm{a}}$ L.T., deriva-se que a entropia total num sistema fechado está sempre crescendo ao seu nível máximo, na medida em que a ordem sempre declina em desordem. Desse modo, sistemas fechados sempre têm um estado final previsível: embora eles possam gerar imprevisibilidades ao longo do caminho, sempre atingirão o equilíbrio de entropia máxima.

Sistema aberto ${ }^{44}$ é aquele no qual energia e matéria fluem dele e para ele. Esse sistema pode usar a energia e a matéria que lhe fluem temporariamente para fazer frente à entropia e, assim, criar ordem, estrutura e padrões por um período de tempo. Assim, comparativamente aos sistemas fechados, os sistemas abertos são muito mais complicados de lidar analiticamente, na medida em que, sendo sistemas de energia livre, pode ser impossível prever seu resultado final, ou até mesmo se atingirão um estado final. Segundo Beinhocker:

A presença de energia livre é o que habilita um sistema adaptativo complexo [...] a permanecer longe do equilíbrio, a criar ordem e ser dinâmico no decorrer do tempo. Se essa energia for removida, a entropia predomina e o sistema decai, e eventualmente atinge um estado estático ou de equilíbrio. ${ }^{45}$ (BEINHOCKER, op. cit., p. 70 ).

A desconsideração da $2^{\mathrm{a}}$ L.T. por parte dos marginalistas e de seus sucessores teria levado a uma classificação inadequada do sistema econômico e, consequentemente, a um tratamento teórico igualmente inadequado. Como adverte Gleiser (2002, p. 13), "Para sistemas dinâmicos complexos, equilíbrio é igual à morte, o fim de sua evolução.”

Ainda sobre esse ponto, Foley complementa que sistemas auto-organizados, complexos e adaptativos, não podem ser ditos em estado de equilíbrio, nem no sentido clássico, nem no sentido termodinâmico. A auto-organização não pode ser observada em um sistema dinâmico estável, porque, nesse caso, as estruturas tendem a entrar em colapso no estado de equilíbrio, tampouco em um sistema completamente instável localmente, resultando

\footnotetext{
${ }^{43}$ Para mais detalhes, vide Foley (2003).

${ }^{44}$ Um entendimento mais detalhado a respeito de sistemas abertos emergiu gradualmente ao longo do século XX e se acelerou com a contribuição do químico russo Ilya Prigogine nas décadas de 1960 e 1970 (BEINHOCKER, 2006, p. 70).

45 "The presence of free energy is what enables a complex adaptative system [...] to stay away from equilibrium, create order, and be dynamic over time. If you remove that energy, then entropy takes over and the system decays and eventually reaches a state of stasis or equilibrium."
} 
num sistema dinâmico caótico, ${ }^{46}$ pois, nesse caso, suas estruturas tendem a se dissipar rapidamente. Retomando o conceito de entropia, sistemas complexos, dos quais emergem a propriedade de auto-organização, não são caracterizados nem por equilíbrio de entropia zero (clássico), nem por equilíbrio de entropia máxima (termodinâmico). Nas palavras do autor, "Estruturas auto-organizadas refletidas em alguns agregados se auto-reproduzem de maneira ordenada. Mas o sistema como um todo está em constante processo de desenvolvimento." 47 (FOLEY, op. cit., p. 13-14).

Portanto, como a economia não é um sistema fechado equilibrado, e sim um sistema aberto desequilibrado ou um sistema complexo adaptativo, devem ser abandonadas as restrições analíticas impostas pelo método de equilíbrio. Sistemas fechados equilibrados não se auto-organizam espontaneamente, não geram padrões, estruturas e complexidade, e, menos ainda, criam novidade constantemente. Como diz Beinhocker:

O crescimento da atividade econômica desde a Idade da Pedra tem sido uma longa história de um embate, em grande escala, contra a entropia - algo que só poderia acontecer num sistema aberto desequilibrado. ${ }^{48}$ (BEINHOCKER, op. cit., p. 71).

Diretamente relacionada à complexidade de um sistema, está a sua não linearidade. Uma característica importante dos sistemas não lineares dinâmicos é a sua sensibilidade às condições iniciais, pois as não linearidades fazem com que pequenas diferenças nas condições iniciais sejam magnificadas ao longo do tempo e assim, ao menos que se saiba o estado inicial do sistema com grande precisão - o que, vale dizer, em se tratando de sistemas complexos, dificilmente acontece -, não há como saber o seu resultado final. Outra característica relacionada, e igualmente importante, é a dependência de trajetória - a qual, sinteticamente, significa que a história importa -, que faz com que quaisquer mudanças na cadeia de eventos possam levar a um resultado muito diferente do que se esperaria antes de sua ocorrência. Essas duas características juntas fazem com que sistemas dinâmicos não lineares ${ }^{49}$ sejam difíceis de lidar e, em muitos casos, torna-se impossível prever seus resultados.

Apesar dos economistas terem reconhecido a existência de não linearidades, tem sido deveras complicado incorporá-las aos modelos de uma forma dinâmica. Porque os sistemas dinâmicos não lineares não eram satisfatoriamente compreendidos até recentemente, a

\footnotetext{
${ }^{46}$ Sistemas dinâmicos caóticos são localmente instáveis, mas globalmente estáveis.

47 "Self-organizing structures reflected in some aggregates reproduce themselves in an orderly fashion. But the system as a whole is in constant process of development."

48 "The growth of economic activity from the Stone Age until now has been one long story of fighting entropy on a grand scale - something that could only happen in an open disequilibrium system."

${ }^{49}$ Importante notar que o estudo de sistemas dinâmicos não lineares ganhou força a partir das décadas de 1960 e 1970 do século XX, quando a combinação de novos ferramentais matemáticos e computacionais reabriu seu estudo (BEINHOCKER, op. cit., p. 107).
} 
Economia Tradicional enfrentou a questão por meio da utilização de relações não lineares em modelos estáticos, ou por meio de relações lineares em modelos dinâmicos, possibilitando, desse modo, a construção da solução das suas equações. A linearidade está correlacionada com ordem, previsibilidade, causas e efeitos interligados, e conhecidas leis universais que levem ao alcance de resultados considerados desejáveis - leiam-se, resultados de equilíbrio. Sob essa perspectiva, as partes constituintes de um sistema forneceriam indicações úteis a respeito do modo de comportamento do todo.

Já a Abordagem da Complexidade, por meio da utilização de ferramentais matemáticos e simulações computacionais desenvolvidas recentemente, procura reconhecer e modelar o sistema econômico como não linear e dinâmico - embora, obviamente, seja um método sujeito a problemas e ainda em processo de desenvolvimento, dado seu caráter relativamente recente. Nesse sentido, Rihani e Geyer (2001) argumentam que a Abordagem da Complexidade se situa no meio do caminho entre o positivismo, que implica que o domínio total da natureza é possível, e o pós-modernismo que, em essência, implica a inação social. A perspectiva da Abordagem da Complexidade aceita que os indivíduos possam agir de forma positiva para melhorar sua condição, mas reconhece que haja limites estritos à previsibilidade e à ação.

No âmbito econômico, os processos e fenômenos complexos emergentes parecem ter ao menos três causas principais: o comportamento dos agentes do sistema, a estrutura institucional do sistema e fatores exógenos ao sistema. As restrições colocadas pelo seu método reducionista teriam levado o mainstream a conceder uma ênfase desproporcional à importância explicativa dos fatores exógenos. Mesmo porque, partindo da hipótese de agente racional maximizador e de métodos analíticos de equilíbrio, as implicações dinâmicas da interação entre os agentes e a estrutura institucional pouco importam, porque já se conhece o resultado final, garantido pelas hipóteses subjacentes ao método reducionista.

Porém, de acordo com Prado (2006), sob a perspectiva de um método sistêmico, tal como propõe a Abordagem da Complexidade, os sistemas econômicos seriam entendidos como composições globais, e não simplesmente como agregações. Essa mudança de perspectiva engrandeceria a importância explicativa do comportamento dos agentes do sistema e da sua estrutura institucional, pois “A interação dos indivíduos condicionada pela estrutura define o modo de composição do sistema, que, por sua vez, modifica em processo o comportamento dos indivíduos." (PRADO, 2006, p. 310). Assim, ao retirar o foco de interesse do resultado e direcioná-lo ao processo, a Abordagem da Complexidade permitiria expandir o escopo analítico da Economia, bem como as suas variáveis de interesse e, 
promissoramente, incrementar o seu poder explicativo.

Outro conceito da Abordagem da Complexidade interessante à discussão de desenvolvimento é a noção de equilíbrio pontuado ${ }^{50}$, o qual se define quando se estabelece um padrão de grandes perturbações separadas por longos períodos de estabilidade global, no entanto com agitada atividade local. O intervalo em que se observa uma aparente inatividade é enganoso. Ondas de mudança vêm e vão sem deixar rastros, mas, eventualmente, eventos relativamente menores - os chamados "efeitos borboleta" - podem conseguir manobrar o sistema para outra direção. Subsequentemente, em um sistema estável, rapidamente se pode estabelecer um novo padrão. Assim, a variedade, e a decorrente flexibilidade, permitem que o sistema mude sua direção e evite sua própria extinção. De acordo com Geyer e Rihani (2010), "O equilíbrio pontuado é facilmente observado nas questões da humanidade, tal como a emergência e a queda de impérios antigos e de poderes hegemônicos mostram claramente." 51 (GEYER E RIHANI, 2010, p. 44).

Para a configuração do padrão de equilíbrio pontuado, concorrem os acidentes $\operatorname{congelados}^{52}$ e os eventos de acesso $^{53}$. Vejamos a definição de cada um deles. Às vezes, eventos casuais do passado se tornam parte integral da dinâmica do sistema e, por isso, são definidos como acidentes congelados. Conforme esses acidentes se acumulam, eles criam regularidades mais gerais. No âmbito dos sistemas socioeconômicos, a combinação dos acidentes congelados com as regularidades pode ser vista, segundo Geyer e Rihani, na estrutura corrente das principais instituições. Eventos de acesso não planejados surgem subitamente, de tempos em tempos, para tornar acessíveis nichos que significam, para alguns, oportunidades novas e inesperadas e, para outros, significam desastres. Como exemplos, citam os autores, “A Revolução Industrial e, mais tarde, a invenção da combustão interna e da Internet são perfeitos exemplos de eventos de acesso, compreendendo a emergência de novos desenvolvimentos e a ocupação constante dos nichos que eles geraram." ${ }^{54}$ (Ibid., p. 45).

Conforme destacam Geyer e Rihani, "Sob uma perspectiva complexa, o aprendizado é um processo contínuo de longa duração, tanto dos indivíduos quanto dos sistemas. Aprender

\footnotetext{
${ }^{50}$ Termo original: punctuated equilibrium.

51 "Punctuated equilibrium is easily observed in the affairs of humankind, as the rise and fall of ancient empires and hegemonic powers clearly shows."

${ }^{52}$ Termo original: frozen accidents.

53 Termo original: gateway events.

54 "The Industrial Revolution and, later, the invention of the internal combustion engine and the Internet are perfect specimens of gateway events, comprising the emergence of new developments and the subsequent steady filling of the niches they bring forth."
} 
como aprender se torna muito mais importante do que a memorização de 'fatos' ou 'leis'." 55 (Ibid., p. 52). A interação entre os elementos e a estrutura do sistema, bem como a sua adaptação às mudanças exógenas, lembrando o caráter aberto do sistema econômico, se mostram importantes para a própria evolução dos sistemas complexos.

Segundo Rihani e Geyer (2001), para evoluir de maneira bem sucedida, um sistema tem que se adaptar em resposta às condições mutantes e sobreviver o suficiente para enfrentar o próximo ciclo de adaptação. Em outras palavras, o sistema deve estar apto a detectar e a responder a mudanças no seu ambiente, incluindo atividades de outros sistemas que coevoluem simultaneamente a ele. Assim, para um sistema existir em um estado de complexidade auto-organizada, ele deve ter tanto uma estrutura adequada, quanto elementos internos capazes de interagir em um nível apropriado de conectividade. Saber o resultado $a$ priori desse processo evolutivo é impossível. No entanto, é certo que, “[...] a complexidade média cresce ao longo do tempo, e os sistemas com a mais alta complexidade tendem a ganhar mais." 56 (RIHANI E GEYER, 2001, p. 240).

Ao trocarem-se, no parágrafo anterior, "sistema" por "sistema econômico nacional" e "complexidade" por "capacidade endógena de geração de riqueza", mostra-se uma maneira como a Abordagem da Complexidade pode contribuir para a discussão da emergência, por um lado, de nações desenvolvidas e, por outro, de nações subdesenvolvidas, a partir das interações dos sistemas econômicos nacionais no âmbito do sistema econômico mundial.

Passemos ao aprofundamento dessa discussão nas duas próximas subseções. $\mathrm{Na}$ subseção 2.2.2, serão tratadas algumas das implicações da Abordagem da Complexidade à discussão do processo de desenvolvimento e, na subseção 2.2.3, do processo de subdesenvolvimento.

\subsubsection{Algumas implicações da Abordagem da Complexidade à discussão de}

\section{desenvolvimento}

A Abordagem da Complexidade seria potencialmente fonte de uma visão mais inclusiva do desenvolvimento justamente pela sua abertura explicativa e pela incerteza que dela deriva. Assim como no mundo natural, segundo Geyer e Rihani, a evolução das nações

\footnotetext{
55 "From a complexity perspective, learning is a continual life-long process of individuals and systems. Learning how to learn becomes much more important than memorization of 'fact' and 'laws'.,

56 " [...] average complexity increases over time, and systems with the highest complexity stand to gain the most."
} 
se realiza como uma atividade cíclica com três componentes: sobrevivência, adaptação e aprendizado. A sobrevivência requer uma estrutura estável maleável, o aprendizado significa o acúmulo e a aplicação de conhecimento relevante, e a adaptação se relaciona a mudanças que melhoram o desempenho e promovem a sobrevivência. Portanto, o sucesso depende de um balanceamento entre a maleabilidade e a estabilidade, de modo a evitar a destruição das estruturas do sistema em virtude de choques, porém, ao mesmo tempo, não se pode impedir o processo de adaptação e, consequentemente, de evolução. Assim, segundo os autores, "[...] sob a perspectiva da Complexidade, o desenvolvimento é um lento, tortuoso e longo processo que dificilmente pode ser apressado." 57 (GEYER E RIHANI, op. cit., p. 137).

Alinhado ao intuito dessa subseção, Rihani (2002) destaca que uma mudança no estudo e na prática do desenvolvimento se faz necessária. O reconhecimento formal de que o desenvolvimento é um processo complexo adaptativo contribuiria em ao menos duas frentes cruciais. Nas palavras do autor:

Primeiramente, apresenta uma síntese teórica para guiar as correntes atuais de mudanças em uma direção mais produtiva. Em segundo lugar, fornece um critério técnico objetivo para determinar as causas fundamentais de falhas de iniciativas de desenvolvimento passadas, bem como medidas apropriadas a serem adotadas de modo a reverter a situação. ${ }^{58}$ (RIHANI, 2002, p. 142).

Tendo em mente essas duas vias de contribuição, síntese teórica e critério técnico objetivo, passemos às contribuições teóricas extraídas de alguns autores que discutiram explicitamente a questão de geração de riqueza e de desenvolvimento sob a perspectiva da Abordagem da Complexidade.

As questões exploradas por Beinhocker - "O que é riqueza?", "Como ela é criada?", "Como ele pode ser incrementada?" - estão, segundo o autor, entre as mais importantes questões para a sociedade, e entre as mais antigas da Economia. A tese central de seu livro é a de que respostas significativamente novas a essas questões fundamentais começaram a emergir em virtude de desenvolvimentos, nas últimas décadas, de novas linhas de pesquisa, tal como a Abordagem da Complexidade.

Referindo-se a Georgescu-Roegen (1971), Beinhocker destaca que seu grande insight residiu no reconhecimento de que a atividade econômica se refere fundamentalmente à criação de ordem realizada pelo próprio processo de evolução. Conforme discutido na subseção anterior, essa criação de ordem está relacionada à luta contra a entropia. Retomemos

\footnotetext{
57 “[...] from a complexity perspective, development is a slow, tortuous and long-term process that can rarely be rushed."

58 "Firstly, it presents a theoretical synthesis to guide the current strands of change into a more productive direction. Secondly, it provides objective technical criteria for determining the fundamental causes of failure of past development initiatives and the appropriate measures that could be adopted to reverse that situation."
} 
brevemente essa ideia.

A $2^{\text {a }}$ L.T. denota que o universo ${ }^{59}$ está inevitavelmente se movendo de um estado de baixa entropia para outro de alta entropia. Assim, deixado às suas próprias forças, o mundo sai de um estado de ordem para outro de desordem. No entanto, se for imputada energia a um determinado sistema - caso dos sistemas abertos - pode-se enfrentar temporariamente a entropia crescente e criar ordem nesse sistema. Como implicação importante, para evitar a sua dissipação e decaimento, um sistema aberto deve manter um fluxo de energia dentro dele para poder enfrentar a entropia. Por outro lado, a entropia desse sistema acaba sendo exportada novamente para o universo na forma de calor e resíduos, implicando que a entropia total do universo continua sempre a aumentar.

Apesar da conotação teórica com aparência de ciência natural, trazer a discussão de entropia para alargar a compreensão do funcionamento dinâmico do sistema econômico se mostra bastante profícua e esclarecedora. Ademais, vale ressaltar que falar de entropia no contexto do sistema econômico não se trata de importar mais uma metáfora de outras ciências. Como bem advertira Georgescu-Roegen, os sistemas econômicos existem no mundo físico real e, portanto, devem obedecer à mesma lei de entropia que rege todos os outros sistemas que compõem o universo.

Beinhocker destaca três importantes observações feitas por Georgescu-Roegen que subsidiariam uma conexão entre a ideia de economia como um sistema complexo e evolucionário com a questão da origem e geração da riqueza: (i) os processos que criam valor econômico são irreversíveis; (ii) qualquer processo econômico necessita de energia para transformar matérias-primas e informação em bens e serviços mais elaborados; e (iii) apesar da criação de produtos e serviços ser uma atividade inerente de criação de ordem, nem toda ordem possui valor econômico.

A partir dessas três observações, Beinhocker define aquelas que seriam as três condições, alcunhadas por ele de condições $G-R$, para levar à criação de valor econômico: (i)' irreversibilidade $^{60}:$ todas as transformações e transações criadoras de valor econômico são termodinamicamente irreversíveis; (ii)' entropia: todas as transformações e transações criadoras de valor econômico reduzem, localmente, a entropia dentro do sistema econômico,

\footnotetext{
${ }^{59}$ Entendido como o sistema que engloba todos os sistemas. No caso dessa tese, o universo é o sistema políticoeconômico mundial, que engloba todos os sistemas econômicos nacionais, cada um deles encarados como sistemas adaptativos complexos. Essa ideia será retomada e desenvolvida no evolver dessa subseção.

${ }^{60}$ Importante observar que afirmar que as transformações ou processos que criam valor econômico são dinamicamente irreversíveis não significa que é impossível reverter um processo criador de valor, e sim que se necessita de energia tanto para fazer, quanto para se desfazer algo. Portanto, em sistemas econômicos, o tempo tem necessariamente uma direção, daí a sua irreversibilidade dinâmica (BEINHOCKER, op. cit., p. 305).
} 
mas, ao mesmo tempo, incrementam a entropia globalmente; e (iii)' adequação: todas as transformações e transações criadoras de valor econômico produzem artefatos e/ou ações que se adéquam aos propósitos humanos.

Desse exercício teórico, Beinhocker conclui que toda riqueza é criada por processos termodinamicamente irreversíveis e redutores de entropia, sendo o ato de criar riqueza um ato de criação de ordem, embora nem toda criação de ordem seja geradora de riqueza. A coevolução das tecnologias físicas, das tecnologias sociais e dos negócios selecionariam as formas de ordem que se adéquam aos propósitos dos homens. ${ }^{61}$ Nas palavras do autor, "Riqueza é então uma forma de anti-entropia. É uma forma de ordem, mas não de qualquer ordem - é uma ordenação adequada." 62 (BEINHOCKER, op. cit., p. 316).

Se a riqueza é de fato uma ordenação adequada, Beinhocker sugere uma palavra mais familiar para descrevê-la. Em Física, ordem é o mesmo que informação. Assim, a riqueza poderia ser definida como informação adequada, ou como conhecimento simplesmente, pois conhecimento é informação com utilidade, ou seja, com a qual se pode fazer algo ou se realizar algum propósito. Então, a origem da riqueza seria o próprio conhecimento. Segundo o autor:

[...] mais do que tratar o conhecimento como uma hipótese, como algo exógeno, como um processo misterioso fora do escopo da economia, a perspectiva baseada na Abordagem da Complexidade, tal como eu delineei, coloca a criação de conhecimento no cerne da economia. ${ }^{63}$ (Ibid., p. 317).

Segue-se desse raciocínio que a evolução seria uma máquina produtora de conhecimento. Toda a ordem, complexidade e conhecimento teriam sido criados e reunidos por meio da receita evolutiva. Em poucas palavras, e resumindo a contribuição de Beinhocker à discussão aqui proposta, a riqueza das nações equivaleria ao conhecimento que acumularam e detêm, bem como ao grau de complexidade e ordenação que atingiram, como resultado do processo evolutivo pelo qual passaram, envolvendo a interação de variáveis sociais, estruturais, culturais e institucionais.

\footnotetext{
${ }^{61}$ Pelo caminho evolucionário, Nelson (2008) realiza uma abordagem semelhante, embora se refira estritamente a crescimento econômico: "A nova teoria evolucionária do crescimento que está emergindo encara o crescimento econômico como resultado da co-evolução de tecnologias, de estruturas de firma e industriais, e de instituições de fomento e governamentais. Eu sugiro que uma teoria satisfatória dos processos envolvidos no crescimento econômico deve considerar todos esses três aspectos, e que a dinâmica dirigente envolve sua interação." (NELSON, 2008, p. 13). Na versão original: "The new evolutionary growth theory that is emerging sees economic growth as the result of the co-evolution of technologies, firm and industry structures, and supporting and governing institutions. I propose that a satisfactory theory of the processes involved in economic growth must consider all three of these aspects, and that the driving dynamics involves their interaction."

62 "Wealth is thus a form of anti-entropy. It is a form of order, but not just any order - it is fit order."

63 " [...] rather than treating knowledge as an assumption, an exogenous input, a mysterious process outside the bounds of economics, the Complexity-based view I have outlined puts the creation of knowledge at the endogenous heart of the economy."
} 
Sobre o caminho evolutivo percorrido (e a ser percorrido) pelas nações para gerarem riqueza e desenvolvimento, vale ressaltar que, se cada sistema econômico nacional é resultado de uma trajetória histórica particular, deduz-se que não existe um único caminho para o desenvolvimento, ou uma receita que valha em qualquer contexto. Sobre essa questão, Badcock (2007) argumenta que as teorias tradicionais do desenvolvimento não teriam sido bem sucedidas, em boa medida, porque se baseavam em uma estrutura de caráter linear. ${ }^{64}$ Segundo o autor, essa chamada estrutura linear teria como pressupostos: (i) há apenas um caminho para o desenvolvimento; (ii) este caminho possui um ponto final estável e alcançável, que equivaleria à condição das nações desenvolvidas, as metas a serem alcançadas; (iii) as nações podem ser individualmente posicionadas neste caminho; (iv) estratégias de políticas apropriadas podem ser desenvolvidas somente por intelectuais; e, por fim, (v) os chamados modelos "de cima para baixo" $" 65$ podem fornecer resultados calculáveis e mensuráveis.

Nesse mesmo sentido, Rihani observa que os projetos de desenvolvimento preconizados por alguns dos pioneiros do desenvolvimento tinham implícita uma trajetória pré-determinada que, supostamente, levaria as nações ao resultado de desenvolvimento. Sob essa perspectiva linear, o processo de desenvolvimento seria, então, finito, previsível e alcançável. De outro modo, indica o autor que, pela Abordagem da Complexidade:

[...] o projeto de desenvolvimento definiria de modo a melhorar o desempenho de uma nação ou comunidade dentro de condições em contínua mudança por meio do engrandecimento das aptidões e adequação de seus membros. O processo é contínuo e o resultado não é pré-determinado. ${ }^{66}$ (RIHANI, 2002, p. 135-136).

A Abordagem da Complexidade possibilitaria um tratamento teórico relativamente diferenciado do desenvolvimento, na medida em que, ao postular um novo paradigma científico, altera a estrutura fundamental das teorias lineares. $\mathrm{O}$ arcabouço teórico da Abordagem da Complexidade contempla o fato de que os mundos natural e humano combinam ordem e desordem, certeza e incerteza, previsibilidade e imprevisibilidade, em um

\footnotetext{
${ }^{64}$ Importante notar que essa observação não invalida a afirmação que se pretende construir nos dois capítulos subsequentes de que há elementos teóricos compatíveis com a Abordagem da Complexidade na obra dos pioneiros do desenvolvimento econômico.

${ }^{65}$ Termo original: "top-down" models. Como bem observam Rihani e Geyer, "Quando o desenvolvimento se tornou a prioridade global depois da II Guerra Mundial, ele era implicitamente encarado como uma incumbência que demandava um direcionamento do topo por meio da ONU, do Banco Mundial e do FMI, de líderes mundiais e agências governamentais especialistas em nações desenvolvidas e em desenvolvimento." (RIHANI E GEYER, op. cit., p. 238). Na versão original: "When development became a global priority after the Second World War, it was implicitly viewed as a task that required direction from the top through the United Nations (UN), the World Bank and IMF, world leaders and specialist governmental agencies in developed and developing countries."

66 " [...] the development project would set out to improve a nation or community's performance within continually shifting conditions by means of enhancing its members' fitness and capability. The process is ongoing and the outcome is not preordained."
} 
sistema complexo adaptativo que não se conforma a leis universais, regras ou prescrições políticas rígidas. O que, novamente, joga luz sobre a necessidade de considerar a heterogeneidade dos sistemas e de seus elementos componentes, sendo essa uma questão fundamental para tratar de desenvolvimento econômico, especialmente no contexto do subdesenvolvimento. Segundo Badcock:

Para a Abordagem da Complexidade, um modelo universal para todas as nações nunca funcionaria, especialmente se não fosse derivado de interpretação e variedade local. Modelos lineares rígidos baseiam-se na noção de que os efeitos podem ser previstos de maneira confiável. ${ }^{67}$ (BADCOCK, 2007, p. 87).

Brunner e Allen (2009) ressaltam que o desenvolvimento se refere a intervenções em um sistema altamente complexo chamado sociedade, da qual o sistema econômico é parte componente. Essas intervenções, altamente sujeitas a incertezas, requerem uma compreensão abrangente dos processos de auto-organização que condicionam o sistema econômico, nos níveis micro e macroeconômico. O que levaria à mudança estrutural e, consequentemente, ao desenvolvimento, seria a reconfiguração das conexões econômicas entre os agentes. Conforme argumentam os autores:

Em uma abordagem de sistemas complexos, processos microeconômicos, auto-catalíticos, levam a comportamentos macroeconômicos, agregados do sistema, e a evolução do nível macro do sistema constrange, a seu turno, o comportamento dos agentes heterogêneos. ${ }^{68}$ (BRUNNER E ALLEN, 2009, p. 348).

As nações devem ser compreendidas como sistemas complexos adaptativos. Todas as nações, independentemente da sua condição socioeconômica em determinado momento, passaram por um longo processo de evolução. De acordo com Badcock, o desenvolvimento, sob a perspectiva da Abordagem da Complexidade, não tem nem começo, nem fim; é sempre inesperado e com seu resultado em aberto. O desenvolvimento se trata de, conforme sintetizam Rihani e Geyer, “[...] um vagaroso processo de exploração de possibilidades.” 69 (Rihani e Geyer, op. cit., p. 45). Por isso também, não há uma única lei universal de desenvolvimento, pois, conforme dito anteriormente, cada país compôs (e compõe) seu próprio processo de evolução. Como bem destaca Badcock:

Diversidade e unicidade são características de sistemas complexos, assim como sua capacidade de se desenvolverem e de se adaptarem a mudanças em seu ambiente local e global, de modo a tornálos sistemas mais robustos no longo prazo. ${ }^{70}$ (BADCOCK, op. cit., p. 90 ).

\footnotetext{
67 "For complexity, a universal model for all countries could never work, especially if it does not allow for local variety and interpretation. Rigid linear models rested on the notion that effects could be reliably predicted."

68 "In a complex systems approach, microeconomic, autocatalytic processes lead to macroeconomic, aggregate behavior of the system, and the evolving macro scale of the system constrains in turn the behavior of heterogeneous actors."

69 "[...] a leisurely process of exploration of possibilities."

70 "Diversity and uniqueness are assets in complex systems as they are able to develop and adapt to changes in their local and global environment, thereby making them stronger systems in the long term."
} 
Portanto, para que as políticas que objetivem o alcance e a manutenção do desenvolvimento possam ser bem sucedidas, elas devem ser necessariamente elaboradas levando em consideração tanto as especificidades do sistema econômico nacional - ou seja, os seus fatores internos - em que serão aplicadas, quanto a natureza de sua inserção no sistema econômico mundial - ou os fatores externos.

A aplicação da Abordagem da Complexidade na área de políticas públicas é muito recente, sendo muitas das sugestões apresentadas apenas especulativas. Porém, na direção do avanço e da superação da perspectiva atomista da Economia Tradicional, vale ressaltar que o grande diferencial e o potencial de contribuição da Abordagem da Complexidade residem justamente em buscar tratar analiticamente do sistema econômico e de suas questões sem desconsiderar a sua própria complexidade, embora ainda seja uma abordagem teórica em processo de desenvolvimento e, especialmente por isso, sujeita a uma série de problemas e inconsistências.

Conforme destacam Geyer e Rihani, ao longo do tempo, embora o conhecimento aumente, os fenômenos físicos, biológicos e humanos são imprevisíveis e evoluem em novos padrões. Assim, embora os atores políticos possam saber mais, os sistemas que eles observam não são estanques. Pelo contrário, estão em permanente processo de evolução e de consequente reinterpretação. Por isso, o conhecimento, embora útil e poderoso, é sempre limitado e incompleto, e o processo de aprendizado nunca chega ao fim. Desse modo, para a consecução de políticas públicas, há que se ter em mente não um ponto final a ser alcançado, mas sim uma busca e preparo contínuo no sentido de promover mudanças e ajustes nessas políticas, dentro de uma estrutura limitada, porém mutável. Os autores concluem que não há uma hierarquia estabelecida (e imutável) de conhecimento ou método nas ciências sociais. Entretanto, certos métodos são mais apropriados para lidar com determinados fenômenos do que outros. De acordo com os autores:

A criação de um entendimento das fronteiras fundamentais combinadas com a aceitação de uma descoberta e abertura contínua é o objetivo final. A chave não está em encontrar a ordem final e implementá-la, mas em encorajar os atores políticos a se adaptarem e se ajustarem às mudanças evolucionárias contínuas. ${ }^{71}$ (GEYER E RIHANI, op. cit., p. 32).

Relacionada às estratégias de desenvolvimento que poderiam decorrer da aplicação dessa perspectiva diferenciada da Abordagem da Complexidade, Beinhocker busca avançar na discussão sobre como essa abordagem poderia contribuir para a compreensão de questões

\footnotetext{
71 "Creation of an understanding of fundamental boundaries combined with an acceptance of continual discovery and openness is the ultimate goal. The key isn't to find the final order and implement it, but encourage the actors in the policy area to adapt and adjust to the continual evolutionary changes."
} 
relacionadas à política e às políticas propriamente ditas. $\mathrm{O}$ autor desenvolve a sua reflexão em torno principalmente de duas questões: a visão de natureza humana e a visão sobre o papel do mercado vis-à-vis o papel do Estado. Para o autor, a Abordagem da Complexidade ofereceria uma nova perspectiva sobre as duas questões, da qual se propõe derivar contribuições para a discussão em diversas áreas, sendo duas delas de particular interesse para essa tese: a pobreza nos países em desenvolvimento e a desigualdade econômica.

De acordo com Beinhocker, uma visão de natureza humana condizente com a Abordagem da Complexidade implicaria negar tanto que os homens são inerentemente egoístas, como inerentemente altruístas. De outro modo, haveria que se admitir tanto um papel para a responsabilidade pessoal, ou seja, de que nem todos os males são falhas sociais (ou sistêmicas) e também que os homens possuem instintos mais generosos (ou cooperativos). Como bem ressalta o autor, os indivíduos são peças componentes do grande quebra-cabeça que é o sistema econômico, e é da combinação interativa do comportamento individual e das estruturas institucionais que se deriva a emergência do comportamento sistêmico.

Essa observação a respeito da organicidade das estruturas institucionais e dos agentes remete à questão seguinte, sobre o papel dos mercados vis-à-vis o papel do Estado. Para Beinhocker, uma evolução baseada no mercado requer um equilíbrio cuidadoso entre cooperação e competição, no qual o governo desempenha um papel crucial, na medida em que pode auxiliar na sustentação da efetividade evolucionária do sistema econômico. Idealmente, o autor argumenta que o papel econômico do Estado seria criar um aparato institucional que sustentasse os processos evolucionários dos mercados, que levasse a um equilíbrio efetivo entre cooperação e competição e que modelasse a função de adequação econômica para servir às necessidades da sociedade Já o papel econômico dos mercados seria o de fornecer incentivos para a descoberta e diferenciação das atividades econômicas. Assim, conclui o autor, “A questão não se refere a Estados versus mercados - e sim a como combinar Estados e mercados para criar um sistema evolucionário efetivo." 72 (BEINHOCKER, op. cit., p. 427).

Vale notar que, apesar de interessante e condizente com a Abordagem da Complexidade, a discussão sobre o papel do Estado e dos mercados proposta por Beinhocker está restrita somente aos fatores internos aos sistemas econômicos nacionais, sem qualquer menção à dimensão sistêmica mundial. Conforme abordado anteriormente, os fatores externos também devem ser incorporados à discussão, especialmente no contexto do subdesenvolvimento, na medida em que as nações subdesenvolvidas apresentam, em algum

\footnotetext{
72 "The question is not states versus markets - it is how to combine states and markets to create an effective evolutionary system."
} 
grau e sentido, alguma forma de dependência com relação às nações desenvolvidas. Sem a inclusão de fatores externos, não há como explicar satisfatoriamente a manutenção das desigualdades entre as nações.

Também sobre o embate entre o papel do Estado e dos mercados, Badcock argumenta que o desenvolvimento de cada nação precisa ser deixado evoluir independentemente de governos autoritários repressivos ou de excessiva intervenção externa, na medida em que eles podem interferir indevidamente nas interações, diversidade e auto-organização locais. Do mesmo modo, as nações precisam ter uma infraestrutura adequada, baseada em regras simples, a partir da qual a auto-organização social possa emergir. Dessa forma, argumenta o autor que um ambiente adequado para que os sistemas econômicos nacionais possam se desenvolver estaria definido entre essas duas fronteiras - quais sejam, entre a ordem impositiva e o caos anárquico. Ou, conforme define sinteticamente Arthur, a mão que caracteriza o Estado deve ser "Nem uma mão pesada, nem uma mão invisível, mas uma mão que sugere." 73 (ARTHUR, 2009, p. 16).

Sobre a importância das características locais ou fatores internos, Rihani (2002) aponta que, como a Abordagem da Complexidade conduz à definição de desenvolvimento como um processo multifacetado, não linear, adaptativo e em andamento, estratégias de desenvolvimento que não decorram de interações e atividades locais não podem ser bem sucedidas, pois o sistema é ele mesmo sustentado pela energia proveniente das interações locais, sendo esse o único meio pelo qual o sistema pode fazer frente às forças que o conduziriam ao caos, tal como indicado pela $2^{\mathrm{a}} \mathrm{L}$. T. Em outras palavras, é por meio de seus fatores internos que as nações podem fazer frente aos fatores externos que sobre elas exercem influência, e é justamente desse processo de embate que pode emergir ou não o seu desenvolvimento.

O desenvolvimento, segundo Badcock, precisa promover diversificação no nível local para possibilitar que interações profícuas floresçam. Ademais, a estratégia de desenvolvimento precisa incluir o desenvolvimento humano - ou seja, melhorar os padrões de saúde, nutrição, alfabetização, democracia e governança -, pois, conforme argumenta Rihani, nenhum desenvolvimento seria possível se a maioria da população de determinada nação não estivesse apta a dirigir seus esforços para esse fim. Essa observação é fundamental porque o conhecimento local específico pode auxiliar no processo de desenvolvimento de uma maior diversidade e interação. De acordo com Badcock, uma grande variedade de recursos precisa

\footnotetext{
73 "Not a heavy hand, not an invisible hand, but a nudging hand."
} 
ser incorporada ao sistema de modo a capacitá-lo a se auto-organizar e a se adaptar, assegurando-lhe resistência em situações futuras que possam vir a desestabilizar as suas estruturas.

Sobre essa questão, Rihani e Geyer concluem que, para uma nação evoluir adequadamente como um sistema complexo adaptativo, os indivíduos que nele interagem devem estar aptos a acumular conhecimento, a interpretar e responder a oportunidades, a ameaças e a outros eventos no seu ambiente de atuação. Além disso, a fim de habilitar uma nação a alcançar um estágio de auto-organização evolutivo, as ações de grupos e indivíduos devem ser facilitadas e protegidas por uma estrutura adequada de regras e regulamentos.

No que se refere especificamente à pobreza nos países em desenvolvimento e à desigualdade econômica, Beinhocker destaca que, apesar das implicações da cultura sobre a política de desenvolvimento estarem começando a ser exploradas, cada vez mais se torna claro que a cultura deve fazer parte da equação do desenvolvimento, sugerindo, inclusive, que os programas que continuarem a ignorar a base cultural da pobreza serão, provavelmente, sempre inócuos. A consideração das condições culturais é bastante pertinente, na medida em que a cultura compõe o conjunto de especificidades nacionais que podem ter implicações importantes para as estratégias de desenvolvimento.

Por outro lado, é importante ressaltar que, levar em consideração que normas culturais podem ajudar a sustentar o desenvolvimento econômico, não significa implicar que existe apenas uma composição cultural condizente com o sucesso econômico. Beinhocker destaca três categorias de normas culturais: (i) normas relacionadas ao comportamento individual, por exemplo, aquelas que incentivam a ética no trabalho e a responsabilização individual; (ii) normas relacionadas ao comportamento cooperativo; e (iii) normas relacionadas à inovação, tanto no que se refere à predileção por explicações racionais e científicas em detrimento de explicações religiosas e místicas, como no que se refere ao incentivo a práticas competitivas. Essas três categorias estariam ainda condicionadas a outra norma, relacionada a como as pessoas encaram a variável tempo. Para o autor, culturas muito arraigadas no passado teriam normas culturais menos estimuladoras do desenvolvimento, pois, como nada do que virá poderá ser melhor do que o observado no passado, não há estímulo a promover mudanças e, sem elas, não há desenvolvimento. Do contrário, em culturas com uma ética que incentive a investir no futuro, os estímulos a realizar mudanças estão dispostos.

Beinhocker sugere que as normas culturais fornecem as regras micro de 
comportamento do agente e o capital social ${ }^{74}$ seria o resultado emergente da criação de redes cooperativas pelos próprios agentes. Essa definição de capital social não teria adentrado o escopo de discussão da Economia Tradicional, porque, sob a perspectiva desta, os indivíduos realizam escolhas racionais ótimas e, na medida em que assim o fazem, levam, necessariamente, ao ótimo social. Já a Abordagem da Complexidade infere que as interações, mesmo de indivíduos bem intencionados, podem fazer emergir resultados socialmente indesejáveis. Dentre esses resultados indesejáveis, está justamente a não verificação do que a teoria econômica convencional garante por hipótese, a geração de bem estar para toda a coletividade.

Expandindo a discussão das desigualdades ao sistema político-econômico mundial, sobre o hiato crescente entre os países ricos e pobres, Rihani e Geyer argumentam que o próprio processo de acumulação de complexidade - de ordenação ou de riqueza - por parte das nações desenvolvidas fez com que elas se distanciassem das outras nações. Nas palavras dos autores:

O hiato entre elas e as nações mais pobres está, inexoravelmente, se ampliando. Mas isso é exatamente o que poderia ser esperado se o desenvolvimento das nações se comporta como um típico sistema complexo adaptativo: a complexidade média cresce e os com alta complexidade tendem a ganhar mais. ${ }^{75}$ (RIHANI E GEYER, op. cit., p. 242).

Tendo em mente esse reconhecimento de que a desigualdade entre nações seria um resultado emergente e esperado do evolver da dinâmica de interação dos diversos sistemas complexos adaptativos nacionais que compõem o sistema político-econômico mundial, na medida em que os sistemas complexos adaptativos estão sujeitos a retroalimentações positivas, passemos, na subseção seguinte, à discussão específica da emergência do subdesenvolvimento, sob uma perspectiva pautada pela Abordagem da Complexidade.

\subsubsection{Alguns caminhos abertos pela Abordagem da Complexidade para a discussão da} emergência e da perpetuação do subdesenvolvimento

Conforme sugerido ao final da subseção anterior, da observação da composição do sistema político-econômico mundial seria possível destacar que a emergência do

\footnotetext{
74 Definido por Robert Putnam como "[...] conexões entre indivíduos - redes sociais e as normas de reciprocidade e grau de confiança que delas emergem." (PUTNAM apud BEINHOCKER, op. cit., p. 435). Na versão original: "[...] connections among individuals - social networks and the norms of reciprocity and trustworthiness that arise from them."

75 "The gap between them and poorer nations is inexorably widening. But that is precisely what one would expect if the development of nations behaved as a typical complex adaptive system: average complexity increases and the highest complexity stands to gain the most."
} 
subdesenvolvimento em algumas nações estaria organicamente interligada à emergência do desenvolvimento em outras. Contrariamente ao que sugeriria uma perspectiva linear do processo de desenvolvimento, da qual se esperariam fases a seres cumpridas no continuum subdesenvolvimento-desenvolvimento, conforme já advertira Prebisch (1949), a estrutura do sistema político-econômico mundial é caracterizada por dois grupos de países distintos, o centro e a periferia, não se tratando o subdesenvolvimento de uma fase rumo ao desenvolvimento, e sim de parte componente dessa estrutura econômica mundial hierarquizada.

Parafraseando Chang (2002), será que a escada que leva ao desenvolvimento do sistema político-econômico mundial comporta que todos os sistemas nacionais subam por ela? Ou, pelo contrário, em virtude da força de diversos mecanismos cumulativos, essa escada necessariamente se rompe em alguns degraus, prendendo algumas nações no subdesenvolvimento? Vejamos, a seguir, alguns caminhos pelos quais a Abordagem da Complexidade pode contribuir: para a compreensão da emergência, por um lado, de nações desenvolvidas, e, por outro, de nações subdesenvolvidas, bem como em que intensidade essas emergências estariam conectadas; e para vislumbrar meios pelos quais os círculos viciosos que resultam no subdesenvolvimento poderiam ser potencialmente rompidos.

Para o aprofundamento da discussão da emergência do subdesenvolvimento sob a perspectiva da Abordagem da Complexidade se mostra pertinente retomar a $2^{\mathrm{a}} \mathrm{L}$. T. e algumas das suas consequências para a discussão da dinâmica do sistema econômico. Como já discutido na subseção 2.2.1, a consideração da $2^{\mathrm{a}}$ L. T. pela Física provocou grandes transformações relativas ao entendimento do funcionamento dinâmico dos sistemas. Relembrando o conceito, a $2^{\mathrm{a}} \mathrm{L}$. T. estabelece que a entropia, medida de desordem sistêmica, é sempre crescente, e o universo como um todo está, inevitavelmente, se alternando entre um estado de ordem e outro de desordem.

Derivado da $2^{\text {a }}$ L.T., e de especial interesse para a Economia, é o conceito de sistema aberto, aquele no qual energia e matéria fluem dele e para ele, sendo que esse sistema pode se valer da energia e matéria que para ele fluem para fazer frente à entropia e, assim, criar ordem, estrutura e padrões por um período de tempo. A economia é um sistema aberto desequilibrado ou, mais precisamente, um sistema complexo adaptativo. Ademais, retomando a observação de Rihani e Geyer, sendo o desenvolvimento um problema de caráter complexo, as nações devem ser encaradas como sistemas complexos adaptativos próprios; e conforme sugerem os mesmos autores e Beinhocker, o grau de complexidade de determinado sistema econômico se relaciona diretamente à sua capacidade de gerar riqueza e de se desenvolver. 
Nesse ponto, vale recuperar uma ideia aventada no final da subseção 2.2.1. Adequando a explicação de Rihani e Geyer ao contexto dessa subseção, e buscando incorporar discussões realizadas na subseção anterior, seria possível sugerir que, com vistas à sua evolução e desenvolvimento, uma nação, enquanto sistema complexo adaptativo, precisa ser capaz de se adaptar às mutantes e instáveis condições internas e externas, de modo a emergir um resultado auto-organizado, qualitativamente melhor do que o inicial. Em outras palavras, a nação deve estar preparada para detectar e responder a mudanças que ocorrem dentro de sua sociedade, mudanças essas resultantes da interação de seus próprios fatores internos, quanto desses fatores internos com os fatores externos, já que fazem parte de um sistema global, composto por outras nações que estão simultaneamente co-evoluindo.

Assim sendo, para que um sistema econômico nacional - adaptativo e complexo possa incrementar suas possibilidades de existir e persistir em um estado de complexidade auto-organizada, com capacidade de prosseguir satisfatoriamente na trajetória evolutiva, refletida em seus resultados de desenvolvimento, ele deveria apresentar, como pré-requisito, ao menos elementos internos adequados. Importante ponderar que, em se tratando de nações periféricas, se existe alguma margem possível de controle, ela se refere aos fatores internos. E se os próprios elementos internos, bem como as propriedades que deles emergem, não podem ser perfeitamente controlados, sobre os elementos externos, por seu turno, a margem de controle é praticamente nula. No entanto, em alguma medida, a combinação de fatores internos poderia, potencialmente, possibilitar um melhor tratamento dos efeitos provocados pelos fatores externos e da interação deles com os próprios fatores internos.

Conforme destacado anteriormente, o subdesenvolvimento econômico não somente não é uma fase prévia ao desenvolvimento, como apresenta, na verdade, uma relação orgânica com ele. Ou seja, são resultados antagônicos, mas intersticialmente interligados. Valendo-se da abordagem teórica discutida nesse capítulo, pensando o universo como o sistema políticoeconômico mundial e cada uma das nações componentes desse universo como um sistema adaptativo complexo único, seria possível derivar como explicação, em termos termodinâmicos, que as nações avançadas, ao diminuirem sua entropia, se complexificarem e se desenvolverem, teriam direcionado a sua desordem para os outros sistemas nacionais, dificultando o alcance da ordem, do incremento de complexidade e do desenvolvimento nesses. Historicamente, esse embate teria ocorrido entre as nações centrais e as nações periféricas. Em poucas palavras, tendo em mente que a entropia do sistema global, respeitando a $2^{\mathrm{a}}$ L.T., é sempre crescente, pode-se sugerir que o enfrentamento da desordem (entropia) e a auto-organização emergente que teria permitido o desenvolvimento em algumas 
nações teria acarretado desordem em outras nações, criando alguns obstáculos à superação do seu subdesenvolvimento.

Os exemplos históricos da transferência de desordem das nações mais ricas às mais pobres, de modo a criar ordem interna, são diversos, e se mostraram em diferentes roupagens ao longo do tempo. Esses diversos modos de transferência de entropia foram permitidos, especialmente, por conta da relação de dominação que os países centrais sempre mantiveram com os países periféricos, seja por meios políticos, seja por meio econômicos. Como exemplos mais marcantes dessas diversas formas de transmissão de desordem das nações mais ricas às mais pobres podem ser elencados: a transferência de maquinário obsoleto, a aplicação de capitais ociosos, a instalação da base de indústrias menos complexas e mais intensivas em mão-de-obra barata e, por fim, a própria relação comercial - importação de bens primários e exportação de bens mais elaborados -, dentre outros. ${ }^{76}$

Todos esses modos de transferência de desordem teriam permitido aos países centrais promover a sua ordem interna, por meio da potencialização dos seus efeitos multiplicadores internos, em virtude dos ganhos e vantagens permitidos pelas formas históricas de dominação, traduzidos, em boa medida, pela tese Singer-Prebisch (Singer, 1950; Prebisch, 1949). Quanto às nações subdesenvolvidas, pelo contrário, receptoras da entropia, o reflexo da desordem interna encontrar-se-ia, justamente, na não apreensão do potencial do efeito multiplicador interno e na perpetuação de várias formas de extrema desigualdade interna - seja em termos de classe, seja em termos regionais - e, consequentemente, no seu aprisionamento ${ }^{77}$ na condição de subdesenvolvimento.

Por conta do efeito das retroalimentações positivas observadas em sistemas complexos adaptativos - e das suas propriedades derivadas, tais como dependência de trajetória ${ }^{78} \mathrm{e}$ aprisionamento -, se não houver intervenção e redirecionamento, de modo a quebrar a lógica própria desses efeitos cumulativos, a tendência é que o hiato entre as nações desenvolvidas e as subdesenvolvidas aumente, assim como os hiatos internos, relativos às desigualdades entre as classes e entre as regiões de determinado sistema econômico nacional. Pois, quanto mais rica, poderosa, estruturada e tecnologicamente avançada for determinada nação, maior a sua capacidade intrínseca de continuar a ser assim; quanto mais pobre for a nação, menor a capacidade (de maneira exponencial) de superar tal condição. Em termos termodinâmicos, quanto mais auto-organizada e, portanto, complexa, for determinada nação, maior seria a sua

\footnotetext{
${ }^{76}$ Alguns desses aspectos são discutidos pelos próprios pioneiros, conforme disposto nos próximos capítulos.

77 Termo original: lock-in.

${ }^{78}$ Termo original: path dependence.
} 
capacidade de continuar a gerar riquezas e apreendê-las internamente, amenizando ou até superando as suas próprias desigualdades internas, se constituindo esse mesmo fato num potencializador do alcance da ordem interna e, consequentemente, de direcionar a sua desordem para outros sistemas nacionais.

No entanto, como tentar promover o redirecionamento da dinâmica dos sistemas nacionais cujo resultado tem sido a perpetuação do subdesenvolvimento? Qual seria a forma de intervenção? E a quem caberia? Em se tratando de um sistema adaptativo complexo, com alta dose de incerteza e com pequena margem de segurança com relação aos resultados de determinada ação, seria necessário, pelo menos, um instrumento de ação de grande alcance e com alto poder de transmissão sistêmica. No caso das nações subdesenvolvidas, essa questão adquire uma entonação ainda mais marcante, na medida em que o objetivo implícito dos programas e políticas que visem o desenvolvimento deve ser justamente a melhora do bem estar da coletividade, diminuindo as desigualdades internas.

Como primeira intuição, e em linha com as observações de alguns autores discutidos na subseção anterior, aos governos das nações caberia intervir para reverter o processo de perpetuação de desigualdades por meio de políticas socioeconômicas, de garantias institucionais e de infraestrutura. A justificativa para essa atribuição é a de que só o Estado possuiria os meios e ferramentas adequados para provocar mudanças sistêmicas, cristalizados na feitura e execução de políticas públicas. Ademais, há que se acrescer que, conforme observam Reis e Cardoso (2010), a efetivação dos condicionantes internos mais importantes para o desenvolvimento perpassa, necessariamente, pela existência de um Estado sustentado por uma coalizão social interessada em promover um projeto nacional de desenvolvimento.

Essa observação traz à tona ao menos o seguinte questionamento: como garantir que essa coalizão social seja em prol de políticas que visem o incremento de bem estar da coletividade se, no caso das nações subdesenvolvidas, às elites políticas e econômicas seria mais vantajoso manter o status quo de desigualdade interna? Embora essa questão não seja objeto de discussão dessa tese, a observação é pertinente por conta da necessidade de ter em conta "[...] a crucialidade da postura das diversas classes sociais, principalmente da elite dominante, na determinação da natureza do desenvolvimento socioeconômico." (REIS E CARDOSO, 2009a, p. 256). De qualquer modo, por mais que o Estado possa sofrer maior ou menor dominância de determinados grupos de interesse, partindo de um contexto de democracia, essa predominância apresentaria determinados limites. ${ }^{79}$ Além disso, o Estado

\footnotetext{
${ }^{79}$ Vale notar desde já que, no caso brasileiro, a condição de Estado democraticamente constituído foi mais exceção do que regra no período 1930-1980. Mesmo assim, essa observação não invalida o intuito
} 
democraticamente constituído deveria, por hipótese, representar todas as classes e grupos de interesse da sua sociedade. Por conta de seus ferramentais e instrumentos de alto alcance, as políticas públicas, somente o Estado - vale dizer, resultado (propriedade emergente) e componente do sistema complexo adaptativo nacional - poderia desempenhar o papel de um mecanismo redirecionador da desordem gerada, tanto interna quanto externamente.

Embora não seja garantidor do resultado final, por natureza imprevisível, sem um mecanismo redirecionador que faça frente aos mecanismos cumulativos que resultam em desigualdades entre as nações, as chances de que o resultado final emerja em forma de desenvolvimento econômico são ainda menores. No entanto, conceder esse papel ao Estado, de gerador e/ou catalizador de ordem sistêmica, não feriria um dos princípios da própria Abordagem da Complexidade, de que sistemas adaptativos complexos não estão sujeitos a um controle geral e, consequentemente, de que há uma impossibilidade lógica de que qualquer agente apresente alguma forma de primazia causal diferenciada sobre a dinâmica do sistema?

A Abordagem da Complexidade é uma perspectiva teórico-metodológica ainda de aplicação recente na Economia. Especialmente sobre os temas relativos ao desenvolvimento econômico, ainda há pouca literatura disponível. Porém, assim como se buscou salientar ao longo do presente capítulo, a Abordagem da Complexidade fornece ferramentais analíticos que podem enriquecer a discussão sobre a emergência do desenvolvimento e do subdesenvolvimento. No contexto do subdesenvolvimento, principalmente, a discussão culmina com a necessidade de reverter a direção dos efeitos cumulativos que prendem as nações em tal condição. Desse modo, mesmo admitindo a impossibilidade de controlar os efeitos de determinada ação e de garantir qualquer resultado em termos sistêmicos, tentativas deliberadas de mudar o curso delimitado pelos efeitos cumulativos são necessárias. E o agente com maior capacidade, ao menos potencial, de influenciar a direção do sistema seria o próprio Estado.

Nos demais capítulos que compõem essa Parte I, discutem-se, dentre outras questões, como os nove pioneiros do desenvolvimento econômico escolhidos, em algum sentido, implicaram ao Estado esse papel de grande responsável pelo planejamento e direcionamento do desenvolvimento, justamente por conta da identificação de algumas causações cumulativas e/ou alguns círculos viciosos característicos do contexto de subdesenvolvimento, que impossibilitariam o escape dessa condição de forma espontânea, requerendo, para tal, uma intervenção direta. Veremos, em que medida, essa intuição inicial se mantém com algumas 
das discussões a serem levantadas com base nos pioneiros.

Além disso, no decorrer da discussão dos pioneiros, implicitamente busca-se discutir se, e em que medida, a Abordagem da Complexidade aplicada à discussão do subdesenvolvimento pode contemplar algumas das críticas que os próprios pioneiros direcionam à abordagem ortodoxa, compondo, desse modo, uma estrutura teóricometodológica mais adequada ao tema. 


\section{SOBRE O SUBDESENVOLVIMENTO}

Realizadas algumas discussões teóricas e metodológicas mais abrangentes derivadas da aplicação do ferramental analítico da Abordagem da Complexidade ao tema geral desenvolvimento econômico, no presente capítulo, a investigação adquire caráter mais direcionado, relacionado à discussão de algumas das particularidades das nações subdesenvolvidas. Conforme apresentado no capítulo anterior, subseção 2.1.1, a chamada Economia do Desenvolvimento ganhou forma e expressão no pós II Guerra Mundial. Contribuíram para sua composição e desenvolvimento uma série de pensadores, conhecidos convencionalmente como pioneiros do desenvolvimento. Sobre essa observação, diz Meier (1984):

Quando terminou a II Guerra Mundial, os economistas foram desafiados por problemas urgentes relacionados ao desenvolvimento. No decorrer da década subsequente, uma série de artigos seminais, relatórios oficiais e livros dominaram o pensamento sobre o desenvolvimento. Os autores desses estudos foram os pioneiros, que inicialmente moldaram o objeto por meio da introdução de conceitos, princípios dedutivos e pela modelagem do processo de desenvolvimento. Alguns dos pioneiros foram estimulados a analisar os problemas relacionados ao desenvolvimento por conta de seus interesses acadêmicos prévios, alguns por sua experiência em atividades de políticas públicas relacionadas, alguns por idealismo e outras por curiosidade intelectual. ${ }^{80}$ (MEIER, p. ix, 1984).

Nesse capítulo, são discutidas as contribuições de sete desses pioneiros, respectivamente: Paul Narcyz Rosenstein-Rodan, Hans Wolfgang Singer, Ragnar Nurkse, William Arthur Lewis, Albert Otto Hirschman, Gunnar Myrdal e Michal Kalecki. ${ }^{81}$ A ordenação escolhida de discussão dos autores busca respeitar a ordem crescente de data de publicação de seus textos selecionados. A seleção dos textos também buscou respeitar um critério de relevância, relativo à contribuição e ao impacto na formação da estrutura teórica da Economia do Desenvolvimento.

\footnotetext{
80 "When the Second World War ended, economists were challenged by the urgent problems of development. During the next decade a few central articles, official reports, and books came to dominate the thinking about development. The authors of these studies were the pioneers who initially shaped the subject by introducing concepts, deducing principles, and modeling the process of development. Some of the pioneers were stimulated to analyze development problems by their previous academic interests, some by their experience in related policymaking activities, some out of idealism, and others by a basic intellectual curiosity."

${ }^{81}$ Conforme ressaltado em outra nota de rodapé, não se pretende passar a impressão de que não houve outras contribuições relevantes, especialmente prévias, à discussão do tema desenvolvimento econômico. O presente capítulo e o próximo compõem uma seleção de nove dos pioneiros que formaram a origem da chamada Economia do Desenvolvimento no pós II Guerra Mundial, num contexto de efervescência da discussão do subdesenvolvimento econômico e de adoção de políticas de viés desenvolvimentista por boa parte das nações, especialmente as latino-americanas.
} 
Tendo em vista o foco desse trabalho, a investigação de textos selecionados de cada um desses pensadores está pautada pela busca de alguns elementos teóricos explicativos compatíveis com a Abordagem da Complexidade, e com o que se espera ser a sua aplicação à discussão dos processos que resultam no subdesenvolvimento econômico. Desse modo, não se pretende realizar aqui um levantamento bibliográfico extenso e completo de cada um dos sete autores selecionados. Vale dizer que, a própria seleção dos autores esteve norteada pela identificação prévia de algum elemento teórico pertinente à discussão que se pretende realizar. No geral, as compatibilidades teóricas levantadas entre os pioneiros e a Abordagem da Complexidade referem-se à identificação de mecanismos cumulativos, círculos viciosos e aspectos impeditivos da superação do subdesenvolvimento, compondo a sua metáfora de armadilha.

A cada autor dedica-se uma seção particular, resultando o capítulo em sete seções: Rosenstein-Rodan e a Teoria do Grande Impulso ${ }^{82}$ (seção 3.1); Singer e a tese Singer Prebisch (seção 3.2); Nurkse e o círculo vicioso da pobreza (seção 3.3); Lewis, a oferta ilimitada de mão-de-obra e a dualidade estrutural (seção 3.4); Hirschman, os encadeamentos para frente e para trás e o caráter desequilibrado do processo de desenvolvimento (seção 3.5); Myrdal e a causação circular cumulativa (seção 3.6); e Kalecki e os problemas cruciais do subdesenvolvimento (seção 3.7). Em cada uma dessas seções, são apresentados os elementos teóricos das obras do pensador em pauta que explicam a perpetuação do subdesenvolvimento de forma potencialmente compatível com a Abordagem da Complexidade, bem como as estratégias sugeridas pelo pioneiro para romper com o subdesenvolvimento. Também no decorrer do capítulo, quando se mostrar pertinente, são apresentados e discutidos eventuais paralelos e comparações entre os próprios pioneiros.

\subsection{Paul Narcyz Rosenstein-Rodan ${ }^{83}$ : Teoria do Grande Impulso}

A contribuição de Rosenstein-Rodan à Economia do Desenvolvimento é aqui discutida principalmente por meio de dois textos selecionados, além de comentários do próprio autor sobre sua obra. O primeiro deles, datado de 1943, corresponde ao texto inaugural da Economia do Desenvolvimento. Nele, o autor discute os problemas econômicos enfrentados

\footnotetext{
${ }^{82}$ No termo original: Big Push Theory.

${ }^{83}$ Economista nascido na Polônia, mas cresceu em Viena. Radicado intelectualmente na Inglaterra, onde, em 1930, se tornou cidadão britânico (1902-1985).
} 
pelo leste e sudeste europeus, as quais denomina de áreas atrasadas ou deprimidas. O outro texto, de 1944, é uma versão expandida do primeiro.

A escolha do estudo dessas regiões é explicada pelo próprio Rosenstein-Rodan (1984). Segundo o pioneiro, a escolha não se realizou por conta de qualquer interesse especial nesses países, mas porque, além de seus governos no exílio estarem, naquele momento, em Londres, os países do leste e o sudeste europeus constituíam um grupo de casos similares, embora não perfeitamente idênticos. Essa observação é importante porque, "Quando se trabalha com um grupo de países similares, eles se diferenciam em um ou outro aspecto, mas não em todos; então é mais fácil examinar qual é a causa e qual é o efeito." ${ }^{84}$ (ROSENSTEIN-RODAN, 1984, p. 207).

Sobre a sua própria contribuição teórica e participação na formação da Economia do Desenvolvimento, sintetiza Rosenstein-Rodan:

Durante a Segunda Guerra Mundial, propus em Londres a formação de um grupo de estudos de problemas dos países economicamente subdesenvolvidos ao invés de um trabalho mais comum sobre os problemas econômicos correntes relacionados à guerra. Se nós sobrevivêssemos, não deveríamos querer retornar ao status quo prévio, mas sim formar um mundo melhor. Um grupo de estudos foi organizado no Instituto Real para Assuntos Internacionais (Chatham House) e trabalhou de 1942 a 1945 pautado nos problemas dos "países subdesenvolvidos". Esse termo apareceu, então, pela primeira vez. Meu artigo de 1943 do Economic Journal serviu como um documento básico para o grupo e está agora em muitas antologias de estudos econômicos do Terceiro Mundo. ${ }^{85}$ (Ibid., p. 207).

Rosenstein-Rodan, a respeito do tratamento teórico adequado do processo de desenvolvimento, define que "Não é uma teoria de equilíbrio estático tradicional, mas uma análise do processo de crescimento desequilibrado que se mostra essencial à compreensão dos problemas do desenvolvimento econômico." ${ }^{86}$ (Ibid., p. 207). Interessante notar que, apesar desse apontamento do próprio autor, ressaltando o aspecto desequilibrado do processo de crescimento, foi associada a Rosenstein-Rodan a chamada teoria do crescimento equilibrado, assim como a Nurkse e Lewis. ${ }^{87}$ A seguir, no decorrer da apresentação da contribuição desse pioneiro dos pioneiros, ficará mais clara essa aparente contradição.

Por fim, antes de passar à discussão dos elementos teóricos apresentados pelo

\footnotetext{
84 "When one takes a group of similar countries, they differ from each other in one or two but not in all respects; it is then easier to examine what is cause and what is effect."

85 "During the Second World War, I proposed in London the formation of a group to study the problems of economically underdeveloped countries instead of the more usual work on current economic problems related to the war. If we were to emerge alive, we should want not to return to the previous status quo but to form a better world. A study group was organized at the Royal Institute for International Affairs (Chatham House) and worked from 1942 till 1945 on problems of "underdeveloped countries". This term appeared then for the first time. My 1943 article in the Economic Journal served as a basic document for the group and is now in many anthologies of economic studies of the Third World."

86 "Not traditional static equilibrium theory but an analysis of the disequilibrium growth process is what is essential for understanding economic development problems."

${ }^{87}$ Vide, por exemplo, Hirschman (1958).
} 
pioneiro, é válido reproduzir uma autorreflexão, feita pelo próprio autor, a respeito do poder explicativo da teoria econômica, e em que medida ela pode contribuir para o crescimento e desenvolvimento econômicos. Em suas palavras:

Depois de cerca de quatro décadas de atenção direcionada ao desenvolvimento, devemos nos perguntar o quanto a Economia pode explicar. A teoria econômica pode determinar as condições necessárias, mas não as suficientes, de crescimento. Os chamados fatores não econômicos respondem pelo hiato entre as condições necessárias e as suficientes. Qualquer avaliação do desenvolvimento pode apenas indicar se as condições necessárias ao crescimento existem ou estão sendo criadas; ela não pode prever com certeza que o crescimento será de fato realizado. É possível aprender muito a partir do desempenho passado, mas os critérios de avaliação são conceitos ex ante. Eles fornecem um julgamento de probabilidade e devem, portanto, ser checados continuamente. ${ }^{88}$ (Ibid., p. 219).

Vale notar que Rosenstein-Rodan, assim como os outros pioneiros a serem aqui tratados, voltaram-se preferencialmente à discussão dos fatores econômicos, o que, obviamente, não invalida suas contribuições. No entanto, o importante a reter dessa observação é que, no mesmo espírito da citação do autor, há que se ter sempre em mente que o desenvolvimento, por sua própria natureza, extrapola o escopo da economia. Desse modo, qualquer discussão que se faça sobre a questão sempre será, em alguma medida, incompleta.

Passemos à discussão da Teoria do Grande Impulso. Para Rosenstein-Rodan (1943), “O objetivo da industrialização das áreas internacionais deprimidas é produzir equilíbrio estrutural na economia mundial, através da criação de emprego produtivo para a população agrária excedente.” (Id., 1943, p. 260). Conforme explica Rosenstein-Rodan (1984), a industrialização significa urbanização. Como as zonas urbanas, comparativamente às rurais, possuem salários mais elevados, a industrialização acaba por se concentrar nelas. Extrapolando essa observação ao nível internacional, as nações ricas seriam as zonas urbanas e as nações pobres, as rurais. Em outras palavras, a industrialização se concentrou em áreas de renda mais elevada, as nações desenvolvidas. E, caso a industrialização se desenvolvesse, em alguma medida, nas nações subdesenvolvidas, também estaria concentrada em determinadas regiões. Vale notar que, apesar da concentração regional também ocorrer em outros contextos, por conta da própria natureza da industrialização, há um particularidade das nações subdesenvolvidas: a industrialização não resultou de progresso técnico prévio na agricultura.

A essa tendência de concentração da industrialização em regiões de renda mais elevada, Rosenstein-Rodan $(1943,1944)$ atribui a razão pela qual se observa o hiato crescente

\footnotetext{
88 "After some four decades of concerned attention of development, we might ask how much economics can explain. Economic theory can determine the necessary, though not the sufficient, conditions of growth. The socalled noneconomic factors account for the gap between the necessary and the sufficient. Any evaluation of development can only state that the necessary conditions for growth exist or are being created; it cannot predict with certainty that growth will actually take place. One can learn a lot from past performance, but the criteria of evaluation are ex ante concepts. They yield a probability judgment and have, therefore, to be continually checked."
} 
entre nações desenvolvidas e subdesenvolvidas. Hiato que não pode ser contido, nem superado, pelos mecanismos de mercado, o qual, deixado às suas próprias forças, apenas faria perpetuar o funcionamento dos mecanismos cumulativos que resultam na desigualdade distributiva, tanto interna quanto internacional. Sobre essa questão, vale reproduzir as palavras do próprio pioneiro: “O mecanismo de mercado não promove o "ótimo" nem em uma nação, nem entre nações, porque ele se baseia em hipóteses tão irrealistas [...] Isso obscurecesse a natureza do processo de desenvolvimento, bem como os riscos envolvidos." 89 (Id., 1984, p. 209).

O movimento de maquinário e capital em direção ao trabalho, ao invés do movimento inverso, do trabalho em direção ao capital, é, segundo Rosenstein-Rodan (1944), o que define o processo de industrialização. Em outras palavras, o capital deve se dirigir para regiões onde há trabalho excedente - ou onde há desemprego disfarçado ${ }^{90}$-, ao invés de se promover a imigração dessa mão-de-obra excedente para regiões mais capitalizadas. Sugere inclusive Rosenstein-Rodan (1984) que, esse desemprego disfarçado "[...] embora seja uma fraqueza, pode representar uma fonte de desenvolvimento e vigor." ${ }^{91}$ (Id., 1984, p. 208). De acordo com o autor, a industrialização, em conjunto com as melhorias na produção agrícola - assunto enfatizado por Kalecki (1960), seção 3.7 -, constitui o aspecto mais importante a ser enfrentado para se alcançar o desenvolvimento econômico dessas regiões atrasadas. E, por meio desse desenvolvimento, seria possível, por extensão, reduzir o hiato de desigualdade entre as nações. Diferentemente do que sugerem Singer (1950) - vide seção 3.2 - e Prebisch (1949) - vide capítulo 4, seção 4.1 -, Rosenstein-Rodan (1984) argumenta que a industrialização deve ser promovida não por causa dos termos de troca, mas porque as economias externas, ou os retornos crescentes, são muito maiores na indústria do que na agricultura.

Com vistas a esse objetivo de desenvolvimento, Rosenstein-Rodan (1943, 1944) elenca duas vias possíveis de industrialização das regiões atrasadas. Pela primeira via, o chamado "modelo russo", as nações se industrializariam por sua própria conta, objetivando a autossuficiência produtiva e sem recorrer ao capital internacional. Essa escolha implicaria a construção de todos os tipos de indústria, tendo como resultado um sistema econômico estruturado numa base industrial verticalmente integrada. Para o autor, essa via de

\footnotetext{
89 "The market mechanism does not realize the "optimum" either in one nation or between nations because it relies on such unrealistic assumptions [...] This obscures the nature of the development process and the risks involved."

${ }^{90}$ Definido nos casos em que a produtividade do trabalhador é praticamente nula ou até negativa.

91 "[...] although a weakness, may represent a source of development and strength."
} 
industrialização incorreria nas seguintes desvantagens: (i) crescimento lento, pois sem capital externo, há que se criar capital internamente e, para tal, impactaria o padrão de vida e de consumo da população; (ii) criação de uma unidade independente na economia mundial, diminuindo as vantagens que poderiam decorrer da divisão internacional do trabalho, pois, quando essa opera, resulta numa maior produção global; por fim, (iii) geração de capacidade ociosa mundial, especialmente de indústrias pesadas, implicando um desnecessário desperdício de recursos.

Já a segunda alternativa de industrialização, qual seja, de promovê-la por meio da inserção dessas regiões mais atrasadas na economia mundial, preservaria as supostas vantagens da divisão internacional do trabalho e estaria baseada em um grande aporte de capital externo. As vantagens dessa segunda alternativa seriam: (i) permitir um progresso mais rápido, sem precisar sacrificar os níveis de consumo; (ii) ao respeitar a divisão internacional do trabalho, essas regiões pautariam sua industrialização somente em indústrias leves, com técnicas intensivas em trabalho; (iii) e mesmo que se observasse uma expansão na economia mundial, as indústrias pesadas já existentes nas nações desenvolvidas seriam suficientes para satisfazer a demanda das regiões atrasadas.

Pela própria construção de sua argumentação, obviamente que Rosenstein-Rodan advoga a favor da segunda via de industrialização. Sobre esse ponto, importante observar que, ao contrário da linha de argumentação como a de Singer, Prebisch e Furtado, RosensteinRodan acredita, em alguma medida, na funcionalidade alocativa da divisão internacional do trabalho. A sua sugestão de industrialização, por conseguinte, refere-se preponderantemente ao desenvolvimento de indústrias mais simples, além da necessidade da formação de uma boa infraestrutura. Assim, pode-se inferir do autor que a formação dos referidos setores já teriam força suficiente para implicar uma trajetória dinâmica que resultaria no desenvolvimento.

Por outro lado, deixadas às forças de mercado, a industrialização das regiões atrasadas não pode emergir e se sustentar espontaneamente, por conta dos mecanismos cumulativos ressaltados anteriormente, entre nível de renda e industrialização. Nesse sentido, RosensteinRodan (1943) ressalta que, para a industrialização das áreas menos desenvolvidas ser bem sucedida, faz-se necessária a criação de um novo ambiente institucional, objetivando uma industrialização planejada em larga escala. Com vistas a esse planejamento, o autor destaca dois pontos cruciais. O primeiro deles refere-se à importância do treinamento planejado de mão-de-obra, pois "O automatismo do laissez-faire nunca funcionou adequadamente nesse campo [...] Embora esse treinamento não seja boa aplicação de capital para a empresa privada, é o melhor tipo de investimento para o Estado.” (Id., 1943, p. 254-255). O segundo ponto 
crucial diz respeito ao investimento em bloco, de modo a garantir a complementação das diferentes indústrias, pois "[...] a criação planejada de um sistema de indústrias complementares [...] reduziria o risco de insuficiência de procura." (Ibid., p. 256).

As sugestões de vias de atuação do planejamento realizadas por Rosenstein-Rodan baseiam-se no conceito de economias externas, responsáveis por retornos crescentes de escala, das quais destaca duas formas. A primeira delas, economias externas tecnológicas, relaciona-se à primeira sugestão, a formação de trabalho especializado. Um conjunto de firmas, por meio de um consórcio, por exemplo, ao investir na formação de trabalho especializado viabilizaria uma decisão que, individualmente, não seria viável. Quanto à segunda forma de economias externas, as economias externas pecuniárias, implicam que a realização de um conjunto de investimentos complementares horizontalmente resulta numa taxa de retorno maior para cada um dos investimentos tomados isoladamente, por conta dos seus efeitos sobre a geração de demanda - vale dizer, na terminologia Keynesiana, efetiva, pois os efeitos se realizam sobre o consumo e sobre o investimento. Como os projetos de investimento, por conta da incerteza, envolvem uma série de riscos relativos ao devir - o que, no caso das nações subdesenvolvidas, é ainda mais evidente -, a estratégia de investimento em bloco mostrar-se-ia interessante e adequada ao contexto do subdesenvolvimento, pois os efeitos da operação das economias externas pecuniárias sobre o nível de demanda efetiva e, portanto, sobre as expectativas, formariam um ambiente mais amigável à realização e continuidade de investimentos. Como resultantes, poderiam ser observadas também economias externas verticais, tanto entre firmas do mesmo ramo, como entre firmas de ramos distintos, permitindo um efeito de retroalimentação de formação de base industrial, tanto horizontalmente quanto verticalmente.

Da geração de economias externas tecnológicas e pecuniárias, e de sua significância dinâmica com vistas ao desenvolvimento, Rosenstein-Rodan deriva a importância da coordenação dos projetos de investimento. Essa coordenação ou planejamento, para o autor, deveria ser algo realizado necessariamente pelo Estado. Dessa forma, por meio do planejamento estatal da industrialização em larga escala, poder-se-ia garantir o balanceamento do processo de mudança, entre os diversos setores, levando à transformação em bloco. Por essa sugestão de balanceamento de investimento entre os setores, de modo a aproveitar os efeitos de complementariedade desses investimentos - o que potencializaria o alcance e os efeitos dinâmicos das economias externas por eles geradas -, é que se inclui a abordagem do autor na chamada teoria do crescimento equilibrado, a ser criticada por Hirschman (1958) na seção 3.5 . 
Interessante notar, e tendo com base um comentário do próprio Rosenstein-Rodan (1984), que um planejamento perfeito, resultando numa trajetória equilibrada, é impossível, porque não há como garantir o resultado final. Em suas palavras:

Em termos da teoria contemporânea, a essência do artigo de 1943 pode ser vista como repousando sobre o questionamento básico de se existirão mercados futuros para todas as mercadorias no contexto de um futuro incerto e cujo final está em aberto. ${ }^{92}$ (Id., 1984, p. 210).

Esse reconhecimento da incerteza sobre o futuro é mais uma compatibilidade teórica com a Abordagem da Complexidade, cujo foco investigativo está sobre o processo, e não sobre o resultado, pois este está necessariamente em aberto. O planejamento seria, então, apenas uma forma de tentar direcionar o programa de desenvolvimento industrial, incrementando as suas chances de sucesso, apesar de não poder garanti-la. Ademais, ressalta o autor que o planejamento dos planos de investimento deve ser suplementar aos mecanismos de preço, além de ser fonte de informações que não podem ser apreendidas a partir dos mercados. Desse modo, os mecanismos de mercado são instrumentos a serem utilizados pelo programa de desenvolvimento, e este não pode deixar se dominar por aqueles.

Ainda sobre a consecução dos projetos de industrialização, Rosenstein-Rodan (1943) sugere que, em seu início, o investimento deveria se concentrar na formação de indústrias básicas e nos serviços públicos, na medida em que ambos possuem alto potencial de fazer surgir novos canais de investimento, sendo, portanto, setores com alta capacidade de geração de retroalimentações positivas para a economia ou região de que se trata; e, mais do que isso, a sua não observação poderia ser impeditiva do desenvolvimento de outros setores. Sobre esse ponto, destaca Rosenstein-Rodan (1984) que a não verificação de uma infraestrutura básica a partir da qual se possam erguer o investimento em outros setores produtivos é um dos principais obstáculos ao desenvolvimento.

Derivada da estratégia de política de industrialização por meio da viabilização de um grande bloco de investimentos sugerida pelo pioneiro Rosenstein-Rodan, foi formada a Teoria do Grande Impulso, segundo a qual, para que o projeto de desenvolvimento possa ter chance de sucesso, há um nível mínimo de recursos que lhe devem ser deslocados. Por isso a comparação metafórica com a decolagem de um avião, pois, nesse caso, há uma velocidade mínima crítica que lhe permite alçar voo. Nesse sentido, se o que se almeja é o desenvolvimento, o qual, no caso dos países subdesenvolvidos, requer grandes e profundas transformações - ou as mudanças revolucionárias de Schumpeter (1912) -, não caberia a ideia

\footnotetext{
92 "In terms of contemporary theory, the essence of the 1943 article may seem to rest on the basic question whether perfect future markets can exist for all the commodities in the context of a future which is both openended and uncertain."
} 
de investimento gradativo, que, no máximo, possibilitaria um voo de galinha. Segundo Rosenstein-Rodan (1984), "Uma quantidade mínima de investimento é uma condição necessária - embora não suficiente - de sucesso.” 93 (Id., 1984, p. 210-211).

No âmbito global, onde se observa a perpetuação da desigualdade distributiva entre as nações avançadas e subdesenvolvidas, Rosenstein-Rodan (1944), aponta que no sistema econômico internacional não há uma contrapartida equivalente ao Estado Nacional que possa exercer uma função redistributiva entre as nações. Para tal, far-se-ia necessária uma ação internacional conjunta para redirecionar essa distribuição de modo a favorecer as áreas mais deprimidas. Dessa maneira, idealmente, o capital internacional deveria estar disponível aos países mais pobres de modo a auxiliá-los a alcançar um nível mínimo de renda, a partir do qual pudessem continuar a crescer autonomamente. Entretanto, o autor ressalta que o principal objetivo da ajuda internacional seria, não a promoção de igualdade de renda, mas da igualdade de oportunidades. Diz o autor que "Essa igualdade de oportunidade entre nações é tão importante quanto aquela entre diferentes classes dentro de uma nação; mas não é fácil de estabelecer." 94 (Id., 1944, p. 159).

A explicação de Rosenstein-Rodan sobre porque essa igualdade não é fácil de estabelecer se baseia na atuação de mecanismos cumulativos, resumida sinteticamente por: quanto mais rica for determinada nação, maior a sua capacidade de gerar mais riqueza; e quanto mais pobre for a nação, mais difícil é deixar de sê-lo. Recorrendo a ditados populares, afirma o autor: "Os ditos "as primeiras mil libras são as mais difíceis de juntar", e "somente os ricos podem ganhar dinheiro", são ainda mais verdadeiros no contexto das nações do que no contexto dos indivíduos." 95 (Ibid., p. 159). O que remete à observação feita pelos autores discutidos na seção 2.2, do capítulo 2, de que quanto mais rica, poderosa, estruturada e complexa for determinada nação, maior é a sua tendência a continuar acumulando vantagens. Ademais, enquanto algumas nações acumulam vantagens, outras acumulam desvantagens.

Para superar o subdesenvolvimento, em linhas gerais, Rosenstein-Rodan não nega a importância de promover melhorias na agricultura; porém, principalmente, destaca a necessidade de promover a industrialização. A grande dificuldade inicial de promovê-la reside na causação circular entre renda e industrialização, ou seja, a industrialização tende a se desenvolver onde já se encontra uma maior disponibilidade de renda, do que o autor deduz a

\footnotetext{
93 "A minimum quantum of investment is a necessary - though not sufficient - condition of success."

94 "This equality of opportunity between nations is quite as important as that between different classes within one nation; but it is not easy to establish."

95 "The saying that "the first thousand pounds are most difficult to make", and that "only the rich can make money", are even truer of nations than of individuals."
} 
tendência à concentração industrial, tanto dentro de uma nação como entre nações. Para reverter essa tendência, indica a necessidade de planejamento de uma industrialização em larga escala, fazendo-se necessária a atuação do Estado, por meio da criação de um novo ambiente institucional. Os pontos cruciais do planejamento, por sua vez, diriam respeito ao treinamento planejado de mão-de-obra e à promoção do investimento em bloco, que permitiriam um melhor aproveitamento das economias externas pecuniárias e tecnológicas, intensificando os efeitos de encadeamento positivo transformadores pela cadeia produtiva, permitindo a formação de um grande impulso, necessário para dar início ao processo de desenvolvimento.

\subsection{Hans Wolfgang Singer ${ }^{96}$ : tese Singer-Prebisch e a distribuição desigual de ganhos}

\section{entre as nações desenvolvidas e subdesenvolvidas}

A investigação dos elementos teóricos explicativos presentes na contribuição do economista Hans Singer, baseia-se especialmente em dois de seus artigos. ${ }^{97}$ No primeiro deles datado de 1949-1950 ${ }^{98}$, o autor apresenta sua definição de tendência à deterioração dos termos de troca das nações primário-exportadoras - compondo a chamada tese Singer-Prebisch - e discute a distribuição desigual dos ganhos entre as nações emprestadoras (desenvolvidas) e as nações devedoras (subdesenvolvidas). Já no artigo de 1952, se propõe discutir as relações entre planejamento e desenvolvimento econômico, bem como os seus problemas relativos no contexto dos países subdesenvolvidos.

Sobre a composição de sua formação intelectual, das quais destaca a influência de Keynes e Schumpeter, diz Singer (1984):

Assim como meu par "pioneiro" Albert Hirschman ${ }^{99}$ destacou, de certa forma, Keynes foi o real
criador da Economia do Desenvolvimento, na medida em que ele rompeu com a "mono-
economia" - a visão de que a Economia compõe um corpo de verdades universais aplicáveis a
todos os países, em todas as condições [...] Como um aluno de Keynes durante os anos de
formação da Teoria Geral (1934-1936) em Cambridge, eu fui certamente pré-condicionado a

\footnotetext{
${ }^{96}$ Economista alemão, radicado intelectualmente na Inglaterra (1910-2006).

97 Além dos dois artigos referidos, recorre-se a outras duas fontes. Em Singer (1985), texto em que o autor discute a relevância de Keynes para as economias em desenvolvimento, o autor faz referência a causações circulares cumulativas que frustrariam a capacidade dos países em desenvolvimento incrementarem seu investimento. Os argumentos sobre essa questão estão dispostos em momento oportuno da presente seção. Por fim, assim como no caso de Rosenstein-Rodan, recorre-se a comentários do próprio autor à sua obra, presentes em Singer (1984).

${ }^{98} \mathrm{O}$ artigo foi apresentado no encontro anual da American Economic Association, em 1949, e publicado pela American Economic Review em 1950. O artigo será aqui referido como Singer (1950).

${ }^{99}$ Os comentários de Hirschman (1984) estão na seção 3.5.
} 
pensar em termos de regras do jogo diferenciadas aplicáveis aos países em desenvolvimento, bem como à ideia de políticas não ortodoxas aplicáveis a eles [...] Antes de Keynes, meu professor foi Joseph Schumpeter, sob a tutela de quem eu estudei em Bonn, antes de ele seguir para Harvard. Então, eu fui criado na Economia do Desenvolvimento desde meus primeiros dias como estudante. ${ }^{100}$ (SINGER, 1984, p. 277).

Ainda sobre Keynes, Singer (1985) destaca que a Teoria Geral ressaltou a tendência a se estabelecer, nos sistemas econômicos, um equilíbrio sem pleno emprego de fatores, e que caso fosse deixado às forças do mercado, esse círculo vicioso nunca seria rompido. Por isso a necessidade de intervenção de algum agente - no caso, o Estado -, de modo a redirecionar as forças ao estabelecimento de um equilíbrio com um maior nível de emprego de fatores. Essa ênfase diferenciada da Teoria Geral sobre a necessidade de políticas intervencionistas, para o autor, seria um dos indicativos da relevância da teoria Keynes para lidar com as nações em desenvolvimento. Além disso, no sistema Keynesiano, o objetivo da análise reside em como mudar uma condição inicial insatisfatória, e não a como simplesmente entender o sistema, como no caso do sistema Clássico. Retomando a discussão da subseção 2.1.2, tal como definira Schumpeter (1912), o desenvolvimento se relaciona a mudanças revolucionárias, e não a como manter o estado inicial em funcionamento.

Singer enfatiza que o problema das economias em desenvolvimento é estrutural, relacionado a gargalos na estrutura produtiva, observação que o aproxima de outros pioneiros, como Kalecki, Prebisch e Furtado. Dessa observação segue que o objetivo das políticas nos países em desenvolvimento deve ser, portanto, pré-Keynesiano, na medida em que, para haver chances de sucesso, passos prévios à aplicação de políticas Keynesianas, relacionadas à demanda agregada, se fazem necessários. ${ }^{101}$ Tais passos prévios se referem à criação de uma economia mais flexível e com maior capacidade de resposta. Assim, o autor ressalta que "[...] o que os países em desenvolvimento precisam, em primeiro lugar, não é apenas de investimento, mas de pré-investimento, no sentido de assistência e treinamento técnicos, pesquisa e desenvolvimento, feitura de projetos e projetos-piloto." ${ }^{102}$ (Id., 1985, p. 134).

Ao distinguir entre economias com pleno emprego e economias com subemprego de

\footnotetext{
100 "As my fellow "pioneer" Albert Hirschman has pointed out, in some sense Keynes was the real creator of development economics insofar as he broke with "mono-economics" - the view that economics consists of a body of universal truth applicable in all countries and in all conditions [...] As a student of Keynes during the formative years of The General Theory (1934-1936) in Cambridge, I was certainly intellectually preconditioned to think in terms of different rules of the game applying to developing countries, and the idea of nonorthodox policies in relation to them [...] My other teacher before Keynes was Joseph Schumpeter, under whom I had studied in Bonn before he left for Harvard. Thus I had been brought up on economic development from my first student days."

${ }^{101}$ Nesse ponto, argumentação de Singer (1985) é muito semelhante à de Kalecki, assunto da seção 3.7. No entanto, o autor não faz nenhuma referência à teoria Kaleckiana.

102 "[...] what developing countries need in first place is not just investment but preinvestment, in the sense of technical training and assistance, research and development, project design, and pilot projects."
} 
fatores, de acordo com Singer, Keynes teria sido seguido por um influente modelo de economia dual, qual seja, de centro e periferia, desenvolvido por Prebisch e Seers. No entanto, tanto o modelo de Keynes quanto o de Prebisch-Seers teriam descendido de outros modelos, pois "Em certo sentido tanto Keynes quanto Prebisch-Seers foram precedidos pelos modelos de economia dual de List e Hamilton, que distinguiram entre os pioneiros industriais (Reino Unido) e os industriais retardatários (Alemanha, Estados Unidos)." ${ }^{103}$ (Ibid., p. 130).

Como período importante para compor sua experiência, Singer (1984) destaca seu envolvimento com o Brasil na década de 1950, onde teve contato, dentre outros, com Roberto Campos e Celso Furtado. Impressionou-se, especialmente, com a situação do nordeste brasileiro, de cuja observação concluiu que não se tratava simplesmente de um problema decorrente de desastre natural, e sim de desenvolvimento.

Enquanto os economistas do mainstream concentravam seus esforços no problema da eficiência alocativa, questão em cuja discussão se mantinha predominante a clássica teoria das vantagens comparativas, Singer destaca que o seu interesse, desde sempre, havia se direcionado a discussões relativas à justiça ou à eficiência distributiva. Nas palavras do próprio pioneiro:

Parecia-me que pensar na distribuição de ganhos somente em termos da quantidade de trabalho economizada pela especialização negligenciava um elemento essencial. A hipótese de intercâmbio igualitário, em mercados imparciais "justos", parecia estar em conflito com a existência de poder de mercado e tecnológico desiguais. Os dados eram jogados contra um dos parceiros comerciais. ${ }^{104}$ (Id., 1984, p. 277).

Com essa observação em mente, de que, se por um lado, alguém estava ganhando no jogo do comércio internacional, por outro lado, alguém estava perdendo, passemos à discussão presente em Singer (1950). A ideia central do autor refere-se ao fato de que as diferenças estruturais entre as nações desenvolvidas e subdesenvolvidas poderiam levar ao declínio relativo dos preços dos bens primários relativamente aos bens manufaturados, a mesma conclusão a que chegara Prebisch (1949). Como resultado, os benefícios do comércio e do investimento seriam “[...] crescentemente distribuídos de maneira desigual entre os dois grupos de países, mais ou menos independentemente do estado de atividade nos países

\footnotetext{
103 "In a sense both Keynes and Prebisch-Seers were preceded by the duoeconomics model by List and Hamilton, which distinguished between industrial pioneers (the United Kingdom) and industrial latecomers (Germany, the United States)."

104 "It seemed to me that to think of the distribution of gains in terms of only the amount of labor saved by specialization was to neglect an essential element. The assumption of equal exchange in impartial "fair" markets seemed in conflict with the facts of unequal market and technological power. The dice were loaded against one of the trade partners."
} 
industriais, ou das idas e vindas dos ciclos comerciais, de curto prazo ou de Kondratieff." 105 (Id., 1984, p. 281).

Singer (1950) ressalta que o comércio internacional seria de grande importância para as nações subdesenvolvidas, pois os resultados que derivavam desse comércio, bem como quaisquer variações nele, afetavam suas rendas nacionais de maneira significativa. ${ }^{106}$ Para o autor, a especialização das nações subdesenvolvidas na exportação de produtos primários, em grande medida como resultado do investimento das nações mais avançadas, não teria resultado em efeitos desencadeadores e retroalimentadores positivos ao seu desenvolvimento. Como o investimento possuía origem externa, muitos dos efeitos secundários e cumulativos decorrentes desse investimento se direcionaram aos seus países de origem. ${ }^{107} \mathrm{E}$, como esses investimentos se direcionaram primordialmente, senão somente, às atividades primárioexportadoras, eles teriam desviado as nações subdesenvolvidas de atividades com maior possibilidade de incorporação de progresso técnico, retirando da trajetória econômica dessas nações a formação de um fator central de radiação dinâmica, necessário para que se desenvolvessem autonomamente. Haveria ainda um terceiro fator, ainda mais importante que os dois primeiros, relacionado aos termos de troca, de que, historicamente, a tendência dos preços teria sido desfavorável aos exportadores de bens primários e favorável aos exportadores de bens manufaturados.

Singer evidencia que o investimento estrangeiro que se direcionou ao fomento da produção primário-exportadora nos países subdesenvolvidos só trouxe benefícios às nações investidoras. Explica o autor que, ao investir na produção de primários, as nações avançadas não apenas detiveram os efeitos benéficos cumulativos do seu investimento, mas também a sua população, enquanto consumidores, usufruiu dos frutos do progresso técnico na produção de primários e, ao mesmo tempo, enquanto produtores, se beneficiaram dos frutos do progresso técnico na produção de manufaturados. O autor sintetiza esse efeito cumulativo, que favorece as nações mais ricas, como segue: “Os países industrializados possuem o melhor

105 “[...] increasingly unequally distributed between the two group of countries, more or less regardless of the state of activity in the industrial countries or the coming and going of trade cycles, short-term or Kondratieffs."

${ }^{106} \mathrm{O}$ setor externo é importante à dinâmica dos países subdesenvolvidos na medida em que são causa causans, no mesmo sentido em que Keynes (1937) atribui essa característica ao investimento: “[...] dada a psicologia do público, o nível de produção e do emprego como um todo depende do montante do investimento. Eu a proponho desta maneira, não porque este seja o único fator de que depende a produção agregada, mas porque, num sistema complexo, é habitual considerar como causa causans o fator mais sujeito a repentinas e amplas flutuações." (KEYNES, 1937, p. 178).

${ }^{107}$ Aqui, vale observar, cabe outro conceito Keynesiano, o multiplicador. Como veremos, esse conceito está analiticamente implícito no discurso de boa parte dos pioneiros - assim como o conceito de acelerador, embora este tenha sido desenvolvido pelos seguidores de Keynes. Importante notar, ademais, que o conceito de multiplicador, do ponto de vista da Abordagem da Complexidade, é deveras elucidativo, tanto no que comporta o encadeamento de efeitos, quanto na impossibilidade lógica de definir, a priori, o seu resultado final. 
dos dois mundos, como consumidores de bens primários e como produtores de artigos manufaturados, enquanto que os países subdesenvolvidos permanecem com o pior dos dois mundos." 108 (Id., 1950, p. 479).

Sobre o desenvolvimento das nações subdesenvolvidas, explicita Singer (1952) que, necessariamente, ele traz consigo uma modificação estrutural, e esta tem que transcorrer de forma a diminuir a importância relativa da agricultura. Em outras palavras, a elevação dos níveis de renda deve ser acompanhada obrigatoriamente por uma correspondente alteração estrutural. Para tal, segundo o autor, não importa se o ponto de partida é a industrialização ou o próprio desenvolvimento agrícola, desde que o resultado final seja uma diminuição relativa da importância do setor agrícola como determinante da renda. Além disso, Singer (1950) destacara que a mais importante contribuição de uma indústria não é o seu produto imediato, tampouco seus efeitos sobre outras indústrias, mas sim seu efeito sobre o nível geral de educação, conhecimento, padrão de vida e capacidade inventiva da sociedade. Por conta dessa diversidade de efeitos é que a indústria seria desejável. Nas palavras do pioneiro:

[...] essa é talvez justamente a razão porque as indústrias manufatureiras são tão desejadas pelos países subdesenvolvidos; isto é, elas fornecem os pontos de crescimento para incrementar o conhecimento técnico, a educação urbana, o dinamismo e a resiliência que procede da civilização urbana. ${ }^{109}$ (Id., 1950, p. 476).

Ainda no sentido de efeitos cumulativos, perniciosos aos países subdesenvolvidos e benéficos aos países avançados, Singer explica o papel ambíguo dos termos de troca no contexto do subdesenvolvimento. Se os preços internacionais dos produtos primários estiverem atrativos e o mercado aquecido, teoricamente haveria espaço para acumular recursos e direcioná-los ao seu desenvolvimento industrial, via, por exemplo, importação de bens de capital. No entanto, justamente por conta do aquecimento do mercado de primários, os recursos excedentes acabam sendo reinvestidos nesse mesmo setor, para que possam aumentar sua produção e aproveitar a demanda aquecida. Por outro lado, quando os preços dos primários deixam de ser atrativos e o mercado desaquece, o desejo de se industrializar aparece, porém, nessa situação, não há recursos disponíveis para realizar tal objetivo. Diz o autor: "Aqui novamente parece que os países subdesenvolvidos correm o risco de cair entre duas armadilhas: falhar em se industrializar em um boom porque as coisas andam bem, e

\footnotetext{
108 "The industrialized countries have had the best of both worlds, both as consumers of primary commodities and as producers of manufactured articles, whereas the underdeveloped countries had the worst of both worlds."

109 "[...] this is perhaps precisely the reason why manufacturing industries are so universally desired by underdeveloped countries; namely, that they provide the growing points for increased technical knowledge, urban education, the dynamism and resilience that goes with urban civilization."
} 
falhar em se industrializar em um período de baixa porque as coisas andam mal." ${ }^{110}$ (Ibid., p. 482).

Singer então conclui que, para quebrar esses efeitos perniciosos às nações subdesenvolvidas e mantenedoras da desigualdade entre as nações, os propósitos dos investimentos externos e do comércio internacional deveriam ser redirecionados para produzirem mudanças graduais na estrutura das vantagens comparativas e da dotação comparativa das diferentes nações, ao invés de reforçarem as vantagens e as dotações comparativas vigentes. Para que o fluxo de investimento internacional nas nações subdesenvolvidas possa de fato contribuir para o desenvolvimento destas, os seus efeitos devem, por conseguinte, ser absorvidos internamente.

Ainda sobre o investimento nos países em desenvolvimento, Singer (1985) elenca as razões pelas quais seu volume estaria limitado. Sobre esse ponto, novamente a argumentação do autor se aproxima a de Kalecki (1960), mas especialmente as de Prebisch e Furtado, a serem discutidos no capítulo 4. Segundo o autor: (i) a capacidade tecnológica própria para produzir bens de capital não está posta e as dificuldades no balanço de pagamentos podem impedir que se importem esses bens; (ii) os insumos complementares, tais como bens intermediários, habilidades e instituições de mercado podem não estar disponíveis; (iii) a pressão nos bens de salário - em especial, alimentos - podem impedir a expansão do investimento e, ao mesmo tempo, a expansão da produção agrícola pode ser limitada parcialmente pela ausência de insumos, ou em parte por conta de instituições socioeconômicas, referentes principalmente à posse de terras; e (iv) o financiamento do investimento requerido por poupança adicional ou por tributação pode ser dificultoso, pois: uma grande parte do setor corporativo (de onde provém o maior volume de recursos) é de propriedade estrangeira, o que significa que os recursos são remetidos ao exterior; a falta de confiança nas instituições domésticas faz com que os investidores potenciais também transfiram seus recursos para o exterior; e a falta de dados e de capacidade administrativa podem inviabilizar um sistema efetivo de arrecadação de impostos. Todas essas razões constituem "[...] condições de causação cumulativa e circular que frustram a tentativa de incrementar o investimento." 111 (Id., 1985, p. 133-134), impedindo, por conseguinte, a consecução de um grande impulso, como derivado de Rosenstein-Rodan (1943, 1944).

Nessa mesma linha de argumentação, destacara Singer (1952) que, por serem as

\footnotetext{
110 "Here again it seems that the underdeveloped countries are in danger of falling between two stools: failing to industrialize in a boom because things are as good as they are, and failing to industrialize in a slump because things are as bad as they are."

111 "[...] conditions of cumulative and circular causation frustrating the attempt to increase investment."
} 
rendas muito baixas nas nações subdesenvolvidas, impunham-se limites bastante estritos ao volume de poupança potencial. Assim, ressaltando outro círculo vicioso, afirma o autor que “A principal esperança de aumento de poupança repousa na possibilidade de poupar uma alta proporção dos incrementos de renda resultantes do próprio processo de desenvolvimento econômico." (Id., 1952, p. 400). Nesse sentido, seria estrategicamente importante que, nos programas de desenvolvimento, fosse concedida uma alta prioridade àqueles tipos de projetos com maior potencial de retenção e multiplicação interna de recursos, o que continuaria a viabilizar novos investimentos.

Para concluir essa seção, ressalte-se novamente que, assim como Rosenstein-Rodan, para superar o subdesenvolvimento, Singer destaca a necessidade do planejamento dos investimentos a serem realizados, direcionando os esforços a setores específicos. No entanto, diferentemente de Rosenstein-Rodan, Singer implica ao comércio internacional a fonte de desvantagens dos países subdesenvolvidos, do que deriva a necessidade de industrialização. Só assim para tentar combater a tendência dos países subdesenvolvidos a acumularem desvantagens, relativas à deterioração dos termos de troca de seus produtos primários de exportação no longo prazo. O autor destaca, ademais, os interesses externos, na forma de seus investimentos, que acabaram por se direcionar, nos países subdesenvolvidos, à produção de bens primários para exportação. Por isso a necessidade de um planejamento tanto interno quanto internacional, na medida em que o direcionamento dos investimentos externos a setores que potencializem o desenvolvimento das nações atrasadas dependeria da cooperação das próprias nações desenvolvidas. Por fim, Singer concede ênfase às questões estruturais assim como fazem, por exemplo, Kalecki, Prebisch e Furtado - relacionadas a gargalos na estrutura produtiva, indicando para a solução deles o que denomina de políticas préKeynesianas.

\subsection{Ragnar Nurkse ${ }^{112}$ : círculo vicioso de pobreza}

Os elementos teóricos sugeridos por Nurkse são colhidos em duas fontes selecionadas. No artigo de 1952 e no seu livro de 1953, o pioneiro procura discutir os problemas de formação de capital nas nações subdesenvolvidas, bem como os entraves que esses problemas impõem ao seu desenvolvimento. Sobre o objetivo de seu livro, diz o autor no prefácio:

\footnotetext{
${ }^{112}$ Economista nascido na Estônia, intelectualmente estabelecido nos Estados Unidos (1907-1959).
} 
É uma tentativa, em pequena escala, do uso da teoria econômica, assim como observação específica visando a elucidar algumas das condições básicas de progresso nas duas terças partes mais pobres do mundo. Se isso estimular a discussão e contribuir para facilitar a percepção dos problemas perturbadores que ela envolve, terá o livro alcançado seu objetivo. (NURKSE, 1953, p. $1)$.

Nurkse define as nações subdesenvolvidas, comparativamente às nações avançadas, a partir justamente das suas dotações de capital; porém, embora o autor considere a dotação de capital uma condição necessária, ela não seria suficiente para a definição do progresso, pois "O desenvolvimento econômico é muito condicionado a peculiaridades humanas, atitudes sociais e políticas e acidentes históricos. Para o progresso, o capital é uma condição necessária, mas não exclusivamente suficiente.” (Ibid., p. 3).

Importante destacar essa qualificação de Nurkse pois, assim como já advertido em observações anteriores, o autor também concentra a sua análise do desenvolvimento e do subdesenvolvimento em fatores econômicos, mais precisamente na formação de capital. Entretanto, o pioneiro deixa claro que garantir a acumulação de capital não é condição suficiente para o desenvolvimento. A busca pela suficiência condicional implicaria o cumprimento de determinadas ações e políticas; algumas delas são discutidas pelo autor, conforme exposto em seguida.

Para Nurkse, o círculo vicioso da pobreza significa simploriamente que "[...] um país é pobre porque é pobre.” (Ibid., p. 8). Segundo o autor, as mais importantes das relações circulares que compõem esse círculo vicioso são justamente aquelas que dificultam a formação de capital nos países atrasados, relacionadas tanto ao lado da oferta, quanto ao lado da demanda de capital. E o ponto comum das relações circulares relativas à demanda e à oferta de capital é a condição inicial dessas nações atrasadas, qual seja, o baixo nível da renda real, refletida em baixa produtividade.

Nurkse (1952) ressalta que a dimensão do mercado é determinada pelo nível geral de produtividade, o qual depende, em grande medida, da utilização de capital. No entanto, a utilização de capital pode ser inibida justamente pela pequena dimensão do mercado. E sem aplicação de capital, não há como se desenvolver. Assim, se se parte de uma situação inicial de mercado de pequena dimensão, como é o caso das economias atrasadas, como quebrar esse círculo vicioso de pobreza? Recorrendo à teoria de crescimento equilibrado - a qual também vincula a Rosenstein-Rodan - explica o autor que uma maneira de quebrar esse círculo vicioso é por meio da aplicação de capital planejada em diferentes indústrias, o que permitiria uma ampliação geral do mercado e um melhor aproveitamento, em prol do desenvolvimento, da 
renda e capital a serem gerados e acumulados. ${ }^{113}$

Nurkse (1953) explica que o tamanho do mercado e o nível de produtividade no longo prazo são os determinantes mais importantes do volume de comércio internacional. Desse modo, a estratégia de crescimento equilibrado, sendo meio de ampliar o mercado e estímulo à inversão de capital, incrementando a produtividade, seria fundamental para expandir o comércio externo das áreas economicamente mais atrasadas. Nesse sentido, o autor indica quais seriam as etapas a serem cumpridas, a começar pelo desenvolvimento do mercado interno. Em suas palavras:

[...] se deve haver qualquer desenvolvimento, será necessário concentrá-lo na produção para as exigências locais, pelo menos no início, e, à medida que o desenvolvimento aumenta, o nível de produtividade - e, portanto, o poder de compra real - tenderá, no final, mais a auxiliar do que a prejudicar o crescimento do comércio internacional. (Id., 1953, p. 26-27).

No entanto, adverte Nurkse, remetendo à observação de condição necessária, mas não suficiente, que o cumprimento das etapas e do planejamento subjacentes à teoria do crescimento equilibrado, apesar de abrir espaço ao investimento internacional, o mesmo não necessariamente verificar-se-ia no caso do capital privado estrangeiro. A explicação do autor para esse fato reside em outro mecanismo cumulativo, relacionado à própria natureza da acumulação: "É como se o capital privado estrangeiro seguisse a regra "do que será dado aos que já têm" [...] É simplesmente outro reflexo da constelação circular geral das forças que afetam a acumulação do capital para o desenvolvimento econômico" (Ibid., p. 33-34).

Nurkse detalha o problema de suprimento de capital, argumentando que adquire natureza distinta a depender se a nação atrasada em questão é pouco ou densamente povoada. Indica o autor que os países densamente povoados sofreriam de desemprego disfarçado em larga escala, significando que, mesmo que não houvesse modificação substancial nas técnicas de produção nos setores onde se observasse esse fenômeno - em geral, setores agrícolas -, grande parte da mão-de-obra poderia ser transferida para outros setores - especialmente, indústrias - sem que esse deslocamento de fator trabalho incorresse na diminuição da produção dos primeiros. Nesses casos, é que como se houvesse uma poupança oculta, pois estaria aberta a possibilidade de deslocar esse excesso de população para projetos de formação de capital, tais como para a formação de infraestrutura. Já nos casos das nações escassamente

\footnotetext{
${ }^{113}$ Vale destacar as críticas que Furtado (1954b) faz diretamente a Nurkse. Para Furtado, o problema de tamanho de mercado insuficiente não seria interno às nações subdesenvolvidas, mesmo porque não se poderia pressupor a existência de um mercado interno significativo, já que são subdesenvolvidas. Portanto, a questão fundamental residiria na inexistência de um mercado externo em expansão. A segunda observação de Furtado diz respeito aos investimentos em bloco. Para Furtado, essa determinação não faria sentido. Nas palavras do autor, "Para uma economia subdesenvolvida começar um processo de desenvolvimento com seus próprios recursos e pela ação espontânea de seus próprios empresários é, para usar uma frase corrente, como levantar-se pelos próprios cabelos." (FURTADO, 1954b, p. 320).
} 
povoadas, sem que se observassem melhorias radicais nas técnicas e métodos de produção, não haveria como deslocar mão-de-obra entre os setores, sem que isso acarretasse diminuição na produção dos setores que liberariam mão-de-obra. Sobre esse ponto, o autor explicita outra causalidade, relativa à relação entre o desenvolvimento agrícola e o industrial, condicionada à densidade populacional. Diz o autor:

Em países densamente povoados, uma melhoria substancial da técnica agrícola pode talvez surgir unicamente como resultado de um desenvolvimento industrial. Em países escassamente povoados, ao contrário, uma melhoria na agricultura é o pré-requisito para a formação de capital e para o desenvolvimento industrial. (Ibid., p. 60).

Em outras palavras, é como se a abundância de fator trabalho retirasse a restrição que incentiva o desenvolvimento de métodos mais produtivos na agricultura, o que seria um aspecto negativo, do ponto de vista do desenvolvimento. Por outro lado, o excesso de mão-deobra $^{114}$, conforme observação de Nurkse, poderia, na verdade, significar uma disponibilidade não aproveitada de recursos. No entanto, para que essa vantagem fosse aproveitada, estaria colocada aqui novamente a necessidade de planejamento, pois os mecanismos de mercado não se encarregariam de deslocar essa mão-de-obra excedente para os setores com maior potencial dinâmico de crescimento e desenvolvimento.

Importante notar ademais que, para Nurkse (1952), a estratégia de crescimento equilibrado deve ser pensada em termos globais, ou seja, não adiantaria uma nação se especializar somente nas produções em que historicamente apresentasse maiores vantagens comparativas, mesmo porque essa opção as prenderia na produção apenas de bens primários, cujo mercado está sujeito a diversas flutuações, conforme destaca a tese Singer-Prebisch. Para o autor, o foco deveria se voltar ao mercado interno. Nas palavras de Nurkse:

Impulsionar as exportações frente a uma demanda inelástica ou mais ou menos estacionária não seria caminho promissor para o desenvolvimento [...] o crescimento econômico dos países subdesenvolvidos deve orientar-se, em grande medida, para o aumento da produção para o mercado interno. (Id., 1952, p. 269).

Essa argumentação, por sua vez, não constituiria, para Nurkse, defesa da autarquia, pois, simultaneamente ao aumento de produtividade permitido pelo incremento do mercado e da aplicação de capital por ele estimulado, observar-se-ia uma transformação da pauta de exportação e importação incrementando, ao invés de reduzir, o comércio externo. Há que se considerar nessa mesma direção que, como resultado da expansão da industrialização na economia global, aquela situação verificada no século XIX - as nações ricas exportando manufaturados para as nações pobres, das quais importavam bens primários - se modificara ao longo do século $\mathrm{XX}$, já que as próprias nações avançadas passaram a comerciar entre si,

\footnotetext{
${ }^{114}$ Questão a ser bastante discutida pelo pioneiro Lewis $(1954,1955)$, conforme apresentado na seção 3.4.
} 
restringindo ainda mais o papel econômico internacional das nações subdesenvolvidas.

No que se refere à oferta de capital para o desenvolvimento, destaca Nurkse que essa situação poderia, a princípio, ser resolvida por meio de capital externo. No entanto, como o nível relativo de renda, e não apenas o absoluto, também determina a poupança, a entrada de capital externo por si só não resolveria a questão do círculo vicioso da pobreza. O autor explica, recorrendo à Teoria de Duesenberry, ${ }^{115}$ que um incremento de renda interna poderia, por meio do chamado efeito demonstração, resultar numa maior propensão ao consumo nas nações mais pobres, reduzindo, por conseguinte, sua capacidade de poupança, mesmo diante do referido aumento de renda. ${ }^{116} \mathrm{O}$ efeito demonstração, assim como ocorreria com os indivíduos quando entrassem em contato com padrões de gastos superiores, também seria observado no plano internacional. Além da resposta direta do efeito demonstração, de emular padrões de consumo, ressalta o autor que "É sempre mais fácil adotar hábitos de consumo superior do que métodos aperfeiçoados de produção.” (Ibid., p. 272).

Ainda sobre o efeito demonstração, faz Nurkse (1953, p. 74) uma interessante observação: “A preocupação do desenvolvimento econômico é, por si só, num sentido óbvio, um efeito de demonstração. Dificilmente seria tão acentuado se estivessem num planeta diferente as nações de rendas altas." 117 Como resultado dessa propensão a consumir incrementada pelo contato com padrões de consumos superiores, observa-se, nas economias atrasadas, uma tendência inflacionária interna e uma tendência ao desequilíbrio no balanço de pagamentos. No entanto, de acordo com o autor, o maior problema residiria justamente no fato de que, ao conduzir ao maior consumo e reduzir a quantidade de poupança interna disponível, o efeito demonstração - ressaltado e estimulado pelas disparidades internacionais de renda - prejudica a própria formação de capital nos países mais atrasados. Em poucas palavras, a desigualdade de renda internacional, por meio do efeito demonstração, alimentaria o funcionamento do círculo vicioso da pobreza, o que, por sua vez, incrementaria ainda mais

\footnotetext{
${ }^{115}$ Nurkse (1952, p. 271) se refere ao livro Income Saving and the Theory of Consumer Behavior, de James S. Duesenberry, em que o autor apresenta "[...] a hipótese de que as funções consumo relacionam-se entre si em vez de serem independentes [...]". Essa hipótese contempla o chamado "efeito demonstração", que sugere que "Quando os indivíduos entram em contato com bens ou esquemas de gastos superiores, podem sentir certa tensão e inquietação - sua propensão ao consumo aumenta." (Ibid., p. 271).

${ }^{116}$ Sobre essa questão, vale destacar a observação de Furtado (1954b), para quem essa sugestão de Nurkse é crucial, pois "[...] põe em evidência que o processo de desenvolvimento dos países atualmente subdesenvolvidos não pode alcançar espontaneamente seu ritmo ótimo." (Ibid., p. 328). Furtado destaca, além disso, que, diferentemente do ocorrido no processo de desenvolvimento das nações ricas, pelo qual se observou uma transformação lenta nos hábitos de consumo, o que passou a ocorrer, por conta dos meios de comunicação e propaganda, foi uma mudança cada vez mais intensa e rápida nos hábitos de consumo. $\mathrm{O}$ efeito dinâmico dessa tendência sobre as nações atrasadas é de justamente dificultar o seu processo de desenvolvimento. Essas questões são retomadas no capítulo seguinte.

${ }_{117}$ Sobre esse ponto, vale ressaltar a semelhança com a teoria da classe ociosa de Veblen (1899); no caso de Nurkse, aplicada às nações.
} 
o nível de disparidade entre as nações ricas e as nações pobres.

Um meio de coibir os efeitos perniciosos do efeito demonstração - ou, diretamente, do desequilíbrio no balanço de pagamentos por ele desencadeado - seria a restrição de importações, especialmente a de bens de luxo. ${ }^{118}$ No entanto, segundo Nurkse, essa política de restrição não seria por si só eficaz, pois o efeito demonstração tende a atuar na função de consumo geral, e não apenas na pauta de importação. Ao concentrar o padrão de consumo em bens supérfluos, o efeito demonstração pode resultar na concentração de capital, já escasso nos países atrasados, em indústrias produtoras desses bens de luxo. O mesmo resultado verificar-se-ia, segundo o autor, no caso das transferências unilaterais de renda dos países ricos aos pobres, no caso de uma melhoria nas relações de troca favorável aos países subdesenvolvidos e no caso do investimento internacional autônomo. Assim, o pioneiro afirma sinteticamente que "O problema não é que isto seja prejudicial mas sim que não consegue contribuir para o desenvolvimento econômico.” (Id., 1952, p. 277). Para o autor, a solução para a acumulação de capital nas economias subdesenvolvidas não pode ser alcançada sem grandes esforços internos.

Para Nurkse (1953), em todos os casos, a formação de capital depende de políticas complementares internas. A ação interna é crucial tanto no que se refere ao uso efetivo, no sentido da formação de capital, dos recursos que se disponibilizem, quanto para abrir novos caminhos para captar e formar mais capital. Como bem ressalta o autor, "Em certo sentido, pois, tudo se resume a isto: capital é realizado em casa." (Id., 1953, p. 160).

Sobre o papel do Estado, enfatiza Nurkse que a maioria das nações subdesenvolvidas precisa de sua participação ativa na condução tanto dos planos de investimento, quanto na promoção de políticas que captem recursos para esse fim. No entanto, o autor ressalta que não há uma fórmula única, cabível a todos os contextos, pois "Cada país deverá ter sua combinação própria, de acordo com as suas necessidades e oportunidades. Não pode haver para isso receita de padrão universal.” (Ibid., p. 173). Essa observação é importante, pois evidencia a crucialidade das especificidades das nações que, mesmo apresentando a característica comum de subdesenvolvimento, são heterogêneas. Conforme discutido no capítulo 2, seção 2.2, cada nação passou por um processo de evolução, ou uma trajetória socioeconômica particular, o que faz de cada uma delas um sistema adaptativo complexo repleto de idiossincrasias.

Nurkse também realiza uma observação que sugere a necessidade de que haja uma

\footnotetext{
${ }^{118}$ Assunto a ser discutido pelos pioneiros latino-americanos no capítulo 4.
} 
coalizão social em prol do programa de desenvolvimento, bem como uma ampla participação dos agentes econômicos internos que compõem o sistema nacional. Diz o autor:

A formação de capital só pode ser permanentemente bem sucedida numa comunidade que tenha consciência do problema; e essa condição, tão importante quer para a manutenção quer para a criação de capital, é atingida por uma ampla difusão das atividades de investimento entre os indivíduos [...] Os hábitos e características pessoais ligados ao uso do capital - entre eles a iniciativa, prudência, engenhosidade e visão - dão uma base mais firme e mais segura para o progresso econômico de uma nação do que os projetos de uma comissão de planejamento. É bom, pois, para o Estado, permitir o exercício dessas qualidades e reduzir as barreiras ao seu desenvolvimento. (Ibid., p. 176-177).

Dessa forma, o Estado, além de atuar de maneira direta na captação e direcionamento, pode e deve fazê-lo indiretamente, por meio, por exemplo, de garantias institucionais e políticas de incentivo que permitam que a sociedade, em conjunto com o Estado, atue para superar as dificuldades de formação de capital que enfrentam as nações subdesenvolvidas, possibilitando-lhes, assim, que tenham chances de ser bem sucedidas no objetivo de se desenvolverem.

Nurkse se reporta a essas dificuldades concernentes à acumulação de capital como um conjunto de circunstâncias que podem levar à conservação de uma economia atrasada num estado de equilíbrio subdesenvolvido; ou, recorrendo ao vocabulário da Abordagem da Complexidade, seria essa uma situação típica de aprisionamento. Além disso, para o autor, o progresso econômico não é gerado espontaneamente. Para tal, se fazem necessárias ações direcionadas pelo Estado e amparadas pela sociedade. No entanto, apesar de todas as dificuldades, defende que "[...] o círculo não é intransponível. E, uma vez rompido em qualquer ponto, pelo próprio fato de ser circular a relação, apresenta-se a tendência de progresso cumulativo." (Ibid., p. 14).

Para concluir a presente seção, em relação aos dois pioneiros discutidos nas seções anteriores, vale ressaltar novamente, primeiramente, uma concordância de Nurkse com relação à teoria do crescimento equilibrado. No entanto, para o autor, a estratégia de crescimento equilibrado deveria ser pensada em termos globais, significando que as nações atrasadas deveriam diversificar sua pauta exportadora na direção de produtos mais elaborados - no que se aproxima da tese Singer-Prebisch - bem como direcionar esforços para o desenvolvimento do mercado interno. Outra observação interessante derivada do autor referese ao efeito demonstração, que implicaria que, se não houver direção de planejamento e grandes esforços internos, estaria colocada uma tendência a direcionar os recursos ou ao consumo propriamente dito de bens de luxo - para o qual o pioneiro sugere controle da importação de bens de luxo, uma das diretrizes do processo substitutivo de importações - ou à concentração de capital em setores produtores desses bens. Haveria ainda uma poupança 
oculta, relativa ao excesso de mão-de-obra, cujo aproveitamento também dependeria de planejamento. O autor então conclui que o Estado, além de atuar de maneira direta na captação e direcionamento de recursos, deve disponibilizar garantias institucionais e políticas de incentivo que permitam a sociedade atuar para superar o círculo vicioso da pobreza.

\subsection{William Arthur Lewis ${ }^{119}$ : oferta ilimitada de mão-de-obra e dualidade estrutural}

A investigação dos elementos teóricos decorrentes da contribuição de Lewis é realizada especialmente por meio de duas fontes. ${ }^{120}$ A primeira delas, datada de 1954, é o artigo em que o pioneiro constrói um modelo de desenvolvimento sob a hipótese de oferta ilimitada de mão-de-obra. A segunda fonte, datada do ano seguinte, 1955, é o livro em que Lewis realiza uma extensa discussão de fatores que considera cruciais para compor uma teoria do desenvolvimento econômico, embora o título original do seu livro se refira a crescimento econômico. Sobre o título do livro referido, conforme o próprio Lewis (1955) explica no prefácio, a sua pretensão não era sugerir que há uma teoria única. Em suas palavras:

Ilusório é o título da obra se sugerir a existência de uma única teoria de desenvolvimento econômico. São inúmeros os fatores que o determinam, e cada qual reúne o seu próprio grupo de teorias [...] "Teorias" do crescimento econômico talvez fosse título mais apropriado, mas houvera sido igualmente ilusório ao sugerir que o livro pretendia examinar a literatura existente sobre desenvolvimento econômico. Não foi minha intenção formular uma teoria, porém traçar um mapa. (LEWIS, 1955, p. 7-8).

No trecho citado acima, é possível inferir, inclusive, a mistura entre os termos crescimento e desenvolvimento. Conforme definido no capítulo 2, subseção 2.1.2, essa tese se baseia na definição de desenvolvimento enquanto processo desencadeado por mudanças estruturais, em determinada nação, que resultam na melhoria do padrão de vida da maioria da sua população e na diminuição substancial da desigualdade de renda e riqueza. No entanto, buscou-se respeitar aqui os termos originais utilizados pelo autor. Vale ressaltar, ademais, que essa mistura entre os termos não ocorre somente com o pioneiro Lewis. Apesar disso, essa confusão entre os termos não implica prejuízos à discussão que se realiza da contribuição dos pioneiros, especialmente porque há um conceito de desenvolvimento norteador. Por fim, os próprios pioneiros, em alguma medida, admitem a não suficiência dos requisitos econômicos para resultar no desenvolvimento.

${ }^{119}$ Economista nascido em Santa Lúcia (pequena ilha no Caribe), formado intelectualmente na Inglaterra (19151991).

${ }^{120}$ Além de comentários do próprio autor sobre sua obra (LEWIS, 1984), à semelhança do realizado com Rosenstein-Rodan e Singer. 
Refletindo de maneira retrospectiva, já na década de 1980, Lewis (1984) aponta que os autores desenvolvimentistas, incluindo ele mesmo, teriam deixado de levar em consideração um fator crucial: a instabilidade política das nações subdesenvolvidas. Seria esse um fator importante porque, em condições de instabilidade, a confiança requerida para realizar projetos de investimento, especialmente os de longo prazo, ficaria altamente comprometida. Nesse mesmo trecho, o autor destaca a superestimação do papel benevolente do Estado nas nações subdesenvolvidas. Em suas palavras:

[...] os países que crescem mais rápido são aqueles cujos cidadãos acreditam ser seguro poupar e investir domesticamente. Nós superestimamos esse fator nos anos 50. Isso provavelmente deixe de ser tão comum conforme as novas soberanias criadas desde a Segunda Guerra Mundial adquiram experiência e legitimidade. Nós também superestimamos a eficiência esperada dos novos governos e do seu comprometimento em melhorar as condições dos pobres (o que varia em larga medida). ${ }^{121}$ (Id., 1984, p. 137).

Realizadas essas observações iniciais, passemos à análise dos textos selecionados do autor. Lewis $(1954,1955)$ faz da oferta ilimitada de mão-de-obra - vale notar, da não qualificada - uma hipótese de seu modelo teórico. O autor define que há ilimitada oferta de trabalho nos países onde a população é tão volumosa, relativamente ao capital e aos recursos naturais, que em diversos setores da economia é possível observar produtividade marginal do trabalho zero ou quase zero, tal como definira Rosenstein-Rodan (1943) como desemprego disfarçado e indicara Nurkse (1953) como poupança oculta.

Para Lewis, o desenvolvimento econômico, no contexto do subdesenvolvimento, não seria um objeto adequadamente tratável, nem pela microeconomia convencional - que se refere à alocação de recursos escassos -, nem pela macroeconomia Keynesiana - pois só admite desemprego, e não subemprego, que é um fenômeno característico das economias subdesenvolvidas com oferta ilimitada de mão-de-obra.

Outra especificidade de fundamental importância apontada por Lewis se refere à dualidade estrutural dos países subdesenvolvidos. Importante observar que a dualidade estrutural não implica necessariamente a atribuição de atrasado ao setor agrícola (ou à zona rural) e moderno ao setor industrial (ou à zona urbana). O interessante é notar que nos países subdesenvolvidos existem ilhas de modernidade num mar de atraso, independentemente do setor produtivo ou região a que se referem. Sobre essa particularidade da dinâmica das nações subdesenvolvidas, diz o pioneiro:

Não temos durante a expansão uma ilha de emprego capitalista cercada de um vasto mar de

121 " [...] countries grow fastest whose citizens think is safe to save and invest at home. We underestimated this factor in the 1950s. It will probably cease to be so common as the new sovereignties created since the Second World War acquire experience and legitimacy. We also overestimated the likely efficiency of new governments and their commitment to improving the conditions of the poor (which varies widely)." 
trabalhadores de subsistência, mas sim, certo número de ilhas diminutas deste tipo. Isto é muito típico nos países que se encontram nas primeiras fases de desenvolvimento. (Id., 1954, p. 414).

Partindo de uma estrutura teórico-analítica clássica e de um modelo de dualidade estrutural, no qual há um setor atrasado no qual a produtividade marginal do trabalho é muito baixa e onde se observa a ocorrência de subemprego, e há um setor moderno regido pelas leis de reprodução do capital, Lewis explica que, a partir do volume capital, se define o número de trabalhadores e, dada a tecnologia, tem-se o produto bruto, distribuído entre as classes, na forma de salários, renda e lucros.

Para Lewis, o grande problema dos países subdesenvolvidos residiria no fato de que a parcela de lucros seria pequena porque a parcela de renda da terra seria muita alta, e não porque a parcela de salários seria alta. Em outras palavras, quando aumenta a parcela da renda da terra no produto líquido, diminui a própria base de acumulação de capital. Desse modo, para aumentar a base de acumulação do capital, far-se-ia necessário o aumento da parcela de lucros, mas não em detrimento da parcela dos salários, e sim da parcela da renda da terra no produto líquido. Mesmo porque, nessa estrutura dual, o setor moderno já se aproveita da dinâmica do setor atrasado, na medida em que este mantém a taxa de salários estável. A chave do processo de expansão estaria, por conseguinte, na distribuição funcional da renda. Diz Lewis:

A chave do processo é a utilização que se faz do excedente capitalista. Na medida em que este é reinvestido a fim de criar novo capital, o setor capitalista se amplia, transferindo-se maior número de indivíduos do setor de subsistência para o setor capitalista. O excedente torna-se então, ainda, maior; a formação de capital aumenta ainda mais e, assim, o processo continua até que desaparece o excedente de mão-de-obra. (Ibid., p. 418).

Portanto, para Lewis, a questão principal do desenvolvimento econômico é a rápida acumulação de capital, sendo o seu problema crucial a distribuição da renda em benefício da classe poupadora. Nesse ponto, o autor destaca a encruzilhada em que se encontram as nações subdesenvolvidas:

Se perguntarmos: "Por que poupam tão pouco?", a verdadeira resposta seria: "Porque são muito pobres", se nos sentíssemos tentados a concluir pelas impressionantes e elogiáveis correlações de Colin Clark. A verdadeira resposta é: "Porque seu setor capitalista é muito pequeno" (lembrando que "capitalista" não significa aqui capitalista privado, mas pode ser igualmente aplicado ao Estado capitalista). (Ibid., p. 425).

Ainda sobre esse ponto, Lewis destaca o problema sociológico da necessidade de surgimento de uma classe capitalista que realize investimentos produtivos de capital. Observa o autor que o surgimento desses capitalistas estaria provavelmente condicionado à existência de novas oportunidades de mercado, associadas a alguma nova técnica de produção. Embora não explique como quebrar esse círculo vicioso, indica que "Uma vez tendo surgido o setor 
capitalista é só uma questão de tempo para que ele atinja uma dimensão considerável." (Ibid., p. 426).

A desconsideração da hipótese de oferta ilimitada de mão-de-obra nas economias atrasadas, segundo Lewis, teria levado os economistas a aconselharem erroneamente os países subdesenvolvidos, na medida em que o excesso de mão-de-obra não qualificada apresenta consequências dinâmicas importantes ao funcionamento do sistema econômico nacional. Diz o autor:

A culpa não cabe à Lei dos Custos Comparativos, que continua sendo válida se vista em termos marginais reais, mas àqueles que se esqueceram de que os custos monetários são completamente desorientadores para as economias em que existe excedente de mão-de-obra ao nível de salário dominante. (Ibid., p. 450).

O pioneiro complementa que, ao mesmo tempo em que a teoria das vantagens comparativas constitui-se em um argumento favorável ao livre comércio nos países que não possuem oferta ilimitada de mão-de-obra, seria um argumento válido em prol do protecionismo no caso dos países com oferta ilimitada de mão-de-obra.

De acordo com Lewis (1955), a investigação das ações humanas deve ser realizada em diferentes níveis, uma vez que além das causas imediatas do desenvolvimento, observam-se as causas dessas causas. $\mathrm{O}$ autor destaca três causas principais, que usualmente são observadas juntas: o esforço de economizar, o aumento do conhecimento e sua aplicação, e a expansão do volume de capital per capita. No entanto, se não houver um ambiente favorável à eclosão dessas forças, elas não se revelariam espontaneamente em prol do desenvolvimento. E, para que se tenha um ambiente favorável, o autor salienta o papel das instituições e das crenças, buscando explicar não apenas quais delas são compatíveis com o desenvolvimento, mas como elas evoluem. Como bem ressalta o autor:

\footnotetext{
As questões de evolução social são ainda mais difíceis de tratar do que as de compatibilidade, já que o método dedutivo muito pouco lhes ajuda a solução. Para se compreender como e por que algo acontece, cumpre ir-se aos fatos; isto é, deve-se aplicar o método indutivo aos dados históricos. (Id., 1955, p. 18).
}

No entanto, adverte Lewis que, como os fatos da História seriam muito menos seguramente estabelecidos do que os fatos da Química ou da Biologia, deveria ser reconhecida a fragilidade de qualquer hipótese que tivesse apenas a História como base.

Lewis destaca que o subdesenvolvimento pode ser definido a partir de ao menos três perspectivas, intimamente correlacionadas entre si. Comparada a outras nações, uma nação pode ser dita subdesenvolvida em relação à sua tecnologia atrasada, às suas instituições desfavoráveis ao investimento ou à sua baixa dotação de capital per capita, resultando em uma baixa renda per capita. E, embora, a depender do caso, possa se destacar um obstáculo 
principal ao desenvolvimento, aquele que se propor a enfrentar o problema "[...] deve ele ter em mente que, se alcançar sucesso, muitas outras mudanças se requerem além do fator com o qual está imediatamente preocupado." (Ibid., p. 25).

Investiguemos o papel das instituições, seguindo a perspectiva de Lewis. Para o autor, tendo como objetivo o desenvolvimento econômico, o papel mais importante a ser desempenhado pelas instituições é o grau de liberdade que permitem aos agentes econômicos, implicando a elas um papel de retroalimentador positivo, seja em prol ou contra o processo de crescimento. Nas palavras do autor:

Segue-se que a mutação se reforça cumulativamente. Iniciado o desenvolvimento econômico, as instituições se transformarão sempre e cada vez mais no sentido favorável ao crescimento, fortalecendo, assim, as forças que o promovem. De outra parte, logo que a taxa de crescimento começar a declinar, as instituições se tornarão menos favoráveis ao desenvolvimento. (Ibid., p. 181-182).

Além disso, há que se notar que o ajustamento das instituições às condições econômicas vigentes pode ser um processo penoso, desequilibrado e incompleto: "O novo e o velho se misturam sem lógica, e em proporções curiosas, que diferem amplamente entre uma sociedade e outra. A transformação nunca é integral.” (Ibid., p. 183). Implicar às instituições um papel de retroalimentador positivo não quer dizer por sua vez que, uma vez posto o desenvolvimento em marcha, que esse ocorrerá para sempre, mesmo porque o desenvolvimento é uma reação resultante de estímulos sucessivos, mas com alcance, em alguma medida, limitado. Assim, diz o autor que "Na prática, o que mais se observa não é uma taxa constante de desenvolvimento, mas sim uma série de explosões de expansão, separadas por períodos de relativa calma." (Ibid., p. 186), observação que remete diretamente à noção de equilíbrio pontuado da Abordagem da Complexidade, discutido na subseção 2.2.1, do capítulo 2. Portanto, a disponibilidade de capital, embora seja condição necessária, não é suficiente para que se configure um processo de desenvolvimento, pois, se não houver ambiente favorável ao seu aproveitamento, acabará sendo desperdiçado. Além disso, o encadeamento dos efeitos relativos ao desenvolvimento não é infinito, sendo esperado um período de absorção desses efeitos, até que se provoquem novas mudanças revolucionárias, tal como definira Schumpeter (1912).

Lewis destaca que os pontos cruciais do processo de desenvolvimento são justamente o seu início e o seu fim, o qual corresponderia a um declínio secular. Com relação ao início do processo, o autor ressalta as dificuldades que podem emergir quando se observa uma concentração de esforços em apenas um setor da economia. Segundo o autor, e aqui o pioneiro se aproxima de Rosenstein-Rodan e Nurkse, os diversos setores deveriam crescer de 
maneira relacionada, caso contrário, não poderiam crescer, pois a inovação em determinado setor acabaria sendo freada.

Por conta das deficiências do mercado interno presentes nos estágios iniciais de desenvolvimento e dos próprios efeitos sobre a procura efetiva em outros setores, explica Lewis que, em geral, a produção para exportação acabava sendo o ponto de inflexão que impulsionava a economia em direção ao progresso. No entanto, o autor adverte que a excessiva concentração no setor exportador pode ser inconveniente, especialmente por conta dos efeitos deletérios potenciais sobre os termos de troca, tal como destacado pela tese Singer-Prebisch. Nos estágios superiores de desenvolvimento, o papel de dinamizador passaria do setor externo ao setor interno, tornando-se esse o principal sustentáculo do progresso econômico. Assim, para que fosse bem sucedido o pontapé inicial do progresso, segundo o autor:

[...] nos programas de desenvolvimento, todos os setores da economia devem crescer simultaneamente, para manter o equilíbrio adequado entre a agricultura e a indústria, e entre a produção para o mercado interno e a produção para a exportação. (Ibid., p. 360).

Quanto ao declínio secular, Lewis destaca uma série de armadilhas em que poderiam cair as nações, em virtude do próprio processo de desenvolvimento, dentre elas, o esgotamento dos recursos naturais, uma invertida desfavorável (ao investimento de capital) da distribuição de renda e o próprio esgotamento das inovações. Além disso, vale destacar novamente que, sob a perspectiva do pioneiro, após um prolongado período de desenvolvimento, seguia-se necessariamente um crescimento mais lento, a estagnação ou mesmo a franca decadência.

O financiamento externo desempenha papel importante na medida em que as nações ainda em processo de desenvolvimento dificilmente satisfariam a sua necessidade de capital só com recursos internos, mesmo porque os programas de desenvolvimento requerem a importação de bens de capital. No entanto, observa Lewis que, a menos que as nações atrasadas, receptoras de influxos de capital, transformem esse influxo em um aumento de produtividade das mercadorias consumidas internamente, não haveria impacto sobre os salários reais. Além disso, há que se observar que o fluxo de capital dos países desenvolvidos aos subdesenvolvidos também estaria sujeito a empecilhos pois " [...] a migração do capital se detém não só pelo fato de que se apresentam continuamente novas oportunidades para investir nos países desenvolvidos, como pelas deficiências em países subdesenvolvidos.” (Ibid., p. 316). A explicação para tal seria a emergência do círculo vicioso da carência de capital, o que se assemelha ao círculo vicioso da pobreza definido por Nurkse, uma vez que a produtividade 
de determinado investimento depende dos investimentos anteriormente realizados.

Segundo Lewis, no contexto das nações subdesenvolvidas, como os problemas de mercado e os altos custos iniciais de novos setores de atividade constituem importantes empecilhos à industrialização desses países, se não fossem adotadas medidas diferenciadas, tal como políticas protecionistas, “[...] o hiato entre estes e as nações industriais continuaria a ampliar-se pela simples razão do impulso dado pela especialização.” (Ibid., p. 450). Por isso também o papel dos governos nas nações atrasadas seria tão estratégico para estimular o desenvolvimento. Entretanto, pondera o autor que não se trata de privilegiar a ação do Estado ou da iniciativa privada, mas sim "[...] verificar qual a contribuição mais adequada de cada um." (Ibid., p. 482).

Essa observação remete à discussão do papel do Estado vis-à-vis o papel do mercado realizado por autores que discutiram assuntos relativos ao desenvolvimento com base na Abordagem da Complexidade ${ }^{122}$, cuja implicação indica justamente que deveria haver um balanceamento entre essas duas esferas enquanto direcionadores do desenvolvimento. No entanto, assumiu-se nessa tese que, no contexto dos países subdesenvolvidos, ao Estado caberia o papel mais importante de direcionador de forças para superar $\mathrm{o}$ subdesenvolvimento, ${ }^{123}$ afirmação corroborada, em alguma medida, por Lewis, conforme destacado no parágrafo anterior, já que qualifica o papel dos governos nas nações atrasadas como estratégico. Lewis sugere inclusive o que seria uma adequada atuação governamental, tendo em vista o objetivo do desenvolvimento. Em suas palavras:

O governo não deve gastar nem pouco nem muito; nem controlar muito nem pouco; nem tomar iniciativas demais, nem de menos; não deve desencorajar os estrangeiros, nem cair-lhes nas mãos; não deve permitir a exploração de classes, nem promover a luta de classes, e assim por diante. (Ibid., p. 533).

Para concluir essa seção, importante destacar novamente a hipótese de oferta ilimitada de mão-de-obra que, embora se aproxime da definição de desemprego disfarçado de Rosenstein-Rodan e de poupança oculta de Nurkse, é a base para a formação do modelo de dualidade estrutural de Lewis, característica diferenciadora dos países subdesenvolvidos, bastante enfatizada por outros pioneiros, como Kalecki - vide seção 3.7 - e Prebisch e Furtado, discutidos no capítulo seguinte. Para o pioneiro, assim como para Rosenstein-Rodan e Nurkse, para superar o subdesenvolvimento, os diversos setores devem crescer simultaneamente. Apesar da importância dinâmica do setor exportador, o autor adverte que a sua excessiva dependência pode ser prejudicial, no mesmo sentido da tese Singer-Prebisch. O

\footnotetext{
${ }^{122}$ Vide subseção 2.2.2, do capítulo 2.

${ }^{123}$ Vide subseção 2.2.3, do capítulo 2.
} 
autor salienta ainda o papel determinante das instituições para que se revelem e se retroalimentem aspectos importantes ao desenvolvimento, por conta do grau de liberdade que permitem aos agentes econômicos. Por fim, no contexto do subdesenvolvimento, o autor indica a importância de medidas diferenciadas e/ou protecionistas, do qual também deriva o papel estratégico dos governos para estimular o desenvolvimento.

\subsection{Albert Otto Hirschman ${ }^{124}$ : efeitos de encadeamento para frente e para trás e o caráter desequilibrado do processo de desenvolvimento}

A presenta seção baseia-se primordialmente na discussão dos elementos teóricos apresentados no livro de Hirschman publicado em 1958, em que o autor discute a estratégia do desenvolvimento econômico, mas também se vale de algumas considerações feitas pelo próprio autor em um texto de quase três décadas depois. Em um texto de 1984, em que se auto-intitula dissidente, Hirschman destaca a sua surpresa em ter ele mesmo se tornado, em termos de Economia do Desenvolvimento, um “clássico”. Em suas palavras:

Quando eu recebi o convite para participar do simpósio como um dos “pioneiros” junto com Raúl Prebisch, Gunnar Myrdal, Arthur Lewis, e outros representantes da Economia do Desenvolvimento, minha primeira reação foi de surpresa. Não porque eu não me considerasse um representante; mas, sob minha perspectiva, eu ainda me via como um rebelde contra a tradição, como uma segunda geração dissidente formadora das proposições que, enquanto pareciam ser novas e heterodoxas, foram rapidamente se tornando, nos anos 1950, uma nova ortodoxia sobre os problemas do desenvolvimento. Minhas ideias ousadas e insurgentes tinham se tornado clássicas, respeitáveis, ou seja, "pesadamente honrosas" e "enfadonhas" à maneira do lamento de Nietzsche? Talvez. $^{125}$ (HIRSCHMAN, 1984, p. 87).

Hirschman enfatiza sua luta contra dois males distintos, mas inter-relacionados. O primeiro deles diria respeito ao hábito dos representantes, políticos ou acadêmicos, dos países desenvolvidos de emitir conselhos e prescrições peremptórios, relativos a políticas econômicas, baseando-se em princípios econômicos de suposta validade universal, sem que se tivesse um conhecimento minimamente adequado da região a ser diagnosticada. O segundo mal seria a atitude passiva dos próprios países subdesenvolvidos - o autor se refere

\footnotetext{
${ }^{124}$ Economista alemão, nascido em 1915, estabelecido intelectualmente nos Estados Unidos.

125 "When I received the invitation to participate in the symposium as one of the "pioneers" alongside Raúl Prebisch, Gunnar Myrdal, Arthur Lewis, and other such luminaries of development economics, my first reaction was one of surprise. Not that I doubted my status as a luminary; but, in my own mind, I still saw myself as a rebel against authority, as a second-generation dissenter from the propositions that, while being themselves novel and heterodox, were rapidly shaping up in the 1950s as a new orthodoxy on the problems of development. Had my once daring and insurgent ideas then become classic, respectable, that is, "distressingly honorable" and "boring" in the manner of Nietzsche's plaint? Perhaps."
} 
especificamente aos latino-americanos - frente à sugestão dessas políticas prejudiciais às suas próprias economias. De acordo com o pioneiro, os latino-americanos teriam sido acostumados a apenas aceitar sugestões externas, tornando-se incapazes de aprender, e de derivar políticas próprias, a partir de suas experiências. A essa postura o autor atribui a alcunha de “fracassomania". Feitas essas breves considerações iniciais, passemos à investigação da obra de Hirschman que lhe elevou ao posto de pioneiro do desenvolvimento.

Hirschman (1958) salienta que, antes que se inicie o processo de desenvolvimento, é difícil visualizá-lo, não apenas em virtude da grande gama de requisitos a serem preenchidos simultaneamente, mas também em decorrência dos diversos círculos viciosos a serem rompidos. No entanto, boa parte da solução dessas questões encontrar-se-ia no próprio processo de desenvolvimento. Encarar a problemática dessa forma permitiria focar numa característica do processo de desenvolvimento fundamental, tanto à sua análise, quanto à elaboração de sua estratégia: a determinação. Em suas palavras:

[...] o desenvolvimento depende menos de encontrar combinações ótimas para recursos e fatores de produção dados e mais em invocar e elencar recursos e habilidades que levem ao desenvolvimento, que estejam escondidos, dispersos ou mal utilizados. ${ }^{126}$ (Id., 1958, p. 5).

Importante notar, e relembrando a definição de poupança oculta de Nurkse e a hipótese de oferta ilimitada de mão-de-obra de Lewis, que, ao menos do ponto de vista do fator trabalho, de fato as nações subdesenvolvidas teriam recursos abundantes disponíveis e mal utilizados.

Hirschman destaca que os fatores econômicos levam a diferentes efeitos de retroalimentação sobre as suas próprias quantidades disponíveis. Especialmente no caso do capital pois, ao gerar renda e poupança, o capital utilizado no processo de formação de alguma atividade produtiva geraria efeitos mais do que suficientes para repô-lo, além de potencialmente levar à formação complementar de capital em outras atividades. Conforme discutido mais à frente, o autor define os chamados efeitos de encadeamento para frente $\mathrm{e}$ para trás que, em boa medida, se assemelham às economias externas definidas por Rosenstein-Rodan (1943, 1944). Além disso, haveria fatores cuja disponibilidade cresceria diretamente por meio de sua própria utilização, destacando a importância do aprendizado enquanto potencializador dos efeitos de retroalimentação positiva.

Ao afirmar que o desenvolvimento depende da habilidade e determinação de uma nação em se organizar para tal, Hirschman afirma que não se trata de tautologia, pois, ao focar

\footnotetext{
126 “[...] development depends not so much on finding optimal combinations for given resources and factors of production as on calling forth and enlisting for development purposes resources and abilities that are hidden, scattered, or badly utilized."
} 
na determinação, leva-se em consideração o contexto específico de retardatários ${ }^{127}$ das nações subdesenvolvidas. Essa é uma observação crucial, na medida em que o atraso relativo dessas nações implicaria que o seu processo de desenvolvimento é “[...] um processo menos espontâneo e mais deliberado do que no caso dos países em que esse processo ocorreu primeiro." 128 (Id., p. 8). Entretanto, a determinação não seria condição suficiente para o desenvolvimento; ela precisaria ser combinada com a percepção de quais necessidades precisariam ser preenchidas, sendo que essa percepção também só seria adquirida gradualmente, ao longo do próprio processo, o que implicaria outra tautologia, ou outro círculo vicioso a ser superado. $\mathrm{O}$ autor então argumenta que, na hierarquia dos círculos viciosos, alguns são mais viciosos do que outros, e concede destaque ao que enfatizou, na medida em que direcionaria o foco ao local onde todas as dificuldades da ação humana se originam: a mente.

Hirschman aventa que, se o atraso econômico se deve à quantidade insuficiente e à velocidade insatisfatória de decisões relativas ao desenvolvimento, o problema crucial residiria na geração e direcionamento adequado da ação humana. Assim, seria a habilidade em tomar essas decisões o recurso escasso que condicionaria as outras dificuldades e escassezes das nações subdesenvolvidas. A chave para resolver esse problema residiria, por sua vez, em mecanismos indutores efetivos do processo decisório.

As considerações teóricas relativas à geração de poupança e a disponibilidade de oportunidades de investimento que valeriam para os países avançados não seriam relevantes no contexto das nações subdesenvolvidas, pois, naqueles casos, se considera como automática a conexão entre poupança e investimento. Hirschman argumenta que, no caso dos países subdesenvolvidos, as dificuldades se encontrariam justamente em como conectar a poupança e o investimento, se aproximando, desse modo, à definição do princípio da demanda efetiva, que traz implícita uma relação de causalidade primordial do investimento sobre a poupança, embora a poupança seja umas das condições, embora não a única, para o investimento. ${ }^{129} \mathrm{Em}$ suas palavras:

[...] o desenvolvimento é contido primeiramente pelas dificuldades de canalizar a poupança existente, ou potencialmente existente, para oportunidades de investimentos produtivos existentes,

\footnotetext{
${ }^{127}$ No termo original: latecomers.

128 "[...] a less spontaneous and more deliberate process than was the case in the countries where the process first occurred."

${ }^{129}$ Sobre o princípio da demanda efetiva, vale notar que se trata de um princípio suficientemente aberto para não pré-determinar um resultado e, por isso, compatível com o método analítico da Abordagem da Complexidade. Como bem observam Cardoso e Lima (2008), “[...] o princípio da demanda efetiva é o mecanismo essencial de adaptação da produção e do emprego em uma economia de mercado. Daí concebermos o ponto de demanda efetiva como propriedade emergente do sistema adaptativo complexo que é a atividade produtiva nessa modalidade de economia." (CARDOSO E LIMA, 2008, p. 374, nr. 11).
} 
i. e., e pela escassez de habilidade em fazer e executar decisões de desenvolvimento. ${ }^{130}$ (Id., p. 36).

A habilidade para investir, segundo Hirschman, é adquirida e incrementada principalmente pela prática, a qual, por sua vez, dependeria do tamanho do setor moderno da economia, o que colocaria o processo em outro círculo vicioso. Entretanto, reforça o pioneiro que, nas nações subdesenvolvidas, haveria tanto recursos disponíveis - por exemplo, o excesso de mão-de-obra, detectável pelo emprego disfarçado - quanto a propensão a investilos. Por conseguinte, novamente, o problema residiria em como conectá-los.

Sobre a habilidade para investir, e destacando os seus efeitos retroalimentadores positivos, sugere Hirschman que o investimento gerado a partir dessa habilidade não constituiria um teto, mas sim um piso, para o volume de investimento resultante. O autor assimila a esse investimento o mecanismo capaz de superar as dificuldades enfrentadas pelas nações subdesenvolvidas, a que denomina de efeito complementaridade do investimento. Diz o autor: "[...] o efeito complementaridade do investimento é, portanto, o mecanismo essencial pelo qual novas energias são canalizadas em direção ao processo de desenvolvimento e por meio do qual o círculo vicioso que parece confiná-lo possa ser quebrado.” ${ }^{131}$ (Id., p. 43). E, conforme avançasse o processo de desenvolvimento e os diversos setores da economia fossem sendo estabelecidos, a importância do efeito complementaridade do investimento tenderia a diminuir, mesmo porque sua funcionalidade passaria a se esvair.

Importante notar que, uma vez iniciado o processo de desenvolvimento, isso não significaria que prosseguiria necessariamente sem percalços. Hirschman destaca que a velocidade do desenvolvimento econômico, bem como o seu sucesso, poderia variar, a depender da presença de forças dinâmicas positivas ou negativas. Por isso, enfatiza o autor, e, de certo modo, justifica o título se seu livro, a “[...] elevada percepção da importância de uma teoria da estratégia do desenvolvimento." 132 (Id., p. 49).

Hirschman defende que o processo de desenvolvimento só pode ser provocado pelos desequilíbrios. O autor critica a teoria do crescimento equilibrado - cujos principais representantes seriam Rosenstein-Rodan, Nurkse e Lewis - argumentando que seria falha como teoria do desenvolvimento. A sua crítica pode ser resumida da seguinte maneira: “[...]

\footnotetext{
130 “[...] development is held back primarily by the difficulties of channeling existing or potentially existing savings into available productive investment opportunities, i.e., by a shortage of the ability to make and carry out development decisions."

131 " [...] the complementarity effect of investment is therefore the essential mechanism by which new energies are channeled toward the development process and through which the vicious circle that seems to confine it can be broken."

132 "[...] heightened consciousness of the importance of a theory of development strategy."
} 
se um país estivesse pronto para aplicar a doutrina do crescimento equilibrado, então, em primeiro lugar, ele não seria subdesenvolvido." ${ }^{133}$ (Id., p. 53-54). A teoria do crescimento equilibrado, de acordo com o autor, implicaria, ao contexto do subdesenvolvimento, tentativas de solução que seriam condizentes ao contexto de desemprego - algo factível no caso das nações avançadas que passam por alguma crise, por exemplo -, demandando das nações subdesenvolvidas experiência, conhecimento e habilidade em tomar decisões de investimento que ainda não possuiriam.

Destarte, a estratégia de crescimento equilibrado não seria a única via possível - e, dependendo do contexto, nem o único meio adequado - para se alcançar o desenvolvimento. Sobre essa questão, explicitando uma de suas influências teóricas, explica Hirschman (1984) que:

\begin{abstract}
Seguindo Gerschenkron, eu via originalidade e criatividade em desviar da trajetória seguida pelos países industriais mais antigos, em pular estágios, e em inventar sequências que tivessem a aparência de um "atalho errado". Eu tenho certeza que foi essa atitude que me permitiu trazer à tona a dinâmica dos encadeamentos para frente e para trás e aclamar como uma proeza dialéticoparadoxal o que mais tarde foi chamada, com intenção depreciativa, de industrialização substitutiva de importações [...] ${ }^{134}$ (Id., 1984, p. 96).
\end{abstract}

A industrialização substitutiva de importações, discutida em mais detalhes nos capítulos seguintes, foi, de fato, uma estratégia de desenvolvimento diferenciada - na medida em que se colocava contra a corrente da teoria das vantagens comparativas - dos países latinoamericanos, incluindo o Brasil. O modelo substitutivo de importações (Tavares, 1972) constituiu a diretriz das políticas econômicas no período desenvolvimentista. As discussões empreendidas por Hirschman, bem como por outros pioneiros, compuseram a fundamentação teórica para a consecução desse modelo de desenvolvimento, que imprimia à industrialização o caminho promissor para a superação do subdesenvolvimento latino-americano.

Para Hirschman (1958), o processo de desenvolvimento envolveria também o aprendizado da tomada de decisão. Muitos dos fatores a cuja escassez alguns autores atribuem a explicação do não desenvolvimento (por exemplo, capital, capacidade empresarial, etc.), só apareceriam no decorrer do próprio processo de desenvolvimento. Logo, não seriam requisito, e sim produto desse processo. Então, a chave do argumento não estaria na ausência de determinados fatores e sim no seu próprio processo combinatório, o que por sua vez remeteria

\footnotetext{
133 " [...] if a country were ready to apply the doctrine of balanced growth, then it would not be underdeveloped in the first place."

134 "Following Gerschenkron, I saw originality and creativity in deviating from the path followed by the older industrial countries, in skipping stages, and in inventing sequences that had a "wrong way around" look. It was surely this attitude that permitted me to ferret out the backward and forward linkage dynamic and to acclaim as a dialectical-paradoxical feat was later called, with disparaging intent, import-substituting industrialization $[\ldots] "$.
} 
à dificuldade de tomar decisões necessárias de maneira adequada e suficiente. Dessa forma, o problema fundamental do desenvolvimento consistiria em gerar e revigorar a ação humana em determinado sentido. Ou seja, em última instância, seria um problema de coordenação. Nessa perspectiva, o problema crucial das teorias do desenvolvimento econômico seria verificar sob que condições as decisões de desenvolvimento poderiam ser promovidas.

Associadas ao processo de desenvolvimento estariam as transformações ou mudanças radicais, no sentido da destruição criativa de Schumpeter (1943). Diz Hirschman:

Se é para a economia continuar avançando, a tarefa das políticas de desenvolvimento é manter as tensões, desproporções e desequilíbrios. Aquele pesadelo da economia equilibrista, a infinita teia de interligações, é o tipo de mecanismo que deve assiduamente ser buscado como um auxílio incalculável ao processo de desenvolvimento. ${ }^{135}$ (Id., p. 66).

Assim sendo, seriam justamente os mecanismos que levam ao afastamento do equilíbrio que formariam um padrão adequado ao processo de desenvolvimento, pois são os desequilíbrios que desencadeiam as mudanças, que por sua vez gerariam novos desequilíbrios. Retomando uma citação de Gleiser (2002), ${ }^{136}$ para sistemas dinâmicos, equilíbrio é igual à morte. No caso das nações subdesenvolvidas, equilíbrio significaria permanecer no subdesenvolvimento. Segundo Hirschman, a cada passo, um determinado setor tomaria as vantagens das economias externas geradas por uma expansão prévia, ao mesmo tempo em que criaria novas economias externas a serem exploradas por outros setores. Esse seria o efeito direto ou contágio do investimento, ou, tal como definira o autor anteriormente, efeito complementaridade do investimento.

Comparativamente à definição convencional de investimento induzido - qual seja, de que o investimento está diretamente relacionado ao crescimento passado da produção -, a consideração do efeito complementaridade do investimento permitiria uma definição de investimento induzido muito mais interessante ao contexto do subdesenvolvimento. Isso porque o investimento induzido por efeitos de complementaridade possuiria o potencial de transformação no sentido Schumpeteriano, o que é necessário para romper o estado de subdesenvolvimento. Para Hirschman, a consideração do efeito complementaridade faz com o que o investimento induzido se assemelhe ao mecanismo do multiplicador Keynesiano. E, vale observar, como há um grande número de repercussões potenciais desse efeito de complementaridade, e por conta da incerteza envolvida no processo, seria impossível listar tudo o que aconteceria ou que poderia vir a acontecer no evolver do processo de

\footnotetext{
135 "If the economy is to be kept moving ahead, the task of development policy is to maintain tensions, disproportions, and disequilibria. That nightmare of equilibrium economics, the endlessly spinning cobweb, is the kind of mechanism we must assiduously look for as an invaluable help in the development process."

${ }^{136}$ Vide subseção 2.2.1, capítulo 2.
} 
desenvolvimento. Do que se destaca, novamente, que os resultados do processo de desenvolvimento estão necessariamente em aberto.

Alinhado ao efeito complementaridade do investimento, Hirschman define os conceitos de encadeamento para trás e para frente. Os encadeamentos para trás referem-se a que "[...] qualquer atividade econômica não primária induzirá esforços para suprir, por meio da produção doméstica, os insumos necessários àquela atividade.” ${ }^{137}$ (Ibid., p. 100); e os encadeamentos para frente a que, “[...] qualquer atividade, que por sua natureza, não atenda exclusivamente a demandas finais, induzirá esforços para que se utilizem seus produtos como insumos em algumas outras atividades." ${ }^{138}$ (Ibid., p. 100). Segundo o autor, o caráter cumulativo do desenvolvimento, bem representado pelos encadeamentos para frente e para trás, mostrar-se-ia na observação de que os efeitos de encadeamento de duas ou mais indústrias vistas em conjunto são mais intensos do que o seriam se os efeitos dessas indústrias fossem analisados isoladamente.

Importante notar igualmente que, quanto à potencialidade de seus efeitos transformadores, os encadeamentos para trás seriam mais importantes do que os encadeamentos para frente. Isso porque, o encadeamento para frente não ocorre sozinho, devendo ser sempre acompanhado pelo encadeamento para trás, que resultaria da pressão de demanda. No entanto, com bem ressalta Hirschman, "Enquanto os encadeamentos para frente não podem ser considerados como um mecanismo de indução independente, ele age como um importante e poderoso reforço para o encadeamento para trás." ${ }^{139}$ (Ibid., p. 117).

Seria justamente a falta de interdependência e de encadeamentos entre os setores que compõem o sistema econômico nacional uma das características típicas das nações subdesenvolvidas. Mesmo porque, essas nações permaneceriam baseadas principalmente na agricultura, especialmente a agricultura de subsistência, caracterizada por raros (ou fracos) efeitos de encadeamento. Sobre esse ponto, diz o pioneiro Hirschman:

[...] a agricultura certamente está condenada ao resultado de sua falta de estímulo direto ao estabelecimento de novas atividades por meio de efeitos de encadeamento: a superioridade da manufatura a esse respeito é esmagadora. Essa pode ser ainda a mais importante razão militando

\footnotetext{
137 “[...] every nonprimary economic activity, will induce attempts to supply through domestic production the inputs needed in that activity."

138 "[...] every activity that does not by its nature cater (sic.) exclusively to final demands, will induce attempts to utilize its outputs as inputs in some new activities." Como medida do grau de interdependência, Hirschman sugere que se meça, para cada indústria: a proporção do seu produto total que não se encaminha para a demanda final e sim para outras indústrias; e a proporção de sua produção que representa a aquisição de outras indústrias (Ibid., p. 105).

139 "While forward linkage cannot therefore be regarded as an independent inducement mechanism, it acts as an important and powerful reinforcement to backward linkage."
} 
contra qualquer completa especialização dos países subdesenvolvidos na produção de primários. ${ }^{140}$ (HIRSCHMAN, 1958, p. 109-110).

O processo de crescimento desequilibrado seria observável também no sentido geográfico. De acordo com Hirschman, o desenvolvimento seria iniciado em um ou poucos centros regionais economicamente fortes. A necessidade de emergência desses pólos de crescimento no evolver do processo desenvolvimento significaria, por sua vez, que a desigualdade internacional e inter-regional do crescimento constituiria uma condição simultânea e inevitável do crescimento em si. Por outro lado, o processo de crescimento desequilibrado geraria pressões e tensões que poderiam potencialmente estimular o crescimento em outras regiões. No entanto, conforme bem observa o autor, se os estímulos se dirigissem apenas a uma região, as forças potenciais de transmissão de crescimento seriam cada vez mais fracas. Como resultado, observar-se-ia a divisão do mundo entre nações desenvolvidas e subdesenvolvidas, bem como a divisão de um país entre regiões mais avançadas e outras mais atrasadas.

Conforme se procurou destacar nessa seção, Hirschman concede muita ênfase aos elementos que emergem no próprio evolver do processo de desenvolvimento, destacadamente a habilidade em tomar decisões, como reflexo da capacidade incrementada de compreensão dos próprios problemas. Nesse sentido, o pioneiro destaca que as próprias tensões que surgem no evolver do processo de desenvolvimento podem adicionar força para que ele prossiga. Dito de outra forma, as tensões, se bem compreendidas e enfrentadas, na verdade podem vir a potencializar o desenvolvimento, por conta dos efeitos dinâmicos que provocam. Nas palavras do autor:

[...] trata-se de lugar comum o fato de que o desenvolvimento carrega consigo muitas distorções e tensões. Mas o que é menos compreendido é o fato de que o desenvolvimento também extrai nova força das tensões que ele cria. Ao chocar-se com essas dificuldades, o desenvolvimento possibilita o enfrentamento delas. ${ }^{141}$ (Ibid., p. 209).

Compreender esse papel positivo que as tensões emergentes podem desempenhar no próprio processo desenvolvimento faria com que fosse concedida uma nova ênfase, e provavelmente maior efetividade, da assistência técnica e política que os países desenvolvidos deslocam às nações subdesenvolvidas. ${ }^{142}$ Como bem ressalta Hirschman, grande parte da

\footnotetext{
140 “[...] agriculture certainly stands convicted on the count of its lack of direct stimulus to the setting up of new activities through linkage effects: the superiority of manufacturing in this respect is crushing. This may yet be the most important reason militating against any complete specialization of underdeveloped countries in primary production."

141 " [...] it is a commonplace that development carries with it many strains and stresses. But what has been less well understood is that development also draws new strength from the tensions it creates. By running up against difficulties, development makes it possible to tackle them".

${ }^{142}$ Vale notar que o próprio pioneiro cumpriu esse papel na América Latina.
} 
resolução do problema do subdesenvolvimento seria encontrado no seu claro entendimento, pois, se não há consciência do problema a ser enfrentado, as soluções que decorrem podem ser fúteis ou brutais demais. Essa observação ganha especial interesse no caso das políticas públicas e do papel do Estado, pois, o sonho do desenvolvimento, na verdade, pode vir a se transformar em um pesadelo. Segundo o autor:

[...] a política econômica pode ser pior do que somente ineficaz: a inutilidade pode ser substituída abruptamente pela brutalidade, pelo desprezo ao sofrimento humano, aos direitos adquiridos, aos procedimentos legais, aos valores tradicionais, em suma, à "tênue e precária camada de civilização". ${ }^{143}$ (Ibid., p. 210).

Pelo exposto acima, central à argumentação de Hirschman, no que se refere à superação do subdesenvolvimento, é o próprio caráter desequilibrado do processo de desenvolvimento. Ignorar esse caráter, não compreendê-lo e não saber extrair dele o potencial que demonstra para o próprio processo é onde residiria a grande falha das políticas e sugestões de política que objetivam retirar as nações do subdesenvolvimento.

Esse seria o grande diferencial analítico de Hirschman com relação aos autores a quem se atribui a teoria do crescimento equilibrado - Rosenstein-Rodan, Nurkse e Lewis. E, de certo modo, aproxima ainda mais análise de Hirschman ao que seria a aplicação da Abordagem da Complexidade à discussão de desenvolvimento, na medida em que não apenas destaca os efeitos de retroalimentação permitidos pelos investimentos - os encadeamentos para frente e para trás - em setores industriais, mas especialmente porque deriva das próprias mudanças - e desequilíbrios - desencadeadas pelo processo uma fonte crucial de efeitos positivos ao desenvolvimento. É como se boa parte das soluções dos círculos viciosos do subdesenvolvimento fossem propriedades emergentes do próprio processo, não podendo, por conseguinte, ser pressupostas a priori. Note-se, além disso, que destacar a propriedade de emergência não significa esperar que essas soluções surgissem espontaneamente. Como bem ressaltara o autor, grande parte da resolução do problema do subdesenvolvimento encontra-se no seu claro entendimento, do que implica que, se houver ação estatal, ela deve estar consciente desses problemas.

\subsection{Gunnar Myrdal $^{144}$ : causação circular cumulativa}

\footnotetext{
143 “[...] economic policy may be worse than ineffectual: futility can be abruptly replaced by brutality, by utter disregard for human suffering, for acquired rights, for lawful procedures, for traditional values, in short, for the "thin and precarious crust of civilization"."

${ }^{144}$ Economista sueco (1898-1987).
} 
Essa seção se baseia na discussão do livro de 1957, em que Myrdal apresenta suas principais ideias e conceitos concernentes à Economia do Desenvolvimento, os quais justificam a sua denominação de pioneiro. Apesar de ser denominado um pioneiro do desenvolvimento, o próprio autor não se consideraria como parte da "linha de frente" da Economia do Desenvolvimento, como fica explícito em suas palavras:

Eu não pertenço aos verdadeiros pioneiros que, imediatamente após a guerra, quando a avalanche da liberação das colônias começou, e, às vezes, mesmo antes da mudança revolucionária na situação política mundial, assumiram o estudo dos problemas relativos ao desenvolvimento dos países subdesenvolvidos. ${ }^{145}$ (MYRDAL, 1984, p. 151).

De maneira semelhante aos demais pioneiros, Myrdal não atribui validade à teoria da convergência da riqueza e desenvolvimento das nações, destacando como uma característica marcante da situação internacional a crescente desigualdade econômica entre os países. No entanto, para o pioneiro, essa não seria uma situação imutável, pois nada no sistema mundial seria, nesse sentido, permanente. E seria justamente no estudo das desigualdades entre as nações que estariam o foco e o propósito de seu trabalho teórico, assim como o autor explica no prefácio a seu livro:

Focalizo aqui um aspecto particular da situação internacional: as enormes e sempre crescentes desigualdades econômicas entre os países desenvolvidos e os subdesenvolvidos [...] Meu propósito é investigar porque e como sobrevieram tais desigualdades, porque persistem e tendem a aumentar. (Id., 1957, p. 12).

Myrdal define o conceito de causação circular e cumulativa, análogo aos mecanismos de retroalimentação enfatizados pela Abordagem da Complexidade. Com base nesse conceito, infere que quanto mais se conhece a maneira como os fatores se inter-relacionam, maior seria a capacidade de alcançar bons resultados em termos de política, em especial, aquelas que tivessem como pretensão alterar o sistema social. Algo que, no contexto dos países subdesenvolvidos, conforme destacado anteriormente, requer mudanças de grande alcance; assim sendo, conhecer as causações entre os fatores auxiliaria a potencializar e a canalizar de forma mais eficaz os efeitos positivos ao desenvolvimento, facilitando a tarefa de superação do subdesenvolvimento.

Segundo Myrdal, a II Guerra Mundial, ao eliminar muitas das estruturas de controle tradicionais que sustentavam o sistema de poder mundial, fez emergir um novo nacionalismo, baseado no qual diversas nações, relativamente mais pobres, passaram a reivindicar, além da liberdade, a igualdade de oportunidades, aspirando, por conseguinte, o alcance do desenvolvimento econômico. $\mathrm{O}$ autor destaca inclusive a mudança de denominação dessas

\footnotetext{
145 "I do not belong to the true pioneers who, immediately after the war, when the avalanche of liberation from colonial bonds began, and sometimes even in advance of this revolutionary change in the world's political situation, took up the study of the development problems of underdeveloped countries."
} 
nações, observada a partir de então, que teria passado de "atrasadas" para "subdesenvolvidas", o que seria reflexo da própria mudança de percepção sobre a situação econômica e a perspectiva futura desse grupo de países. Nas palavras do pioneiro:

É interessante notar que passamos a denominar essa maioria de países muito pobres de "subdesenvolvidos". Esse termo dinâmico, que só veio a prevalecer depois da II Guerra Mundial, reflete a grande mudança ocorrida na situação política a que já me referi. A expressão que se usava até há bem pouco tempo era o termo estático: "países atrasados". (Ibid., p. 25).

Posicionando-se criticamente à teoria convencional, Myrdal indica que a noção de equilíbrio estável traria implícita a ideia de que, em resposta a uma mudança em determinada direção, surgiriam, automaticamente, mudanças secundárias em direção oposta à primeira, de modo a neutralizá-la. Relacionada à noção de equilíbrio estaria também a ideia de que seria suficiente analisar a realidade social baseando-se somente em fatores econômicos. No entanto, para o autor, a omissão desses fatores não econômicos, que corresponderiam aos principais meios de causação circular cumulativa, representaria uma das principais deficiências da teoria econômica. Além disso, a incorporação de fatores não econômicos, necessários para discutir o tema desenvolvimento, tornaria inviável a utilização de métodos equilibristas. Em suas palavras:

É precisamente no âmbito dessa grande parte da realidade social que a análise econômica deixa de fora pela abstração dos fatores "não econômicos", que a premissa do equilíbrio cai por terra. Esses fatores não econômicos não podem ser tidos como consumados e estáticos; as suas reações se fazem normalmente por meio de desequilíbrios. (Ibid., p. 28-29).

Não seria verificável uma tendência automática à estabilização do sistema social, pelo contrário, haveria sim uma tendência de afastamento do estado dito de equilíbrio. Segundo Myrdal, a explicação dessa dinâmica está no processo de causação circular cumulativa, pois:

Em geral uma transformação não provoca mudanças compensatórias, mas, antes, as que sustentam e conduzem o sistema, com mais intensidade, na mesma direção da mudança original. Em virtude dessa causação circular, o processo social tende a tornar-se acumulativo e, muitas vezes, a aumentar, aceleradamente, sua velocidade. (Ibid., p. 34).

Conforme dito anteriormente, em linha com a argumentação dos demais pioneiros, observa Myrdal que se o processo cumulativo, alimentado pela causação circular, não fosse controlado, promoveria desigualdades crescentes. Entretanto, para o pioneiro, é possível atingir uma posição estável por meio de interferências políticas planejadas. Para tal, faz-se necessário conhecer e compreender, em alguma medida, como os diversos fatores se interrelacionam.

Para Myrdal, um país pode ser definido como subdesenvolvido quando “[...] os poucos impulsos que estão sendo deferidos não resultaram em aumento substancial e contínuo da demanda, renda, investimentos e produção [...]" (Ibid., p. 61). O autor argumenta que quanto 
mais alto fosse o nível do desenvolvimento de uma nação, mais fortes tenderiam a ser os efeitos propulsores. Desse modo, "A neutralização dos "efeitos regressivos", quando um país alcança um alto nível de desenvolvimento [...] refletir-se-á no desenvolvimento econômico e se tornará, assim, fator importante do processo acumulativo.” (Ibid., p. 62). Nesse sentido, o autor aponta que parte da explicação dos males dos países subdesenvolvidos reside no fato de os "efeitos propulsores" serem fracos. Deixado às forças do mercado, o que se observa é a geração ou ampliação de desigualdades regionais, sendo que as próprias desigualdades representam obstáculos ao progresso. De acordo com o autor, "Esta é uma das relações interdependentes, por meio das quais, no processo acumulativo, "a pobreza se torna sua própria causa"." (Ibid., p. 63), conclusão que se assemelha muito àquela apresentada por Nurkse (1953, p. 8), quando define o círculo vicioso da pobreza e indica que um "país é pobre porque é pobre". ${ }^{146}$ A referência de Myrdal à debilidade dos efeitos propulsores guarda também paralelos com os encadeamentos para frente e para trás de Hirschman (1958), e com a promoção de investimentos em bloco para potencializar os efeitos propulsores das economias externas de Rosenstein-Rodan (1943, 1944). As sugestões de políticas derivadas de Rosenstein-Rodan - bem como de Nurkse (1952, 1953) e Lewis (1954, 1955), na medida em que compartilham da teoria do crescimento equilibrado - e de Hirschman se direcionariam, justamente, a enfrentar os efeitos propulsores fracos definidos por Myrdal.

Myrdal também interliga as desigualdades regionais internas e as desigualdades internacionais. $\mathrm{O}$ autor argumenta que esses “[...] dois tipos de desigualdade são causa um do outro, na forma circular do processo acumulativo" (Ibid., p. 86). A explicação para essa interdependência se inicia pela relação entre a falta de integração econômica nacional e o próprio atraso econômico, pois os baixos níveis, por exemplo, de mobilidade social e de educação, significariam maiores obstáculos aos efeitos propulsores de um determinado movimento expansionista, dificultando, por conseguinte, uma maior integração nacional, e criando e perpetuando desigualdades internas.

Explica Myrdal que, no plano internacional, o comércio não opera no sentido de promover igualdade. Pelo contrário, especialmente no contexto do subdesenvolvimento, o comércio internacional pode acabar provocando efeitos regressivos. $\mathrm{O}$ mesmo raciocínio seria válido para o movimento de capitais, que tenderiam a se esquivar dos países subdesenvolvidos. Então, o autor reforça que o desenvolvimento econômico tem de ser promovido necessariamente por meio de interferências políticas. Pois, no final das contas, os

\footnotetext{
${ }^{146}$ Vide seção 3.3.
} 
efeitos propulsores fracos entre os países seriam na verdade um reflexo da fraqueza dos efeitos propulsores internos, que são tanto consequência como causa do baixo nível de desenvolvimento. Dessa forma, "Nessas circunstâncias, as forças de mercado tendem a acentuar acumulativamente (sic.) as desigualdades internacionais" (Ibid., p. 92). Nessa mesma linha de argumentação, o autor discorre sobre o que denomina de falta do Estado Mundial. Em suas palavras: "Em nível mais profundo, a explicação é que não existe para toda humanidade base psicológica na qual pode fundar-se tal política: a base de mútua solidariedade humana" (Ibid., p. 103).

Especificamente sobre o papel do Estado ${ }^{147}$, Myrdal destaca que parte da explicação da permanência na pobreza de alguns países se encontra nas próprias políticas estatais. De acordo com o autor, nos países pobres, os esforços para promover políticas de integração nacional teriam sido fracos, ao contrário do ocorrido nos países ricos. Ademais, as medidas políticas igualitárias seriam ainda mais dificultosas nas nações pobres por conta da debilidade dos efeitos propulsores, que ocasionam maiores desigualdades. Diz o autor: "Nos países mais ricos, por outro lado, o progresso econômico e os níveis ascendentes de renda oferecem oportunidades para todos e, portanto, dão mais força aos ideais de generosidade consciente." (Ibid., p. 71). O autor então destaca a interdependência das medidas, pois o combate eficiente dos efeitos regressivos por meio dos efeitos propulsores possibilitaria um ambiente mais propício à implementação das medidas políticas igualitárias.

Myrdal ressalta que a mudança mais importante a ser empreendida na esfera política das nações subdesenvolvidas é a compreensão da crucialidade do estabelecimento de um plano nacional de desenvolvimento econômico, o qual, em termos de modelo abstrato, deveria ter como base um estudo da causação circular entre os fatores relevantes para determinar a dinâmica do sistema econômico. Diz o autor sobre o plano nacional de desenvolvimento:

[...] deve ser o esquema do processo acumulativo de desenvolvimento econômico de um país, a previsão do evoluir desse processo, quando deflagrado, mantido e controlado por certas mudanças exógenas, induzidas no sistema social, mediante interferências estatais deliberadas. Esse esquema pressupõe, pois, um estudo da causação circular de todos os fatores relevantes do sistema social do País, quer sejam "econômicos" ou "não-econômicos". (Ibid., p. 133).

No entanto, como bem ressalta Myrdal, em geral, o Estado nos países subdesenvolvidos é fraco. Ainda sobre o plano nacional de desenvolvimento econômico, o autor indica que não pode ser elaborado baseando-se em critérios de lucratividade privada, pois a maior parte dos investimentos a ser realizada pelo plano não é lucrativa individualmente, por isso também a necessidade de interferência estatal, observação bastante

\footnotetext{
${ }^{147}$ Entendido por Myrdal como “[...] todas as interferências organizadas nas forças do mercado.” (Ibid., p. 73).
} 
semelhante à de Rosenstein-Rodan (1943, 1944), quando argumenta sobre o planejamento estatal da industrialização em larga escala. Além disso, Myrdal ressalta que, para de fato haver chance de êxito no programa de desenvolvimento econômico, deve-se priorizar a criação de escolas e universidades, destinadas à preparação de cientistas e pesquisadores.

Nesse sentido, observa Myrdal que "Os países subdesenvolvidos contam, para seu próprio uso, com a teoria econômica tradicional; mas, nesse ponto também, não devem aceitála sem crítica, e sem reformá-la para que se ajuste aos próprios problemas e interesses" (Ibid., p.152). O pioneiro defende que, para ser realista, a teoria econômica tem que se transformar numa teoria social. Com vistas a esse objetivo, deve romper com a teoria do equilíbrio estável e com os princípios do laissez-faire, dos quais decorreriam os fundamentos para defender a teoria do livre intercâmbio. A sua contribuição teórica teria como propósito justamente se desenvolver nessa direção, qual seja, de indicar a inadequação dos fundamentos da teoria tradicional para lidar com questões relativas ao desenvolvimento. Para o autor, a principal hipótese de uma teoria econômica supostamente mais realista deveria buscar contemplar a "[...] causação circular entre todos os fatores do sistema social, resultantes do processo acumulativo" (Ibid., p. 154-155). Algo que, obviamente, não se trata de tarefa trivial, se é que seria na verdade possível. No entanto, vale destacar da observação do autor a importância da consideração, em alguma medida, da relevância dinâmica das relações de retroalimentação e causação mútua entre os fatores que compõem o sistema econômico, discussão essa contemplada pela Abordagem da Complexidade.

Para concluir a presente seção, ressalte-se novamente que, ao se levar em consideração a cumulatividade do processo econômico, Myrdal destaca que o comércio internacional funciona como meio de provocação e perpetuação de desigualdades crescentes entre os países desenvolvidos e os subdesenvolvidos, caracterizados pela predominância de efeitos propulsores fracos, que explicam e perpetuam as próprias desigualdades internas dessas nações. Por isso a necessidade de interferências políticas deliberadas para promover o desenvolvimento econômico. Quanto ao plano nacional de desenvolvimento econômico, este deveria ter, então, como base, um estudo da causação circular entre os fatores relevantes, econômicos e não econômicos, a fim de incrementar as chances de superação do subdesenvolvimento. 


\subsection{Michal Kalecki ${ }^{148}$ : problemas cruciais do subdesenvolvimento}

Kalecki, além de ser considerado pioneiro do desenvolvimento econômico, na medida em que se debruçou especificamente sobre os problemas das regiões subdesenvolvidas, desenvolvendo para tal uma abordagem teórica própria, é, ao lado de Keynes, precursor de uma abordagem de teoria econômica crítica ao mainstream, fundadora da macroeconomia moderna e base da abordagem macroeconômica heterodoxa subsequente. Além de também ter definido o princípio da demanda efetiva, bem como suas implicações analíticas e dinâmicas relativas ao sistema econômico, diferentemente de Keynes, adentrou a discussão de questões distributivas e buscou, explicitamente, a formação de uma teoria dinâmica de crescimento, o que o torna ainda mais interessante, em termos teóricos, à discussão do subdesenvolvimento econômico.

Kalecki reconhecia em sua formulação teórica a divisão da sociedade em classes, trazendo implícitas nas suas teorias dos preços e da distribuição da renda, as relações de poder (de mercado ou de classe) típicas do sistema capitalista. Sobre essa questão, diz Robinson (1974):

Com esse pano de fundo, Kalecki enfatizou, muito mais do que Keynes, o elemento político em todos os desenvolvimentos econômicos e colocou no centro do argumento a questão clássica, a qual Keynes estava inclinado a não tratar, a respeito da divisão da produção mundial entre as classes da comunidade. ${ }^{149}$ (ROBINSON, 1974, p. 8).

Embora o intuito principal dessa seção seja discutir a obra de Kalecki na área de Economia do Desenvolvimento, vale tecer algumas considerações sobre a contribuição teórica do autor à teoria econômica em geral. Essa contribuição compõe um preâmbulo importante à discussão a ser realizada subsequentemente e, inclusive, apresenta alguns paralelos potenciais com a Abordagem da Complexidade. ${ }^{150}$

Diferentemente de Keynes, Kalecki desenvolveu sua teoria sem qualquer influência Marshalliana. A sua principal influência teórico-metodológica foi Marx, do qual extraiu as categorias propriamente econômicas, tais como a diferenciação entre capitalistas e trabalhadores, os conceitos de consumo e de investimento e a sua causação específica, relacionada ao problema da reprodução.

A teoria de preços de Kalecki (1954) explicita a distribuição de poder de mercado,

\footnotetext{
${ }^{148}$ Economista polonês (1899-1970).

149 "With this background, Kalecki stresses, far more than Keynes, the political element in all economic developments and he brings into the centre of the argument the classical question, which Keynes was inclined to smooth over, of the division of the produce of the earth between the classes of the community."

${ }^{150}$ Alguns desses paralelos são retomados a seguir. Para mais detalhes, vide Cardoso (2008).
} 
destacando os diferentes graus de monopólio e, por conseguinte, abandonando completamente a hipótese de concorrência perfeita e, por conseguinte, de homogeneidade entre os agentes econômicos. Conforme observam Possas e Baltar (1981), o poder de fixação de preços refletido no grau de monopólio sintetiza a complexidade das relações de concorrência entre as empresas, da relação destas com suas fornecedoras e com seus trabalhadores.

No que se refere à formulação do princípio da demanda efetiva, Kalecki distingue o padrão de gastos entre as classes, adicionando, portanto, mais um nível de heterogeneidade ao seu esquema analítico. A consideração da heterogeneidade dos agentes econômicos - algo implicitamente realizado pelos demais pioneiros no nível das nações - por parte de Kalecki afasta sua abordagem da hipótese clássica de "agente representativo" e, em boa medida, a aproxima da Abordagem da Complexidade, que tem como a hipótese da heterogeneidade dos agentes, implicando à sua interação uma importante fonte de efeitos de retroalimentação e, por conseguinte, inviabilizando a adoção dos métodos analíticos agregativos da abordagem macroeconômica convencional.

O padrão de gastos definido por Kalecki está composto por investimento, consumo dos capitalistas e consumo dos trabalhadores. Baseado no esquema de três departamentos produtores de bens de investimento, de bens de consumo dos capitalistas e de bens de consumo dos trabalhadores - e considerando a hipótese simplificadora de que os trabalhadores gastam tudo o que ganham, o autor apresenta o resultado de que os capitalistas ganham o que gastam. Esse esquema de três departamentos proposto por Kalecki permitiria ainda aplicações de caráter dinâmico. Possas e Baltar enfatizam que o esquema de três departamentos deixaria em aberto a possibilidade de uma análise setorial dinâmica de integração analítica micro e macroeconômica, tal como realizado por alguns trabalhos relativamente recentes. ${ }^{151}$

Ademais, de acordo com Possas e Baltar, a eliminação das hipóteses simplificadoras sobre os gastos dos trabalhadores não alteraria essencialmente as conclusões a respeito do funcionamento da demanda efetiva a que chega Kalecki, pois o importante a reter é a ideia de que o gasto capitalista é, por excelência, autônomo, na medida em que só os capitalistas investem. Assim sendo, no esquema Kaleckiano, a distribuição funcional da renda seria uma variável importante para compor a análise das implicações dinâmicas do princípio da demanda efetiva.

Sobre a dinâmica implicada pelo princípio da demanda efetiva segundo a perspectiva

\footnotetext{
${ }^{151}$ Por exemplo, vide Possas, Dweck e Reif (2004) e Dweck (2006).
} 
de Kalecki, o essencial a destacar é justamente a determinação da renda pelos gastos. ${ }^{152}$ Os gastos determinam a renda - via processo multiplicador -, dados parâmetros estruturais como a propensão a consumir das classes e a distribuição de renda. $\mathrm{O}$ investimento, quando realizado, geraria simultaneamente a poupança necessária para financiá-lo. Dessa forma, a relação entre poupança e investimento, a partir do princípio da demanda efetiva, deveria ser vista como uma identidade contábil, acrescida de uma relação de determinação causal do último para aquela. No entanto, vale observar que a elasticidade de produção e a existência de capacidade ociosa seriam requisitos essenciais para que o nível de produção real pudesse se ajustar ao nível de demanda efetiva, ainda que em termos nominais a determinação fosse imediata e verdadeira. Essa observação é importante pois, como discutido adiante, a insuficiência de capacidade produtiva dos países subdesenvolvidos implicaria a necessidade de um tratamento teórico diferenciado, no qual não valeria, desde sempre, o princípio da demanda efetiva.

Como uma das implicações mais marcantes do modelo Kaleckiano, note-se o papel dual do investimento que, ao mesmo tempo em que gera estímulos, via investimento, à demanda agregada, cria capacidade produtiva, de modo que o segundo efeito poderia se constituir em um desestímulo à consecução de novos investimentos. Assim sendo, no caráter dual do investimento residiria parte da explicação das flutuações no nível de atividade econômica. Por fim, como destacado por Possas (1987), a conclusão a que chega Kalecki ao final da discussão da sua teoria da dinâmica econômica, de que a explicação para a tendência de crescimento de longo prazo do sistema capitalista residiria nos chamados fatores de desenvolvimento $^{153}$, dentre eles o progresso técnico, abriria um flanco para a complementaridade analítica da teoria dinâmica de Kalecki e da teoria do desenvolvimento de Schumpeter, compondo a primeira a esfera de explicação macroeconômica ${ }^{154}$ e a segunda a esfera de explicação microeconômica. Para Kalecki, as inovações possuiriam um efeito atrativo para a realização de novos investimentos.

Não obstante, conforme ressaltado pela discussão apresentada a seguir, baseada em

\footnotetext{
${ }^{152}$ Vale dizer que, diferentemente de Keynes, a dedução do princípio da demanda efetiva realizada por Kalecki não traz explícitos o processo de formação de expectativas e a incerteza, o que poderia ser consequência do fato de o conteúdo temporal no modelo de Kalecki possuir natureza puramente contábil e ex post.

153 Segundo Kalecki (1954, p. 128), “[...] os fatores de desenvolvimento, tais como as inovações, não permitem que o sistema se assente numa posição estática, gerando uma tendência ascendente a longo prazo. A acumulação de capital, que resulta do fato de que o investimento a longo prazo se encontra acima do nível da depreciação, por sua vez aumenta a amplitude da influência dos "fatores de desenvolvimento", contribuindo dessa maneira para a manutenção da tendência a longo prazo."

${ }^{154}$ No modelo de integração micro-macro sugerido por Possas (1987), a teoria de Keynes também compõem a esfera de discussão macroeconômica.
} 
Kalecki enquanto pioneiro do desenvolvimento, as conclusões apresentadas no parágrafo anterior seriam perfeitamente aplicáveis ao contexto das nações desenvolvidas. Sobre esse ponto, Dutt (2001) ressalta que a mudança tecnológica interpretada por Kalecki em um sentido Schumpeteriano estimulava o nível de atividade econômica ao estabelecer um impulso para os planos de investimento, querendo dizer que "Nos modelos de Kalecki, o crescimento é determinado por fatores do lado da demanda, uma vez que a oferta não restringe a economia, nem mesmo no auge do ciclo" (DUTT, 2001, p. 33). De outro modo, no contexto do subdesenvolvimento, como bem destacado pelo pioneiro Kalecki, as restrições de oferta em virtude de gargalos na estrutura produtiva constituem problemas cruciais.

Passemos à discussão de Kalecki como pioneiro do desenvolvimento econômico. Os textos discutidos foram publicados entre meados da década de 1950 e a início da década de 1970, e apresentam conceitos e discussões importantes para compor a contribuição teórica de Kalecki sobre as particularidades do subdesenvolvimento.

Como bem destaca Kalecki (1960), o desemprego e o subemprego nos países subdesenvolvidos são de natureza inteiramente distinta. Eles resultam mais da limitação de capacidade produtiva do que da insuficiência de demanda efetiva. $\mathrm{O}$ autor aponta para $\mathrm{o}$ gargalo na oferta de bens de primeira necessidade (alimentos), que dependem da elasticidade (ou inelasticidade) da produção agrícola nessas nações. O resultado de qualquer crescimento no emprego implicaria, caso a produção agrícola não respondesse prontamente ao incremento de demanda, uma resposta inflacionária dos preços dos bens de primeira necessidade. Desse modo, para evitar a pressão inflacionária e não agravar a questão do desemprego e do subemprego no contexto dos países subdesenvolvidos, far-se-ia necessária a expansão da produção agrícola. Singer (1985) também discute essa questão, conforme destacado na seção 3.2, indicando que a pressão sobre os preços dos bens de salário, especialmente dos alimentos, constituía uma das condições de causação cumulativa que dificultaria o incremento do investimento nas nações subdesenvolvidas. Essa discussão a respeito do gargalo na oferta de alimentos igualmente remete a Lewis $(1954,1955)$, que, partindo da hipótese de oferta ilimitada de mão-de-obra não qualificada, definira a estrutura produtiva dual das economias subdesenvolvidas. A importância dinâmica da baixa produtividade da agricultura para os sistemas econômicos nacionais subdesenvolvidos é também objeto de discussão de Prebisch e Furtado, conforme exposto no capítulo 4.

Kalecki (1968) explica, então, que o problema crucial das nações subdesenvolvidas é aumentar o investimento, não com o intuito de incrementar a demanda efetiva, mas sim de expandir a capacidade produtiva. Haveria, no entanto, ao menos três obstáculos ao incremento 
do investimento: (i) o próprio volume de investimento privado, que poderia não alcançar uma taxa desejável; (ii) poderia não haver recursos disponíveis para produzir mais bens de capital; e (iii) mesmo que as primeiras duas questões estivessem resolvidas, a fim de evitar uma potencial pressão inflacionária, restaria o problema de garantir uma oferta adequada de bens de primeira necessidade, especialmente em decorrência do aumento do nível de emprego.

Portanto, seria necessário planejar não somente o volume, mas também a estrutura do investimento, entre a produção dos bens de primeira necessidade, aqueles menos essenciais e os de capital, buscando, dessa forma, um relativo balanceamento entre os setores, conforme destacado especialmente pelos pioneiros relacionados à teoria do crescimento equilibrado. Para tal, assim como os demais pioneiros, o autor indica que deveria haver uma intervenção governamental relativamente profunda, seja via investimento, seja via planejamento. Segundo Kalecki (1954b):

O investimento pode ser limitado não por causa das dificuldades de financiar seu crescimento sem causar inflação, mas pela falta de vontade dos empresários expandirem seus dispêndios em capital. Em tal situação, o investimento público adquire uma importância crucial para o processo de rápido desenvolvimento econômico [...] ${ }^{155}$ (KALECKI, 1954b, p. 46).

A argumentação de Kalecki no trecho selecionado se assemelha especialmente a de Rosenstein-Rodan (1943, 1944), apresentado na seção 3.1, quando esse autor apontara para a necessidade da atuação governamental para a geração das economias externas pecuniárias e tecnológicas por meio dos investimentos em bloco, com destaque especial para a infraestrutura, a fim de estimular os investimentos do setor privado.

Quanto a assegurar uma produção adequada de bens de primeira necessidade, segundo Kalecki (1968), sem que observassem mudanças institucionais substanciais, relacionadas especialmente à posse de terra, não seria possível acelerar o desenvolvimento agrícola. Essa observação é fundamental, na medida em que fundamentaria a necessidade de promoção de reforma agrária para racionalizar a produção agrícola, conforme argumentado adiante pelos pioneiros Cepalino-estruturalistas Prebisch e Furtado. Também por conta do hiato entre o crescimento e a oferta de bens de primeira necessidade, bem como as dificuldades de saná-lo internamente, para Kalecki (1967), o crédito externo poderia ser importante, embora devesse estar sujeito a critérios de avaliação, assunto a ser discutido em parágrafo mais à frente.

Kalecki (1954b) discorre sobre as potenciais vantagens de importar capital. A quantidade de poupança necessária para financiar o investimento seria reduzida na medida em que se importasse capital, o que por sua vez diminuiria as pressões inflacionárias internas. A

155 "Investment may be limited not because of the difficulties of financing its increase without causing inflation, but by the unwillingness of the entrepreneurs to expand their capital expenditures. In such a situation, public investment acquires a crucial importance for the process of rapid economic development [...] ". 
importação de capital seria ainda funcional para aliviar uma possível escassez de comércio externo, mesmo porque o próprio processo de desenvolvimento estabeleceria uma tendência constrangedora do balanço de pagamentos em virtude da necessidade de importações crescentes.

Nesse mesmo sentido, Kalecki (1970) destaca que os créditos externos afetariam não apenas a questão da oferta dos bens de primeira necessidade e o equilíbrio do comércio externo em outras commodities, mas também o problema do financiamento do investimento, reduzindo a necessidade de taxação da importação dos bens menos essenciais, bem como dos grupos de mais alta renda, essa última requerida para diminuir justamente o consumo de bens menos essenciais. Por outro lado, retomando observação de Nurkse $(1952,1953)$ relativa ao efeito demonstração, se não fossem verificadas restrições à importação ou ao consumo de bens de luxo, a tendência ao direcionamento e concentração de recursos para a satisfação do consumo ou para a produção desses bens continuaria posta. Por isso, mais uma vez, a necessidade de avaliar as condições de absorção de recursos externos.

Na prática, conforme adverte Kalecki (1954b), financiar o desenvolvimento por meio da importação de capital, no geral, incorreria em problemas frequentemente insuperáveis, relacionados ao balanço de pagamentos. Somar-se-ia a esse problema potencial a grande dificuldade que os países subdesenvolvidos encontrariam em estabelecer condições a eles mais favoráveis, ou ao menos mais seguras, relativas à importação de capital. Por isso, a importância de, no contexto do subdesenvolvimento, melhorar os termos comerciais, conforme argumentado na tese Singer-Prebisch.

Para avaliar a validade da ajuda externa, Kalecki e Sachs (1966) elencam inicialmente dois critérios a serem contemplados: se a ajuda externa implica uma melhora nas condições externas de crescimento da nação que recebe o auxílio; e se a avaliação da ajuda externa se baseia em um conhecimento satisfatório dos problemas relacionados ao desenvolvimento econômico da nação receptora.

Entretanto, Kalecki e Sachs ressaltam que haveria o risco do influxo de recursos externos ser dissipado em consumo adicional de bens de luxo. Assim, segundo os autores, há que se levar em consideração em que medida a entrada de ajuda externa melhorou não apenas a situação do balanço de pagamentos, mas se essa melhora foi funcional para remover os gargalos na oferta de bens de capital, de bens de primeira necessidade, de bens intermediários e inclusive de bens de luxo. Além disso, há que se questionar se os recursos financeiros adicionais foram instrumentais para elevar a taxa de crescimento via a permissão de uma maior taxa de investimento (relativamente aos recursos internos disponíveis) e se, caso sim, se 
financiaram um acréscimo no consumo desses bens ou se foram materializados em serviços sociais. Nesse sentido, os autores concluem que a ajuda externa pode ser considerada como utilizada adequadamente se incrementar, tudo o mais constante, os investimentos outros que não na produção de bens de luxo e se aumentar, tudo o mais constante, o consumo de bens de primeira necessidade e/ou a produção de serviços sociais. Desse modo, como bem ressaltam os autores:

[...] o papel da ajuda externa somente pode ser avaliado no contexto de uma análise abrangente dos problemas do desenvolvimento do país receptor, visto como um todo. Essa análise requer a concepção de um plano e, por conseguinte, um planejamento abrangente deveria ser considerado como um pré-requisito de qualquer ação que se destinasse a uma utilização racional da ajuda externa disponível. ${ }^{156}$ (KALECKI e SACHS, 1966, p. 69).

Assim, em poucas palavras, a ajuda externa seria eficiente na medida em que contribuísse para resolver os hiatos entre a demanda e a oferta no processo de desenvolvimento da nação receptora dos recursos. Essa colocação remete à contribuição de Singer (1950), que indicara os efeitos perniciosos dos investimentos externos nas nações subdesenvolvidas, na medida em que a sua tendência era se concentrar na perpetuação da produção de bens primários, o que só acabava intensificando o aprisionamento no subdesenvolvimento, na medida em não lhes permitia superar os efeitos deletérios de longo prazo da deterioração dos termos de troca dos bens primários. Por isso Singer derivara a necessidade de planejamento direcionando os recursos a setores específicos, justamente aqueles com maior possibilidade de incorporação de progresso técnico e potencial de radiação dinâmica. Por um caminho distinto, porém com a mesma motivação, Kalecki e Sachs indicam a necessidade da elaboração de um planejamento e avaliação prévios ao recebimento e captação de recursos externos, assunto a ser retomado nos capítulos seguintes, especialmente quando da discussão das causas da crise da dívida externa enfrentada pelo Brasil em virtude da natureza de seu endividamento.

Antes de encerrar a presente seção, vale reproduzir trecho em que Kalecki (1968) sintetiza aquela que seria a grande diferença entre as nações desenvolvidas e as nações subdesenvolvidas, fundamentando-a na dotação de recursos disponíveis. Em suas palavras:

Em um caso, as dotações de recursos devem ser utilizadas e o capitalismo moderno aprendeu o artifício de fazê-lo. No outro caso, as dotações de recursos devem ser criadas e isso requer reformas de longo alcance que levem a mudanças revolucionárias. ${ }^{157}$ (KALECKI, 1968, p. 27).

\footnotetext{
156 " [...] the role played by foreign aid can be evaluated only in the context of a comprehensive analysis of the development problems of the recipient country seen as a whole. Such an analysis requires the framing of a plan and, therefore, comprehensive planning should be considered as a prerequisite of any action aimed at a rational utilization of available foreign aid."

157 "In one case, existing resources have to be utilized and modern capitalism has learned the trick of doing it. In the other case, existing resources have to be built up and this requires far-reaching reforms amounting to revolutionary changes."
} 
Mudanças revolucionárias no sentido de Schumpeter (1912), tal como destacado na subseção 2.1.2 do capítulo 2, retomando que no contexto do subdesenvolvimento as mudanças teriam que ser impactantes o suficiente para retirarem as nações de uma condição inicial de atraso para resultar numa condição de desenvolvimento. Entretanto, mesmo tendo em vista as grandes dificuldades a serem enfrentadas pelos países subdesenvolvidos para conseguirem empreender essas mudanças, Kalecki (1963) pondera de maneira otimista que, apesar dos grandes obstáculos, esses não seriam problemas insuperáveis. No entanto, enfatiza que, sem planejamento deliberado e reformas institucionais profundas, de modo a remover os obstáculos institucionais ao rápido crescimento, de fato, seria tarefa impossível às nações subdesenvolvidas superarem suas dificuldades.

Guardadas suas diferenças e até possíveis incompatibilidades, os elementos e as discussões levantadas pelos pioneiros relativos a algumas das particularidades das nações subdesenvolvidas parecem apresentar possíveis relações de complementaridade, ou seja, de certa forma e em algumas direções, a combinação de algumas contribuições de pioneiros distintos se mostram potencialmente frutíferas para a discussão do tema. Embora com entonações ou destaques variados, a indicação da necessidade da promoção de reformas estruturais, relacionadas a diversos aspectos - estrutura agrária, ciência e tecnologia, educação, tributação e etc. - e especialmente de planejamento estatal, de consecução de programas de desenvolvimento, com ênfase na industrialização, são assuntos recorrentes de discussão dos pioneiros abordados por esse capítulo.

As intervenções e direcionamentos, por meio especialmente dos meios disponíveis ao Estado, sugeridos pelos pioneiros, seriam necessários no contexto do subdesenvolvimento porque as causações circulares à la Myrdal ou os círculos viciosos da pobreza à la Nurkse que se formavam no contexto das nações subdesenvolvidas implicariam a tendência de perpetuação das disparidades, desequilíbrios internos e outros diversos problemas - refletidos principalmente na perpetuação do dualismo estrutural, como bem definido por Lewis, e na sujeição aos efeitos de deterioração dos termos de troca tal como definido pela tese SingerPrebisch -, bem como, consequentemente, da não diminuição e, inclusive, alargamento, do hiato de desenvolvimento entre as nações centrais e as nações periféricas. Para fazer frente a essas causações circulares cumulativas que faziam emergir o resultado de subdesenvolvimento seria possivelmente funcional um grande impulso à la RosensteinRodan, para o qual concorreriam a promoção de investimentos em bloco, abrangendo os diversos setores da economia, permitindo o aproveitamento das economias externas e dos 
encadeamentos para frente e para trás de Hirschman.

No que se referem a paralelos e compatibilidades entre a Abordagem da Complexidade e os pioneiros do desenvolvimento econômico, destacam-se: (i) a consideração de heterogeneidade das nações por parte dos pioneiros, implicando a necessidade de um tratamento teórico diferenciado, uma vez que os ferramentais de teoria econômica disponíveis à época partiam da hipótese de agente representativo, e, por conseguinte, de uma consequente padronização de políticas econômicas; (ii) a consideração de efeitos cumulativos - ou de retroalimentação - entre as esferas micro e macroeconômica, na forma de fatores externos e internos, em contraposição a uma perspectiva econômica tradicional, que teria como pressuposto a existência de mecanismos automáticos de estabilização, do que derivariam à tendência ao equilíbrio ótimo.

Em poucas palavras, do que seria uma abordagem ortodoxa sobre o desenvolvimento, implicava-se a adoção de políticas padrão, funcionais ao contexto das nações já desenvolvidas, e sem a necessidade de intervenção estatal direta, uma vez que o mercado disporia de mecanismos automáticos de estabilização que supostamente recolocariam os sistemas econômicos na trajetória de desenvolvimento. Como resultado, seria observada uma convergência entre o padrão de vida vigente nas diversas nações. Já para os pioneiros, a tendência que se mostrava era justamente outra, qual seja, de divergência crescente entre as nações, por isso a necessidade de intervenção deliberada via Estado.

Assim sendo, tanto no que se referem aos meios de explicação da perpetuação do subdesenvolvimento quanto aos possíveis meios para tentar superá-lo, a Abordagem da Complexidade parece poder contemplar a resolução de parte das críticas à teoria econômica apontadas pelos pioneiros. Mesmo no que se refere à necessidade de intervenção do Estado, conforme aventado ao final do capítulo 2, apesar da Abordagem da Complexidade implicar que não há um mecanismo global de controle, sendo os resultados totalmente em aberto, implicar ao Estado o papel de interventor e de potencial redirecionador da tendência em prol do desenvolvimento não significa que o resultado final esteja garantido.

Conforme argumentado nessa seção, Kalecki não escapou a essa regra de implicações dos demais pioneiros, apontando para o enfrentamento de gargalos da estrutura produtiva, especialmente no setor produtor de alimentos, para o que implicava a necessidade de promoção de uma reforma agrária.

No próximo capítulo, muitos dos questionamentos aqui realizados acabam sendo retomados, porquanto a discussão de certas especificidades ao contexto do subdesenvolvimento continua sendo o foco. Como discutido a seguir, os pioneiros latino- 
americanos, comparativamente aos pioneiros aqui discutidos, teriam concedido uma maior ênfase a importância de reformas estruturais, não à toa tendo recebido a alcunha de estruturalistas. 


\section{OS PIONEIROS DO DESENVOLVIMENTO ECONÔMICO II: A CONTRIBUIÇÃO LATINO-AMERICANA}

Assim como no capítulo anterior, no presente capítulo, os focos de discussão continuam sendo o contexto e as particularidades das nações subdesenvolvidas. Entretanto, agora a discussão submerge a um nível mais profundo de especificidade teórica, relacionado à perspectiva de um grupo específico, embora não homogêneo, de países subdesenvolvidos: os latino-americanos.

Debruçados especialmente sobre o lado latino-americano do subdesenvolvimento, a Escola Estruturalista Cepalina, por meio de dois de seus principais representantes, encerra a discussão da contribuição dos pioneiros do desenvolvimento. Guardadas as especificidades de seus argumentos, o argentino Raúl Prebisch e o brasileiro Celso Furtado enfatizaram o papel central do desenvolvimento industrial para a superação da dependência externa e do subdesenvolvimento econômico, destacando a importância da participação ativa do Estado na condução da economia por meio de suas políticas públicas e de atuação direta enquanto agente econômico.

Nesse sentido e, a fim de justificar um capítulo somente à contribuição latinoamericana, vale citar as palavras de Prebisch (1949) sobre o que deveria ser uma investigação sistemática dos problemas da América Latina:

Dificilmente se poderia pretender, na verdade, que os economistas dos grandes países, empenhados em gravíssimos problemas próprios, viessem a dedicar sua atenção preferencialmente ao estudo dos nossos. Compete primordialmente aos próprios economistas latino-americanos o conhecimento da realidade econômica da América Latina. Somente se viermos a explicá-la racionalmente e com a objetividade científica é que será possível obtermos fórmulas eficazes de ação prática. (PREBISCH, 1949, p. 80, nr. 1).

A ligação e proximidade teórica entre Prebisch e Furtado também é evidente. Furtado inclusive dedica seu livro A Economia Brasileira, de 1954, a Prebisch. ${ }^{158}$ Antes disso, Furtado traduzira o texto de Prebisch de 1949 para o português. Furtado (1985) relata:

\footnotetext{
Não tive dúvida de que aquele documento poderia vir a ser um tournant no pensamento políticoeconômico na América Latina, pelo que continha e por quem o escrevia. Procurei Prebisch, que se aprestava para embarcar para Havana e lhe pedi autorização para traduzi-lo para o português e publicá-lo na Revista Brasileira de Economia. Essa a razão pela qual foi na versão portuguesa, que o famoso "manifesto" fundador da escola cepalina teve sua primeira ampla difusão. (FURTADO, 1985, p. 63).
}

\footnotetext{
${ }^{158}$ A respeito desse fato, Furtado (1985) detalha: “A publicação de A Economia Brasileira difundia uma linha de pensamento em clara oposição à escola ortodoxa que, dominando as publicações da Fundação Getúlio Vargas, pretendia monopolizar o enfoque "científico" dos problemas econômicos. Partindo das posições de Prebisch, a quem era dedicado o livro, eu tentava ampliar o horizonte de reflexões em várias direções.” (FURTADO, 1985, p. 172).
} 
Sobre a importância demarcatória da tese Singer-Prebisch, Furtado (1967) ressaltara que "O estudo dos fatores responsáveis pela perda de dinamismo da procura internacional de produtos primários abriu a porta a uma crítica em profundidade da teoria tradicional do comércio internacional." (Id., 1967, p. 228). Sobre o mesmo ponto, citando a teoria de Prebisch, Furtado diz enfaticamente a respeito da tendência à perpetuação do subdesenvolvimento em condições de laissez-faire:

\begin{abstract}
$\mathrm{O}$ tipo de relações que existe entre o centro e a periferia estaria na base do fenômeno de concentração da renda em escala mundial, que se realiza principalmente por meio da deterioração persistente dos termos de intercâmbio dos países periféricos. A análise das economias contemporâneas, de um ângulo dinâmico, indicaria que não existe tendência à passagem automática de uma fase qualquer a outra superior. Ao contrário, a única tendência visível é para que os países subdesenvolvidos continuem a sê-lo. (Ibid., p. 143).
\end{abstract}

Com relação ao papel importante e diferenciado da CEPAL, na medida em que constituiu um grupo de estudos específico para avaliar as nações latino-americanas, Furtado (1976) destaca que esses estudos teriam permitido uma compreensão melhor da natureza da dependência externa das nações latino-americanas, constituindo-se num divisor de águas, pois “A partir dessas análises já não cabia admitir como hipótese de trabalho a possibilidade de reversão a uma situação em que as exportações de produtos primários desempenhavam o papel de principal centro propulsor do desenvolvimento regional.” (Id., 1976, p. 377).

Em seu prefácio à Formação Econômica da América Latina, Furtado destaca a consciência crescente de que, na América Latina, mais do que em qualquer outra região, os obstáculos ao desenvolvimento seriam principalmente de natureza institucional e, por conseguinte, estrutural. O enfoque estruturalista, segundo o autor, tenderia a colocar em primeiro plano os problemas agrários, contrariando a tendência corrente de manter o foco apenas no estudo da industrialização. Sobre essa questão, diz o autor:

À medida que os obstáculos à industrialização se acumularam e que esta se mostrou menos eficaz do que se havia esperado como fator de transformação das estruturas tradicionais, todo um horizonte de novas preocupações se abriu. (Ibid., p. 388-389).

Vale notar, ademais, que o estruturalismo também já se mostrava entre muitos dos pioneiros discutidos no capítulo anterior, no sentido de seu ceticismo com relação à eficácia regulatória do mecanismo de preços, e da conviç̧ão de que o planejamento e o controle governamentais deveriam compensar, de alguma forma, as falhas de mercado. Em alguma medida, esses pioneiros concordavam que, por diversas razões, o mecanismo de preços não funcionava muito bem no contexto dos países subdesenvolvidos e que, portanto, a teoria econômica do mainstream seria amplamente inaplicável nesses casos.

Esse capítulo está dividido em duas seções, uma dedicada a cada autor. A discussão de 
suas contribuições teóricas, assim como no capítulo anterior, se baseia em alguns textos selecionados, nos quais os pioneiros teriam apresentado as suas principais ideias relativas ao subdesenvolvimento latino-americano. Passemos à discussão da contribuição teórica desses dois pioneiros latino-americanos, a começar por Raúl Prebisch, a tese Singer-Prebisch e a dinâmica centro-periferia (seção 4.1), e posteriormente, Celso Furtado e o capitalismo periférico (seção 4.2).

\subsection{Raúl Prebisch: ${ }^{159}$ tese Singer-Prebisch e a dinâmica centro-periferia}

Essa seção, além de se basear no artigo seminal de Prebisch publicado em 1949, recorre a textos selecionados de documentos da CEPAL, ${ }^{160}$ escritos pelo autor nas décadas de 1950 e 1960. Destacam-se inclusive, quando elucidativos, comentários do autor sobre a sua própria obra.

Prebisch apresenta como interesse especial a compreensão da função desempenhada pelos países subdesenvolvidos (ou periféricos) no fluxo de comércio internacional. Segundo o pioneiro:

Meu ingresso na CEPAL em 1949 ocorreu quando minhas ideias já tinham atingido maturidade, e eu estava, portanto, apto a cristalizá-las em vários estudos publicados no início dos anos 1950. Nesses estudos, eu busquei tanto diagnosticar os problemas como sugerir políticas que serviriam como alternativas àquelas propostas pelo pensamento ortodoxo. Graças aos horizontes mais amplos que minhas novas responsabilidades me permitiram, esses estudos se referiam não apenas à Argentina, mas à América Latina como um todo. ${ }^{161}$ (PREBISCH, 1984, p. 176).

A principal crítica de Prebisch se dirige à teoria do comércio internacional pautada pela teoria das vantagens comparativas, baseada na premissa de que os frutos do progresso técnico tenderiam a ser distribuídos equitativamente entre as nações participantes do comércio internacional. Seguindo esse raciocínio, as nações especializadas na produção de bens primários, além de não precisarem, não deveriam se industrializar, para assim se beneficiar dos frutos do progresso tecnológico originado nas nações industrializadas. A respeito da importância da industrialização para o estabelecimento de um novo padrão de desenvolvimento, diz Prebisch:

\footnotetext{
${ }^{159}$ Economista argentino (1901-1986).

${ }^{160}$ Compilados por Bielschowsky (2000).

161 "My entry into CEPAL in 1949 took place when my ideas were already reaching maturity, and I was therefore able to crystalize them in various studies published in the early 1950s. In these studies I tried both to diagnose the problems and to suggest policies which would serve as alternatives to those proposed by orthodox thinking. Thanks to the broader horizon which my new responsibilities permitted me, these studies concerned not only Argentina but Latin America as a whole."
} 
Minha política de desenvolvimento proposta estava orientada no sentido do estabelecimento de um novo padrão de desenvolvimento que permitiria a superação das limitações do padrão anterior. Essa nova forma de desenvolvimento teria a industrialização como seu principal objetivo. ${ }^{162}$ (Ibid., p. 177).

Sobre certas questões, a abordagem de Prebisch é bastante similar a de Singer (1950), por isso a denominação de tese Singer-Prebisch. Os dois pioneiros definiram a tendência à deterioração dos termos de troca dos bens primários e discutiram os seus efeitos perniciosos sobre o desenvolvimento das nações primário-exportadoras. No entanto, Prebisch se diferencia de Singer porque desenvolveu seu raciocínio baseado em uma definição teórica diferenciada: a relação centro-periferia. Centro porque é o epicentro dos ciclos, relacionados ao progresso tecnológico especialmente, e periferia porque absorve os efeitos que dele decorrem.

Ao contrário do que sugeriria uma interpretação precipitada de Prebisch, em nenhum momento esse autor sugeriu que os países da periferia deveriam fechar suas economias. A sua recomendação de política aponta para a necessidade de transformar a estrutura produtiva tornando-a mais moderna via industrialização, permitindo extrair as vantagens das interações internacionais e possibilitando escapar da armadilha da tendência à deterioração dos termos de troca. Conforme ressalta o próprio autor:

De maneira geral, minha crítica ao protecionismo no centro e minha defesa do protecionismo na periferia têm sido mal interpretados. Eu encarava o último tipo de proteção como necessário durante um bastante longo período de transição, no qual essas disparidades na elasticidade da demanda deveriam ser corrigidas. O protecionismo no centro agrava essas disparidades, enquanto que, na periferia, ele tende a corrigi-las, desde que não excedam certos limites. Quanto maior a disparidade, maior a necessidade de substituição de importação [...] ${ }^{163}$ (Ibid., p. 181).

A priorização da industrialização e a adoção de algumas políticas protecionistas, como a substituição de importações, não significaria que as economias periféricas deveriam interromper a exportação de produtos primários e nem que a transformação dessas economias deveria levar necessariamente ao fechamento da economia ou ao seu protecionismo indiscriminado. Prebisch (1949) destaca que o desenvolvimento eficaz do setor primário é importante para o processo de industrialização da periferia, na medida em que a exportação de produtos primários é a fonte de divisas para a importação de máquinas e equipamentos necessários à modernização da estrutura produtiva. Diz o autor: “A solução não está em

\footnotetext{
162 "My proposed development policy was oriented toward the establishment of a new pattern of development which would make it possible to overcome the limitations of the previous pattern. This new form of development would have industrialization as its main objective."

163 "Generally speaking, my attack on protectionism at the centers and my defense of protectionism at the periphery has been misinterpreted. I envisaged the later type of protection as necessary during a rather long transition period in which these disparities in demand elasticity should be corrected. Protection at the centers aggravates these disparities, while at the periphery it tends to correct them, provided they do not exceed certain limits. The wider the disparity, the greater the need for import substitution [...]".
} 
crescer à custa do comércio exterior, mas em saber extrair, de um comércio exterior cada vez maior, os elementos propulsores do desenvolvimento econômico.” (Id., 1949, p. 73). Nesse mesmo sentido, o autor argumenta que o desequilíbrio de renda entre o centro e a periferia poderia ser diminuído se, por meio do progresso técnico, fosse aumentada a eficácia produtiva, e se, por meio da industrialização e de uma legislação social adequada, fosse elevado o nível real de salários.

Prebisch aponta ainda para a importância dos investimentos estrangeiros no processo de desenvolvimento econômico de algumas nações latino-americanas, mesmo porque, em boa parte delas, não haveria recursos internos suficientes para dar início e sustentação àquele processo. Ressalte-se, no entanto, a sua qualificação de "ajuda transitória", o que seria indicativo da necessidade de avaliação e planejamento, tal como discutido, no capítulo anterior, especialmente por Singer (1950) - vide seção 3.2 - e por Kalecki e Sachs (1966) vide seção 3.7. Nas palavras do pioneiro:

Com efeito, a produtividade desses países é muito baixa, porque falta capital; e falta capital por ser muito estreita a margem de poupança, em virtude dessa baixa produtividade. Para romper esse círculo vicioso, sem deprimir exageradamente o atual consumo das massas, em geral muito baixo, é necessária a ajuda transitória do capital estrangeiro. (Ibid., p. 109).

Igualmente, há que se admitir a possibilidade da necessidade de reduzir o coeficiente de importações, eliminando os bens menos essenciais do ponto de vista da industrialização. Importante lembrar que - e ressaltando o caráter cíclico a que estaria sujeita a periferia de forma passiva - a redução do coeficiente de importações seria uma “[...] mera adaptação das importações à capacidade de pagamento conferida pelas exportações. Se estas crescessem suficientemente, não seria necessário pensar em restrições.” (Ibid., p. 119). Contudo, isso não implicaria que o desenvolvimento industrial em si tornaria a periferia menos vulnerável às flutuações de suas exportações, pois seria preciso que as exportações atingissem uma proporção relativamente pequena da renda nacional, o que, na verdade, significaria que “[...] o país já teria deixado de ser periférico, convertendo-se num centro cíclico [...]” (Ibid., p. 124). Dessa observação o autor deriva a importância das políticas anticíclicas como complementares às políticas de desenvolvimento, atenuando o desemprego de fatores quando fossem verificadas flutuações nas exportações.

À semelhança de outros pioneiros, tal como Nurkse $(1952$, 1953) que definira a existência de uma poupança oculta, Prebisch aponta que a produtividade poderia ser aumentada pelo emprego de mão-de-obra na indústria de pessoas antes alocadas em setores de baixa produtividade, permitindo, desse modo, um aumento da disponibilidade de recursos internos e uma diminuição da necessidade de recursos externos. No entanto, adverte o autor 
que essa tentativa só poderia ser bem sucedida se acompanhada de um esforço de capitalização que não seria compatível nem com o perfil de consumo de alguns estratos sociais, nem com certas formas de despesas fiscais, pois ambas não contribuiriam, em nenhuma medida, com os incrementos de produtividade. Isso, segundo o autor, seria, à semelhança do efeito demonstração discutido por Nurkse (1952), uma manifestação do propósito das nações subdesenvolvidas, por meio de sua elite, de assimilar, de maneira abrupta, certos padrões de consumo que os países mais avançados foram formando progressivamente, em decorrência de seu aumento de produtividade.

Em tese, a teoria das vantagens comparativas sugere que o bem estar das nações seria incrementado pela interação comercial internacional na medida em que lhes permitiria se especializar apenas na produção em que apresentassem maiores vantagens comparativas. Entretanto, como bem demonstra Prebisch, esse incremento de bem estar só se observara nos países do centro, explicação que realiza com base na observação da tendência à deterioração dos termos de troca dos bens primários (exportados pelos países periféricos) relativamente aos bens manufaturados (exportados pelos países centrais).

Com base em dados de 1876 a 1947, ${ }^{164}$ o autor afirma que, ao contrário do que seria esperado se os preços refletissem os incrementos de produtividade, os termos de troca moveram-se adversamente à periferia. A tendência à deterioração dos termos de troca se constituíra por conta da diferença na elasticidade-renda das importações do centro (inelástica) e da periferia (elástica). Assim sendo, quando ocorreram incrementos de renda, as importações dos países centrais cresceram relativamente menos do que as importações dos países da periferia. E, mais do que isso, no período referido, “[...] enquanto os centros preservaram integralmente o fruto do progresso técnico de sua indústria, os países periféricos transferiram para eles uma parte do fruto do seu próprio progresso técnico.” (Ibid., p. 83).

Seriam observáveis, inclusive, ganhos de produtividade do trabalho do centro, no período de expansão, que permitiram tanto o crescimento dos lucros quanto dos salários, o que seria explicável, em certa medida, pela própria organização da classe trabalhadora. No período de contração dos países centrais, caíam os lucros e os salários, mas num ritmo mais lento do que a queda da atividade econômica, por conta da estrutura de mercado oligopolista (os preços não tenderiam a cair tanto) e dos sindicatos organizados (os salários não tenderiam a sofrer grandes quedas). Já nos países da periferia, nos períodos de expansão, aumentariam

\footnotetext{
${ }^{164}$ Dados do Relatório do Conselho Econômico e Social das Nações Unidas, de 1949, intitulado "Postwar Price Relations in Trade Between Underdeveloped and Industrialized Countries”, conforme indica Prebisch (1949, p. 80, nr. 2).
} 
os lucros, porém os salários permaneceriam os mesmos, ou cresceriam menos do que proporcionalmente aos lucros, implicando pioras na distribuição de renda. $\mathrm{Na}$ fase de contração, os lucros cairiam (embora menos do que as exportações) e os salários não se sustentariam (por conta da oferta ilimitada de mão-de-obra) para compensar a queda na receita do setor primário. Sobre essa questão, diz Prebisch:

\footnotetext{
Quando, na fase descendente, o lucro tem que se contrair, a parte que se transformou nos citados aumentos perde sua liquidez no centro, em virtude da conhecida resistência à queda dos salários. A pressão desloca-se então para a periferia, com força maior do que a naturalmente exercível [...] Assim, quanto menos a renda pode contrair-se no centro, mais ela tem que fazê-lo na periferia. (Ibid., p. 87).
}

O importante a notar desse trecho é justamente a sugerida relação orgânica entre o centro e a periferia, como se esta fosse extensão daquele, tal como implica a conhecida denominação de quintal. Lembrando a terminologia termodinâmica, essa citação evidenciaria a desordem (ou a entropia) que decorreria do centro e seria transferida para a periferia. As nações do centro seriam as geradoras de ciclos e as nações da periferia sofreriam a influência desordenadora deles. Se as nações periféricas não estiverem internamente bem preparadas para lidar com essa desordem, o resultado acabaria sendo o seu aprisionamento no subdesenvolvimento.

Vale ressaltar também que, para conter essa suposta desordem proveniente do centro, não adiantaria conter o fluxo de comércio internacional, pois esse é fundamental para a periferia. Prebisch explica que os países do centro possuem uma tecnologia homogênea e uma estrutura produtiva completa, que lhes permite, ao menos potencialmente, a produção de qualquer coisa. Assim, para essas nações, o comércio internacional permitiria acessar os bens que não foram escolhidos para serem produzidos internamente. Já os países da periferia possuem uma tecnologia heterogênea e sua estrutura produtiva se concentra na produção de bens primários, principalmente para exportação. Por isso também, para a periferia, o comércio internacional desempenharia um papel crucial, porque só por meio dele essas nações poderiam ter acesso aos bens que (ainda) não seriam capazes de produzir internamente. $\mathrm{O}$ que, no caso da industrialização substitutiva de importações, adquire uma importância estratégica ainda maior.

Discorrendo a respeito da interpretação Cepalina, Prebisch (1952) explicita duas proposições teóricas: a de que a industrialização seria a forma de crescimento imposta pelo progresso técnico aos países latino-americanos periféricos, e a de que esse crescimento traria implícita uma tendência ao desequilíbrio externo. A própria tendência ao desequilíbrio externo decorreria, em alguma medida, das transformações geradas pelo progresso técnico, 
seja do lado da oferta - relacionadas a formas mais eficientes de produção e, destacadamente, à redução da importância relativa dos produtos primários no valor dos produtos finais ${ }^{165}$-, seja do lado da demanda - relacionadas a novos padrões de consumo, também tendentes a diminuir a importância relativa dos produtos primários, direcionando-se aos bens mais elaborados. Para o autor, estaria justamente na eliminação desse desequilíbrio externo o caminho para se alcançar um crescimento ordenado da economia, pois, em suas palavras:

A combinação de todos esses fatos [...] tem uma consequência de importância primordial para a periferia [...] a elasticidade-renda da demanda de importações primárias dos centros tende a ser menor do que um. (Id., 1952, p. 183).

Ou seja, dado o progresso técnico, a tendência à deterioração dos termos de troca dos bens primários relativamente aos bens mais elaborados seria inevitável e irreversível. Além disso, há que se destacar que o aumento da produtividade nas nações do centro lhes possibilitaria produzir os produtos primários de maneira mais eficiente do que as nações periféricas, podendo tornar-se concorrentes no mercado internacional desses produtos. Em outros casos, poderiam inclusive recorrer a políticas protecionistas de sua produção interna de produtos primários, dificultando ainda mais o influxo de produtos primários originários da periferia nos mercados do centro.

Apesar de todas essas dificuldades, argumenta Prebisch que as nações periféricas, por conta do próprio estágio de desenvolvimento em que se encontravam, possuiriam condições de crescer mais do que as nações centrais. Para esse feito, seria crucial a dinâmica que poderia ser implicada pela industrialização da periferia, pois, assim, seria possível crescer a um ritmo mais elevado do que o do crescimento das exportações de produtos primários, sujeitas aos diversos problemas tendenciais discutidos anteriormente. A industrialização, além de contribuir para absorver a mão-de-obra de outros setores menos dinâmicos, possibilitaria aos países periféricos a produção de itens antes importados e de outros de difícil importação, por conta da capacidade limitada de importar da periferia.

Nesse sentido, e em virtude dos efeitos possíveis sobre a demanda decorrentes do próprio processo de crescimento, para que esse processo de industrialização pudesse ser bem sucedido, seria necessária uma adequada administração da pauta de importações. Um exemplo desses efeitos sobre a demanda seria o de que o aumento da renda per capita, geralmente concentrada em uma pequena proporção da população periférica, alteraria o perfil da demanda em prol dos chamados bens de luxo, pressionando por sua importação. Porém, do ponto de

\footnotetext{
${ }^{165}$ Prebisch (1952, p. 182-183) explicita três motivos para a diminuição da importância relativa dos produtos primários no valor dos produtos finais: as transformações técnicas passaram a exigir igualmente matérias-primas mais elaboradas e refinadas; os avanços técnicos possibilitaram uma utilização mais eficiente das matériasprimas; e passaram a ser produzidos substitutos sintéticos dos produtos naturais.
} 
vista da industrialização, os bens de luxo seriam justamente os menos essenciais. Diz o autor: “[...] a necessidade de modificar a composição das importações resulta de fatores essencialmente dinâmicos, inerentes ao processo de crescimento. Quando não há substituição e mudança, não pode haver crescimento." (Ibid., p. 188).

Tendo como objetivo o aumento da renda real, seriam colocados dois problemas relacionados a como empregar os recursos disponibilizados pelo processo de crescimento. $\mathrm{O}$ primeiro deles faria referência a quanto deslocar para a atividade exportadora, de modo que fornecessem mais divisas para as importações essenciais ao processo de industrialização, e a quanto direcionar para a produção interna. $\mathrm{O}$ segundo problema diria respeito ao quanto e ao que importar, ou produzir internamente. Vale lembrar que esse balanceamento entre setor interno e externo fora destacado, por exemplo, por Lewis (1955) - vide seção 3.5, capítulo 3 -, cuja indicação apontara para a necessidade de manutenção de um equilíbrio adequado entre a agricultura e a indústria, e entre a produção para o mercado interno e a produção para a exportação, para que o pontapé inicial do desenvolvimento fosse exitoso.

De acordo com Prebisch, considerando que a elasticidade-renda da demanda por produtos primários dos países centrais é menor do que um e que não existe mobilidade perfeita de fatores produtivos entre as nações, poderia ser interessante às nações periféricas, do ponto de vista da dinâmica do desenvolvimento, deslocar a sua mão-de-obra excedente para a produção interna de bens, mesmo que esses fossem relativamente mais caros do que os seus similares importados. Seria, por conseguinte, uma forma de aproveitamento da poupança oculta, na forma de mão-de-obra, definida por Nurkse.

Sobre essa indicação de utilização da mão-de-obra excedente, diz Prebisch:

Se a mobilidade fosse perfeita, essa proposição seria inaceitável [...] Mas a realidade difere desse modelo teórico [...] Assim, dificilmente se poderia examinar com essa teoria o desenvolvimento econômico dos países periféricos. (Ibid., p. 188).

Dessa observação, deriva o autor a importância da elaboração de uma teoria do desenvolvimento econômico condizente com o contexto da periferia, assim como destacara, por exemplo, Lewis $(1954,1955)$ quando partira da hipótese de oferta ilimitada de mão-deobra. Nesse mesmo sentido, outra observação pertinente do autor se refere ao fato de que haveria produções que, mesmo se apresentando menos frutíferas do que outras, deveriam ser empreendidas por conta de seu valor estratégico, qual seja, de diminuir a vulnerabilidade externa das nações periféricas.

Sobre a propagação do progresso tecnológico do centro para a periferia, explica Prebisch que, nas nações periféricas, as inovações tecnológicas não percorrem a mesma 
trajetória que percorreram nas nações centrais. Essa questão se mostra crucial, pois, a tecnologia que se propaga para a periferia não está adaptada à sua dotação de recursos, implicando-lhe alguns problemas e desordens ao dinamismo do seu sistema econômico. Por outro lado, dada a irreversibilidade do progresso tecnológico, não estaria colocada alternativa às nações subdesenvolvidas senão absorver esse progresso tecnológico. Nas palavras do autor:

\begin{abstract}
[...] dada a relativa escassez de capital e a relativa abundância de potencial humano que prevalece nesse tipo de países, concebe-se uma densidade ótima de capital que é inferior à dos países mais desenvolvidos. Contudo, dada a natureza do progresso técnico e seu caráter irreversível, os países menos desenvolvidos não têm muitas possibilidades de buscar, na prática, a densidade ótima que lhes seria correspondente. (Ibid., p. 200).
\end{abstract}

Os problemas que decorriam da propagação de tecnologia do centro para a periferia se traduziam na insuficiência de capital para absorver a mão-de-obra que se deslocava dos setores menos capitalizados ou aquela economizada pelo próprio incremento de capital. Segundo Prebisch, esses problemas persistiriam enquanto houvesse diferenças internas significativas nas densidades de capital e na produtividade dos setores componentes do sistema econômico das nações periféricas; em outras palavras, enquanto se observasse a dualidade estrutural, também destacada por Lewis. Por isso, para Prebisch, "[...] a política de investimentos deve procurar estabelecer uma clara distinção entre a conveniência dos empresários e os interesses gerais da economia." (Ibid., p. 207), uma vez que a tendência dos investimentos privados poderia ser a de continuar a economizar mão-de-obra, direcionando mais recursos para o fator capital, implicando uma intensificação do desequilíbrio, seja no nível da densidade de fatores produtivos por setor, seja na própria alocação dos fatores disponíveis no sistema econômico.

Prebisch (1964) observa que, se deixada exclusivamente às forças do mercado, as alterações na relação de preços dos produtos primários e industrializados resultaria numa distribuição de renda desigual, tanto no plano interno, ${ }^{166}$ quanto no plano internacional. Para quebrar essa tendência, far-se-iam necessárias, por exemplo, políticas de defesa de preços agrícolas no plano interno, e medidas de defesa no plano internacional. No que se refere às indústrias, o autor destaca que, para que atingissem a eficiência e rompessem o círculo vicioso da produção baixa e dos custos elevados, necessitariam dispor de mercados em expansão. Para essa questão, são apontadas duas soluções protecionistas, além da proteção do próprio

\footnotetext{
${ }^{166}$ Prebisch (1984) ressalta que até o fim dos anos 1950, ele não havia prestado suficiente atenção ao fato de que o crescimento não havia beneficiado as camadas mais pobres da população. Nas palavras do próprio autor, "Talvez essa minha atitude seja algo remanescente de meu passado neoclássico, que assumia que o crescimento, por si só, afinal corrigiria as grandes disparidades de renda por meio do jogo das forças de mercado.” (Id., 1984, p. 181). Na versão original: "Perhaps this attitude of mine was a remnant of my former neoclassicism, which assumed that growth in itself would eventually correct great income disparities through the play of market forces." A discussão da questão distributiva da renda é retomada adiante.
} 
mercado interno, que pressuporiam cooperação entre as nações: as nações periféricas deveriam dar preferência às importações precedentes de outras nações na mesma condição; e os países centrais deveriam dar preferência às importações originárias das nações periféricas. Contando com uma relativa solidariedade internacional, também argumentara Singer (1950), apesar de sua argumentação direcionar-se aos investimentos, indicando que os propósitos dos investimentos externos deveriam ser redirecionados para produzirem mudanças graduais na estrutura das vantagens comparativas das nações subdesenvolvidas. Segundo Prebisch:

\footnotetext{
Não seria de surpreender que, a princípio, os países industrializados hesitassem em aceitar um sistema passível de promover a concorrência dos países em desenvolvimento com algumas de suas próprias indústrias. Mas é indubitável que, com o tempo, eles perceberiam as vantagens desse sistema, pois ele constituiria um meio de aumentar as vendas feitas aos países em desenvolvimento. (Id., 1964, p. 399).
}

Sobre a importância do planejamento do programa de desenvolvimento nas nações periféricas, ressalta Prebisch que, a natureza de seus problemas, resultantes de uma trajetória socioeconômica secular, requereria obrigatoriamente medidas adequadas ao seu contexto, destacando-se novamente aqui a questão da heterogeneidade dos sistemas econômicos nacionais, possivelmente uma das considerações mais cruciais contempladas pelo tratamento do tema desenvolvimento econômico sob a ótica da Abordagem da Complexidade. Conforme destaca o pioneiro Cepalino, "A tarefa de corrigir um atraso econômico secular não pode ser comparada ao problema da recuperação econômica europeia, nem mesmo depois de uma guerra destrutiva." (Ibid., p. 422).

Ainda sobre os problemas particulares enfrentados pela América Latina, e ressaltando o seu aspecto estrutural, Prebisch (1963) enfatiza que não se trata de fenômenos circunstanciais ou transitórios, pois são reflexo e resultado de sua própria estrutura. As políticas até então adotadas, por sua vez, não teriam levado em consideração esse aspecto estrutural dos problemas, e por isso não teriam resolvido os problemas em sua raiz.

Especialmente no que se refere à desigual distribuição de renda que caracteriza as nações latino-americanas, as quais se refletem em um baixo padrão de vida da maioria da população, Prebisch (1963) enfatiza que essa é a questão sobre qual é preciso concentrar primordialmente os esforços dos planos e programas de desenvolvimento. De acordo com o autor, "A ideia, ainda não extinta, de que este funciona espontaneamente, sem um esforço racional e deliberado para ser conseguido, provou ser uma ilusão, tanto na América Latina quanto no resto da periferia mundial." (Id., 1963, p. 453).

No entanto, comparativamente às outras regiões periféricas, a renda média da população latino-americana seria consideravelmente maior, implicando às nações latino- 
americanas um ponto de partida relativamente mais vantajoso para o alcance do desenvolvimento, o qual deveria se refletir na eliminação da pobreza da maioria de seus cidadãos. Não obstante, sem uma mudança profunda na estrutura social, ${ }^{167}$ as transformações na forma de produção e na estrutura econômica implicadas para que se obtivesse uma absorção adequada do progresso técnico do centro não poderiam ser satisfatoriamente realizadas, resultando na persistência dos desequilíbrios que acabariam por dificultar ainda mais a sustentação do processo de desenvolvimento da periferia, podendo implicar, inclusive, o seu próprio esgotamento.

Segundo Prebisch, "A prova da robustez dinâmica de um sistema está em sua capacidade de imprimir velocidade ao ritmo de desenvolvimento e de melhorar progressivamente a distribuição de renda.” (Ibid., p. 455). Para tal, seriam imprescindíveis as transformações estruturais, a começar pela contenção do consumo dos grupos de mais alta renda. De acordo com o autor, a combinação de uma política de austeridade relativa ao consumo de luxo, com o aporte de recursos internacionais, permitiria incrementar a acumulação de capital e promover uma política redistributiva.

A fim de justificar a necessidade de intervenção política em prol da distribuição da renda, Prebisch compara o que teria sido a trajetória percorrida pelas nações centrais e as suas diferenças com relação ao contexto do subdesenvolvimento. O pioneiro explica que, no caso das nações desenvolvidas, primeiro se realizou a acumulação de capital e posteriormente se promoveu, de maneira gradativa, a distribuição de renda. Já no caso das nações atrasadas, não haveria outra maneira de resolver a questão senão por meio do enfrentamento direto de uma das contradições mais marcantes do desenvolvimento latino-americano, que corresponde à acumulação insuficiente de capital exigida, por um lado, e ao padrão de consumo emulador das elites, por outro.

Vale destacar novamente que, pela perspectiva Prebischiana, os recursos internacionais seriam funcionais até que as transformações estruturais permitissem o enfrentamento dos estrangulamentos externos e internos e, por conseguinte, possibilitassem uma utilização mais eficaz dos recursos disponíveis para investimento. Por outro lado, como bem destacado por Prebisch, a tendência latente ao desequilíbrio mostrar-se-ia ainda mais forte conforme se avançasse no processo de desenvolvimento econômico, especialmente porque a estrutura de comércio internacional não se modificara. Ou seja, as nações periféricas,

\footnotetext{
${ }^{167}$ Prebisch (1963) afirma que a estrutura social latino-americana se caracteriza por: baixa mobilidade social, dificultando inclusive o surgimento de agentes inovadores; e privilégio na distribuição de riqueza e da renda, o qual não se traduz em um ritmo satisfatório de acumulação de capital (PREBISCH, 1963, p. 454).
} 
mesmo em processo de desenvolvimento, continuavam a exportar bens primários e a importar manufaturados, estando ainda sujeitas aos efeitos dinâmicos perniciosos da tendência à deterioração dos termos de troca dos bens primários, mantendo reduzida, dessa maneira, a sua capacidade interna de acumulação de capital. Essa tendência refletiria, segundo o autor, a “[...] debilidade congênita dos países periféricos para reter integralmente o fruto do seu progresso técnico." (Ibid., p. 459), do que seria dedutível, mais uma vez, a necessidade de promover deliberadamente o direcionamento de mudanças profundas, aqui relativas à reconfiguração das pautas de importação e também de exportação da periferia, tornando-a mais apta a enfrentar as restrições externas que lhe eram colocadas e que lhe implicavam dificuldades de aproveitamento dos esperados efeitos positivos ao desenvolvimento do progresso técnico.

Assim como Kalecki (1960), quanto aos fatores internos de estrangulamento, Prebisch concede destaque à produção agrícola, no que concerne ao regime de posse da terra, à dificuldade de assimilação da técnica, bem como à ação deficiente do Estado em adaptá-la e difundi-la, e à precariedade dos investimentos direcionados a esse setor. Para o autor, se esses pontos de estrangulamento fossem superados, o setor primário estaria habilitado a uma melhor retenção do fruto do seu progresso técnico, tanto no que se refere à esfera internacional, incrementando a pauta exportadora, quanto à interna, satisfazendo o mercado interno de forma mais eficiente. Como conseqüência, a disparidade de renda entre o campo e a cidade poderia ser atenuada, funcionando, desse modo, como um meio de redistribuir melhor a renda, nos diversos níveis.

Prebisch ressalta que, assim como a acumulação de capital não seria condição suficiente para a intensificação do desenvolvimento, a industrialização, por si só, não corrigiria a disparidade de distribuição de renda rural e urbana. Pelo contrário, tenderia na verdade a acentuá-la. Além dos fatores estruturais do campo acima destacados, a explicação para essa acentuação potencial estaria na própria insuficiência dinâmica do desenvolvimento interno que não estimularia devidamente a elevação da renda agrícola. Isso sem contar que, por conta do protecionismo em prol da industrialização, o ônus também acabava recaindo sobre os produtores agrícolas. A respeito da disparidade de renda entre o campo e a cidade, diz enfaticamente o autor:

Assim, o campo carreia indigência, frustração e ressentimento para as cidades, onde já são muito conspícuas as manifestações da concentração da renda. É uma clara prova da explosiva polarização social do desenvolvimento, por sua insuficiência dinâmica e sua distribuição perversa. (Ibid., p. 464).

Para Prebisch, haveria um ritmo mínimo de crescimento requerido para que as 
indústrias e as atividades correlatas pudessem absorver mão-de-obra e estimular outras atividades com a mesma finalidade. O que, de certa forma, remeteria à condição atribuída à Teoria do Grande Impulso, derivada da contribuição de Rosenstein-Rodan, que indicara a necessidade de um nível mínimo de investimentos como condição necessária para que se impulsionasse o desenvolvimento, não sendo cabível, consequentemente, a ideia de investimento gradativo.

Os motivos principais para a insuficiência dinâmica do sistema econômico periférico fariam referência, segundo Prebisch, ao desequilíbrio entre a produtividade resultante e os investimentos realizados, o qual apresentaria como consequência dinâmica a incapacidade do sistema econômico periférico absorver o fator mão-de-obra - justamente o sua dotação mais abundante -, tanto a que se deslocava de atividades menos capitalizadas, quanto a que acabava sendo economizada pela própria capitalização. E boa parte para a explicação desse desequilíbrio estaria na própria natureza da tecnologia que as nações periféricas estavam assimilando, porquanto não estava adaptada às suas dotações de recursos. Outra boa parte da explicação, para o autor, estaria relacionada à questão do planejamento, cuja resolução não poderia ser deixada à lógica individual empresarial. Conforme alerta o pioneiro:

A acumulação de capital não basta para absorver [...] a mão-de-obra que provém das atividades expulsivas de menor produtividade ou renda por trabalhador. Os empresários adotam em seus investimentos as técnicas que se mostram mais convenientes para eles. (Ibid., p. 469).

Outro problema decorrente da disparidade da distribuição de renda evidenciado por Prebisch era que, como o consumo das classes mais abastadas tendia a se dirigir aos bens mais elaborados ou intensivos em capital, os quais, se produzidos internamente, o seriam nas zonas urbanas, os efeitos multiplicadores da renda, além de se concentrarem nas cidades, direcionavam-se a setores produtivos menos intensivos no fator trabalho. O resultado era uma grande concentração, em diversos níveis, de recursos já escassos. Em outras palavras, se bem distribuídos, os recursos disponíveis para investimento possivelmente já seriam insuficientes para impulsionar uma trajetória sustentada de desenvolvimento. Sendo eles mal distribuídos, as dificuldades que se colocavam para a superação do subdesenvolvimento tornar-se-iam potencialmente intransponíveis.

Para concluir essa seção, ressalte-se novamente o posicionamento de Prebisch quanto à questão destacada ao final do capítulo 2, que indicara ao Estado periférico o papel potencial de redirecionador da suposta desordem absorvida das nações centrais, a qual seria retroalimentada pelos próprios fatores internos. Tanto no que se refere ao planejamento de investimentos, quanto à política redistributiva, infere-se de Prebisch que o Estado 
desempenha papel crucial como elaborador e executor do plano de desenvolvimento. Entretanto, vale observar que, para que fossem alcançados resultados satisfatórios relativos a melhoras no padrão de vida do conjunto da população, far-se-ia necessário que, além da transformação da estrutura produtiva, ocorresse uma profunda transformação social. Sem isso, os benefícios da transformação produtiva seriam concentrados apenas pelas elites, perpetuando e até acentuando as desigualdades e disparidades existentes e, por conseguinte, mantendo a condição de subdesenvolvimento.

Dessa implicação de Prebisch sobre a importância de uma profunda transformação social como condição necessária para incrementar as possibilidades de alcance de resultados positivos em termos de desenvolvimento, note-se, igualmente, que a explicação do autor recorre a diversas causalidades, em variadas direções, entre o modelo de crescimento (ou seja, a forma como se define a priorização de setores e/ou onde concentrar os recursos de investimento), a forma de absorção do progresso tecnológico proveniente do centro e as desigualdades e disparidades iniciais e resultantes na periferia. Em poucas palavras, o pioneiro argentino contempla aquele que seria um dos requisitos importantes para uma discussão de desenvolvimento sob a ótica da Abordagem da Complexidade, qual seja, a consideração da relevância explicativa das relações de retroalimentação entre os fatores micro (internos) e os fatores macro (externos). ${ }^{168}$

Muitas dessas questões levantadas por Prebisch, conforme apresentado na próxima seção, são amplamente discutidas pelo também estruturalista e Cepalino Celso Furtado.

\subsection{Celso Furtado: ${ }^{169}$ o capitalismo periférico}

Antes de passar à análise teórica de Furtado do subdesenvolvimento, vale destacar algumas questões metodológicas e definicionais mais gerais abordadas pelo autor. Essas considerações iniciais podem auxiliar na compreensão do tratamento que o autor dispensa à teoria do desenvolvimento e, inclusive, à discussão do caso brasileiro, a ser realizada no capítulo seguinte.

Especificidades à parte, assim como os demais pioneiros, Furtado reconhece a limitação do ferramental da Economia, então disponível, em tratar da totalidade de aspectos que abrangem o desenvolvimento. Como bem observa Furtado (1954b):

\footnotetext{
${ }^{168}$ Essa discussão é retomada no capítulo 5, seção 5.1.

${ }^{169}$ Economista paraibano (1920-2004).
} 
A teoria do desenvolvimento econômico não cabe, nos seus termos gerais, dentro das categorias da análise econômica [...] A análise econômica não nos pode dizer por que uma sociedade se desenvolve e a que agentes sociais se deve esse processo. Não obstante, a análise econômica pode precisar o mecanismo do desenvolvimento econômico. (FURTADO, 1954b, p. 321).

Em prefácio à edição francesa, Furtado (1967) define a teoria do desenvolvimento como a tentativa de explicação das transformações dos conjuntos econômicos complexos. E, no mesmo tom da citação anterior, o autor explicita algumas das limitações da teoria econômica naquele momento:

Ao estabelecer a significação do não-econômico nas cadeias de decisões que levam à transformação dos conjuntos econômicos complexos, a teoria do desenvolvimento encarrega-se de pôr a descoberto sua próprias limitações como instrumento de previsão. (Id., 1967, p. xiii).

Essa discussão é retomada no decorrer do livro, quando o autor indica a necessidade de combinar as perspectivas macro e microeconômicas por conta da complexidade envolvida no desenvolvimento de teorias em Economia. Vale reproduzir suas palavras:

Em síntese, a microeconomia constitui um simples conjunto de regras de racionalidade formal e a macroeconomia, um esforço de captação a posteriori, e sua tradução em linguagem econômica, de um processo histórico no qual o "econômico" e o "não-econômico" se condicionaram mutuamente em todos os instantes. $\mathrm{O}$ avanço da análise econômica requer a combinação desse duplo enfoque: por um lado o estudo dos processos históricos, ou das realidades sociais globais, e a construção de tipologias referidas aos mesmos; por outro, o aprofundamento na compreensão do comportamento dos agentes econômicos a partir de contextos perfeitamente definidos. (Ibid., p. 85-86).

Segundo Furtado, o problema metodológico que estaria posto ao economista seria o de definir o nível de generalidade de seus modelos abstratos sem que isso invalidasse a sua eficácia explicativa, quando confrontados com a realidade histórica. Tal problema metodológico assumiria destacada importância na teoria do desenvolvimento, pois: (i) não haveria como eliminar o fator tempo ou eliminar a irreversibilidade dos processos históricos; e (ii) não seria possível ignorar as diferenças estruturais entre as economias com graus diversos de desenvolvimento. No que se refere ao fator (i), nos remete à discussão da $2^{\mathrm{a}}$ Lei da Termodinâmica ( $2^{\mathrm{a}}$ L. T.) realizada no capítulo 2, subseção 2.2.2, em que Beinhocker (2006) comenta a contribuição de Georgescu-Roegen (1971), indicando que, em sistemas econômicos, o tempo tem necessariamente uma direção, por isso a irreversibilidade dinâmica das transformações que envolvem o sistema econômico. Dessa discussão, por sua vez, decorre o caráter cumulativo e dependente da trajetória dos processos transformadores pelos quais passaram e passam as nações. Quanto ao fator (ii), o qual, em boa medida, deriva de (i), enfatiza a importância da consideração teórica, pela teoria do desenvolvimento, da heterogeneidade das nações, especialmente quando se comparam nações centrais e nações periféricas. Então, sobre a questão metodológica, Furtado conclui que “A complexidade da ciência econômica - seu caráter abstrato e teórico - aparece, assim, com toda a plenitude na 
teoria do desenvolvimento econômico." (Ibid., p. 4).

Nesse mesmo sentido, Furtado (1961) salientara que as distintas dotações de fatores, as diferentes características institucionais e os diversos graus de desenvolvimento faziam de cada economia nacional um fenômeno particular de desenvolvimento. Por outro lado, embora o desenvolvimento econômico fosse um fenômeno com nítida dimensão histórica, uma vez que o processo de desenvolvimento de cada economia levava ao enfrentamento de problemas específicos, isso não significaria que o trabalho do economista deveria se limitar a uma simples descrição de casos históricos de desenvolvimento, requerendo, para tal, um instrumental analítico adequado.

Com relação às matrizes teóricas que teriam fundamentado a teoria do desenvolvimento, adequada ao mundo subdesenvolvido, Furtado destaca os Clássicos, o Marxismo e o Keynesianismo. Em suas palavras:

[...] o marxismo fomentou a atitude crítica e inconformista, a economia clássica serviu para impor a disciplina metodológica, sem a qual logo se descamba para o dogmatismo, e a eclosão keynesiana favoreceu melhor compreensão do papel do Estado no plano econômico, abrindo novas perspectivas ao processo de reforma social. (Id., 1961, p. 18-19).

Ainda na linha das matrizes teóricas, Furtado (1967) destaca a contribuição de Schumpeter à formação de uma teoria do desenvolvimento econômico:

Observando o progresso econômico basicamente do lado da produção, Schumpeter colocou-se em posição privilegiada para perceber a importância do progresso técnico como fator dinâmico na economia capitalista. Seu enfoque é, assim, basicamente diverso do dos demais economistas neoclássicos. (Id., 1967, p. 47).

Não obstante, Furtado sugere que a contribuição Schumpeteriana valeria mais pela mudança de enfoque do que pela sua capacidade de explicar o processo de desenvolvimento econômico, pois, embora as inovações, promovidas pelos empresários schumpeterianos, fossem um dos elementos motores do desenvolvimento, o cerne deste estaria na acumulação de capital, assunto que Schumpeter não teria discutido. No modelo de Schumpeter, a ação do empresário inovador é facilitada pela existência e disponibilidade de um sistema de crédito. Porém, segundo Furtado, tendo em vista a discussão de processo de desenvolvimento, seria um equívoco pretender formular a teoria das inovações independentemente da teoria da acumulação de capital: “A ideia do empresário sem capital pode ajudar a esclarecer certos conceitos, mas se distancia muito da realidade." (Ibid., p. 49). Com essa observação de Furtado em mente, vale ressaltar que, no contexto das nações periféricas, além da dificuldade em promover inovações e compor uma tecnologia autônoma, principalmente a questão da disponibilidade de capital estaria muito longe de ser trivial, não por acaso compondo elemento central da discussão de subdesenvolvimento realizada pelos pioneiros do 
desenvolvimento.

Já sobre a obra de Keynes, Furtado afirma que representa um marco importante na elaboração de uma teoria explicativa do funcionamento dos conjuntos econômicos complexos, pois, além ter se dado conta de que o motor da economia estava no investimento, percebeu que o modelo analítico de equilíbrio geral dificultava uma compreensão adequada do processo econômico. ${ }^{170}$ Entretanto, para o autor, a análise dos fatores que induzem o empresário a investir seria a parte menos profícua da obra de Keynes. Ainda sobre Keynes, Furtado destaca que ele teria se limitado a observar o investimento como um fator gerador de renda, sendo que o investimento também é criador de capacidade produtiva. ${ }^{171}$

De acordo com Furtado, o conceito de desenvolvimento compreende a ideia de crescimento superando-a, uma vez que, para que seja configurado, deve satisfazer às múltiplas necessidades do conjunto econômico nacional, estando ainda sob a ação contínua de uma grande multiplicidade de fatores sociais e institucionais. Diz o autor: “[...] o crescimento de um conjunto complexo sem desenvolvimento seria aquele do qual estivesse ausente toda modificação na estrutura [...]" (Ibid., p. 92). Essa não correspondência direta entre crescimento e desenvolvimento seria ainda mais evidente no caso das economias periféricas ou dependentes. Novamente nas palavras do autor:

Pode-se conceber a hipótese de crescimento sem desenvolvimento no caso de uma economia dependente, na qual todos os benefícios do progresso técnico do setor exportador fossem retidos no exterior. O desenvolvimento, neste caso, se manifestaria no conjunto maior que inclui tanto a economia dominada como a dominante. (Ibid., p. 92, nr. 2).

Do trecho acima, destaque-se a similaridade com a ideia discutida no capítulo 2, subseção 2.2.3, potencialmente derivável da $2^{\mathrm{a}}$ L.T., que indicaria uma relação orgânica entre a emergência do desenvolvimento em algumas nações e a emergência do subdesenvolvimento em outras, com as nações centrais direcionando entropia - ou desordem - para as nações periféricas, o que permitiria a emergência da auto-organização e o desenvolvimento das

\footnotetext{
${ }^{170}$ Para complementar essa afirmação de Furtado a respeito do diferencial da abordagem Keynesiana vis-à-vis à teoria convencional, ressalte-se novamente, conforme destacado por Cardoso e Lima (op. cit.), que o princípio da demanda efetiva seria um princípio de determinação adequado à visão de economia como sistema complexo adaptativo, na medida em que não pré-determinaria resultados. Pelo seu dinamismo, complexidade e imprevisibilidade, o funcionamento do sistema econômico seria insuficientemente tratável teoricamente por um método estático e equilibrista, cujo resultado estaria definido por hipótese; por isso a fecundidade da contribuição de Keynes. Por fim, no que se refere à discussão específica de desenvolvimento econômico no contexto do subdesenvolvimento, relacionado a transformações e mudanças revolucionárias no sentido Schumpeteriano, a incerteza e a imprevisibilidade que circundam o processo são ainda mais marcantes, do que se infere a potencial fecundidade da aplicação da ótica da Abordagem da Complexidade para a discussão de desenvolvimento econômico.

${ }^{171}$ Requisito cumprido por Kalecki (1954a), conforme brevemente discutido na seção 3.7 do capítulo 3, bem como por autores seguidores de Keynes, como Roy Harrod, Joan Robinson (também seguidora de Kalecki) e Nicholas Kaldor.
} 
primeiras. Nesse sentido, outra delimitação importante feita por Furtado diz respeito à necessidade do tratamento teórico diferenciado do que é subdesenvolvimento e do que é desenvolvimento, destacando que seriam fenômenos distintos, embora organicamente interligados. Nas palavras do autor:

O subdesenvolvimento é aqui tratado como fenômeno coetâneo do desenvolvimento, consequência da forma como se vem propagando até nossos dias a revolução industrial. Constitui, portanto, uma temática à parte, requerendo para sua interpretação um trabalho autônomo de teorização. (Ibid., p. xiv).

Fundamental à teoria do desenvolvimento, segundo Furtado (1975), seria o conceito de economia nacional, uma vez que permitiria integrar duas esferas de decisão, relativas às decisões econômicas e às decisões políticas. Ademais, conforme destacado por Furtado (1967), se se tiver em vista que o objetivo final do sistema econômico seria a satisfação das necessidades da coletividade, como nas sociedades modernas o Estado-Nação é a forma de organização sociopolítica mais importante, seriam as economias nacionais que deveriam servir de base à investigação e discussão do desenvolvimento econômico. Furtado (1975) situa o estudo das economias nacionais no escopo da teoria dos sistemas abertos ${ }^{172}$, pois seria difícil saber “[...] se esta ou aquela decisão decorre da pressão de forças internas ou externas, ou de forças internas autônomas ou funcionalmente integradas com interesses externos." (Id., 1975, p. 35). Essa observação ganharia especial importância no caso das economias subdesenvolvidas, por conta da importância dinâmica das relações externas. Nas palavras do autor:

As relações externas decorrem, seja da participação em mercados internacionais particulares, seja do controle externo de decisões relacionadas com a produção e o investimento. Em um e outro casos o conteúdo político das decisões econômicas pode ser maior ou menor, em função da importância relativa e da natureza das atividades controladas do exterior. E quanto maior esse conteúdo político, mais difícil será encontrar coerência interna no sistema econômico se se pretende analisá-lo como um sistema fechado. (Ibid., p. 35).

Furtado destaca que as nações periféricas não possuiriam centros próprios de decisão capazes de efetivamente coordenar as suas atividades internas. Segundo o autor, nesses casos, "Os ajustamentos oferta-demanda dependem do comércio exterior. Em todo caso, trata-se de estruturas rígidas com escassa capacidade de adaptação." (Ibid., p. 56). Assim, conclui o autor que a deterioração dos termos de intercâmbio, tal como destacado pela tese Singer-Prebisch, teria a raiz de seu problema residindo na rigidez estrutural e na incapacidade dos centros internos de decisão em introduzir as modificações necessárias nessas estruturas, compondo essa a questão crucial do fenômeno da dependência externa.

\footnotetext{
${ }^{172}$ Conceito discutido na subseção 2.2.1, capítulo 2. Em termos termodinâmicos, sistema aberto seria aquele no qual energia e matéria fluem dele e para ele, podendo esse sistema utilizar esse fluxo de energia e matéria para fazer frente à entropia e, assim, criar ordem, estrutura e padrões por um período de tempo.
} 
Relacionada a essa questão de dependência externa, Furtado (1961) destaca que, ao crescerem pela simples assimilação de técnicas já existentes ${ }^{173}$, os países subdesenvolvidos incorreriam no risco, quase certo, de provocar subemprego estrutural de fatores. Para o autor, "Nesse desajustamento básico entre oferta virtual de fatores e orientação da tecnologia reside, possivelmente, o maior problema que enfrentam atualmente os países subdesenvolvidos" (Id., 1961, p. 86). Parte da explicação para a falta de correspondência entre a disponibilidade de recursos e as combinações deles requeridas pela tecnologia que estava sendo absorvida do exterior residiria no caráter exógeno das transformações que se observavam nas economias subdesenvolvidas por meio, especialmente, da inserção de empresas estrangeiras, que ainda resguardavam estruturas pré-capitalistas e seriam ainda tecnologicamente defasadas.

Furtado (1954b) acrescenta que, no caso das nações subdesenvolvidas, não ocorreria, necessariamente, uma combinação inadequada dos fatores existentes. No geral, o que se observava era a falta de um fator específico: o capital. Na falta de capital, o que acabava sendo observado era o desperdício de outro fator: o trabalho. Formava-se, desse modo, um círculo vicioso, na medida em que, como o capital é trabalho realizado no passado e que não foi consumido, não ter capital suficiente, por um lado, significaria uma má utilização do trabalho anteriormente realizado e, por outro lado, implicaria uma má utilização do trabalho então disponível. Para o autor, "Esse círculo vicioso [...] nas economias rudimentares quase sempre é quebrado pela ação de fatores externos." (Id., 1954b, p. 322).

Como decorrência dos três parágrafos anteriores, em que Furtado (1954b, 1975) discute a questão da dependência externa, poderia transparecer que o autor implicaria, necessariamente e em todos os casos, uma relativa - ou quase total - insignificância dinâmica dos fatores internos das economias periféricas relativamente aos fatores externos. Contudo, para discutir os efeitos dinâmicos observados nos sistemas econômicos nacionais, há que se diferenciar entre as estruturas subdesenvolvidas, que variariam segundo o grau de complexidade implicado por seus fatores internos. Furtado (1961) denomina como estruturas subdesenvolvidas mais complexas aquelas em que coexistiriam três setores dentro da economia: um ligado às atividades de subsistência, outro diretamente ligado ao comércio exterior e o terceiro relacionado ao mercado interno de produtos manufaturados. Embora o fator dinâmico básico continuasse a ser a procura externa, nessas estruturas subdesenvolvidas

\footnotetext{
${ }^{173}$ Como bem destaca Furtado (1961) - à semelhança da observação de Prebisch (1952, p. 200) destacada na seção anterior - haveria uma interdependência “[...] entre a evolução da tecnologia nos países industrializados e as condições históricas do seu desenvolvimento econômico. Essa tecnologia, na forma em que se apresenta hoje, incorporada aos equipamentos industriais, resulta, portanto, de um lento processo de decantação.” (Id., 1961, p. 159).
} 
mais complexas poderiam ocorrer reações cumulativas tendentes a provocar transformações estruturais no sistema. Isso seria possível porque, diferentemente da estrutura subdesenvolvida menos complexa, nas economias desenvolvidas mais complexas, a dinâmica estimulada pelo impulso interno poderia se multiplicar internamente. Por outro lado, como a expansão do setor externo seria acompanhada de melhora na capacidade de importação, poder-se-ia reduzir a magnitude do multiplicador interno da renda, em virtude da concorrência dos importados. E, no caso de uma baixa no setor externo, imprimir-se-ia uma tendência à concentração de capitais em setores menos dependentes de importações, mas também com menor capacidade de provocar modificações na estrutura de emprego, de modo que o seu aumento relativo seria o próprio freio para seu processo de crescimento.

Furtado prossegue explicando que uma etapa ainda superior seria alcançada pelos países subdesenvolvidos quando se diversificasse o setor industrial de modo a produzir equipamentos necessários à expansão da própria capacidade produtiva. Entretanto, também nessa etapa superior, não seria possível internalizar totalmente o elemento dinâmico, pois esse ainda estaria, em alguma medida, pautado pela demanda externa, e não em inovações próprias introduzidas no processo produtivo. Essa impossibilidade de internalização total do centro dinâmico, por conseguinte, seria, mesmo que tivessem sido formadas estruturas mais complexas, um dos reflexos da configuração do subdesenvolvimento, pois a dependência externa, de alguma forma, continuaria presente. Diz o autor:

[...] o subdesenvolvimento não constitui uma etapa necessária do processo de formação das economias capitalistas modernas. É, em si, um processo particular, resultante da penetração de empresas capitalistas modernas em estruturas arcaicas. (Id., 1961, p. 170-171).

Para Furtado (1975), as economias subdesenvolvidas, ao adotarem precocemente uma tecnologia poupadora de mão-de-obra, importada do exterior, teriam induzido as suas próprias estruturas a perpetuarem a heterogeneidade tecnológica, refletida na esfera social sob a forma de uma massa de população subempregada. Por isso, o autor sintetiza que "A sociedade se moderniza antes de que a economia se desenvolva." (Id., 1975, p. 86); ou, como diz Furtado (1967) "O desenvolvimento (ou melhor, progresso na concepção vulgar) passou a confundirse com importação de certos padrões culturais, ou seja, com a modernização dos estilos de vida.” (Id., 1967, p. 247). Novamente aqui, vale retomar Nurkse (1952, 1953), e sua explicação das consequências do chamado efeito demonstração, ${ }^{174}$ que resume bem a ideia

\footnotetext{
${ }^{174}$ Vale relembrar, conforme apresentado no capítulo 3, seção 3.3, que o próprio Furtado (1954b, p. 328) destacara a relevância dessa observação de Nurkse, indicando que a sua explicação com base no efeito demonstração, ao resultar numa maior propensão ao consumo nas nações mais pobres, colocava em evidência que o processo de desenvolvimento dos países subdesenvolvidos não poderia alcançar espontaneamente um ritmo adequado.
} 
apresentada por Furtado nas duas citações destacadas acima, qual seja, de que o contato com nações desenvolvidas imprimiria uma tendência das nações subdesenvolvidas a emularem padrões de consumo superiores por meio de suas classes mais abastadas, cuja demanda acabaria acarretando a concentração de recursos na produção desses bens a que somente elas teriam acesso - e que, vale dizer, equivalem a setores produtivos ainda mais intensivos em capital e, portanto, ainda menos absorvedores de mão-de-obra. Portanto, a persistência do subdesenvolvimento seria observável mesmo com a modernização da estrutura produtiva. Segundo Furtado:

As causas iniciais da heterogeneidade estrutural são de natureza econômica, mas são fatores de ordem tecnológica que a aprofundam, dão-lhe permanência e fazem do subdesenvolvimento um processo fechado, que tende a autogerar-se. (Id., 1967, p. 197).

Assim sendo, para Furtado, o subdesenvolvimento seria fruto das condições históricas que criaram obstáculos à absorção do setor pré-capitalista e que transformaram o dualismo numa característica estrutural permanente dessas economias. Retomando metáfora de Lewis (1955), a dualidade estrutural poderia ser descrita como ilhas de modernidade num mar de atraso, independentemente do setor produtivo ou região a que se referissem. No mar de atraso, era onde se observava especialmente a disponibilidade de uma oferta ilimitada de mão-deobra não qualificada, cuja absorção pela ilha de modernidade dependeria, em grande medida, do emprego de uma tecnologia absorvedora de mão-de-obra, algo que não estava disponível aos países subdesenvolvidos. Por isso também a importância destacada por Furtado do desenvolvimento da pesquisa científica e tecnológica própria nos países periféricos.

No que se refere aos meios de quebrar os círculos viciosos da pobreza, tal como indicara Nurkse $(1952,1953)$, ou as causações circulares cumulativas, tal como definira Myrdal (1957), que prenderiam as nações periféricas no subdesenvolvimento, um conceito interessante discutido por Furtado (1973, p. 110; 1976, p. 186) é o de poder germinativo ou capacidade germinativa de determinados setores produtivos. Quanto maior o poder germinativo, maior seria a capacidade de engendrar transformações no sistema econômico. Segundo Furtado (1976):

Tudo se passa como se o processo de desenvolvimento fosse uma cadeia de situações interdependentes, na qual certas situações dependem das que ocorreram anteriormente, mas também possuem capacidade germinativa própria, capaz de modificar as tendências que até então se vinham manifestando [...] A intensidade com que se efetua o desenvolvimento depende da eficácia dos centros que tomam decisões estratégicas e da plasticidade das estruturas. (Id., 1976, p. 200-201).

Esse conceito de capacidade germinativa remete diretamente a dois outros pioneiros: Rosenstein-Rodan $(1943,1944)$ e a sua defesa da promoção de investimentos em bloco para melhor aproveitamento das economias externas pecuniárias e tecnológicas, permitindo a 
formação de um grande impulso, necessário para dar início a uma trajetória sustentada de desenvolvimento econômico; e Hirschman (1958) e sua definição de encadeamentos para frente e para trás, sugerindo a concentração inicial dos recursos disponíveis para investimento nos setores que apresentassem maior potencial de promoção de encadeamentos pela estrutura produtiva, intensificando a sua transformação. Todos esses conceitos - capacidade germinativa, economias externas e efeitos de encadeamento - têm implícitas relações de retroalimentação positivas, cuja esperada força poderia funcionar como uma contra-tendência aos círculos viciosos ou relações cumulativas que faziam perpetuar a condição de subdesenvolvimento.

Ainda sobre o mesmo trecho extraído de Furtado, note-se que o aproveitamento da capacidade germinativa teria ao menos dois condicionantes internos cruciais, relativos à tomada de decisões - ou ao planejamento - e às condições estruturais. Sobre a necessidade de planejamento, guardadas as suas especificidades, todos os pioneiros partiram dessa consideração, indicando, como decorrência, a importância da atuação estatal. Quanto às condições estruturais, embora todos os pioneiros de algum modo tenham abordado a questão, concedendo-lhe relevância, Kalecki e Prebisch, além do próprio Furtado, seriam, possivelmente, os pioneiros que mais avançaram nessa direção, implicando às condições estruturais uma capacidade nada negligenciável de determinação das chances de sucesso dos efeitos positivos possibilitados pelo avanço da matriz produtiva emergirem sob a forma de desenvolvimento econômico. E essas modificações estruturais não seriam geradas espontaneamente; sua efetivação implicaria a atuação direta e planejada do Estado.

Enquanto elemento propulsor do desenvolvimento - e com alto poder germinativo -, o setor industrial recebe mais destaque de Furtado do que o setor externo, porque traria, supostamente, a chave da libertação da dependência das nações periféricas. Furtado (1967) argumenta que, para que o setor industrial pudesse desempenhar autonomamente o papel de elemento propulsor do desenvolvimento, sua estrutura deveria implicar que a utilização de sua capacidade produtiva tivesse como contrapartida a realização de um nível adequado de investimentos no conjunto de toda a economia. Em outras palavras, assim como também argumentaram Rosenstein-Rodan (1943, 1944), Nurkse (1952, 1953), Lewis (1955) e Prebisch (1952), deveria haver um balanceamento de desenvolvimento entre os diversos setores da economia, tanto para potencializar os seus efeitos de encadeamentos positivos, quanto, possivelmente, para que não representassem empecilhos ao aproveitamento desses efeitos cumulativos positivos à transformação da estrutura produtiva. Quanto ao setor externo, segundo Furtado, embora o seu crescimento pudesse levar ao incremento da eficácia na 
utilização dos recursos, não seria em si um elemento propulsor do desenvolvimento, pois “Esse passa a originar-se diretamente na diversificação estrutural.” (Id., 1967, p. 244).

Principalmente após a década de 1930, tendo em vista a crise mundial, boa parte das nações latino-americanas recorreu à estratégia de substituição de importações. Essa estratégia, por sua vez, pressupunha o desenvolvimento da capacidade produtiva interna, bem como a disponibilidade de divisas para possibilitar as importações essenciais ao processo substitutivo. Em linha com o discutido no parágrafo anterior, Furtado destaca a importância da diversificação da estrutura produtiva, como um dos requisitos para se alcançar uma trajetória de desenvolvimento sustentável, mas alerta para a insuficiência de tal requisito. A não suficiência da satisfação da condição de diversificação produtiva para os fins do desenvolvimento encontraria parte de sua explicação na própria situação de dependência externa das nações subdesenvolvidas. Nas palavras do autor:

Desta forma, a diferenciação estrutural obtida pela industrialização substitutiva de importações é causa necessária mas não suficiente para alcançar um desenvolvimento estável. Reencontramos, assim, o problema fundamental já referido: o comportamento das economias subdesenvolvidas não pode ser explicado sem que se tenham em conta as normas que regem sua inserção no sistema econômico internacional. Em conclusão: uma teoria do subdesenvolvimento pressupõe algumas hipóteses explicativas do fenômeno da dependência externa. (Ibid., p. 244-245).

Destaque-se desse trecho, bem como da discussão iniciada anteriormente, justamente a necessidade de levar em conta tanto os fatores internos, quanto os fatores externos, para discutir a estratégias de desenvolvimento. Observação essa ainda mais relevante no caso das nações que compõem a periferia do sistema. Conforme discussão iniciada no capítulo 2 , subseção 2.2.3, sob a ótica da Abordagem da Complexidade e do que seria seu tratamento do tema desenvolvimento no contexto do subdesenvolvimento, para a compreensão da emergência e perpetuação do subdesenvolvimento, far-se-ia necessária uma investigação que contemplasse os efeitos de retroalimentação entre os fatores externos ao sistema econômico nacional e os fatores internos a ele, não concedendo, a priori, maior ou menor significância explicativa a nenhum deles. ${ }^{175}$

A diferenciação teórica do desenvolvimento das nações periféricas, sob a perspectiva de Furtado, estaria sintetizada no conceito de desenvolvimento periférico, que o autor define como: "Desenvolvimento periférico passa a ser, portanto, a diversificação (e a ampliação) do consumo de uma minoria cujo estilo de vida é ditado pela evolução cultural dos países de alta produtividade e onde o desenvolvimento se apoiou, desde o início, no progresso tecnológico". (Ibid., p. 248). E, por suas benesses estarem restritas a um pequeno conjunto da população, a

\footnotetext{
${ }^{175}$ Essa discussão é retomada no capítulo seguinte, quando se discute e apresenta a abordagem historiográfica de Furtado sobre o caso brasileiro.
} 
própria difusão do progresso técnico importado do exterior - e dos seus efeitos sobre a produtividade - mostrar-se-ia prejudicada, implicando uma retenção do próprio processo de desenvolvimento. Novamente, há que se destacar a dimensão cultural do dualismo, ligada ao quadro estrutural da dependência das nações periféricas, que tenderiam a imitar o padrão de consumo das nações centrais, mesmo antes de ter desenvolvido suficientemente as suas estruturas.

Tendo em vista a importância dinâmica dos fatores externos, ressalte-se novamente a investigação das economias nacionais no escopo da teoria dos sistemas abertos, tal como aventado anteriormente. Para Furtado, não haveria como compreender o fenômeno do dualismo estrutural sem levar em consideração a influência externa a que está sujeita a economia dependente. Nas palavras do autor:

[...] na economia dependente existirá, sob a forma de um "enclave" social, um grupo culturalmente integrado nos subsistemas dominantes. O dualismo tem, portanto, desde o início uma dimensão cultural [...] Para o economista que observa uma economia subdesenvolvida como um sistema fechado, esse fenômeno se apresenta como um "desequilíbrio ao nível dos fatores", decorrente da "inadequação" da tecnologia. Escapa-lhe que o referido fenômeno é, fundamentalmente, uma decorrência de formas de comportamento ligadas ao quadro estrutural da dependência. (Ibid., p. 249-250).

Furtado conclui que a industrialização, por si só, não conduziria ao desenvolvimento. Pelo contrário, assim como destacara Prebisch (1963) com relação às políticas de intuito redistributivo de renda e riqueza, sem que se observassem políticas complementares à industrialização, visando o desenvolvimento como resultado, poderia ser observado, em decorrência da industrialização, um fortalecimento das disparidades existentes.

A respeito da compatibilização dos objetivos da política econômica, Furtado (1967) destaca a necessidade de os instrumentos de política econômica fazerem frente à complexidade dos seus objetivos. Mesmo reconhecendo a importância dos modelos matemáticos ${ }^{176}$ na formulação de políticas complexas, o autor alerta que, no caso das nações subdesenvolvidas, requerentes de amplas reformas estruturais, os modelos referidos teriam alcance limitado, pois, de certa forma, face à quantidade de mudanças revolucionárias a serem empreendidas, em certo sentido, tudo seria variável. Diz o autor:

Uma vez introduzidas, as reformas podem modificar fundamentalmente o comportamento das variáveis econômicas, sendo necessário redefinir toda a estrutura do modelo [...] Desta forma, supera-se o domínio da política econômica convencional para abordar o das estratégias, visando a transformar as estruturas. (Id., 1967, p. 271-272).

Os países subdesenvolvidos, como bem ressalta Furtado, antes de formularem uma

\footnotetext{
176 Segundo Furtado, "Chamamos de modelo a um conjunto coerente de relações entre dados passiveis de expressão quantitativa, capaz de explicar o funcionamento de uma unidade econômica simples ou complexa." (Id., 1967, p. 268).
} 
política quantitativa de desenvolvimento de tipo convencional, necessitariam conceber uma estratégia de modificação da própria estrutura. Sobre essas políticas adicionais, além do já referido Prebisch, vale notar a indicação de Singer (1985) sobre a necessidade de adoção de políticas pré-Keynesianas e a observação de Kalecki (1960), que apontara para aquela que seria a diferença crucial dos países subdesenvolvidos com relação aos países desenvolvidos: a restrição não seria de demanda, e sim de oferta, de modo que não caberia uma avaliação da dinâmica das economias subdesenvolvidas com base no princípio da demanda efetiva; antes seria necessário resolver os gargalos do lado da oferta. Por isso, para Furtado, o problema central dos países subdesenvolvidos não seria a formulação de planos convencionais de desenvolvimento, e sim a escolha de uma estratégia que permitisse modificar igualmente as suas estruturas. Portanto, se não fossem engendradas reformas estruturais profundas, não haveria como conceber planos de desenvolvimento bem sucedidos.

Em decorrência também da inadequação das suas estruturas, o processo de crescimento e desenvolvimento das nações periféricas implicariam uma série de desequilíbrios. Referindo-se especialmente ao desequilíbrio no balanço de pagamentos e à inflação, Furtado (1961) destaca a necessidade de investigação das causas estruturais que permitiriam explicar a persistência dos desequilíbrios que acompanham as transformações das economias subdesenvolvidas. Nesse sentido, diz o autor: "A menos que se possam prever e evitar esses desajustamentos, pagaremos, para não ter inflação e desequilíbrio externo, o preço de aceitar a estagnação ou, no mínimo, um ritmo mais lento de crescimento.” (Id., 1961, p. 200).

Outro desequilíbrio importante destacado por Furtado refere-se à tendência à sobreinversão em determinadores setores, gerando capacidade ociosa nesses e insuficiência de capacidade produtiva em outros, mantendo os gargalos produtivos tal como destacado por Kalecki (1960). Isso ocorreria porque o risco inerente ao investimento em setores ainda não consolidados ou maduros no mercado interno seria muito maior. Desse modo, se os recursos para investimento aumentassem, os investidores privados tenderiam a alocá-los em setores mais tradicionais ou com mercado consumidor mais consolidado. Assim, mais um motivo se colocava à necessidade de planejamento, pois se não houvesse uma orientação de onde alocar os recursos, se formava uma tendência a criar um desequilíbrio interno entre a estrutura de oferta e a composição da procura.

Destacando o que seria o cerne do problema das economias latino-americanas, com tendência à manutenção das grandes disparidades de concentração de renda e riqueza, explica Furtado (1973): 
[...] em países de mercados relativamente pequenos, a coexistência de um setor pré-capitalista com um setor industrial que absorve tecnologia cada vez mais orientada para economias de escala e impõe um coeficiente de capital em rápido crescimento, o padrão de distribuição de renda tende a aplicar os recursos produtivos de forma a reduzir sua eficiência econômica, concentrando ainda mais a renda, num processo causal circular. (Id., 1973, p. 148).

Furtado, assim como Prebisch, conclui que o cerne do problema das economias periféricas não estaria no comportamento dos agentes econômicos, que supostamente se guiariam por critérios racionais de decisão, e sim nas condições estruturais que delimitavam o campo social no qual as decisões relevantes eram tomadas. Daí, novamente, derivava-se a crucialidade da promoção de modificações estruturais profundas, por meio de reformas.

De acordo com Furtado (1975), o que fazia com que a oferta ilimitada de mão-de-obra não qualificada fosse fator decisivo na determinação da distribuição de recursos - como já bem ressaltara Lewis $(1954,1955)$ - eram os fatores estruturais, relacionados tanto às condições de apropriação do excedente econômico quanto a uma relativa falta de autonomia das decisões ligadas ao mercado interno, dado o contexto de dependência. Assim, sem que se observasse a promoção de reformas estruturais complementares, a eliminação da economia de subsistência não seria uma solução suficiente para melhorar o padrão de vida da maior parte da população, pois, segundo o autor:

Basta que o excedente seja consumido por uma minoria privilegiada que diversifica e amplia permanentemente um consumo abastecido do exterior e/ou invertido no exterior para que se mantenha o equilíbrio de subdesenvolvimento, mesmo que desapareça totalmente o setor de subsistência. (Id., 1975, p. 36).

Sobre o primeiro elemento estrutural destacado no parágrafo anterior, referente à apropriação do excedente econômico, Furtado o assimila à estrutura de poder - especialmente, o sistema político $^{177}$ - da sociedade. Com relação a essa questão, o autor sugere inclusive que a manutenção das desigualdades dependeria muito menos do controle por grupos privados dos bens de produção, do que do controle por esses grupos, seja diretamente ou por intermédio do Estado, da criatividade científica e tecnológica. Para o autor, haveria uma relação de retroalimentação entre a forma de dominação política, a forma de dominação cultural e a maneira de apropriação dos frutos do progresso tecnológico. Em suas palavras:

A forma particular de difusão dos frutos de um progresso tecnológico socialmente orientado cria para a minoria que se apropria do excedente uma situação de dominação cultural, a partir da qual ela legitima ideologicamente o sistema político. (Ibid., p. 44).

Nesse mesmo sentido, argumentara Furtado (1967) que, no controle das estruturas de poder, bem como na apropriação e utilização do excedente por ele permitido, estariam os principais obstáculos ao desenvolvimento dos países subdesenvolvidos. Assim sendo, o autor

\footnotetext{
177 Segundo Furtado (1975), “O sistema político compreende o conjunto de normas cuja aplicação assegura a apropriação e reprodução desse excedente.” (Id., 1975, p. 42).
} 
concluíra que:

Da interdependência entre a tendência à concentração da renda, criada pelos agentes que exercem poder econômico e tomam decisões estratégicas, e a necessidade de manter os mercados em expansão, resulta um teto à proporção do produto que a economia tende a inverter espontaneamente. (Id., 1967, p. 127).

Identificada essa relação de mútua causalidade, para inverter a tendência à estagnação, seria necessário romper os obstáculos estruturais responsáveis por ela. Esse feito só poderia ser realizado, segundo Furtado, por meio de uma atuação simultânea no lado oferta, conferindo-lhe maior flexibilidade, e no lado da demanda, de modo a modificar seu perfil, colocando-se, então, o problema de como coordenar as modificações em ambas as esferas. Para o autor, "Essa complexa coordenação de decisões somente é viável no quadro do planejamento, isto é, de uma estratégia capaz de condicionar os processos econômicos no seu conjunto." (Ibid., p. 290-291).

Em um texto intitulado "A Armadilha Histórica do Subdesenvolvimento", Furtado (1992) destaca que a forma de assimilação periférica do progresso técnico passou a ser denominada de modernização nos anos 1970, em virtude de se realizar quase que exclusivamente no plano do estilo de vida, sem provocar grandes transformações na estrutura produtiva. Como discutido acima - e na seção anterior com base em Prebisch -, esse processo de modernização teria agravado a concentração de renda e riqueza, tornando inevitável a formação e perpetuação do dualismo estrutural. Dessa maneira, segundo o autor, seria possível inferir que "[...] a inserção inicial no processo de difusão do progresso tecnológico pelo lado da demanda de bens finais de consumo conduz a uma conformação estrutural que bloqueia a passagem do crescimento ao desenvolvimento." (Ibid., p. 47). Estava posta, para o autor, a questão relacionada a "[...] como sair da armadilha do subdesenvolvimento." (Ibid., p. 54), o que, conforme discutido, apresentava como condição necessária a consecução de reformas estruturais das mais diversas naturezas.

Essa conclusão de Furtado relaciona, assim como fizera Prebisch, o modelo de crescimento, a forma de absorção do progresso tecnológico e as desigualdades e disparidades iniciais e resultantes na periferia. A resultante dos efeitos de retroalimentação desses fatores conduzira a uma conformação estrutural que acabava por bloquear o alcance do desenvolvimento, mesmo que se tivesse conquistado o crescimento econômico. Para tentar reverter essa situação, as reformas estruturais, relacionados tanto do lado da oferta quanto do lado da demanda, comporiam condições necessárias.

Guardadas as suas especificidades, os pioneiros discutidos no capítulo anterior, em geral, apesar de indicarem, em alguma medida, a relevância de políticas complementares e/ou 
de reformas institucionais, apresentavam como foco principal de discussão as transformações na estrutura produtiva, indicando meios e estratégias para potencializar os efeitos propulsores dos investimentos e, de certa forma, atenuar as condições de escassez de capital da qual partiam as nações subdesenvolvidas. Não que eles implicassem uma condição de suficiência à industrialização, muito pelo contrário.

Já Prebisch e Furtado, comparativamente aos demais pioneiros, e guardadas as suas diferenças de abordagem, teriam concedido uma maior ênfase à discussão das mudanças e reformas estruturais, extrapolando as suas considerações do escopo da estrutura de oferta propriamente dita, jogando luz sobre as relações de causalidade e retroalimentação entre as estruturas de poder e distribuição do excedente econômico, à tecnologia, ao perfil de demanda resultante, à dependência externa e a perpetuação do dualismo estrutural que já compunha a condição inicial. Vale notar, igualmente, que as reformas estruturais também não seriam condição suficiente para romper com a armadilha do desenvolvimento. Assim sendo, em boa medida, os pioneiros latino-americanos se aproveitariam ainda mais do que os demais pioneiros da validade explicativa das relações de retroalimentação entre os diversos fatores externos e internos - e esferas que compõem e determinam a dinâmica do sistema econômico, contribuindo, especialmente, para um maior detalhamento de alguns fatores internos e de algumas das suas relações de causalidade.

Por fim, face ao exposto acima e retomando discussão aventada ao final do capítulo 3, a respeito das compatibilidades e paralelos com a Abordagem da Complexidade, os pioneiros latino-americanos também partem da consideração de (i) heterogeneidade das nações, inclusive entre as próprias nações subdesenvolvidas, e (ii) da identificação de algumas tendências cumulativas e relações de retroalimentação que prenderiam as nações na armadilha do subdesenvolvimento.

Como implicação de todos os pioneiros discutidos nessa Parte I, ressalte-se novamente a necessidade de intervenção direta do Estado, por meio de suas políticas públicas, com os mais diversos objetivos, para tentar fazer frente à tendência de permanência na condição de subdesenvolvimento. E, mesmo assim, sem a menor garantia sobre os resultados, constituindo-se, tão somente, em uma tentativa. De outro modo, na ausência de tentativas intencionadas, a tendência apontaria necessariamente para a perpetuação do subdesenvolvimento.

Essas questões são retomadas na Parte II, já no contexto do subdesenvolvimento econômico brasileiro. 
PARTE II: A EMERGÊNCIA DO SUBDESENVOLVIMENTO ECONÔMICO BRASILEIRO: DISCUTINDO O PERÍODO DESENVOLVIMENTISTA SOB A ÓTICA DA ABORDAGEM DA COMPLEXIDADE 


\section{BRASILEIRO}

Nesse capítulo, em larga medida, mantém-se a mesma linha investigativa dos capítulos 3 e 4, com a diferença de agora estar norteada para a discussão de uma nação específica e com base em um único autor, passando, portanto, a um maior nível de especificidade. A Abordagem da Complexidade continua a ser a base teórico-metodológica norteadora da investigação dos elementos teóricos com ela compatíveis. No entanto, a investigação adquire aqui um caráter historiográfico mais acentuado.

A escolha de Celso Furtado se justifica por ter sido ele um pioneiro do desenvolvimento econômico, por ter se debruçado especificamente sobre o caso brasileiro e por apresentar em sua estrutura teórica elementos compatíveis com a Abordagem da Complexidade. No entanto, vale destacar que o intuito deste capítulo não é defender a abordagem Furtadiana como a mais adequada para entender o caso brasileiro, nem adentrar profundamente o vasto campo de discussão do pensamento historiográfico brasileiro.

A contribuição de Celso Furtado à discussão do caso brasileiro sob a perspectiva da Abordagem da Complexidade é realizada por meio de textos selecionados, cujas datas de publicação variam de desde a década de 50 até o início da década de 90 do século XX. Em linha com os capítulos anteriores, realiza-se uma discussão de natureza teórica, objetivando identificar paralelos com a Abordagem da Complexidade, pressuposta como detentora de arcabouço teórico-metodológico potencialmente interessante à compreensão dos processos concernentes ao tema mais geral desenvolvimento econômico. Nesse capítulo, o foco está sobre o caso brasileiro no período 1930-1980, em que foram implementadas políticas desenvolvimentistas, cujos fundamentos, em larga medida, encontravam-se nas obras dos pioneiros do desenvolvimento econômico - inclusive do próprio Furtado - discutidos nos dois capítulos precedentes.

O capítulo está dividido em três seções. Antes de passar efetivamente à análise das obras de Celso Furtado, realiza-se uma breve discussão a respeito do método de pesquisa histórico e da importância da história para a Economia - seção 5.1 - e da perspectiva metodológica da historiografia econômica brasileira - seção 5.2 -, a fím de situar a contribuição analítica da obra de Furtado. São esses temas bastante controversos, relacionados à filosofia da história e à vasta literatura historiográfica brasileira. Para os objetivos dessa 
tese, no entanto, a discussão desses temas é feita de forma mais modesta e limitada, na medida em que não se pretende adentrar em polêmicas e controvérsias dos temas tratados. Parte-se de um corte particular, delimitado pela Abordagem da Complexidade, e com a finalidade específica de discussão da temática do desenvolvimento econômico. Por isso, essas duas primeiras seções desempenham apenas papel introdutório à discussão da obra de Furtado relativa à economia brasileira.

Na última seção - 5.3 - apresenta-se a perspectiva de Furtado, bem como se discute o seu método, buscando traçar paralelos com a Abordagem da Complexidade. Essa seção está dividida, a partir de critério cronológico, em cinco subseções. A discussão se inicia na fase colonial, onde se encontram as raízes da formação econômica e social do Brasil, e cuja análise de Furtado apresenta conceitos e definições importantes para entender as fases subsequentes. No entanto, o foco está sobre o período desenvolvimentista, de 1930-1980, em que a economia brasileira passou por importantes transformações produtivas e sustentou grandes taxas de crescimento, porém essas não teriam sido suficientes para romper com a sua condição de subdesenvolvimento.

\subsection{A complexidade do evolver histórico: algumas considerações sobre o papel dos}

\section{historiadores}

Conforme discussões iniciadas em capítulos anteriores, por meio de autores vinculados à Economia do Desenvolvimento, a investigação histórica é um ferramental necessário não apenas para entender como as condições vigentes se formaram, mas inclusive para poder vislumbrar soluções, caminhos e estratégias para escapar da armadilha do subdesenvolvimento. Como pioneiro do desenvolvimento econômico, e como estudioso da formação econômica e social brasileira, Celso Furtado recorreu largamente ao método de pesquisa histórico e, em diversos momentos de sua obra, desenvolveu argumentos metodológicos justificando a sua importância analítica. ${ }^{178}$

Sinteticamente, os intuitos dessa seção são: demarcar a relevância e importância da história e de seu método no campo das ciências sociais, especialmente com relação ao tema que permeia essa tese, a emergência e perpetuação do subdesenvolvimento; e ressaltar o paralelo existente entre a relevância concedida ao método histórico de investigação e a

\footnotetext{
${ }^{178}$ Vide, por exemplo, trechos selecionados apresentados no início da seção 4.2, do capítulo 4.
} 
hipótese de heterogeneidade de agentes da qual parte a Abordagem da Complexidade. Essa seção compõe, dessa forma, um pano de fundo - e inclusive uma justificativa - para a discussão de um caso específico de subdesenvolvimento, o brasileiro, sob a ótica de uma abordagem que busca tratar analiticamente das especificidades condicionais e da heterogeneidade que delas emergem.

Bourdieu (1986) argumenta que o relato - ou o ato de contar histórias - ordena acontecimentos que, mesmo não tendo se desenrolado de maneira cronologicamente linear, tendem, ou pretendem organizar-se, em sequências ordenadas. Dito de outro modo, o fato, ou momento histórico, pode ser o mesmo, mas há diversas maneiras possíveis de organizar e discutir teórica e cronologicamente os elementos necessários à sua compreensão. Seria justamente no contexto de ampliação do escopo investigativo que emergiria a importância da investigação histórica e, consequentemente, do papel do historiador: a busca por tentar destrinchar a riqueza de fatores que circundam o evolver histórico, alargando potencialmente o seu horizonte de compreensão.

Uma ciência social aplicada como a Economia, se divorciada da pesquisa histórica, perde grande parte de seu sentido, não apenas enquanto teoria, mas inclusive como prática. Há diversos meios de justificar a importância da História, relacionados ao incremento da compreensão global do objeto sob análise, na medida em que permite a elucidação e ponderação de elementos e fatos importantes, processo que vem a depender também da perspectiva que se adota, bem como da finalidade pretendida. Especialmente com relação ao objetivo de discutir as condições de emergência e superação do subdesenvolvimento, vale retomar que, tal como discutido no capítulo 2, sendo as economias nacionais sistemas complexos adaptativos repletos de idiossincrasias, a não consideração, em alguma medida, de suas particularidades, que compõem e que se formaram a partir de sua trajetória histórica, delimitaria indevidamente $o$ horizonte de compreensão dos fatos relativos ao subdesenvolvimento de determinadas nações.

O evolver histórico é demonstrativo da importância da consideração da dependência de trajetória, e de que a sociedade e a economia são resultado de processos cumulativos e dependentes de contextos particulares, o que remete, por sua vez, à relevância analítica das especificidades do objeto sob investigação. O passado, enquanto fonte informativa, pode ter usos distintos: a organização das informações que disponibiliza pode ser realizada de diferentes maneiras, condicionadas pela perspectiva e interesses de quem investiga. Como reflexo, se apresenta a potencialidade e riqueza do ato de contar as histórias, das quais decorre, por conseguinte, a fecundidade do trabalho de investigação do historiador. Essa 
perspectiva contrapõe-se diretamente a uma perspectiva determinista - ou de que um fato leva necessariamente a outro - e desprovida de contexto - ou que ignore as especificidades de seu objeto de investigação. Como bem argumenta Cepêda (2008):

Interpretar historicamente é caminhar entre "o passado e o futuro", mas os caminhos que o pensamento pode trilhar nesse percurso não são únicos. Variam tanto na definição do elenco de problemas detectados como fundamentais, no método de interpretação, quanto no desenho dos objetivos que se procura alcançar (e que, de maneira vigorosa, dirige grande parte das escolhas anteriores). Desta maneira torna-se fundamental observar tanto as peculiaridades endógenas de uma obra quanto seus nexos com o tempo histórico em que foi produzida. (CEPÊDA, 2008, p. 45).

Como aventado acima, a investigação histórica seria fundamental para a discussão do desenvolvimento econômico e, ainda mais especialmente, para o contexto do subdesenvolvimento, como é o caso do Brasil - temática subjacente à parte da literatura de história econômica, e central à obra de Celso Furtado. Importante destacar desde já que o método analítico do qual se vale Celso Furtado sintetiza, em larga medida, não apenas a investigação histórica, mas o faz em diversos níveis de análise. Embora esse seja objeto de discussão da próxima subseção, vale adiantar que Furtado busca não restringir sua perspectiva nem a um nível micro-analítico, nem a um nível macro-analítico: a tensão permanente entre a micro e macro percorre as suas elucubrações teóricas. A consideração dessa tensão permanente entre os diversos níveis de investigação, na forma de retroalimentações e influências mútuas, é uma das hipóteses fundamentadoras da Abordagem da Complexidade, assim como a consideração da heterogeneidade.

Essa observação da tensão permanente entre a micro e a macro, entre o interno e o externo, é importante na medida em que, partindo do conceito de centro-periferia e, portanto, da heterogeneidade das nações que compõem o sistema político-econômico mundial, destacadamente com relação às diferenças relativas às influências diversas que promovem ou recebem, a interação dinâmica entre fatores micros e fatores macro - ou entre fatores internos e fatores externos - não deve ser negligenciada. E, no caso da periferia, que mais recebe influência do que promove, a desconsideração do contexto macro ou externo mais amplo em que está inserida pode conduzir à insuficiência explicativa. Por outro lado, conceder primazia somente aos fatores externos, pode incorrer em semelhante insuficiência, na medida em que, em se tratando de sistemas nacionais constituídos, possuem dinâmica interna própria, que não pode ser ignorada. $\mathrm{O}$ trecho selecionado de Cepêda - de texto que faz referência à obra de Celso Furtado - sintetiza bem essa questão: “[...] o problema do subdesenvolvimento é consequência da herança colonial e, como esta, é explicada em primeiro lugar como o resultado da oposição entre interno versus externo [...]" (Ibid., p. 52).

Conforme discutido no capítulo 2, o desenvolvimento e o subdesenvolvimento são 
fenômenos complexos, por isso requereriam um aporte teórico-metodológico adequado que permitisse lidar, em alguma medida, com a riqueza de elementos e propriedades que lhe envolvem. Ressalte-se aqui que um tratamento considerado adequado da pesquisa de História Econômica deveria buscar contemplar uma abordagem que integrasse analiticamente elementos relacionados tanto à esfera microeconômica, quanto à macroeconômica. Vale enfatizar que a definição de micro ou macroeconômico não deve ser tratada como estanque; deve ser dependente do objeto que se pretende investigar - ou da pergunta que se pretende responder -, bem como do escopo teórico de investigação.

Em determinados contextos, é possível fazer uma assimilação direta entre fatores microeconômicos e fatores internos, e entre fatores macroeconômicos e fatores externos. Essa assimilação é aqui realizada por conta da função desempenhada pelo Brasil na divisão internacional do trabalho, algo importante para compreender a fonte principal de impulsos dinâmicos, assim como os seus efeitos em termos de desenvolvimento. Desse modo, na direção da construção de um tratamento teórico da História Econômica compatível com a Abordagem da Complexidade, seria necessária a consideração da causalidade bidirecional dos fatores externos e dos fatores internos - macro e microeconômicos - e do próprio caráter cumulativo do evolver histórico.

Uma justificativa central do por que a História é essencial para a pesquisa econômica é a de que, por meio da investigação histórica, é possível caminhar na direção de desvendar a riqueza de elementos, fatos, contextos e circunstâncias que envolvem tanto, de um ponto de vista mais abstrato, o evolver das ideias e métodos de pesquisa científicos, ${ }^{179}$ quanto, de um ponto de vista mais prático - e de especial interesse à discussão do tema desenvolvimento econômico -, da trajetória socioeconômica das nações, possibilitando, consequentemente, abrir caminhos para a compreensão e solução de seus problemas. Todas as nações passaram por um longo e peculiar processo de evolução e, por isso, cada uma delas representa um sistema adaptativo complexo próprio. Por conseguinte, o desenvolvimento econômico não pode ser derivado naturalmente de um rol de políticas padrão que desconsidere a heterogeneidade das nações e a especificidade do processo de formação de cada uma delas.

A seguir, desenrola-se uma breve discussão a respeito da evolução da perspectiva analítica da historiografia econômica brasileira, na qual estaria inserida de forma

\footnotetext{
${ }^{179}$ Embora essa discussão mais abstrata não seja o foco do presente trabalho, vale destacar que as visões ou crenças do cientista sobre o que é ciência influenciam diretamente a maneira pela qual o mesmo interpreta a história da ciência. Idealmente, abordar o evolver científico sob a perspectiva do historiador implica nem encarar a ciência como imune a outras influências, nem como totalmente determinada por fatores externos (GOODWIN, 1998). Há uma relação complexa e adaptativa latente entre o desenvolvimento da ciência e os aspectos sociológicos, institucionais, culturais e conjunturais.
} 
idiossincrática a contribuição de Celso Furtado. $\mathrm{O}$ foco de discussão refere-se às mudanças observadas com relação ao grau de consideração concedido à importância explicativa dos fatores internos e externos para compreender a dinâmica da formação econômica e social brasileira.

\subsection{Um breve panorama da historiografia econômica brasileira}

Para boa parte da literatura que discute a historiografia econômica brasileira, a década de 1930 representou um marco. Isso porque, até então, as abordagens históricas que buscavam analisar e compreender os aspectos socioeconômicos brasileiros se baseavam, quase que unicamente, em considerações étnico-raciais e, por isso, eram incompletas e insatisfatórias. Como resposta a esta incompletude analítica, passaram a surgir críticas que apontaram para a necessidade de uma História que problematizasse o quadro social, que atentasse para ele como uma totalidade e que apreendesse os movimentos de mudança e evolução das estruturas e instituições.

Seguindo a periodização de Iglésias (1970), as primeiras manifestações da historiografia tomaram primeiramente a forma de obras descritivas (séculos XVI, XVII e XVIII) - "Tratado descritivo do Brasil em 1587" de Gabriel Soares de Sousa, "Diálogo das grandezas do Brasil" de Ambrósio Fernandes Brandão e "Cultura e opulência do Brasil" de Antonil - e de obras de "quase" História Econômica (séculos XVIII e XIX) - "Minas e os quintos de ouro" de Diogo Pereira Ribeiro de Vasconcelos, "Instrução para o governo da Capitania de Minas Gerais" de José João Teixeira Coelho. Já no século XX, nos anos 20, a História Econômica teria aparecido como objeto específico, adquirindo uma caracterização mais global; representante dessa fase são as obras: "História da formação econômica do Brasil", de Vitor Viana e "Pontos de partida para a história econômica do Brasil" de Lemos Britto. Essas obras, apesar de não serem rigorosamente de História Econômica, valiam como fontes em si mesmas e pelas notícias históricas que forneciam.

Já no final da década de 1930, é publicada a "História Econômica do Brasil" de Roberto Simonsen, ${ }^{180}$ livro no qual, segundo Gorender (1985), a teoria dos ciclos - com sua dinâmica baseada no principal produto da pauta exportadora, por exemplo, "ciclo do açúcar", "ciclo da mineração" e "ciclo do café" - teria atingido seu acabamento final. Contudo,

\footnotetext{
${ }^{180}$ Livro que serviu de inspiração para Celso Furtado escrever a Formação Econômica do Brasil, publicada em 1959. Vide Furtado (1985), conforme descrito adiante.
} 
conforme argumenta Iglésias, embora tenha sido importante e demarcatória, à concepção de Simonsen faltaria certo sentido de totalidade, além de lhe ser atribuída uma natureza estanque, perpetuando uma visão compartimentada e, por conseguinte, descontinuada da história.

Diferentemente de Simonsen, Caio Prado Júnior teria encarado o contexto econômico como um processo global (IGLÉSIAS, 1970) e os ciclos como manifestações sequenciais de algo mais profundo, ou de uma realidade permanente (GORENDER, 1985). O sentido da colonização, tal como definido por Prado Júnior (1942), forneceu elementos para a compreensão dos elementos socioeconômicos centrais relacionados à formação e à evolução históricas das colônias. O paradigma Pradiano - ou visão plantacionista - teria se enraizado de tal modo na historiografia brasileira que, segundo Ricupero (2000), sua referência tornou-se algo até redundante.

A abordagem de História Econômica Brasileira colonial, por muito tempo, esteve pautada por essa perspectiva derivada a partir da abordagem de Caio Prado Júnior, cujos principais representantes são o próprio Caio Prado Júnior, Fernando Novais ${ }^{181}$ e Celso Furtado $^{182}$. Segundo Prado Júnior (1942), o sentido da colonização explica a natureza e as características da colônia brasileira a partir do intuito comercial da metrópole de gerar um fluxo de bens lucrativo no mercado europeu. Desse conceito, o autor derivou as características definidoras da estrutura produtiva que se desenvolvera na colônia, que apresentava como atividade principal aquela extração ou produção que viabilizasse o fluxo de comércio almejado pela metrópole. Do caráter tropical da terra, dos objetivos dos colonizadores e das condições gerais da nova ordem econômica global inaugurada com a expansão ultramarina, emergiu como resultado a grande exploração rural, célula fundamental da economia agrária brasileira, caracterizada por grande propriedade, monocultura ou extração e trabalho escravo.

No entanto, a colonização acabou realizando algo a mais que um simples contato fortuito dos europeus com o meio a ser explorado. Paralelamente à grande atividade extrativomonocultora, desenvolveram-se atividades de subsistência, subsidiárias daquela que constituía o núcleo e fim produtivo da colônia, destinados unicamente a amparar e tornar possível a realização do sentido da colonização. Portanto, o corolário geral do modelo teórico Pradiano é que tudo se dispõe no sentido da colonização, tanto no que se refere à estrutura quanto às atividades desenvolvidas na colônia. Desse modelo de colonização exploradora dos trópicos decorre a concentração extrema de riqueza, o papel de simples fornecedor do comércio internacional e o vácuo imenso entre os extremos da escala social, os senhores e os escravos,

\footnotetext{
${ }^{181}$ Novais (1990).

${ }^{182}$ Furtado (1959).
} 
os únicos elementos organicamente inseridos no sistema sob a perspectiva do modelo Pradiano.

Em suma, esse modelo teórico de Caio Prado Júnior derivado a partir do sentido da colonização configura uma perspectiva externalista, ou pautada quase que exclusivamente em fatores externos. Esse modelo teórico seria aplicável para todas as fases da colônia brasileira. Os fatores não contemplados por seu modelo, sob sua perspectiva teórica, não seriam fundamentais para entender o essencial do evolver do período colonial brasileiro. Esses fatores, como a grande população que não era nem proprietária, nem cativa, eram classificados como inorgânicos, ou seja, no limite, a sua ausência não faria diferença para a explicação do todo. ${ }^{183}$

Especialmente desde os anos 70 do século XX, quando emergiram as primeiras críticas teóricas ${ }^{184}$ e as primeiras evidências empíricas ${ }^{185}$ que se contrapuseram ao paradigma, diversos trabalhos têm revisto a interpretação Pradiana. Em geral, as implicações do sentido da colonização que se veem questionadas são a suposta preponderância do capital mercantil metropolitano, a insignificância de um mercado interno na colônia, a configuração de uma sociedade polarizada (senhores e escravos) e a irrelevância relativa dos processos de acumulação endógena.

Com base em novas evidências empíricas, alguns estudiosos questionaram a generalidade e a eficácia explicativa do paradigma Pradiano norteado por uma perspectiva primordialmente externalista. As críticas, em geral, jogaram luz sobre a importância dos fatores internos para explicar a dinâmica das economias coloniais e se dirigiam: à existência e importância de mercado interno constituído - e, por conseguinte, da relevância dinâmica dos mecanismos de acumulação endógena; ${ }^{186}$ à propriedade escravista ou sobre a representatividade da grande propriedade; ${ }^{187} \mathrm{e}$, à necessidade de se levar em conta aspectos

\footnotetext{
${ }^{183}$ Embora Caio Prado Júnior não seja foco de discussão dessa tese, importante ponderar e ressaltar que não se quer dizer que o autor não tenha se debruçado de maneira suficientemente profunda sobre a investigação dos fatores internos. Muito pelo contrário, a obra de Caio Prado Júnior é uma fonte bastante rica de informações relativas a essas questões. No entanto, para a composição de seu modelo teórico da dinâmica colonial brasileira, em termos de relevância analítica, no sentido de ser causa causans - assim como se referira Keynes (1937, p. 178) ao papel do investimento -, o autor concede maior importância explicativa aos fatores externos, na medida em que seriam os responsáveis pelas perturbações e flutuações e, por conseguinte, englobariam a maior parte da significância explicativa da dinâmica observada na colônia.

${ }^{184}$ Essas críticas se referem especialmente às interpretações centradas no caráter extrovertido da economia colonial. Por exemplo, vide: Gorender (1985), para o qual a perspectiva analítica do paradigma Pradiano estaria equivocada; Castro (1984), para o qual o sentido da colonização estaria fora de foco; e Cardoso (1979), que realiza críticas ao que denomina de circulacionismo.

${ }^{185}$ Novas evidências empíricas foram trazidas à tona por meio da descoberta e investigação de fontes primárias de dados. Vide, por exemplo, Costa \& Nozoe (1989) e Costa (1992).

${ }^{186}$ Por exemplo, vide Fragoso e Florentino (2001) e Costa (1995).

${ }^{187}$ Por exemplo, vide Schwartz (1988) e Silva \& Reis (1989).
} 
internos às colônias - ou de desenvolver o processo analítico de "dentro para fora" -, o que se contrapunha ao método do paradigma Pradiano - "de fora para dentro".

Sinteticamente, a concepção externalista do paradigma Pradiano pode conduzir a uma análise que concede, demasiadamente, um papel coadjuvante, e totalmente passivo, às colônias, o que remete à busca de explicações para os problemas e contradições apenas à sua própria condição de colônias, desprovidas, em qualquer medida, de vontade própria. Jogar luz sobre a importância dos fatores internos às colônias, de outra forma, retiraria essa carga extrema de vitimização, colocando-as também como corresponsáveis no processo socioeconômico contraditório e problemático que enfrentaram, especialmente após sua independência, principalmente no que diz respeito à questão do desenvolvimento econômico e da sua sustentabilidade.

De maneira geral, uma perspectiva pautada em fatores externos, e tão delimitada como o modelo teórico Pradiano, não contempla a riqueza de fatores internos que são imprescindíveis para a compreensão do processo histórico que levou à formação econômica e social pois, sob essa perspectiva, não seriam necessários para a explicação do seu objeto. Por outro lado, uma perspectiva que só leve em consideração fatores internos ignora o contexto mais global relacionado à estrutura e dinâmica do sistema econômico-político mundial - ou seja, as restrições externas -, o que pode levar a uma caracterização inadequada, porque insuficiente, da realidade. Por exemplo, o Brasil-colônia possuir uma dinâmica interna relativamente autônoma não elimina o fato de ser ele uma colônia e, por conseguinte, de cumprir um papel específico na divisão internacional do trabalho e estar, desse modo, sujeito a restrições externas específicas ao seu contexto.

Retomando discussão realizada na seção anterior, na direção da construção de um tratamento teórico da História mais compatível com a Abordagem da Complexidade, far-seiam necessárias as seguintes considerações: a causalidade bidirecional dos fatores externos e dos fatores internos e, portanto, de que todos esses fatores são potencialmente interessantes do ponto de vista analítico; as nações periféricas possuem estruturas socioeconômicas internas cuja dinâmica não se reduz exclusivamente ao impacto de sua ligação com o mercado mundial; a existência de responsabilidade dos grupos que compõe a nação, principalmente as elites que influenciam as decisões políticas, nas escolhas realizadas, mesmo que restritas, em alguma medida, pelo contexto internacional; e, por fim, e como decorrência das questões anteriormente citadas, o próprio caráter cumulativo do evolver histórico.

Para algumas mudanças de perspectiva da historiografia econômica brasileira, contribuíram os trabalhos críticos já referidos ao paradigma Pradiano, na medida em que 
permitiram ampliar a compreensão da complexidade de fatores internos que compunham o sistema colonial brasileiro, importantes para compreender a nossa formação econômica e social. O que não quer dizer, por outro lado, que superaram ou prescindem das importantes conclusões e conceitos desenvolvidos a partir da perspectiva Pradiana.

Dessa forma, do ponto de vista da compreensão do objeto, parece mais profícuo adotar a perspectiva de complementariedade das perspectivas - viesadas mais ou menos por fatores internos ou externos, macro ou microeconômicos - ao invés da superação ou total negação de qualquer uma delas. Pois, quando se fala em superação, é como se a perspectiva abandonada estivesse completamente errada, ou não servisse, em nenhuma medida, como fonte explicativa. Por outro lado, quando se fala apenas em reforço, pode-se formar a impressão de que houve apenas uma sofisticação da abordagem, mas sem implicar mudanças fundamentais de perspectiva, o que não é o caso das críticas que emergem tanto das evidências empíricas quanto de embates teóricos que acabaram por contradizer algumas definições do paradigma Pradiano. ${ }^{188}$

Em alguma medida, embora passível de diversas ponderações, parte da obra de Celso Furtado se insere na perspectiva geral do paradigma Pradiano. A influência de Caio Prado Júnior talvez seja mais facilmente verificável nos livros nos quais Furtado realiza uma discussão detalhada do período colonial brasileiro, tais como A Economia Brasileira, de 1954 e a Formação Econômica do Brasil, de 1959. Nesses livros o período colonial é explicado, primordialmente, a partir da dinâmica ensejada pelo setor externo. Então, assim como em Caio Prado Júnior, os impulsos dinâmicos da economia colonial são fundamentalmente externos. Para Furtado, o deslocamento do centro dinâmico para o mercado interno só ocorreu na década de 1930.

Conforme discutido adiante, essa delimitação cronológica coincidiria com uma mudança de abordagem do autor, que passa a incorporar e considerar, de maneira crescente, a importância dos fatores internos, o que afasta a análise Furtadiana do paradigma Pradiano e a aproxima de uma perspectiva do processo histórico mais condizente com a Abordagem da Complexidade, ou seja, que leva em consideração as relações de retroalimentação entre os fatores internos e entre os fatores externos. Aventa-se, portanto, que a mudança de método no enfoque da literatura de História Econômica brasileira, de uma baseada primordialmente em fatores externos para aquela que progressivamente joga luz à centralidade dos fatores internos,

\footnotetext{
${ }^{188}$ A partir desse embate teórico, parece ser mais interessante falar em um novo paradigma para o pensamento historiográfico brasileiro, mas aqui, conforme argumentado, com uma delimitação distinta daquela realizada por Kuhn (1972), que necessariamente implica superação - ou o estabelecimento de um novo paradigma.
} 
seria identificável no próprio evolver da obra de Furtado.

Apenas para ilustrar essa discussão sobre a perspectiva Furtadiana e adiantando discussões a serem desenvolvidas na próxima seção, vale destacar, em diferentes momentos do tempo, definições do próprio Celso Furtado sobre o método do qual se valia. Por exemplo, Furtado (1985) faz um relato sobre como concebeu a ideia de escrever a Formação Econômica do Brasil. O autor descreve que, um pouco antes - meados da década de 1950 -, adquirira uma versão mais recente de História Econômica do Brasil de Roberto Simonsen, o qual já havia lido cerca de uma década antes. Ao folhear novamente o livro, lhe ocorreu a ideia de elaborar um modelo da economia do açúcar em meados do século XVII. O trecho selecionado explicita a preocupação do autor em pautar seu método pela combinação da análise econômica com a investigação histórica. Nas palavras do autor:

Foi dessa ideia que surgiu a Formação Econômica do Brasil, redigida entre novembro de 1957 e fevereiro de 1958 nas "sobras de tempo" que ia furtando ao festival do debate teórico. O método era o mesmo que utilizara em trabalhos anteriores: aproximar a História (visão global) da análise econômica; extrair desta perguntas precisas e obter respostas para as mesmas na História. (FURTADO, 1985, p. 205).

Novamente a respeito de seu método, discorrera Furtado, na introdução ao seu livro Análise do Modelo Brasileiro, de 1972. O trecho abaixo reproduzido destaca a importância da consideração do fator tempo - e, novamente, da trajetória histórica -, bem como da interação dos fatores internos e externos. Nas palavras do autor:

\footnotetext{
Os dois ensaios reunidos no presente volume estão concebidos segundo o método que o Autor vem utilizando há dois decênios: a partir de uma globalização histórica, identificam-se os elementos estruturais que permitem, num corte temporal, reduzir a realidade social a um sistema a que se podem aplicar os instrumentos da análise econômica. O corte temporal torna-se necessário, a fim de que certos elementos ganhem suficiente invariância para que possamos considerá-los estruturais. A globalização histórica, por sua vez, permite continuar a observar tais elementos como variáveis, que mudam de significação quando se passa de um a outro corte temporal [...] A partir do momento em que o captamos [o quadro estrutural], o comportamento das variáveis endógenas deve encontrar explicação no sistema e nas leis que presidem as relações deste com suas fronteiras internas e externas. É a partir deste ponto que a análise econômica adquire maior precisão, dando-nos os instrumentos com que identificar tendências e descortinar o horizonte de opções com que se confrontam os agentes responsáveis pelas decisões mais significativas. (Id., 1972, p. 3-4).
}

Realizada essa pequena introdução sobre o que poderia ser denominado de complexo método Furtadiano, passemos à investigação e discussão de sua obra de historiografia econômica brasileira, iniciando no período colonial e encerrando com a crise da década de 1980, que demarca o fim da fase desenvolvimentista brasileira.

\subsection{A perspectiva complexa de Furtado sobre o caso brasileiro}


Para compor a investigação de história econômica que norteia essa seção, foram selecionados textos de Furtado publicados entre a década de 50 e a década de 90 do século $\mathrm{XX}$, que se voltaram especialmente à investigação do caso brasileiro. Sobre o tom da obra de Furtado, Coutinho (2008) sugere que, nos textos datados de até meados da década de 1960, especialmente Formação Econômica do Brasil, o tom argumentativo de Furtado era, de certa forma, otimista, na medida em que demonstrava a crença de que o processo substitutivo de importações levaria o Brasil a desenvolver toda a sua matriz industrial e conquistar o desenvolvimento. No entanto, segundo o autor, no final dos anos 60, Furtado já demonstraria seu pessimismo, provavelmente em virtude dos problemas que passaram a ser enfrentados pela economia brasileira, relativos ao esgotamento do modelo de desenvolvimento baseado na substituição de importações, culminando com a crise do início da década de 1980.

A apresentação da perspectiva Furtadiana sobre a Economia Brasileira é feita em termos cronológicos, o que, em certa medida, coincide com a própria cronologia dos textos do autor. Inicia-se com uma breve discussão do período colonial, do século XIX e do começo do século XX, passando à década de 1930, quando se inaugura o chamado período desenvolvimentista brasileiro. A discussão com base em Furtado da Economia Brasileira termina no início da década de 1980, fim do período desenvolvimentista.

Além da apresentação da contribuição de Furtado à compreensão da trajetória socioeconômica brasileira, é realizada uma discussão a respeito do seu método analíticoinvestigativo. Discute-se, implicitamente, a hipótese - aventada na seção anterior - de que seria possível identificar na obra de Furtado uma mudança metodológica que sintetizaria a própria mudança de perspectiva observada na abordagem da historiografia econômica brasileira ao longo do século XX. Como visto, essa mudança é, em larga medida, reflexo das críticas dirigidas ao paradigma Pradiano - ou à visão plantacionista -, que ganharam força especialmente a partir da década de 1970.

O aspecto focado da mudança de ênfase de Furtado é a importância crescente concedida aos fatores internos vis-à-vis os fatores externos - ou, a depender do contexto, fatores microeconômicos vis-à-vis os fatores macroeconômicos -, porém sem que isso tenha significado a atribuição de não importância explicativa dos fatores externos. É justamente nesse sentido que Furtado, também em sua abordagem historiográfica, seria um autor que se valeria de um método analítico compatível com a Abordagem da Complexidade: sua análise busca não perder de vista a importância explicativa para compreender a dinâmica da economia brasileira, seja dos fatores internos, seja dos fatores externos e, consequentemente, 
também da interação deles.

A presente seção está dividida em cinco subseções, cada uma delas referindo-se a um período de tempo: a subseção 4.3.1 discute o período colonial até 1930; a subseção 4.3.2 aborda o período 1930-1945; a subseção 4.3.3 apresenta o período do pós-guerra e a década de 1950; a subseção 4.3.4 discorre sobre a década de 1960; e, por fim, a subseção 4.3.5, perpassa a década de 1970. Em cada uma dessas subseções, realiza-se uma apresentação da análise Furtadiana da trajetória socioeconômica no período em voga e uma discussão do método do autor, destacando: a mudança do grau de importância concedido à importância explicativa dos fatores internos e externos, bem como de sua interação; e, paralelos e compatibilidades entre a sua perspectiva e a Abordagem da Complexidade.

\subsubsection{Do período colonial até 1930: breves considerações sobre as raízes da formação}

\section{econômica e social brasileira}

Antes de passar efetivamente ao período de interesse de investigação dessa tese, que se inicia na década de 1930, vale tecer algumas discussões relativas ao período prévio, na medida em que são importantes para compor a estrutura analítico-argumentativa Furtadiana sobre o caso brasileiro, e às quais o autor costumeiramente faz referências. Nessa subseção, a discussão se refere ao período colonial ${ }^{189}$, aos séculos XIX e XX, até 1930, quando se inicia a Era Vargas.

Discorrendo sobre o funcionamento da economia exportadora-escravista, Furtado (1959) compara que, enquanto numa economia industrial a inversão faria crescer diretamente a renda da coletividade - pois a inversão se transforma automaticamente em pagamento a fatores de produção -, parte da inversão feita numa economia exportadora-escravista se transformava em pagamentos feitos no exterior - importação - e outra parte tinha como origem a utilização da força de trabalho escravo. Furtado (1954a) explica que na economia exportadora-escravista, o empresário poderia transformar todo o aumento de produtividade, obtido em virtude de melhoramentos nas técnicas produtivas, em maiores lucros. Como esse aumento de lucros não era incorporado à renda nacional e sim transferido à metrópole, não haveria nenhuma garantia de que o lucro acumulado se revertesse em nova inversão na

\footnotetext{
${ }^{189}$ Como bem define Furtado (1954a), “A qualificação de sistema de economia colonial [...] aplica-se àquele que não pode crescer senão por indução do crescimento de um outro sistema [...]” (FURTADO, 1954a, p. 15). Sobre a mesma questão, o autor diz mais à frente: "É neste sentido que a economia colonial não constitui, propriamente falando, um "sistema econômico" e sim parte dependente de um sistema." (Ibid., p. 63).
} 
colônia. Dessa forma, "O aumento da produtividade no núcleo industrial de natureza colonial não é, portanto, necessariamente, um elemento dinâmico tendente a absorver a economia estacionária preexistente.” (Id., 1954a, p. 56).

Ademais, como os fatores de produção pertenciam quase que totalmente ao empresário, a renda monetária gerada ficava praticamente toda concentrada nas mãos deste. Renda essa revertida para a importação de bens e de mão-de-obra escrava, bem como para a utilização desta. Por isso, "[...] o fluxo de renda se resumia na economia açucareira a simples operações contábeis, reais ou virtuais.” (Id., 1959, p. 50), pois, nessa economia, em termos de expressão econômica, o mercado interno não possuía significância dinâmica. Apesar de ser essa descrição um quadro simplificado da realidade, Furtado (1954a) ressaltara que "[...] mesmo que se completasse o quadro, não se modificaria a essência do fenômeno que é esta: o aumento da capacidade produtiva, isto é, a inversão, faz-se sem que aumente a renda monetária da coletividade." (Id., 1954a, p. 73).

Hipoteticamente, se o mercado externo absorvesse quantidades crescentes de açúcar a um nível adequado de preços, o sistema econômico escravista poderia ter crescido até ocupar todas as terras disponíveis. De qualquer forma, o crescimento da economia açucareira foi considerável e persistiu durante todo o século XVI. Entretanto, “[...] esse crescimento se realizava sem que houvesse modificações sensíveis na estrutura do sistema econômico [...] Crescimento significava, neste caso, ocupação de novas terras e aumento de importações." (Id., 1959, p. 51). Eis o "paradoxo do açúcar": não havia nenhuma possibilidade de que o crescimento com base no impulso externo - embora, naquele momento, bastante significativo - gerasse um processo de desenvolvimento de autopropulsão, pois o mecanismo que regia a lógica de funcionamento da economia exportadora-escravista não permitia uma articulação direta entre os sistemas de produção e de consumo, inviabilizando a estruturação de um mercado interno, que seria, por hipótese, um elemento dinâmico fundamental para promover o desenvolvimento econômico.

A mesma discussão é realizada por Furtado a respeito da economia mineratória. Comparativamente à economia açucareira, a necessidade de mobilização de capital por escravo, ou por unidade de produção, era bem inferior. No limite, se não tivesse capital para iniciar a extração, era possível atuar como faiscador, sem a necessidade, portanto, de incorrer em custos fixos para iniciar o processo. A elevada lucratividade do negócio mineratório induzia a concentrar todos os recursos disponíveis na própria mineração, implicando uma grande especialização produtiva. Comparada à renda média da atividade açucareira, a renda média na atividade mineratória era menor, o que seria explicado pela maior participação da 
população livre ou liberta. Em contrapartida, as importações representavam menor proporção do dispêndio total - mesmo porque, a distância dos portos encarecia consideravelmente os artigos importados do exterior - e a renda era menos concentrada, pois a população livre era muito maior, em grande parte reunida em grupos urbanos e semiurbanos. Como consequência, a composição da demanda era mais diversa, com maior peso para bens de primeira necessidade.

Dadas essas características, a potencialidade de formação de mercado interno da economia mineira era consideravelmente maior do que a da economia açucareira, o que poderia ter desencadeado um processo de desenvolvimento endógeno ou autopropulsionado. Entretanto, como indica Furtado, o processo de desenvolvimento endógeno da economia mineratória foi praticamente nulo. ${ }^{190}$ Essa ausência de desenvolvimento interno o autor atribui especialmente à incapacidade técnica dos imigrantes para iniciar atividades manufatureiras, explicada por um fator externo. O Tratado de Methuen, de 1703, que Portugal estabeleceu com a Inglaterra, teria destruído o pequeno desenvolvimento manufatureiro que tivera aquele país, o que teria ocasionado problemas não apenas a Portugal, mas também à sua colônia brasileira, na medida em que teria estancado o desenvolvimento do conhecimento manufatureiro por parte dos portugueses.

Segundo Furtado (1954a), do ponto de vista econômico, a colonização comercial dos séculos XVI, XVII e XVIII deixou como principal legado a formação de uma extensa economia de subsistência, responsável pelo povoamento de parte importante do território nacional e, especialmente, constituinte de uma fonte significativa de reserva de força de trabalho. $\mathrm{O}$ autor explica que essa extensa economia de subsistência “[...] não era outra coisa senão os restos reunidos e justapostos de todas as economias de exportação que tinham perdido sua razão de ser." (Id., 1954a, p. 86).

Conforme explica Furtado (1959), a importância dinâmica dessa extensa área de economia de subsistência é que acabava por desempenhar um papel de acomodação em tempos de crise do setor exportador. Sob uma perspectiva de curto prazo, sua funcionalidade era positiva, na medida em que garantia no mínimo as condições de subsistência da classe não proprietária. No entanto, as consequências de longo prazo foram altamente negativas. Ao acomodar períodos de crise, em primeiro lugar, a existência dessa vasta região ajudava a reduzir o incentivo a qualquer mudança produtiva. Ademais, ao garantir as condições

\footnotetext{
${ }^{190}$ Com relação a essa afirmação, discorda, por exemplo, Schwartz (2001). O autor aponta para a formação de uma economia vicinal no núcleo econômico minerador, cujo cerne seria caracterizado por unidades agrícolas diversificadas internamente, que produziam para o seu próprio consumo e vendiam os excedentes em mercados locais ou regionais. E seriam esses excedentes a fonte de recursos para a importação de escravos.
} 
mínimas de subsistência, também estimulava o crescimento vegetativo dessa população, compondo um grande contingente populacional subocupado em atividades de baixíssima produtividade.

Em linhas gerais, para Furtado (1959), a primeira metade do século XIX representou um período de involução econômica e, consequentemente, de retrocesso social. ${ }^{191} \mathrm{~A}$ involução é diretamente derivada, para o autor, do desaquecimento do setor exportador. Os momentos em que se observaram alguma melhoria relativa, o autor os denomina todos de falsa euforia. Segundo o autor, praticamente todos os produtos da colônia se beneficiaram de elevações temporárias de preços. ${ }^{192}$ No entanto, essa prosperidade estava fundamentada em condições de anormalidade.

Para Furtado, na primeira metade do século XIX, em que se observaram grandes transformações das estruturas econômicas dos países mais avançados, e no qual o Brasil teria permanecido desintegrado do comércio mundial, criaram-se diferenças profundas entre o Brasil e os países mais avançados. Estaria nesse período de involução, para o autor, uma das chaves explicativas para o subdesenvolvimento econômico brasileiro - ou do seu distanciamento com relação às nações mais avançadas. Nesse sentido, o autor contesta a suposição de que estaria ao alcance do Brasil, naquele contexto da primeira metade do século XIX, adotar uma política idêntica à dos Estados Unidos. O desenvolvimento dos Estados Unidos teria constituído um capítulo integrante do desenvolvimento da economia europeia, sendo resultado, em algum grau, da adoção de políticas protecionistas.

O fundamental para Furtado, no que se refere à comparação da trajetória de Brasil e Estados Unidos, são as suas diferenças de composição social: “[...] enquanto no Brasil a classe dominante era o grupo dos grandes agricultores escravistas, nos EUA uma classe de pequenos agricultores e um grupo de grandes comerciantes urbanos dominava o país." (Id., 1959, p. 101). Essas diferenças sociais, por sua vez, teriam influenciado a escolha e

\footnotetext{
${ }^{191}$ Essa caracterização da primeira metade do século XIX como fase de decadência é contestada por Buescu (1970). O autor resgata o mesmo período com base em variáveis políticas, sociais, culturais e econômicas - com destaque especial para a emergência de interesses internos. Sobre os comentários de Furtado a respeito da renda per capita decadente, Buescu destaca que conduzem a uma minimização da importância das "sementes" que estavam sendo plantadas na primeira metade do século XIX, e que só viriam a dar "frutos" em meados deste. Conforme constata o autor, depois de uma queda secular da renda per capita, o processo de queda estanca no período 1800/50, quando então começa a subir: "[...] várias alterações devem ter acontecido exatamente naquele período para permitir a futura direção ascendente da curva. A época de Mauá só foi possível graças à de Cairu." (BUESCU, 1970, p. 231). Talvez o mais interessante a extrair da controvérsia entre Furtado e Buescu é justamente a importância dos fatores extra econômicos para compreender a profundidade de questões que, aparentemente, muitas vezes se referem - ou induzem - a considerações puramente economicistas.

${ }^{192}$ Por exemplo, região açucareira quando do colapso da colônia açucareira do Haiti; demanda de algodão por parte dos ingleses, produzido no Maranhão e Nordeste; dificuldades nas colônias espanholas repercutem no mercado de produtos tropicais e couro.
} 
prioridade de políticas e o direcionamento e aproveitamento de recursos e, por conseguinte, a configuração ou não das condições necessárias para garantir um desenvolvimento autopropulsionado.

Conforme interpretação de Furtado, a condição básica para o desenvolvimento do Brasil na primeira metade do século XIX era a expansão de suas exportações. Promover a industrialização naquele momento seria impensável pois, como não existia uma base técnica pré-existente, fazia-se necessária a importação de tecnologia, o que por sua vez pressupunha um determinado grau de capacidade de importação, o qual só poderia ser satisfeito por disponibilidade de divisas. Naquele contexto, o estrangulamento externo parecia insolúvel, porque não havia divisas suficientes em decorrência do desaquecimento do setor exportador. Com o desaquecimento do setor exportador (segundo estimativas de Furtado, cresceram a $0,8 \%$ ao ano) e a tendência de crescimento populacional (de 1,3\% ao ano), seria possível deduzir uma tendência marcada de queda no nível de renda per capita na primeira metade do século XIX. A tendência de queda do nível de renda per capita só poderia ter sido modificada pelos fatores discutidos anteriormente - os quais, como visto, não se processaram. Nesse caso, somente um desenvolvimento intenso pautado no mercado interno poderia ter amenizado o declínio do setor exportador.

O declínio foi revertido com a expansão da produção cafeeira, que teria colocado o Brasil novamente como participante ativo do mercado internacional, mas com características marcadamente distintas da fase anterior. Nas palavras de Furtado (1954a):

A economia que assim se formava apresenta diferenças profundas com respeito à economia colonial anterior [...] Esta última caracterizava-se por um elevado grau de estabilidade e sua estrutura mantinha-se imutável através de seu crescimento e decadência. A nova economia colonial apresentará características distintas, graças às quais se criarão as bases para que se tenha início a formação dentro do país de uma economia autônoma de mercado interno. (Id., 1954a, p. 89).

Para a atividade cafeeira, os fatores produtivos cruciais eram a mão-de-obra especializada (o que se constituiu inicialmente em um problema, em virtude de sua escassez) e a terra (fator abundante). Segundo Furtado (1954a), é importante ressaltar que a expansão da economia cafeeira ocorreu em um país com significativa ocupação territorial e com grande reservatório de mão-de-obra (embora não-especializada). A esse reservatório, acresceu-se a possibilidade de recorrer à imigração europeia. Para o autor, se não houvesse essa oferta abundante de mão-de-obra, não teria sido possível organizar uma economia agrícola à base do regime assalariado, por conta da pressão que seria observada em prol do aumento dos salários 
dos trabalhadores especializados deslocados à atividade cafeeira. ${ }^{193}$

O grau de capitalização da produção de café, comparativamente aos engenhos, era muito mais baixo, pois a expansão da produção de café se realizava de maneira puramente extensiva. Como havia reserva de mão-obra e abundância de terras, aos cafeicultores, do ponto de vista de sua lucratividade, não lhes era vantajoso incrementar o fator capital. Outra diferença importante da economia cafeeira com relação às economias açucareira e mineratória decorria da formação de uma nova classe empresária cafeeira, de natureza profundamente distinta das anteriores. Nas economias açucareira e mineratória, os antigos empresários haviam se tornado uma classe de rentistas ociosos, alienados de sua função e interesses econômicos. Já na economia cafeeira, desde o início, os interesses de produção e do comércio estiveram interligados e desempenhados pela classe empresária do café, que teria percebido, desde cedo, a importância do governo enquanto instrumento de ação econômica. Diz Furtado sobre essa elite cafeeira: “É por essa consciência clara de seus próprios interesses que eles se diferenciam de outros grupos dominantes anteriores ou contemporâneos.” (Id., 1959, p. 116).

Como bem enfatiza Furtado, "O fato de maior relevância ocorrido na economia brasileira no último quartel do século XIX foi, sem lugar à dúvida, o aumento da importância relativa do setor assalariado." (Ibid., p. 151). E é justamente o fator mão-de-obra a principal fonte de diferenças do fluxo de renda da economia cafeeira vis-à-vis as economias açucareira e mineratória. Na economia exportadora escravista, o fluxo de renda monetária se direcionava essencialmente para fora e o fluxo monetário e real interno era praticamente inexistente. Por isso, não se verificava, nessas economias, o funcionamento interno, minimamente significativo em termos dinâmicos, do multiplicador da renda e do dispêndio. Na economia cafeeira, foram empregados trabalhadores assalariados com intensidade crescente, constituindo os salários da cafeicultura um núcleo mais robusto de formação de mercado interno, com maior capacidade de autopropulsão. Segundo Furtado (1954a):

A massa de salários paga no setor exportador vem a ser, portanto, o núcleo central de uma economia de mercado interno. Esta economia [...] poderá crescer com mais intensidade que a economia de exportação, se bem que o impulso último de crescimento venha desta última. (Id., 1954a, p. 90-91).

Outra observação importante se refere à tendência ao desequilíbrio externo que apresentaria uma economia baseada no trabalho assalariado, algo que não se observava na economia exportadora escravocrata, em que a procura monetária acabava sendo equivalente às exportações. Numa economia com base assalariada, a procura monetária tenderia a crescer

\footnotetext{
${ }^{193}$ Sobre esse ponto, vale retomar o pioneiro Lewis $(1954,1955)$ - vide seção 3.4, capítulo 3 - que explicara que a oferta ilimitada de mão-de-obra não qualificada permitia manter os salários estáveis, possibilitando que a parcela de lucros na distribuição funcional de renda aumentasse.
} 
mais que as exportações, em virtude do próprio incremento do volume de pagamento de fatores e da decorrente ativação do mercado interno. Nesse caso, "O aumento da renda se realiza, portanto, em duas etapas: em primeiro lugar graças ao crescimento das exportações, e em segundo pelo efeito multiplicador que tem o impulso externo.” (Ibid., p. 96). No caso, por exemplo, de uma crise no setor exportador, como o efeito multiplicador se propagava lentamente, a capacidade de resposta em termos de importação, diminuindo-a, não seria imediata, por isso a tendência ao desequilíbrio externo das economias exportadoras baseadas em mão-de-obra assalariada. Dessa tendência ao desequilíbrio externo seria derivável outra tendência potencial ao desequilíbrio, só que dessa vez interno, sob a forma de pressões inflacionárias. ${ }^{194}$

Entretanto, apesar de sua maior complexidade, em termos de formação de mercado interno e de sua dinâmica consequente, não se observou como decorrência da economia cafeeira a formação de uma robusta economia baseada no mercado interno, ou de uma economia industrial. A explicação para esse fato, segundo Furtado, residiria nos próprios mecanismos de defesa da economia cafeeira de exportação, ${ }^{195}$ que acabaram dificultando a transformação da economia colonial em uma economia industrial. Diz o autor:

[...] o mecanismo geral de defesa que se foi formando na luta contra as crises externas, criou condições pouco propícias ao desenvolvimento da economia de mercado interno. O espírito de concorrência em vez de desenvolver-se no adestramento de uma classe empresária, se foi debilitando. Por outro lado, a maquinaria estatal, ao ser chamada a mancomunar-se de forma progressiva com os interesses dos exportadores, facilitou a consolidação desses interesses, em prejuízo dos de outros grupos que estavam começando a desenvolver-se. (Ibid., p. 109).

Feita uma breve síntese da análise Furtadiana, passemos à discussão de seu método. Em primeiro lugar, nota-se que a recorrência a fatores internos (ou microeconômicos), como fatores explicativos cruciais para o entendimento da dinâmica interna da economia brasileira, coincide com o evolver da própria trajetória socioeconômica, caracterizada por incrementos de complexidade da formação de sua estrutura e da potencialização dos seus efeitos multiplicadores internos.

\footnotetext{
${ }^{194}$ No contexto específico da época, Furtado $(1954 a, 1959)$ denomina esse problema como a incapacidade da economia exportadora baseada em trabalho assalariado em funcionar dentro do padrão-ouro, pois o pleno funcionamento desse padrão exigiria imensas reservas metálicas para sanar o desequilíbrio externo e para readequar a taxa de câmbio.

${ }^{195}$ Vale notar que, como o Brasil respondia pela maior parte da oferta de café mundial, isso lhe permitia manipular a oferta mundial de café e, consequentemente, seu preço internacional. Porém, como bem observa Furtado (1954a), "[...] o mecanismo de defesa da economia cafeeira era, em última instância, um processo de transferência para o futuro da solução de um problema que se tornaria mais grave.” (Id., 1954a, p. 115). Isso porque a retenção da oferta por parte dos produtores brasileiros possibilitava a manutenção de preços elevados no mercado internacional, que funcionavam como estímulo para que continuassem a serem feitas inversões em mais produção de café. Face à estabilização da demanda internacional de café, a manutenção artificial do seu preço internacional, que conduzira ao estímulo ao incremento da produção não apenas brasileira, de solução, passaria a ser fonte de problemas.
} 
Para discutir a dinâmica do início da fase colonial, Furtado recorre pouco a considerações relacionadas a fatores internos à colônia, mesmo porque o fluxo monetário interno era praticamente inexistente e, por conseguinte, não se derivava uma dinâmica autônoma interna de dimensões suficientemente relevantes. Seguindo a perspectiva Pradiana, os aspectos mais importantes para entender a dinâmica da colônia, por conseguinte, eram contemplados satisfatoriamente pelos fatores externos. Os impulsos dinâmicos provinham somente do setor exportador, que os refletiam, quase em sua totalidade, novamente para o exterior. A economia criatória que se desenvolve conectada à produção açucareira tem a funcionalidade analítica apenas de acomodar os impulsos externos negativos, sem qualquer possibilidade de imprimir uma dinâmica autônoma ou uma transformação estrutural - pelo contrário, para Furtado, a sua funcionalidade de acomodação teria impedido transformações mais profundas.

Sobre a economia mineratória, Furtado destaca sua maior potencialidade de formação de um mercado interno, por conta da distribuição de recursos relativamente melhor, considerado pré-requisito para a conquista de um desenvolvimento autopropulsionado. Todavia, essa potencialidade não teria se efetivado por conta de um fator externo, a capacidade técnica dos portugueses. Por conseguinte, assim como no período anterior, a variável explicativa fundamental continua sendo externa. E, nos dois casos, quando cessaram os impulsos externos positivos, a economia entrou em decadência e em involução econômica, o que deixa claro que, para o autor, os fatores internos eram, naqueles momentos, analiticamente irrelevantes.

A análise que Furtado realiza a respeito da primeira metade do século XIX deixa muito clara essa perspectiva externalista do autor - e, portanto, confirmando a sua alcunha de Pradiano -, pois o único meio possível de quebrar o processo de involução era a retomada da dinâmica do setor exportador o que sugeriria, inclusive, sobre essa questão, um relativo economicismo por parte de Furtado.

A mudança de perspectiva e análise de Furtado começa a se alterar de maneira mais patente quando da gestação da economia cafeeira e, especialmente, quando da introdução de uma variável-chave crucial: a mão-de-obra assalariada. Nessa variável se encontra a grande fonte de diferenças da economia cafeeira relativamente às economias açucareira e mineratória. Dessa variável, Furtado deriva a formação de um importante núcleo de mercado interno, cuja existência terá implicações dinâmicas importantes - permitindo a retenção de alguns efeitos multiplicadores internos -, embora o impulso dinâmico crucial continue sendo externo. 
Conforme argumentado nas próximas subseções, a partir de 1930, com a internalização do centro dinâmico da economia brasileira, a análise Furtadiana passa a conceder maior relevância aos fatores internos, na medida em que a própria economia se torna mais complexa - ou seja, com maior capacidade de aproveitamento dos efeitos multiplicadores da renda e do emprego internamente -, contudo, sem perder de vista a sua condição periférica e, por conseguinte, ainda altamente dependente de impulsos externos.

\subsubsection{De 1930 a 1945: a internalização do centro dinâmico e a industrialização não intencionada}

Realizado um breve panorama sobre a abordagem historiográfica e o método analítico de Furtado para discutir a dinâmica e a trajetória da economia brasileira pré-1930, essa subseção discute o período 1930-1945, que engloba a Era Vargas, instituída após a Revolução de 1930.

Furtado representa uma interpretação clássica da crise dos anos $1930 .{ }^{196}$ Para o autor, a política de defesa dos preços café, adotada em virtude da crise de superprodução, teria sido a principal responsável pela acomodação dos impactos da Grande Depressão. Como garantia de preços mínimos de compra aos produtores de café, a política de defesa de preços teria permitido a manutenção do nível de emprego na economia exportadora e, indiretamente, via efeito multiplicador da renda, também nos setores ligados ao mercado interno. Dessa maneira, essa política teria amenizado os efeitos negativos de desemprego nos demais setores da economia e, consequentemente, atenuado a queda de demanda e renda internas. Segundo o próprio autor, “[...] a política de defesa do setor cafeeiro nos anos da grande depressão concretiza-se num verdadeiro programa de fomento da renda nacional." (Id., 1959, p. 192). Consequentemente, a recuperação da economia brasileira após a Grande Depressão não encontraria explicação em qualquer fator externo, e sim numa política internamente concebida, embora de maneira inconsciente e em prol de um grupo de interesse específico, os cafeicultores.

Fundamental ao entendimento do diagnóstico de Furtado é a observação da diferença dos efeitos da acumulação de estoques, realizada antes e depois da Grande Depressão. Antes, a acumulação de estoques ocorria com uma contrapartida de débito contraído no exterior, o

\footnotetext{
${ }^{196}$ Uma interpretação distinta, por exemplo, é a de Fishlow (1972). Para o autor, a industrialização substitutiva de importações começara já na década de 1890 .
} 
que implicava, internamente, uma inversão líquida nula. Depois da crise, a acumulação de estoques de café baseada na expansão de crédito implicou, internamente, uma criação de renda e, consequentemente, de poder de compra, o que evitou uma queda mais profunda da demanda efetiva nos setores relacionados ao mercado interno, e que dependiam indiretamente da renda criada no setor exportador. Embora o efeito da acumulação de estoques de café não tenha apresentado como contrapartida a criação de capacidade produtiva, acabou estimulando a utilização da capacidade instalada, como bem explica o autor:

[...] esse aspecto do problema tem importância secundária em épocas de depressão, as quais se caracterizam pela sub-ocupação da capacidade produtiva já existente. É por esta razão que nessas etapas é de muito maior importância criar procura efetiva que induza a utilizar capacidade produtiva ociosa, que aumentar essa capacidade produtiva. (Id., 1954a, p. 133).

Assim, apesar de não ter implicado a criação de capacidade produtiva adicional, por ter mantido a demanda efetiva e o nível de emprego, a política de defesa do café teria contribuído sobremaneira para o processo de mudança estrutural observado na década de 1930, o qual teria significado um deslocamento do centro dinâmico da economia brasileira ${ }^{197}$, que de quase totalmente externo passara a ser fundamentalmente interno.

Furtado explica que a política de fomento da renda, implícita na defesa dos preços do café, implicou um desequilíbrio externo com tendência a aprofundar-se, por conta da demanda por importação. A correção de tal desequilíbrio externo se realizou por meio de uma forte diminuição do valor da moeda nacional - e, implicitamente, um encarecimento dos produtos importados. Aquela renda, que antes era direcionada ao consumo de importados, se voltou, em parte, para a oferta interna. Assim, a mudança estrutural observada seria explicável fundamentalmente pelo aumento relativo dos preços dos bens manufaturados importados, comparativamente aos dos bens produzidos internamente. $\mathrm{O}$ barateamento relativo do produto doméstico teria deslocado a demanda interna a seu favor, impulsionando a industrialização e deslocando o centro dinâmico para o mercado interno. Nas palavras do autor:

Depreende-se facilmente a importância crescente que, como elemento dinâmico, irá logrando a procura interna nessa etapa de depressão. Ao manter-se a procura interna com maior firmeza que a externa, o setor que produzia para o mercado interno passa a oferecer melhores oportunidades de inversão que o setor exportador. Cria-se, em consequência, uma situação praticamente nova na economia brasileira, que era a preponderância do setor ligado ao mercado interno. (Id., 1954a, p. 137; Id., 1959, p. 197).

O aumento da rentabilidade da produção industrial ocorria simultaneamente à queda

\footnotetext{
197 "Deslocamento do centro dinâmico" é o título do capítulo 32 de Formação Econômica do Brasil e parte do título do capítulo IV de A Economia Brasileira - "A crise do setor colonial e o deslocamento do centro dinâmico". Conforme discutido ao final dessa subseção, essa denominação de deslocamento do centro dinâmico seria paradigmática da mudança do método analítico de Furtado, aproximando-o do que se aventou que seria uma abordagem historiográfica da trajetória socioeconômica mais compatível com a Abordagem da Complexidade.
} 
da taxa de lucros do setor exportador, o que teria desviado capitais deste para o setor ligado ao mercado interno. Ou seja, o crescimento da produção industrial interna se alimentava não apenas pela acumulação de seus próprios lucros, mas também pela atração de capitais que estavam antes investidos em outras atividades. O crescimento industrial foi possível inclusive na produção de bens de capital, setor que, em condições diversas da década de 1930, teria encontrado grandes dificuldades de se instalar em uma economia dependente como a brasileira, em virtude do ainda reduzido mercado de consumo desses bens, conforme explica Furtado (1954a):

[...] as indústrias de bens de capital são aquelas com respeito às quais, por motivos de tamanho de mercado, os países subdesenvolvidos apresentam maiores desvantagens relativas. Somando-se essas desvantagens relativas às facilidades de importação que prevalecem nas etapas em que aumenta a procura de bens de capital, tem-se um quadro do reduzido estímulo que existe para instalar as referidas indústrias nos países de economia subdesenvolvida. Ora, as condições que se criaram no Brasil nos anos trinta quebraram esse círculo. (Id., 1954a, p. 139).

O aumento da produção industrial teria se realizado primeiramente via ocupação da capacidade produtiva instalada, inclusive de indústria de bens de capital. Posteriormente, a própria acumulação permitida pelo aumento dos lucros teria sustentado a ampliação subsequente da capacidade produtiva, para a qual teria contribuído o desenvolvimento do setor produtor de bens de capital. Havia ainda a possibilidade de adquirir, a baixos preços, equipamentos usados no exterior. Segundo o autor, "Algumas das indústrias de maior vulto instaladas no país, na depressão, foram com equipamentos provenientes de fábricas que haviam fechado suas portas em países mais fundamente atingidos pela crise industrial." 198 (Ibid., p. 139). Já num segundo momento, teria se verificado um aumento na importação de bens de capital.

Desse modo, a manutenção da renda possibilitada pela política de defesa dos preços do café, combinada ao encarecimento relativo brusco das importações e à existência de capacidade ociosa nas indústrias que produziam para o mercado interno, seria a explicação para que a produção industrial tivesse ascendido tão rapidamente, tornando-se o principal fator dinâmico de determinação da renda. Entretanto, as grandes modificações na estrutura econômica trouxeram consigo desequilíbrios persistentes, dentre os quais Furtado destaca o de balança de pagamentos. Para fazer frente ao desequilíbrio externo, foi necessário que subissem os preços relativos dos bens importados, o que estimulou o desenvolvimento de indústrias substitutivas de importações.

\footnotetext{
${ }^{198}$ Esse trecho de Furtado remete à discussão iniciada no capítulo 2, subseção 2.2.3, a respeito das possíveis formas históricas de transferência de desordem das economias desenvolvidas às economias subdesenvolvidas. Uma delas era justamente a absorção, por parte da periferia, de máquinas obsoletas e sem utilização nos países centrais.
} 
O problema do desequilíbrio externo se recolocaria, então, quando se observasse a recuperação do setor exportador, incrementando a disponibilidade de divisas e a capacidade de importar. Nas palavras de Furtado, "Seria essa uma situação extremamente instável, a qual poria de manifesto que o crescimento relativo do setor dedicado ao mercado interno, tornava impraticável o funcionamento de um sistema cambial com taxa flutuante.” (Ibid., p. 144). Isso porque, por conta da concorrência entre produtores internos e importadores, as consequências de quaisquer alterações na taxa cambial passaram a ser bastante significativas. De acordo com o autor, essa mudança estratégica do papel da taxa de câmbio foi responsável, em grande medida, pelas modificações estruturais na matriz produtiva que continuaram a ocorrer. $\mathrm{E}$ as consequências dos desajustamentos relativos ao desequilíbrio externo se fizeram notar, especialmente, no pós II Guerra Mundial.

Em sua essência, a política adotada nos anos de guerra foi semelhante àquela adotada quando da deflagração da crise do início da década de 1930. Manteve-se o nível de renda por meio da criação de poder de compra (fixou-se a taxa cambial), mas sem que houvesse uma contrapartida na oferta de bens e serviços. Dessa forma, em um momento de diminuição da oferta de produtos importados, tal como no período de guerra, o efeito da fixação da taxa de câmbio foi incrementar a renda do setor exportador. Acresça-se a isso a compra de estoques de café. Porém, diferentemente do início da década de 1930, não havia capacidade produtiva interna ociosa. Como resultado, diz Furtado:

\footnotetext{
Se se tem em conta, ademais, a pressão resultante dos gastos de guerra e a baixa de produtividade provocada pelas dificuldades de toda a ordem criadas pela mesma guerra, compreende-se o extremo esforço a que foi submetido o sistema econômico e a estagnação em que esteve submerso nesse período. (Ibid., p. 154).
}

Assim como adiantado no início dessa subseção, o período que se inicia em 1930 caracteriza-se, segundo Furtado, pelo deslocamento do centro dinâmico da economia brasileira, que passa a ser interno. Não que esse deslocamento tenha sido resultado de uma política deliberada ou intencional do recém-instituído governo Vargas. A política de defesa dos preços do café foi uma reação à crise externa, que permitiu a manutenção do poder de compra e da renda internas. No entanto, como consequência intencionada ou não, fato é que a adversidade das condições externas acabou por desencadear um incremento do influxo de recursos para setores que produziam para o consumo interno, fomentando a industrialização, passando ela a responder por parte significativa do dinamismo da economia brasileira a partir de então, e de maneira cada vez mais crescente, conforme se foi avançando no grau de complexidade das indústrias instaladas. Nesse contexto, os fatores internos passaram a ser cruciais para compor o modelo Furtadiano. 
No entanto, vale destacar que, embora os fatores internos tenham passado a ser uma fonte analítica indispensável, isso não significa que Furtado tenha passado a negligenciar a importância dos fatores externos, principalmente aqueles que se referem às restrições que o país enfrentava por ser uma economia periférica e dependente. Esse padrão mantém-se na investigação dos períodos subsequentes, conforme apresentado nas próximas subseções.

\subsubsection{Do pós-guerra à década de 1950: consolidação da base industrial}

O período discutido por essa subseção engloba o fim do primeiro governo Vargas, o governo Dutra (1946-1951), o $2^{\circ}$ governo Vargas (1951-1954), o governo Café Filho (19541955) e o governo Juscelino Kubitscheck (1955-1961).

Sob a ótica de Furtado (1981), esse foi um período marcante para a industrialização. O autor afirma que:

Em 1949 a indústria brasileira havia de alguma forma ocupado todo o espaço que the proporcionava a capacidade de financiamento do sistema. O país era praticamente autônomo no que respeita a bens manufaturados não duráveis destinados ao consumo final. (Id., 1981, p. 30).

Por isso, para o autor, "Sem lugar à dúvida, os anos 50 são a fase decisiva da industrialização brasileira." (Ibid., p. 31), de modo que, em 1959, o setor metal-mecânico já era o mais importante em termos de volume de produção, respondendo por cerca de $27 \%$ da produção total, e a contribuição da indústria local à oferta de bens de capital havia aumentado de $36 \%$ para 66\% no decorrer da década de 1950 (Ibid., p. 32).

Vejamos a seguir, em mais detalhes, como se deu e quais os problemas que decorreram desse processo de consolidação da base industrial com fundamental participação do Estado, atraindo capital e técnica externos, concedendo incentivos e subsídios aos empresários industriais ${ }^{199}$ e por meio de atuação direta em setores não atrativos à iniciativa privada $^{200}$.

Importante ter em mente que, conforme ressalta Furtado (1989), a composição do comércio internacional sofreu uma transformação fundamental, qual seja, passou a ser

\footnotetext{
${ }^{199}$ Conforme destaca Furtado (1981), a atuação dos Grupos Executivos foi crucial, por meio do direcionamento de investimentos para a produção de bens intermediários, cuja demanda crescia rapidamente. Dentro os setores relacionados, destacam-se os de química, celulose e papel, metais não ferrosos e cimento. Segundo o autor, "O apoio financeiro do BNDE, as facilidades introduzidas pela Resolução 113 da SUMOC, os subsídios implícitos na política cambial e a disciplina da lei de similares foram os instrumentos que permitiram ampliar a base do sistema industrial." (Ibid., p. 81).

${ }^{200}$ Por exemplo, o setor siderúrgico, cujo primeiro complexo iniciara suas atividades em 1946. Outro investimento, embora não produtivo, de grande impacto no período foi a construção de Brasília, à qual Furtado atribui grande responsabilidade pelo estreitamento da capacidade de financiamento criada no início da década de 1950, provocando tensões inflacionárias (Ibid., p. 32).
} 
principalmente multilateral e dominado pelo intercâmbio de bens manufaturados, o que se refletiu, por sua vez, no incremento do comércio entre os próprios países industrializados. Aos países periféricos especializados na exportação de matérias-primas, lhes foram colocadas duas alternativas: aceitar uma condição cada vez mais subalterna na esfera internacional - e, por conseguinte, cada vez mais sujeita aos efeitos da deterioração a longo prazo dos termos de troca dos bens primários - ou promover transformações produtivas e estruturais. Como no pós-guerra, à exceção do petróleo, nenhum produto primário de exportação tivera sua demanda beneficiada, o autor conclui: "Excluída para o Brasil a possibilidade de desenvolvimento apoiado na exportação de produtos primários, o caminho da industrialização era menos uma opção do que um imperativo.” (Id., 1989, p. 28).

No contexto do imediato pós-guerra, Furtado (1954a) discute que, com a regularização das condições de oferta externa e em virtude do barateamento relativo dos bens importados, ${ }^{201}$ o coeficiente de importações aumentou de maneira abrupta. ${ }^{202}$ Ou seja, o nível relativo de preços que havia fundamentado o desenvolvimento industrial desde a crise do início da década de 1930 não mais se verificava.

Em virtude da intensificação da demanda por bens importados e do decorrente esgotamento das reservas que haviam sido acumuladas no período de guerra, para corrigir o potencial desequilíbrio externo, foi realizado um controle seletivo das importações, ${ }^{203}$ o qual teria sido crucial para o prosseguimento e intensificação do processo de industrialização. Embora, novamente, conforme sugere Furtado, essa não tenha sido uma política industrial intencional.

A combinação da política cambial com a política seletiva de importações teria resultado na concentração do aumento da renda nas mãos dos empresários industriais, bem como na ampliação das suas oportunidades de investimentos. Conforme Furtado (1989), como o mercado local era protegido, facilitava-se a consecução de investimentos de baixo risco e de alta rentabilidade esperada, baseando-se em tecnologia e mesmo em equipamentos já amortizados, processo esse altamente facilitado pela presença de grandes empresas

\footnotetext{
${ }^{201}$ Furtado (1954a, p. 163) explica que, entre 1939 e 1949, os preços internos e os de exportação caminharam mais ou menos paralelos, enquanto que os preços de importação cresceram com muito menor rapidez. A explicação para essa inversão relativa de preços residia, por sua vez, na própria elevação interna de preços.

${ }^{202}$ Segundo estimativas de Furtado (1954a, p. 166), o coeficiente de importações atingiu em 1947 praticamente o mesmo valor vigente em 1929.

${ }^{203}$ De acordo com Furtado (1981, p. 31), as restrições às importações ocorreram das seguintes maneiras: controle quantitativo até 1953, câmbio diferenciado com leilão de divisas até 1957 e, em seguida, considerável elevação das tarifas de importação.
} 
transnacionais com considerável aporte de recursos tecnológicos e financeiros. ${ }^{204}$

Além disso, o próprio processo inflacionário teria favorecido a apropriação pelos empresários industriais de uma parcela crescente do aumento de produtividade econômica decorrente da melhora na relação de preços de intercâmbio externo. Essa redistribuição involuntária se observou porque os benefícios da queda relativa do preço dos bens importados concentraram-se no setor que era o maior absorvedor de divisas, o setor industrial. Nas palavras de Furtado:

[...] a consequência prática da política cambial adotada com vista a combater a alta de preços, foi que se reduziram relativamente as importações de manufaturas acabadas de consumo, e se incrementaram as de bens de capital e de matérias-primas. $\mathrm{O}$ setor industrial era assim favorecido duplamente: por um lado, porque a possibilidade de concorrência externa se reduzia ao mínimo através do controle de importações; por outro, porque as matérias-primas e os equipamentos podiam ser adquiridos a preços relativamente baixos. (Id., 1954a, p. 168).

Uma importante fonte de pressão sobre os preços internos seria o próprio comportamento do setor exportador - naquele momento, ainda especialmente do café. Quando ocorria uma alta de preços de exportação, os fatores tendiam a deslocar-se do setor interno para o setor externo, reduzindo a oferta interna de produtos agrícolas, pressionando a subida de preços internos. E, dado o período de maturação da agricultura, muitas vezes o que se observava como resultado futuro era uma situação de superprodução. Como a essa altura já teriam subido suficientemente os preços internos, ao nivelarem-se esses aos preços de exportação, se iniciava um processo inverso, com transferência de recursos do setor externo para o setor primário interno, mas num momento de contração da renda dos consumidores. Desse modo, o setor primário da economia brasileira constituía-se num mecanismo de ampliação dos efeitos dos desequilíbrios provenientes do exterior.

Essas observações de Furtado evidenciam as dificuldades com que se deparava a economia brasileira para estabilizar o nível interno de preços e os riscos, ao desenvolvimento, que poderiam implicar, naquelas condições, as políticas de estabilização. $\mathrm{O}$ trade off entre crescimento e inflação é explicitado pelo autor:

Pretender alcançar essa estabilidade sem ter em conta a natureza e as dimensões do problema, pode ser totalmente contraproducente do ponto de vista do crescimento da economia. E numa economia de grandes potencialidades e de baixo grau de desenvolvimento, a última coisa a sacrificar deve ser o ritmo de seu crescimento. (Id., 1954a, p. 187).

Para Furtado, o desenvolvimento econômico não precisava apresentar como

\footnotetext{
${ }^{204}$ Há que se notar desde já que, segundo Furtado, a contrapartida das facilidades de acesso à tecnologia criadas pela presença de transnacionais atuando no mercado brasileiro teria sido uma certa dissociação do empresário local com relação à criação de tecnologia própria. Nas palavras do autor: "A forma como se deu no Brasil o ciclo de industrialização apoiada na formação do mercado interno restringiu a área de iniciativa empresarial no campo tecnológico. Prevaleceu a mentalidade de que a tecnologia é algo que está à venda no supermercado internacional [...]" (Id., 1989, p. 32).
} 
implicação necessária a redução da participação do comércio exterior. O que se notaria concomitantemente ao desenvolvimento econômico seria, sim, uma modificação do papel do comércio exterior. Numa primeira etapa, a indução externa desempenharia o papel de fator dinâmico principal para determinar o nível de demanda efetiva e, por conseguinte, de renda. Numa segunda etapa, aumentaria a importância estratégica do comércio exterior no processo de formação de capital: "A etapa intermediária de desenvolvimento caracteriza-se assim, por modificações substanciais na composição das importações e por uma maior dependência do processo de ampliação da capacidade produtiva com respeito ao comércio exterior." (Id., 1959, p. 234). Para o autor, a transformação estrutural mais importante seria a redução progressiva da importância relativa do setor externo no processo de capitalização.

Assunto recorrente de Furtado são as disparidades regionais em termos de desenvolvimento, especialmente no que se refere à região nordestina. ${ }^{205}$ Sobre o subdesenvolvimento nordestino, o autor afirma que "[...] o ecológico, o social e o político se entrelaçaram para produzir o duro cimento em que se alicerçou o subdesenvolvimento do Nordeste.” (Id., 1989, p. 23). Com essa consideração em mente, Furtado (1958) inicia sua discussão sobre as perspectivas de desenvolvimento futuro da economia brasileira a partir do seu grau de integração. Diz o autor sobre o panorama naquele momento, meados da década de 1950:

Para o observador que o considere de uma perspectiva bastante ampla, o Brasil surge como imenso contínuo territorial, dotado de unidade política e cultural, mas descontínuo e heterogêneo do ponto de vista econômico. Aproximadamente duas terças partes do território nacional constituem imenso vazio demográfico e econômico. (Id., 1958, p. 10).

Furtado explica que onde havia ocupação territorial significativa, era possível observar dois sistemas econômicos autônomos: o sistema nordestino, compreendendo da Bahia ao Ceará, e o sistema sulino, de Minas Gerais ao Rio Grande do Sul. Em relação ao sistema nordestino, o autor observa que, rigorosamente, a região não apresentava o grau de integração necessário para constituir um sistema econômico de fato, na medida em que o seu produto per capita era ainda muito baixo e, por isso, o alcance dos efeitos multiplicadores internos nesse

\footnotetext{
${ }^{205}$ Importante relembrar e ressaltar que o nordestino Celso Furtado não apenas discutiu o Nordeste brasileiro em teoria: militou ativamente em prol de políticas específicas para o desenvolvimento dessa região, tendo sido o idealizador e o Superintendente da SUDENE (Superintendência para o Desenvolvimento do Nordeste) desde sua concepção no final de 1959, até ser destituído pelo golpe militar de 1964 . O autor relata no fím de A Fantasia Organizada, referindo-se aos seus pensamentos ao final da década de 1950: "Inclinei-me a pensar que ter escrito um livro como Formação Econômica do Brasil, que poderia ajudar a nova geração a captar a realidade do país e identificar os verdadeiros problemas deste, representara o melhor emprego de meu tempo. Concluíra-o apontando para os dois desafios a serem enfrentados no futuro imediato: completar a industrialização e deter o processo de crescentes disparidades regionais. Como nordestino cabia-me prioritariamente dar uma contribuição na segunda dessas frentes de luta. Desta vez eu voltava para o Brasil com um projeto definido." (Id., 1989, p. 227).
} 
sistema era bastante fraco ${ }^{206}$ e descontínuo: "Uma economia com tal nível de renda pode ser descrita como uma série de "manchas" de atividade econômica sem muita articulação umas com as outras." (Ibid., p. 11). Para reverter essa situação de atrofia do sistema nordestino fazia-se necessária, então, a atuação de fatores externos - por exemplo, intervenção governamental, por meio de introdução de novas culturas de exportação ou injeção de capital para criar nova atividade manufatureira -, permitindo incrementos de produtividade e a geração de excedentes comercializáveis. Sobre esse mesmo assunto, Furtado (1959) apresenta uma observação importante, relacionada à atrofia da região nordestina, a qual, ao representar e refletir os resquícios do Brasil-colônia, seria simbólica do caráter desigual - e de limitado alcance - do processo de desenvolvimento vivenciado pelo Brasil. Nas palavras do autor:

[...] é um fenômeno secular, muito anterior ao processo de industrialização do sul do Brasil. A causa básica daquela decadência está na incapacidade do sistema para superar as formas de produção e utilização dos recursos estruturados na época colonial. (Id., 1959, p. 241).

Com respeito ao sistema econômico sulino, Furtado (1958) argumenta que constituía um sistema relativamente integrado, com a permanência de faixas de atividade econômica não vinculadas ao mercado - especialmente, atividades de subsistência -, tendo a economia monetária penetrado de maneira desigual em seu território. No entanto, mesmo onde se observava certa descontinuidade, já se seriam notadas interligações e interdependências dinamicamente importantes, com algumas regiões, inclusive, apresentando relativa homogeneidade. O dinamismo do sistema sulino se devia a duas fontes: o setor ligado ao mercado internacional - especialmente, exportação de café, caracterizada por alta produtividade - e o setor industrial. Dessa combinação resultou que, no sistema econômico sulino, "O impulso de crescimento vindo de fora, ao invés de filtrar-se para o exterior - como ocorreria numa economia de menor grau de integração como é o caso da economia do Nordeste - encontrou nas atividades industriais meios de expandir-se.” (Id., 1958, p. 13). Na medida em que o sistema industrial alcançasse certo grau de autonomia - em relação, principalmente, ao abastecimento dos bens de capital de que necessitava -, o seu papel dinâmico no sistema econômico adquiriria maior alcance e complexidade, constituindo-se em força propulsora fundamental de crescimento e desenvolvimento.

Entretanto, em meados da década de 1950, na etapa de desenvolvimento em que estava a economia sulina, ainda tendia-se a agravar os desequilíbrios externos e internos, em especial em virtude do não investimento suficiente em setores industriais mais complexos. Como resultado, gerava-se capacidade ociosa em alguns setores e excesso de demanda de

\footnotetext{
${ }^{206}$ À semelhança dos efeitos propulsores fracos destacados por Myrdal (1957). Vide seção 3.6 do capítulo 3.
} 
bens importados em outros setores. Seria justamente nessa criação de uma série de desequilíbrios, decorrentes do processo de crescimento, que se refletia a incapacidade da economia brasileira em manter uma taxa adequada e sustentável de crescimento, pois “A defeituosa orientação dos investimentos, característica da etapa de desenvolvimento em que se encontra o Brasil, provoca permanente desgaste de recursos.” (Id.,1958, p. 17).

Em grande medida, para Furtado, a própria forma de desenvolvimento da economia brasileira teria agravado as suas disparidades regionais, presentes desde a fase colonial. Furtado (1962) sintetiza o que seriam as relações de causalidade entre o sistema econômico sulino e o sistema econômico nordestino como segue:

[...] a economia do Nordeste tende a comportar-se, vis-à-vis da do Centro-Sul, de forma similar ao setor artesanal de uma economia em processo de industrialização, em face de novas manufaturas. Não podendo concorrer, traumatiza-se ou desagrega-se. Emigram os capitais, e, não ocorrendo o mesmo à mão-de-obra, desagrega-se o sistema econômico por partes, amontoando-se o sobrante de população nas cidades ou estendendo-se o setor de subsistência na agricultura. (Id., 1962, p. 50).

Considerando que os problemas de disparidade regional não se resolveriam espontaneamente, derivava-se a necessidade, naquele momento, de que qualquer programação de desenvolvimento levasse em consideração o fato de que a economia brasileira não constituía um sistema integrado, e tampouco homogêneo. Uma sugestão apresentada por Furtado (1958, p. 54-55) seria a promoção de uma política nacional de colonização, tendo especialmente como objetivo o incremento da oferta de alimentos ${ }^{207}$ e como foco principal a região Nordeste, da qual seria deslocada a população excedente para povoar e desenvolver outras regiões. Também sobre o problema do Nordeste, Furtado (1962, p. 59) enfatiza que, nessa região, o esforço de capitalização deveria realizar-se em conjunto com a adaptação ao meio, exigindo inclusive a criação de uma tecnologia própria.

Além das disparidades regionais, Furtado destaca a disparidade em outro nível, qual seja, o de classes. No início da década de 1960, o autor afirmou de maneira categórica a não observação de melhoras significativas no padrão de vida da maior parte da população, mesmo tendo o país atravessado por mudanças e crescimento significativos. Em suas palavras:

Sabemos que o desenvolvimento de que tanto nos orgulhamos, ocorrido nos últimos decênios, em nada modificou as condições de vida de três-quartas partes da população do país. Sua característica principal tem sido uma crescente concentração social e geográfica da renda. As grandes massas que trabalham nos campos, e constituem a maioria da população, praticamente nenhum benefício auferiram desse desenvolvimento. (Id., 1962, p. 14).

Para Furtado, outro aspecto negativo decorrente do modelo de desenvolvimento brasileiro até aquele momento fora a concentração de recursos nas mãos de grupos

\footnotetext{
207 Para a discussão da relevância dessa medida, vide Kalecki (1960), conforme discutido na seção 3.7 do capítulo 3 .
} 
privilegiados, especialmente por conta da estrutura de subsídios - cambiais e creditícios -, montada pelo Estado, que acabou por premiar preferencialmente investimentos em setores produtores de bens supérfluos.

Além dessa tendência ao sobre-investimento em alguns setores em detrimento de outros, e seus efeitos perniciosos à sustentabilidade da taxa de crescimento, Furtado destaca os efeitos também prejudiciais ao crescimento da inelasticidade da oferta de alimentos, assunto bastante enfatizado pelo pioneiro Kalecki (1960). A inexistência de uma agricultura moderna ligada ao mercado interno seria, então, uma das principais responsáveis pela tendência da economia brasileira a apresentar desequilíbrio interno, especialmente na forma de inflação. Essa tendência estaria posta já que uma decorrência esperada do crescimento da economia seria justamente um aumento da demanda por alimentos, pois a mão-de-obra que se deslocava do setor agrícola para o setor industrial e de serviços o fazia não em virtude de um incremento de produtividade na produção agrícola, mas sim em busca de melhores salários, os quais lhes proporcionariam um maior poder de compra. Assim sendo, mantido o gargalo na oferta de alimentos, "Quanto maior for o impulso de crescimento criado pela procura externa e pelo setor industrial, maior será a tendência ao desequilíbrio.” (Id., 1958, p. 19).

De acordo com Furtado, em nenhuma parte como no setor agrário, as tensões estruturais ocasionadas pelo rápido crescimento industrial foram tão significativas, em virtude do grande incremento por demanda de produtos agrícolas e da inelasticidade da oferta. Sob as condições estruturais vigentes, a pressão de demanda, ao encarecer os produtos agrícolas, ao invés de estimular o aumento da oferta, acabava se traduzindo em crescimento da renda da terra, dificultando ainda mais a reorganização da estrutura agrária em prol da satisfação da demanda crescente de alimentos. ${ }^{208}$ A política de desenvolvimento requerida por um país subdesenvolvido deveria possuir, portanto, um caráter essencialmente qualitativo - e revolucionário, no sentido Schumpeteriano -, e por isso “[...] exige um conhecimento da dinâmica das estruturas que escapa à análise econômica convencional.” (Id., 1962, p. 38). As reformas de base deveriam, então, ser compreendidas como uma via tentativa de eliminar os fatores estruturais que estariam dificultando a adaptação dos diversos setores da economia brasileira à dinâmica engendrada pelo seu rápido crescimento industrial.

Como diretriz de ação, Furtado aponta para a crucialidade de tornar as estruturas do

\footnotetext{
${ }^{208}$ Partindo da hipótese de oferta ilimitada de mão-de-obra não qualificada e da condição de dualidade estrutural, Lewis $(1954,1955)$ discutira os efeitos em termos de distribuição funcional da renda, entre salários, lucros e renda da terra. Conforme argumentara o autor, tendo em vista o desenvolvimento, era necessário incrementar a parcela de lucros, mas não em detrimento da parcela de salários, e sim da parcela de renda da terra. Para mais detalhes, vide seção 3.4, capítulo 3 .
} 
país mais elásticas, por meio da realização de diversas reformas, tais como a agrária, a administrativa, a fiscal e a bancária. ${ }^{209}$ Sobre essa questão, Furtado realiza uma importante observação sobre o papel do Estado brasileiro, que teria se modificado substancialmente, mas sem que tivesse sua estrutura igualmente se modificado para se adaptar adequadamente a essas alterações de papel. Em suas palavras:

[...] o Estado brasileiro teve suas funções substancialmente ampliadas, nos últimos decênios, como principal instrumento do desenvolvimento econômico nacional. Teria sido necessário não uma, mas várias reformas visando a capacitar o poder público para o desempenho de suas novas e complexas funções. Mais importante dentre todas essas reformas teria de ser aquela que proporcionasse ao Estado a capacidade fiscal para arrecadar os recursos necessários à cobertura financeira dos seus gastos ampliados. Nada de concreto, entretanto, foi realizado nessa direção [...] A consequência prática, conhecemo-la todos: são os déficits do setor público e o seu financiamento com simples emissões de papel-moeda. (Ibid., p. 42-43).

Vale destacar, ademais, que as consequências perniciosas da inflação acabariam recaindo especialmente sobre a parcela da população que já menos de beneficiava do processo de desenvolvimento.

A política de industrialização orientada para substituir importações teria criado a necessidade de intensificar o próprio processo substitutivo, na medida em que as indústrias instaladas eram cada vez mais densamente capitalizadas, implicando uma pressão permanente e crescente sobre a capacidade de importação. Como resultado, conforme palavras do autor, "Essa pressão permanente sobre o setor externo criou sérias dificuldades à consecução da estabilidade na economia brasileira, cuja tendência à elevação do nível de preços e ao endividamento externo é amplamente conhecida." (Id., 1964, p. 99-100).

Furtado explica a interação de retroalimentação observada entre os processos de acumulação de capital e o inflacionário. Até então, a industrialização havia se apoiado em dois pilares: a substituição de importações e a transferência de renda, provocada pela inflação, em favor do setor industrial, possibilitando-lhe uma grande acumulação de recursos, a qual também se reforçava pela transferência espontânea de recursos provenientes do setor exportador. Sobre o papel distribuidor de renda da inflação, diz o autor:

\begin{abstract}
A inflação não foi o fator primário do desenvolvimento, mas operou como agente de afrouxamento das estruturas e transferiu recursos, em fase de crescimento do produto, em favor dos setores mais dinâmicos, tributando os consumidores e provocando uma maior intensificação dos investimentos. Cabe, entretanto, reconhecer que as possibilidades dinâmicas da substituição de importações já se esgotaram. (Ibid., p. 119).
\end{abstract}

Furtado se refere ao período iniciado em 1930 como um processo de desenvolvimento sem uma política específica de desenvolvimento. A industrialização dos anos 1930 teria sido uma consequência indireta da política de defesa dos preços do café; e, no imediato pós II

\footnotetext{
${ }^{209}$ Vale notar que essas reformas serão contempladas pelo Plano Trienal elaborado pelo próprio Celso Furtado.
} 
Guerra Mundial, a política cambial adotada visava combater o viés industrialista dos anos de guerra, resultando no rápido esgotamento das reservas então acumuladas e na necessidade de reverter novamente essa política cambial, por meio do controle do câmbio, o que, indiretamente teria beneficiado o setor industrial; porém, acabou incrementando os investimentos especulativos em indústrias menos essenciais e estratégicas do ponto de vista do desenvolvimento.

Reafirmando o seu argumento de que a industrialização não era intencionada, o autor diz que "Observando, retrospectivamente, os últimos três decênios, chega-se à conclusão de que o nosso desenvolvimento resultou muito mais de uma imposição histórica do que da tomada de consciência da realidade nacional pelos homens que dirigiam o país.” (Id., 1962, p. 65). ${ }^{210}$ Prova dessa ausência de intencionalidade no processo de desenvolvimento no período referido seriam os próprios desequilíbrios gerados e perpetuados, tal como discutido anteriormente, porque, de outro modo, hipoteticamente, se tivessem sido elaborados planos de desenvolvimento industrial, teriam sido tomadas medidas para fazer frente ou a fim de tentar eliminar esses desequilíbrios.

Nesse contexto, Furtado ressalta novamente o papel crucial do Estado que, da organização quase que exclusivamente destinada à prestação de serviços passara, nos últimos decênios, a assumir a responsabilidade de transformar a estrutura econômica, embora não estivesse preparado para desempenhar esse papel. Nas palavras do autor:

O Estado não está devidamente aparelhado para exercer nenhuma das funções básicas de uma política de desenvolvimento econômico. As políticas monetária, fiscal, de exportação e importação, cambial, de fomento industrial, de assistência técnica à agricultura, dependem todas, entre nós, de medidas mais ou menos improvisadas e quase sempre tomadas de forma desconexa. (Ibid., p. 78).

Particularmente nas regiões mais pobres do país, estratégias e políticas baseadas no laissez-faire implicavam, como bem destaca Furtado, a própria perpetuação da miséria. Por isso, "Para romper esse círculo vicioso, é mister modificar fundamentalmente a orientação dos investimentos, o que exige ação decidida do setor público.” (Ibid., p. 88). Em um primeiro estágio, os investimentos deveriam se concentrar na formação de infraestrutura, ${ }^{211}$ área de

\footnotetext{
${ }^{210}$ Furtado (1962) afirma que a partir de 1953 começaram a ser estruturadas as linhas de uma política de desenvolvimento. Cita como exemplos o Banco Nacional de Desenvolvimento Econômico (BNDE) e o Conselho de Desenvolvimento Econômico. Nesse sentido, sugere que "Apreciando em conjunto o período que se inicia em 1953, comprova-se que está praticamente superada aquela etapa intermediária, iniciada em 1930, e que se caracterizou pela busca de novos caminhos." (Ibid., p. 68).

${ }^{211}$ Não que o governo brasileiro não tivesse realizado nenhum investimento em infraestrutura importante até então. Furtado (1962, p. 112) destaca que alguns setores básicos estrategicamente importantes, tais como a siderurgia e a indústria petrolífera, haviam sido formados, estavam sob a administração e o controle estatais e desempenharam papel fundamental, enquanto condicionantes, na trajetória de desenvolvimento da matriz industrial brasileira.
} 
investimento que, como bem advertiram os diversos pioneiros discutidos nos capítulos 3 e 4 , dificilmente seria contemplada pela iniciativa privada, mesmo porque a ineficiência dos serviços básicos implicava deseconomias externas ao setor privado. Em fase subsequente, seriam criados os estímulos para que o investimento privado pudesse reorientar-se, modificando deliberadamente, portanto, a estrutura de investimentos, algo que dificilmente seria observado como resultado espontâneo.

Da análise de Furtado sobre o período do pós-guerra e da década de 1950, vale destacar, especialmente, a sua insistência na relativa falta de clareza de objetivos por parte do Estado brasileiro, padrão que teria sido observado desde a década de 1930, no governo Vargas. Mesmo na fase do governo Juscelino Kubitscheck, apesar de ser possível inferir uma intenção pró-industrialização, a impressão é que, mesmo nesse caso, as políticas foram sendo adotadas sem grande programação ou planejamento, em seu sentido mais amplo, na medida em que o próprio Estado não se estruturara adequadamente para tal.

Essa observação é importante na medida em que, conforme aventado na última seção do capítulo 2, no contexto do subdesenvolvimento, caberia ao Estado, por meio especialmente de suas políticas públicas, o papel de direcionador das forças que permitiriam às nações escapar aos círculos viciosos que compõem a armadilha do subdesenvolvimento. No caso brasileiro, embora o Estado tenha se mostrado cada vez mais atuante, as suas estruturas e ferramentas não teriam se transformado adequadamente. Como resultado, observaram-se diversos níveis de desequilíbrios que acabavam por atenuar, e até esterilizar, os efeitos positivos decorrentes do desenvolvimento da matriz produtiva.

Nas duas subseções subsequentes, a ênfase de Furtado sobre a crucialidade do papel do Estado e da inadequação dos meios continua presente, bem como a identificação da permanência de desequilíbrios e disparidades.

\subsubsection{Década de 1960: crise, golpe, reestruturação e milagre}

Essa subseção se contextualiza no final do governo de Juscelino Kubitscheck (19561961), no breve governo Jânio Quadros (janeiro a agosto de 1961), no governo de João Goulart (setembro de 1961 a abril de 1964) e na instauração da ditadura militar, com os governos Castello Branco (1964-1967) e Costa e Silva (1967-1969). ${ }^{212}$

Diante do quadro de crise e esgotamento do dinamismo do modelo de substituição de

\footnotetext{
212 O governo Médici se inicia em outubro de 1969, por isso refere-se mais à próxima subseção, onde sua discussão encontra-se contemplada.
} 
importações, naquele momento, início da década de 1960, Furtado se questiona: "Abriremos uma nova fase de transformações qualitativas em nossa formação de nação continental, ou caminharemos para uma cristalização da estrutura já estabelecida?” (Id., 1962, p. 107). Sobre as opções que se colocavam nos anos 60, Furtado (1981) afirma que:

\begin{abstract}
A perspectiva que nos proporciona a distância no tempo permite-nos descortinar o horizonte de opções que se apresentavam no começo dos anos 60 [...] Se o objetivo era preparar o sistema econômico para alcançar níveis mais altos de desenvolvimento, fazia-se necessário reforçar sua capacidade de autotransformação, mas também definir melhor os objetivos a lograr. (Id., 1981, p. 37).
\end{abstract}

Para alcançar essa capacidade de autotransformação, segundo Furtado, era preciso: dotar o setor produtor de bens de capital de maior autonomia tecnológica, significando “[...] estar capacitado para dar solução aos próprios problemas, em contraste com o simples esforço de adaptar a sociedade a modelos importados." (Id., 1981, p. 38); e orientar o sistema industrial para os mercados externos, permitindo uma diversificação da própria pauta exportadora. Uma maior capacidade de autotransformação era, entretanto, condição necessária, mas não suficiente para que a economia prosseguisse no seu processo de desenvolvimento de maneira sustentável. Era fundamental incrementar a capacidade de financiamento para viabilizar os investimentos necessários para alcançar a almejada capacidade de autotransformação. De acordo com o autor, "Aumentar o esforço de poupança e canalizar os investimentos em função de prioridades claramente definidas era o desafio que se colocava ao Brasil no começo dos anos 60 [...]” (Ibid., p. 39). No entanto, os caminhos trilhados e as decisões tomadas não teriam sido esses indicados pelo autor. Vejamos, a seguir, alguns fatos que compuseram a trajetória econômica brasileira na década de 1960.

Conforme relata Furtado (1989), no fim de setembro de 1962, ele recebeu de João Goulart o convite para assumir o Ministério Extraordinário do Planejamento, por indicação do então Ministro das Relações Exteriores, e posteriormente Ministro da Fazenda, San Tiago Dantas. A Celso Furtado caberia a responsabilidade pela elaboração de um plano de governo. Furtado aceitou o convite, com a condição de que conservasse a SUDENE sob seu controle. Citando suas próprias palavras, relembra o autor que, assim quando tomou posse, buscou ressaltar em seu discurso a importância de promover modificações estruturais. Diz o autor:

[...] chamava a atenção para a especificidade de nosso caso, onde o crescimento exige modificações estruturais. "Para evitar as tensões inflacionárias - disse - é necessário que tais modificações sejam antecipadas." Somente assim conseguiremos reduzir o custo social de nosso crescimento. Assinalava, por último, as dificuldades a serem enfrentadas numa primeira fase, posto que "medidas de curto prazo se impõem". Assim, pretendi deixar claro que dispositivos visando ao ajustamento da economia seriam integrados ao planejamento. Destarte, o plano deveria abrir caminho a reformas estruturais e, ao mesmo tempo, comportar ajustamentos de curto prazo. (Id., 1989, p. 154). 
Essas eram as diretrizes explícitas no Plano Trienal, cuja primeira redação ficara pronta em meados de dezembro de 1962 e fora apresentada ao Conselho de Ministros. A essência do Plano, segundo o próprio Furtado, era promover medidas de ajustamento com o intuito de corrigir os desequilíbrios internos e externos, embutidas numa política que assegurasse o crescimento da economia e, ao mesmo tempo, estimulasse as transformações estruturais necessárias para diminuir o custo social desse crescimento. Para o autor, "Sem lugar a dúvida, a confiança que o Plano despertou contribuiu amplamente para a esmagadora vitória obtida pelo presidencialismo no plebiscito realizado nos primeiros dias de 1963." (Ibid., p. 162), pois a tarefa, apesar de ser complexa, mostrava-se exaltante, e o próprio texto estaria marcado por um tom marcadamente otimista.

O Plano Trienal foi apresentado pelo presidente Jango em seu discurso de ano novo. Segundo Furtado, “[...] pela primeira vez entre nós, um Plano de Governo continha um conjunto de diretrizes das reformas de base mais urgentes - a administrativa, a bancária, a fiscal e a agrária [...]" (Ibid., p. 162). Assim como explicitado no próprio documento "Plano Trienal de Desenvolvimento Econômico e Social 1963-1965”, as reformas administrativa e bancária diziam respeito à racionalização da ação governamental, e as reformas fiscal e agrária se referiam à eliminação de entraves institucionais à utilização ótima de fatores. ${ }^{213}$

Com a posse de Jango, Furtado permaneceu como Ministro do Planejamento, porém por apenas mais alguns meses, sendo desempossado em julho de 1963. Um pouco antes, o autor relatara:

A começos de maio de 1963, o ministro das Relações Exteriores, Hermes Lima, solicitou-me que presidisse a delegação brasileira ao X Período de Sessões da CEPAL, a realizar-se em Mar del Plata, Argentina. A luta em que nos havíamos empenhado, no quadro do Plano Trienal, para manter sob controle a situação econômica estava praticamente perdida. ${ }^{214}$ (Ibid., 1989, p. 166).

Em um livro escrito às vésperas do golpe militar de $1964,{ }^{215}$ Furtado (1964) buscara realizar um diagnóstico da crise pela qual passava a economia brasileira. Sinteticamente, indicava que, naquele momento, o desenvolvimento industrial alcançado pelo Brasil lhe

\footnotetext{
${ }^{213}$ Essa descrição encontra-se em livro organizado por Rosa Freire d'Aguiar Furtado, 2011, p. 424. A discussão do Plano Trienal é retomada, em mais detalhes, no capítulo seguinte.

${ }^{214}$ Também por mais pouco tempo estaria Furtado à frente da SUDENE. Com o golpe militar, fora não apenas afastado da instituição a que dedicara muitos anos de trabalho, mas também convidado a se retirar do país. Furtado relata ao final de A Fantasia Desfeita: "Em poucos minutos, meu avião decolava rumo ao Pacífico. Sentira certa angústia ao cortar o último vínculo com o mundo que por tanto tempo dera sentido à minha vida. Dedicara anos a organizar minha fantasia, na esperança de um dia transformá-la em instrumento de ação a serviço do meu pobre e desvalido Nordeste. Agora, essa fantasia estava desfeita, desmoronara como uma estrela que se estilhaça." (Id., 1989, p. 201).

${ }^{215}$ A introdução do livro referido, A Dialética do Desenvolvimento Econômico, fora escrita em janeiro de 1964, tendo a primeira edição sido lançada em junho de 1964, cerca de dois meses após o golpe que instaurou a ditadura militar no país.
} 
permitia o abastecimento de bens de consumo quase que totalmente via produção interna, e que os investimentos podiam ser efetivados apoiando-se principalmente na oferta interna de equipamentos, mesmo as importações de bens de capital ainda desempenhando papel fundamental de transmissão de progresso tecnológico. No entanto, conforme discutido acima, a capacidade de autotransformação ainda não havia sido conquistada.

O esgotamento do processo substitutivo de importações ocorrera, segundo Furtado, porque as substituições a serem realizadas requeriam investimentos altamente capitalizados e, em geral, com período de maturação de longo prazo. Nesse contexto, a capacidade para importar passara a ser um grande entrave ao desenvolvimento. E, em virtude da deterioração dos termos de troca a partir de 1955, as dificuldades se tornaram ainda mais graves. A tentativa de resolução de tais dificuldades se voltou à recorrência ao endividamento externo, cujos efeitos a médio prazo foram uma contração ainda maior da capacidade para importar, por conta do serviço da dívida, que crescia cada vez mais.

Desse modo, na tentativa de solucionar o problema da redução da capacidade de importação, via recorrência ao endividamento externo, o resultado foi a criação de mais um processo cumulativo pernicioso ao desenvolvimento, “[...] um processo cumulativo circular pelo qual as medidas tomadas para contornar a barreira da capacidade para importar tenderam a elevar essa barreira." (Id.,1964, p. 119). Nesse quadro de deterioração dos termos de troca, a inflação perdera a sua função de distribuidora de renda em favor dos setores mais dinâmicos da economia, tornando-se prejudicial inclusive àquele setor que anteriormente se beneficiara dela.

O mais importante a reter desse processo de esgotamento do modelo de desenvolvimento baseado na substituição de importações, naquele momento, era que ocorrera antes que a economia brasileira tivesse alcançado um grau de desenvolvimento de sua matriz industrial que lhe permitisse autonomia frente ao setor externo. Segundo Furtado:

\footnotetext{
Existe ampla evidência de que a industrialização levou o Brasil muito perto daquela posição em que o desenvolvimento é um processo circular cumulativo que cria os próprios meios de que necessita para seguir adiante. No caso do Brasil, esse ponto seria alcançado quando fosse superada a barreira da capacidade para importar. (Ibid., p. 120).
}

Porém, como o próprio prosseguimento no desenvolvimento industrial dependia da capacidade para importar, as chances de romper esse círculo vicioso foram se tornando ainda menores quando o comando sobre a utilização da capacidade para importar disponível fora diminuído, por exemplo, por meio do processo de desnacionalização pelo qual passara a 
economia brasileira, em virtude de concessões a grupos externos. ${ }^{216}$ De acordo com Furtado, "Criou-se, assim, uma contradição entre os interesses mais amplos do desenvolvimento nacional e os interesses particulares das milhares de empresas controladas por grupos estrangeiros que operam com custos em divisas de tipo mais ou menos irremovível." (Ibid., p. 133). Para a composição desse quadro, segundo Furtado (1981), teriam contribuído as modificações institucionais realizadas entre 1964 e 1967, ${ }^{217}$ cujas principais beneficiárias teriam sido as empresas transnacionais.

Furtado $(1969)^{218}$ prossegue no intuito de identificar as causas da paralisia da economia brasileira na década de 1960, apresentando como conclusão que "[...] as causas últimas são complexas e estão enraizadas na estrutura do sistema econômico de nosso país." (Id., 1969, p. 13). Uma das causas básicas, de acordo com Furtado, se referiria à existência no sistema econômico brasileiro de uma deformação estrutural, a qual se refletiria no perfil da demanda global e se traduziria, no plano social, sob a forma de uma grande concentração dos benefícios do desenvolvimento. Essa deformação estrutural seria a responsável tanto pela penetração lenta do progresso tecnológico, quanto pela difusão escassa dos frutos de aumento de produtividade por toda a economia, impedindo que a economia brasileira - mesmo sendo dotada de recursos naturais em abundância, de uma grande população e de um relativo grau de desenvolvimento - se beneficiasse satisfatoriamente das benesses do progresso tecnológico, o que lhe permitiria, em tese, avançar no seu processo de desenvolvimento.

Importante assinalar ademais que, conforme bem destaca Furtado, o desenvolvimento de uma economia dependente, sendo reflexo do progresso tecnológico das nações centrais, apresenta como elemento dinâmico fundamental não a irradiação do progresso tecnológico em si, mas a diversificação das formas de consumo. Dessa observação, o autor deduz uma relação de retroalimentação entre a tecnologia e a concentração da renda. Em suas palavras, “[...] existe um processo causal circular entre a forma como se assimila a tecnologia moderna e a concentração de renda, o que exige, se se pretende romper o círculo vicioso, que se concentre a pressão sobre um dos elos da cadeia." (Ibid., p. 15).

\footnotetext{
${ }^{216}$ Importante ponderar, entretanto, que, segundo Furtado (1967), a experiência brasileira seria um caso especial, na medida em que se apresentam: o controle por grupos nacionais da produção exportável, a abundância de recursos naturais e as dimensões relativamente grandes do mercado interno em formação. Por isso, "Trata-se, portanto, de um tipo de estrutura econômica subdesenvolvida bem mais complexo que o da simples coexistência de empresas estrangeiras com remanescentes de um sistema pré-capitalista. Nas estruturas subdesenvolvidas de grau inferior, a massa de salários gerada no setor exportador constitui o único fator capaz de induzir modificações estruturais." (Id., 1967, p. 193).

${ }^{217}$ As reformas institucionais desse período são discutidas em mais detalhes no capítulo 6.

${ }^{218}$ Uma parte significativa das discussões presentes em Furtado (1969) são retomadas em Furtado (1973). No entanto, com base em critério cronológico, as referências serão realizadas reportando-se a Furtado (1969).
} 
Outra causa de paralisia apontada por Furtado diz respeito à estrutura agrária, a qual implicaria efeitos, semelhantes aos discutidos acima, ao perfil da demanda que se estabelecera no mercado brasileiro, na medida em que era mais uma fonte importante de concentração de riqueza e de barreira aos incrementos de produtividade e da disseminação de suas benesses por toda a economia nacional. Na agricultura brasileira haveria um grande desperdício de mão-de-obra e uma baixa eficiência no uso do capital, deformação a que o autor atribui a dois motivos: à extrema miséria e insuficiência alimentar da população rural, e à concentração de terras, na forma de latifúndios. A elevação do nível de vida da população rural teria, para o autor, ao menos dois efeitos dinâmicos: o próprio incremento de produtividade, em virtude das melhores condições de vida, aumentaria a oferta agrícola; e o aumento do poder de compra da população rural significaria mais demanda por bens industriais.

Outra deformação estrutural e fonte de paralisia destacada por Furtado se relaciona às grandes empresas, que estariam exercendo funções de direito público sob a cobertura de entidade privada. Por meio especialmente da política de preços administrados, os benefícios dos incrementos de produtividade acabavam sendo retidos especialmente na forma de lucros, ao invés de serem repassados na forma de redução de preços ao consumidor. Essa situação só era possível, vale observar, no contexto de substituição de importações e de limitada capacidade de importar, ou seja, já havia demanda garantida para os bens substituídos. Acresça-se a isso a existência de um grande excedente estrutural de mão-de-obra, mantendo os salários em níveis relativamente baixos, e pouco sensíveis aos incrementos de produtividade.

A referida deformação estrutural adquiria maior gravidade quando essas empresas eram estrangeiras, na medida em que, por meio do mecanismo de autofinanciamento mobilização de reservas de amortização e de uma fração constante dos lucros -, elas estariam em condições de se apropriar, de maneira crescente, da riqueza que se criava no país. Além disso, os setores em que seria mais rápido o progresso tecnológico estavam sob o controle justamente de grandes empresas estrangeiras. Sobre o assunto, diz o autor:

$\mathrm{O}$ grande poder financeiro dessas filiais, assim como o fato de que as mesmas estão integradas em complexos sistemas multinacionais, criaram rigidezas (sic) à economia do país, a ponto de que seu comportamento nem sempre possa assimilar-se ao de um sistema, ou seja, um conjunto articulado e coerente. (Ibid., p. 30).

Segundo Furtado, o mais importante a reter a respeito da observação referente às grandes empresas estrangeiras concerne ao poder de interferência na distribuição da renda que elas possuíam, na medida em que dominavam determinado setor produtivo da economia e atuavam especialmente nos setores que concentravam as inovações tecnológicas. E por meio 
dessas inovações, possuiriam poder para condicionar o comportamento das massas consumidoras. $^{219}$

Em síntese, de acordo com Furtado, o progresso tecnológico vinha sendo no Brasil uma consequência do desenvolvimento e não o seu motor. Ademais, a assimilação da tecnologia acabou resultando na própria alienação da capacidade de decisão interna da economia brasileira. Para o autor, a única maneira de conter essa tendência seria o desenvolvimento de pesquisa científico-tecnológica própria, o que por sua vez exigiria maiores atenção e investimento em educação e qualificação de mão-de-obra.

$\mathrm{Na}$ medida em que avançou o processo de substituição de importações, passando de indústrias mais simples para indústrias mais complexas, incrementou-se a relação capitaltrabalho o que, face ao excedente estrutural de mão-de-obra, resultou na pressão pela acentuação da concentração da renda. Se a concentração de renda fora funcional quando da substituição de bens menos complexos, quando se passou à substituição de bens mais elaborados, a concentração teria atingido tal ponto que teria implicado a contenção do próprio processo de desenvolvimento. Esse problema estrutural tendeu a se agravar especialmente com a rápida aceleração do progresso tecnológico observada no pós II Guerra Mundial, orientado no sentido da economia de mão-de-obra, fator relativamente escasso nos países desenvolvidos, mas excedente nos países subdesenvolvidos, como o Brasil. Furtado explica a dinâmica dessa questão como segue:

Em síntese: o fluxo de renda que surge do polo dinâmico traduz-se em um certo perfil de demanda,
o qual tem um maior ou menor poder germinativo de desenvolvimento. Ainda que pareça
paradoxal, a substituição de importações, nas condições em que ocorreu entre nós, ao passar das
indústrias leves para as pesadas, foi perdendo impulso multiplicador. Somente assim se explica
que o sistema industrial de nosso país, não obstante haja alcançado elevado grau de integração,
não tenha criado condições para um desenvolvimento auto-sustentado. (Ibid., p. 34).

Desse modo, Furtado conclui que, no contexto de subdesenvolvimento da economia brasileira, quanto mais se concentrava a renda, mais se imprimia a tendência à diversificação das formas de consumo de grupos privilegiados, restringindo as possibilidades de realização da industrialização a campos cada vez mais estreitos. O resultado se refletia na inadequação da evolução do perfil da demanda no sentido do aproveitamento das economias de escala de produção, exigindo cada vez mais capital (recurso escasso) e cada vez menos mão-de-obra (recurso excedente). Por isso a assimilação apenas superficial do progresso tecnológico e a reduzida dispersão de seus benefícios por toda a sociedade. Porém, importante destacar que os

219 Ressaltem-se, novamente, as implicações do efeito demonstração destacado por Nurkse (1952) que concorrem para a definição de determinados padrões de consumo. Para mais detalhes, vide seção 3.3 do capítulo 3. 
problemas refletidos no perfil de demanda emergente não seriam consequência direta do progresso tecnológico, mas sim do sistema de decisões, relacionado ao quadro institucional, à orientação das políticas cambial, de crédito, de preços e de salários. Assim, conclui o autor: “A solução do problema não está, portanto, em frear a penetração do progresso tecnológico, e sim em modificar o sistema de decisões, de forma a que ele não tenha as consequências negativas que hoje se manifestam.” (Ibid., p. 45). Dito de outro modo, não haveria como bloquear a influência do fator externo representado pela tecnologia absorvida do exterior; por isso, fazia-se necessário preparar-se internamente para tentar redirecionar os efeitos do progresso tecnológico no sentido de impulsionarem o processo de desenvolvimento.

Para Furtado, esse problema só encontraria solução mediante um condicionamento do perfil da demanda. Com vistas a esse objetivo, implicava-se a necessidade de certo grau de centralização das decisões de investimento, sem a qual dificilmente seria possível transformar a estrutura de uma economia subdesenvolvida e dependente como a brasileira, porém com o seguinte critério: os meios utilizados para direcionar as decisões de investimento não poderiam implicar mais concentração de renda e riqueza.

Furtado ressalta que dois aspectos fundamentais estariam relacionados ao planejamento. O primeiro deles engloba o horizonte temporal, visando especialmente às decisões que buscassem incrementar a participação das indústrias de bens de capital na estrutura produtiva; e o segundo diz respeito à estruturação espacial, relacionado a medidas que ajudassem a combater a tendência à concentração regional da produção industrial. Com a descentralização produtiva, estaria facilitado o acesso da maior parte da população aos frutos do desenvolvimento. Na discussão das duas dimensões, tempo e espaço, o autor faz referência ao argumento da indústria nascente que fundamentara a industrialização de muitos países centrais $^{220}$, destacando, por conseguinte, a necessidade de adoção de políticas protecionistas. Sobre as diretrizes da política de desenvolvimento que permitiria ao Brasil superar a crise em que se encontrava, recuperando o fôlego no processo de desenvolvimento, o autor sintetiza:

[...] a política de desenvolvimento do setor industrial se desdobraria em duas pistas. A primeira compreende as transformações em profundidade da estrutura do sistema econômico, no tempo e no espaço; nela cabe papel decisivo ao planejamento. A segunda diz respeito ao perfil da demanda global, a ser modificado de forma significativa, numa primeira fase e, em seguida, submetido a controle, a fim de que se possam neutralizar as tendências estruturais à concentração da renda. Se esses objetivos forem alcançados, o setor industrial estará em condições de desempenhar o papel de polo de um processo de crescimento capaz de beneficiar o conjunto da coletividade. (Ibid., p. 57-58).

Conforme aventado anteriormente, a variável-chave do processo de substituição de

\footnotetext{
${ }^{220}$ Vide especialmente List (1856).
} 
importações é a capacidade para importar. A queda relativa da capacidade para importar da economia brasileira refletiria, em primeiro lugar, o próprio comportamento do comércio mundial de matérias-primas, conforme bem explicaram Prebisch (1949) e Singer (1950). A reação a essa tendência estrutural da economia brasileira foi a substituição de importações. No entanto, conforme destaca Furtado, a forma assumida pela industrialização até então acabou por desqualificar ou despreparar as indústrias formadas internamente para a concorrência internacional. Como consequência, mesmo diante da diferenciação do sistema econômico, a pauta exportadora não se modificara de maneira significativa. Sobre essa assimetria na estrutura produtiva, diz o autor: "[...] as importações acompanharam a evolução estrutural, mas não as exportações: o Brasil do decênio atual, com seu considerável parque industrial, apresenta uma pauta de exportações similar à do Brasil do começo do século [...]” (Ibid., p. 67).

Ainda sobre a questão da pauta exportadora brasileira, Furtado (1975) faz uma importante observação. Em razão da estrutura agrária brasileira, extremamente concentrada, baseada em latifúndios, mesmo que a mão-de-obra não fosse fator excedente, sempre seria barata, porque as condições de vida eram baixas; desse modo, mesmo que se introduzissem melhorias técnicas, isso não implicaria necessariamente um aumento dos salários agrícolas. Além disso, há que se considerar que os próprios salários baixos, refletidos em precárias condições de subsistência, acabavam não estimulando a penetração do progresso técnico, perpetuando formas predatórias do uso da terra, o que encontraria parte da explicação no próprio despreparo da mão-de-obra que atuava no campo.

Dessa maneira, segundo Furtado, sendo o baixo nível de vida da população rural um fator crucial na determinação do salário da força de trabalho não especializada urbana, tratar o problema da agricultura somente em termos da necessidade de se criarem excedentes exportáveis poderia apresentar como efeito principal a perpetuação da então estrutura produtiva agrária, bem como o baixo custo de reprodução da mão-de-obra, o que criaria condições, inclusive, para que a renda continuasse a ser concentrada também nas zonas urbanas. Assim, por exemplo, o subsídio à mecanização agrícola poderia levar à formação de excedentes exportáveis, porém, sem que estivesse disponível uma ocupação alternativa à mãode-obra rural, e sem modificações no padrão de distribuição de renda e riqueza, "Uma tal política poderá ter efeitos positivos sobre o balanço de pagamentos, mas agravará necessariamente as desigualdades sociais já existentes.” (Id., 1975, p. 110-111).

Furtado complementa que, da maneira como estava estruturado o modelo de desenvolvimento brasileiro, o excedente gerado no setor primário-exportador acabaria sendo 
utilizado, por sua vez, em prol da modernização das formas de consumo da minoria privilegiada. Em sua conclusão sobre a questão, o autor salienta que não há dúvidas de que a industrialização substitutiva de importações contribuíra significativamente para intensificar o processo de concentração da riqueza e da renda; no entanto, a causa básica desse processo de concentração deveria ser buscada no baixo custo de reprodução da mão-de-obra no setor agrícola. Desse modo, é possível inferir que, de acordo com o autor, no caso brasileiro:

\begin{abstract}
Manteve-se a taxa de investimento (público + privado) reprodutivo e declinou significativamente, em termos relativos, o custo de reprodução de mão-de-obra. Cabe, portanto, inferir que o aumento de produtividade serviu principalmente para financiar investimentos improdutivos (principalmente sob a forma de automóveis e outros bens duráveis) e para ampliar o consumo das classes médias e altas. (Id., 1975, p. 136).
\end{abstract}

Ao final da década de 1960, iniciou-se o chamado período do "milagre" brasileiro, com significativo crescimento da produção industrial. Entretanto, esse suntuoso crescimento se realizou a despeito de reformas estruturais, tendo a capacidade de autofinaciamento e o coeficiente de exportação se mantido praticamente estáveis. Em virtude da grande liquidez internacional, o influxo de poupança externa teria produzido certa ilusão de flexibilidade, levando as empresas a se endividarem, com vistas à aquisição de equipamentos mais modernos. ${ }^{221} \mathrm{Ou}$ seja, de certa forma, a possibilidade de recorrer a recursos externos acabava retirando um suposto incentivo a se desenvolverem formas autônomas de financiamento dos investimentos, assim como ocorrera com a questão tecnológica. No que se refere à funcionalidade do endividamento externo para o processo de desenvolvimento, o autor indica que "Uma tal abertura seria positiva se houvesse a contrapartida de um fluxo de exportações de nível tecnológico superior ao de exportações tradicionais. Ora, no caso, a contrapartida era um simples processo de endividamento exterior." (Id., 1981, p. 41).

Com o auxílio do endividamento externo ${ }^{222}$, o reaquecimento da indústria brasileira pôde ser ativado sem que o sistema tivesse aumentado a sua capacidade endógena de autotransformação. E, note-se, esse reaquecimento pautou-se, novamente, pela modificação da composição da cesta de consumo na direção de bens mais sofisticados e supérfluos - em sua maioria, bens duráveis de consumo - tendo, ademais, os salários reais básicos permanecido estacionários, ou até declinado no período. ${ }^{223}$ Sobre esse fato, o autor questiona:

\footnotetext{
221 Para ilustrar a dimensão do incremento das importações no período, financiadas por dívida externa, diz Furtado (1981): "Entre 1966 e 1972, a participação das importações na oferta interna de bens da indústria mecânica aumentou de 28,8 para 40,2 por cento; na de material elétrico de 11,1 para 24,9 por cento, e na de produtos metalúrgicos de 16,9 para 18,7 por cento. O coeficiente de importação do setor de bens de capital praticamente dobrou durante esse período. (Id., 1981, p. 41).

${ }^{222}$ Também para efeitos de ilustração, segundo Furtado (1981, p. 41), a dívida externa saltou de 3 bilhões de dólares em 1964 para quase 13 bilhões de dólares em 1973.

${ }^{223}$ A política salarial do período da ditadura é discutida em mais detalhes no capítulo 6.
} 
Se bem que a poupança compulsória da massa dos assalariados aumentou em termos relativos, com a criação dos fundos de Integração Social e de Garantia de Tempo de Serviço, o coeficiente médio de poupança permaneceu praticamente estável. Como escapar à conclusão de que a propensão marginal a poupar dos beneficiários de concentração da renda haja sido negativa? (Ibid., p. 42).

Dessa maneira, embora a concentração da renda tenha sido funcional para dinamizar a indústria por um tempo, especialmente a de bens de consumo duráveis, ela também teria contribuído para esterilizar o potencial de autofinanciamento da economia brasileira, requisito para alcançar a capacidade de autotransformação discutida por Furtado.

Sobre a década de 1960, Furtado, assim como concluíra sobre o período anterior, continua a insistir na importância do planejamento, sem o qual, a política de desenvolvimento acabava por adquirir um caráter de improvisação ou de ausência de qualquer norte de direção. Na elaboração do Plano Trienal, por exemplo, o então Ministro Extraordinário do Planejamento indicara a crucialidade da promoção de reformas de base, visando também corrigir as condições de atuação estatais, dotando o Estado de ferramentais mais adequados para desempenhar seu papel de planejador e de agente econômico. Para o autor, só assim seria possível vislumbrar quaisquer possibilidades de alcançar resultados satisfatórios e sustentáveis em termos de desenvolvimento.

Note-se também, para esse período, a importância crescente que é concedida à interação perniciosa, em termos de resultados de desenvolvimento, que se desenvolve entre as condições estruturais brasileiras, a forma como se difunde o progresso tecnológico e a insistência do modelo de desenvolvimento em pautar sua dinâmica na demanda de bens de consumo duráveis, aos quais têm acesso apenas uma camada privilegiada da população. A insistência nessa forma de desenvolvimento, não apenas não teria conduzido a determinadas transformações estruturais e à diminuição das desigualdades, de renda e riqueza - que também compõem as condições iniciais e resultam das condições estruturais -, como dificultou a superação das dificuldades, na medida em que intensificou ainda mais o processo de concentração de recursos, o qual, segundo a ótica de Furtado, constituiria uma das questões de mais difícil solução relacionada à composição dos círculos viciosos que formam a armadilha do subdesenvolvimento.

Outra questão importante bastante enfatizada por Furtado é a recorrência à dívida externa como fonte para dar prosseguimento à insistência naquele modelo de desenvolvimento norteado pelo consumo de bens de luxo. A possibilidade e a facilidade de obter recursos externos teria retirado uma possível restrição, que se traduziria em incentivo, o qual poderia ter estimulado a consecução de certas mudanças estruturais, relacionadas 
especialmente à capacidade de autofinanciamento da economia brasileira, considerada, pelo autor, como condição complementar à capacidade de autopropulsão.

Em larga medida, todas essas questões, destacadamente a questão do endividamento externo, são retomadas pela análise Furtadiana do período seguinte, conforme apresentado na próxima subseção.

\subsubsection{Década de 1970: o Brasil pós-milagre, II PND e a crise da dívida}

O período coberto por essa subseção, que encerra o período de investigação da fase desenvolvimentista do Brasil sob a ótica de Celso Furtado, engloba os governos Médici (1969-1974), Geisel (1974-1979) e o início do governo Figueiredo (1979-1985).

Em seu prefácio, Furtado (1981) retoma o questionamento que fizera no início da década de 1960, no auge da crise pela qual passava a economia brasileira. O atual contexto é do início da década de 1980, também em meio a uma crise, de proporções ainda mais profundas. Duas décadas se passaram entre os questionamentos expressos pelo autor. Dentro desse período, se encontra justamente o chamado "milagre" brasileiro e a consecução do II Plano Nacional de Desenvolvimento (II PND). Conforme demonstram as palavras do autor, as inquietações resultantes da crise na década de 1980, após um período de prosperidade, não teriam se alterado com relação àquelas da década de 1960:

As malformações da sociedade brasileira são tão evidentes, tão grande o contraste entre a penúria e o desperdício, que todos devemos questionar-nos como foi possível que chegássemos a isso. Como conciliar essa realidade com as potencialidades do país e com o notável esforço de desenvolvimento já realizado? (Id., 1981, p. 15).

Conforme discussão iniciada na subseção anterior, embora o período do "milagre" tenha sido de grande dinamismo industrial e crescimento, mais uma vez na história econômica brasileira, esse crescimento não se traduzira na conquista da autonomia e da sustentabilidade do processo de desenvolvimento da economia nacional.

A respeito das condições internacionais vigentes no início da década de 1970, vale destacar observações feitas por Furtado (1992). O autor sugere que os grandes desequilíbrios observados na economia internacional a partir de então estavam relacionados, em boa medida, à “[...] não existência de um centro principal dotado de efetiva capacidade ordenadora [...]" e que a "Manifestação flagrante desses desequilíbrios é a enormidade da dívida externa das economias periféricas.” (Id., 1992, p. 68). Em outras palavras, teria sido a desordem promovida no sistema financeiro internacional, provocada pelo excesso de liquidez gerado pela crise do dólar, a desencadeadora do endividamento de boa parte das nações periféricas, 
especialmente as latino-americanas. ${ }^{224}$ Tal quadro de desajuste foi agravado com o choque do petróleo em 1973, conforme explicita o autor:

$\mathrm{O}$ esforço de abertura adicional das economias industriais, realizado em seguida à contração do aumento do preço do petróleo, teve como contrapartida o incremento das importações dos países periféricos, assim como uma transformação do excesso de liquidez dos bancos internacionais em créditos sobre esses países. As economias subdesenvolvidas, que lutavam tradicionalmente com grande escassez de capital, encontraram-se repentinamente em face de uma oferta completamente elástica de recursos financeiros no mercado internacional a taxas de juros negativas. (Id., 1992, p. $68)$.

Com o choque do petróleo em 1973, a vulnerabilidade do modelo de desenvolvimento subjacente ao "milagre" teria sido posta a descoberto. Furtado explica que o sistema industrial vinha operando com plena utilização de sua capacidade produtiva, em condições cambiais altamente e crescentemente favoráveis, com a moeda supervalorizada. Se as condições se mantivessem, a pressão implícita à balança de pagamentos não teria necessariamente se transformado num problema real; contudo, caso mudassem, o problema poderia ser muito grave.

Em meados da década de 1970 foi implementado o II PND (1974-1979), cujos objetivos, de acordo com Furtado, poderiam ser resumidos em: ampliação da base do sistema industrial e incremento do grau de inserção da economia no sistema de divisão internacional do trabalho. A respeito dos objetivos do Plano, o autor comenta:

Sem lugar a dúvida, esses objetivos são em si mesmos corretos, se bem que apareçam envoltos na bruma de uma visão paranóica (sic) da economia brasileira, idealizada como um sistema capaz de sustentar a longo prazo uma taxa de crescimento de 10 por cento anual e de abrir mercados no exterior de forma a aumentar suas exportações em termos reais com uma velocidade duas vezes maior. (Id., 1981, p. 46-47).

Diferentemente do que ocorrera no período de crescimento relacionado à fase do Plano de Metas (1955-1961), o qual também se caracterizava por pressão sobre a balança de pagamentos, no contexto subjacente ao II PND, a estreiteza da capacidade para importar não mais levaria à redução dos investimentos por meio de pressões inflacionárias, as quais poderiam, portanto, desencadear uma reversão da pressão na forma de desequilíbrio externo. O quadro em 1974 era distinto, segundo Furtado, em virtude de fatores aparentemente contraditórios: por conta do choque do petróleo, as condições cambiais se degradaram rapidamente, no entanto, “[...] a possibilidade de endividamento externo criou a falsa euforia de que tudo continuaria como antes, ${ }^{225}$ sendo a turbulência externa um incidente passageiro."

\footnotetext{
${ }^{224}$ Ressalte-se novamente discussão iniciada na seção 2.2 .3 do capítulo 2, em que se indicara a absorção de capitais externos, ociosos nas nações centrais, pelas nações periféricas, como mais uma forma potencial de transferência de desordem ou entropia do centro para a periferia.

225 "Tudo continuar como antes" refere-se às condições existentes no período do "milagre", quais sejam, "[...] conjunção do uso de capacidade produtiva ociosa, de melhoria nos termos de intercâmbio, de grande
} 
(Ibid., p. 44).

Com base em falso diagnóstico, e tendo em vista a necessidade de incrementar o investimento para cumprir os objetivos do II PND, bem como de conter parte das pressões inflacionárias, permitiu-se um considerável aumento do volume de importações, segundo dados de Furtado, enquanto o volume de exportações declinava. Em termos de dívida externa, essa teria saltado de 12,5 para 21,2 bilhões de dólares entre 1973 e 1975 (Ibid., p. 48). Assim, "É natural, portanto, que se hajam formado tensões na economia de profundidade muito maior do que as provocadas pelas turbulências de origem externa." (Ibid., p. 44-45). A forte propensão a importar é atribuída pelo autor, em grande medida, ao fato de que o período do "milagre" implicou um significativo aumento dos custos de produção, em termos de divisas, para o pagamento da importação de equipamentos e de bens intermediários, assim como de serviços técnicos e financeiros.

Como a economia vinha passando por um processo de desnacionalização, com participação crescente das multinacionais e transnacionais, essa pressão por importação era ainda mais intensificada. Uma maneira de contrabalançar essa tendência ao desequilíbrio na balança de pagamentos seria via incremento do coeficiente de exportações, algo que acabou não se observando. Furtado indica que, em 1974, “[...] as importações cresceram com velocidade três vezes maior do que o Produto Interno, elevando o coeficiente de importações a nível que se desconhecia desde 1929." (Ibid., p. 45). Como resultado, o custo da dívida externa tendeu a crescer mais rapidamente do que as exportações e a disponibilidade interna de recursos. Importante assinalar que, segundo o autor, a recorrência aos recursos externos não teria sido resultado de uma política consciente do risco em que se poderia incorrer. Em suas palavras, “[...] o endividamento exacerbado da segunda metade dos 70 foi subproduto de uma política anti-inflacionária que pretendeu eludir o caráter estrutural das tensões que originavam a inflação.” (Ibid., p. 51).

Furtado se indaga se o grande endividamento externo ocasionado pelo II PND teve em sua origem, de fato, um esforço para ocasionar mudanças estruturais profundas na base produtiva da economia brasileira, ${ }^{226}$ o que possibilitaria o incremento da sua capacidade de autotransformação. Vejamos os argumentos do autor para defender a hipótese de que esse esforço não teria sido realizado na prática.

prosperidade nos países industriais principais importadores do Brasil e de endividamento externo em condições excepcionalmente favoráveis." (Id., 1981, p. 47).

${ }^{226}$ Uma interpretação do II PND alternativa à de Furtado e talvez a mais aceita pela literatura, é a de Castro e Souza (1985), para os quais o II PND teria buscado atacar os problemas da economia brasileira em sua raiz. Essa avaliação do II PND é retomada em mais detalhes no capítulo 6. 
De acordo com Furtado (Ibid., p. 52-53), para que fosse engendrada a reestruturação da economia, como pré-requisito, era necessário o incremento da taxa de investimento. No entanto, os dados disponíveis à época indicariam que a taxa de investimento em capital fixo entre 1975-1979 fora, em média, a mesma do quinquênio anterior, 23,7\%. Já o consumo agregado teria aumentado cerca de 3,6\% de um quinquênio para o outro. Com base nesses dados, o autor reafirma que não foram verificadas modificações significativas na estrutura produtiva da economia brasileira, pois, a participação do setor industrial no produto nacional teria se mantido estacionária desde 1975 e, mesmo dentro do setor industrial, o setor que mais havia crescido no período do II PND teria sido o setor produtor de bens duráveis de consumo. Assim, sobre o endividamento externo promovido pelo II PND, ${ }^{227} \mathrm{o}$ autor conclui que ele não teria implícito o objetivo de ocasionar as tais mudanças profundas na estrutura produtiva brasileira. Em suas palavras:

Tudo indica que a entrada de recursos externos reais constituiu tão-somente uma operação destinada a absorver pressão inflacionária, ela mesma em parte gerada pela acumulação de reservas de câmbio. A brusca intensificação dos fluxos de recursos externos, que permitiu o substancial aumento das importações no começo do período e a subsequente acumulação de reservas de câmbio, operou de forma similar a uma degradação nos termos de intercâmbio, dando origem a um processo circular pelo qual o efeito perverso inicial requereu novo influxo de recursos para compensá-lo, e assim por diante. (Ibid., p. 54-55).

Conforme discutido anteriormente, para Furtado, a reconfiguração do sistema produtivo tinha como condição necessária a elevação da capacidade de autofinanciamento da economia brasileira. Entretanto, o cumprimento desse quesito conflitava com a diretriz geral do modelo de desenvolvimento brasileiro, apoiada essencialmente na busca pelo crescimento rápido do mercado de bens de consumo duráveis. $\mathrm{O}$ autor sugere, inclusive, que essa diretriz geral teria sido inserida no modelo de desenvolvimento nacional com o patrocínio das empresas transnacionais e a fim de beneficiar os grupos de mais alta renda.

Assim, de acordo com Furtado, a insistência nessa forma de desenvolvimento, pautada pelo consumo de bens de luxo, teria esterilizado os recursos, já escassos, que deveriam ter sido utilizados para provocar mudanças estruturais profundas na base produtiva que permitissem a diversificação e ampliação do sistema industrial, o incremento do coeficiente de exportação e o redirecionamento do setor energético. E a recorrência ao endividamento externo, tampouco, teria tido como fundamento a busca desses três objetivos de transformação estrutural da base produtiva; teria sido sim uma saída encontrada para que a economia brasileira continuasse crescendo com base no consumo de bens duráveis.

Em 1979, quando ocorreu o segundo choque do petróleo, a margem de manobra de

\footnotetext{
${ }^{227}$ Essa discussão sobre o endividamento externo é retomada no capítulo 6.
} 
atuação do governo brasileiro nos campos cambial, monetário e fiscal, era, segundo Furtado, quase inexistente. $^{228} \mathrm{O}$ resultado foi a criação de mais um círculo vicioso, senão uma verdadeira armadilha, quase que intransponível. Nas palavras do autor:

Posto que o serviço da dívida externa compete com os investimentos na absorção de poupança, se esse serviço cresce mais do que o Produto a taxa de investimento deverá declinar. Essa situação se vem evitando mediante o refinanciamento permanente da dívida. Ora, esse refinanciamento engendra uma carga financeira que hipoteca o futuro do país. Por outro lado, já não é possível manter a taxa de investimento sem continuar a aprofundar o endividamento. Portanto, o problema que se apresenta ao país é de como escapar a essa engrenagem sem levar a economia à estagnação e sem abrir mão da autonomia de decisão. (Ibid., p. 56).

Também em 1979, o governo estadunidense implementara uma política de choque de juros. O efeito colateral sobre as nações periféricas, inclusive o Brasil, foi de grande impacto. Sobre a questão, Furtado (1992) conclui que "[...] dois processos de ajustamento ocorridos nas economias cêntricas [...] se encontram no ponto de partida da enorme dívida que pesa atualmente sobre os países que constituem a periferia do sistema capitalista." (Id., 1992, p. 70), referindo-se ao esforço de recuperação do equilíbrio externo por parte das economias centrais em seguida à primeira elevação de preços do petróleo em 1973 e à política de juros restritiva dos Estados Unidos utilizada como forma de financiar seu próprio déficit.

Com a crise da dívida no início da década de 1980, encerra-se o chamado período desenvolvimentista brasileiro e se inicia uma fase marcada especialmente por políticas de inspiração neoliberal, seguindo as diretrizes provenientes das nações centrais.

Para a análise da década de 1970, Furtado retoma as mesmas questões que valeram para a década de 1960, especialmente aquelas relacionadas à fase em que se inicia o período do "milagre". A insistência no modelo de desenvolvimento dinamizado primordialmente pelo consumo de bens de luxo, facilitada, em grande medida, pelo endividamento externo, novamente teria bloqueado qualquer incentivo potencial à promoção de diversas mudanças estruturais profundas, necessárias para o país alcançar a sua capacidade de autotransformação. Em síntese, os círculos viciosos que compunham a armadilha do subdesenvolvimento não apenas continuaram os mesmos na década de 1970, mas foram ainda mais agravados, sob a forma de um enorme endividamento externo, que culminou com a crise da dívida na década de 1980.

As observações realizadas ao longo das cinco subseções que discutiram, sob a ótica de Furtado, a formação econômica e social do Brasil e a sua trajetória econômica no período desenvolvimentista buscaram destacar, com relação ao método Furtadiano, especialmente a

\footnotetext{
${ }^{228}$ Segundo Furtado, “[...] antes mesmo do segundo choque petroleiro, a economia brasileira já se encontrava em situação de ter de dedicar cerca de 5 por cento do seu Produto Interno e três quartas partes das divisas geradas por suas exportações ao serviço de capitais estrangeiros investidos no país.” (Id., 1981, p. 49).
} 
sua recorrência à: interação analítica de fatores internos e externos, micro e macroeconômicos; interação analítica entre economia e sociedade, entre teoria econômica e história econômica. Essas são características que fariam do método Furtadiano um método complexo, por conta da abrangência de fatores e perspectivas analíticas que o autor busca contemplar para compor a sua abordagem historiográfica, assim como fizera em sua abordagem teórica, embora não divorciada da história, relativa à discussão do subdesenvolvimento, tal como discutido na seção 4.2 do capítulo anterior. E por também buscar levar em consideração em sua análise sobre a economia brasileira a interação dinâmica de diversos fatores, econômicos e não econômicos, internos e externos, em certos momentos traduzidas em círculos viciosos e causações circulares multifatoriais e multidirecionais, o método de Furtado parece apresentar diversas compatibilidades com a Abordagem da Complexidade.

Celso Furtado desempenhou papel crucial na composição do pensamento econômico brasileiro, para a compreensão da formação econômica e social do Brasil e para se pensar criticamente a respeito de políticas de desenvolvimento econômico. E talvez, justamente por conta de sua riqueza, complexidade e abrangência, a obra de Celso Furtado é passível de diversas críticas e ponderações, as quais, historicamente, desencadearam importantes desenvolvimentos teóricos e metodológicos posteriores, o que, do ponto de vista do evolver científico, é extremamente produtivo. Como deixara claro o próprio autor na introdução de Formação Econômica do Brasil, esse era exatamente o seu objetivo:

O presente livro pretende ser tão somente um esboço do processo histórico de formação da economia brasileira [...] A preocupação central consistiu em descortinar uma perspectiva o mais possível ampla. Na opinião do autor, sem uma adequada profundidade de perspectiva torna-se impossível captar as inter-relações e as cadeias de causalidade que constituem a urdidura dos processos econômicos. (Id., 1959, p. 1).

Em linhas gerais, uma particularidade da abordagem Furtadiana, presente em toda a sua obra, é seu aspecto interdisciplinar. Implícita a essa escolha teórica está a não consideração da suposta suficiência dos fatores econômicos, o que também faria o seu método compatível com o da Abordagem da Complexidade. No entanto, mais do que não considerar a suficiência dos fatores econômicos, Furtado não restringe à sua análise a fatores estritamente econômicos. Como bem destaca Cepêda, a interpretação de economia brasileira empreendida por Furtado conecta questões sociais e econômicas de maneira inédita no pensamento brasileiro. Diz a autora sobre a abordagem Furtadiana:

Possui uma originalidade e uma força teórica que advém da intersecção proposta entre desajustes econômicos e desajustes sociais, entre atraso e modernidade, itens que predominavam na agenda do debate teórico nacional desde o início do século, porém tratados isoladamente. (Cepêda, 2008, p. 50). 
Relacionada à consideração de aspectos sociológicos, estaria a conexão subjacente ao trabalho de Furtado, entre teoria e história, o que faz de sua obra uma fonte informativa importante tanto do ponto de vista estritamente teórico, quanto do ponto de vista estritamente histórico. Exatamente por ter sido construído firmemente sobre esses dois pilares, o método de Furtado seria bastante adequado à discussão dos temas concernentes ao desenvolvimento e ao subdesenvolvimento econômicos; e, também pela sua organicidade, levando em consideração fatores de diversas naturezas. Sobre a relação entre teoria e história na obra de Furtado, diz Oliveira:

O novo em Celso Furtado, assim como nos clássicos demiúrgicos da década de 1930, é a construção de uma complexa relação entre teoria e história. Assim, não há uma teoria que se aplique à história, nem o contrário, uma história que seja explicada pela teoria: o andamento se faz tecendo os fios de uma construção auto-estruturante, em que a história é teoria e a teoria é história. (OLIVEIRA, 2003, p. 84).

De forma semelhante à Oliveira, Coutinho (2008) destaca que a abordagem teórica de Furtado contemplaria um duplo caráter, o abstrato e o real, que não pode ser negligenciado pela análise econômica, constituindo o real um limite importante à construção abstrata. Segundo o autor, "Com efeito, este foi o compromisso permanente de Furtado: a aplicação de princípios gerais a realidades econômicas dotadas de historicidade". (COUTINHO, 2008, p. 142).

Dessas observações de Oliveira e Coutinho a respeito do método de Furtado, sobre a teoria combinada à história e a organicidade, ressalte-se novamente que o método de Furtado guardaria certos paralelos com a Abordagem da Complexidade, que tem como hipóteses: (i) a heterogeneidade dos agentes, para cuja consideração concorre a investigação histórica da trajetória econômica das nações, na medida em que aquela investigação permite identificar certas especificidades da nação a ser investigada e (ii) a consideração das relações de retroalimentação e causalidade mútua entre os fatores, requisito que Furtado buscou cumprir ao tentar contemplar uma diversidade de fatores, econômicos e não-econômicos, e especialmente, conforme destacado nesse capítulo, no que se refere às interações entre fatores internos e externos.

Ao longo desse capítulo, além de apresentar a perspectiva de Furtado sobre a experiência brasileira, buscou-se apontar algumas das particularidades do método analítico de Furtado, dando continuidade à discussão de sua abordagem iniciada no capítulo precedente. No que se refere às suas conclusões sobre a experiência brasileira, dando prosseguimento às considerações apresentadas no final do capítulo 4, vale ressaltar novamente a importância concedida por Furtado às reformas estruturais - ou reformas de base, conforme denominara na 
elaboração do Plano Trienal - como condições necessárias para que os efeitos transformadores provenientes das modificações na estrutura produtiva brasileira pudessem ao menos ter chances de se traduzir em melhores condições de vida da maioria da população brasileira, atenuando os grandes níveis de disparidade regional e de desigualdade distributiva.

No próximo capítulo, a discussão do caso brasileiro tendo em mente a perspectiva da Abordagem da Complexidade continua, trazendo novamente à discussão os pioneiros do desenvolvimento econômico e algumas das suas contribuições à compreensão da emergência e da perpetuação do subdesenvolvimento, agora aplicadas à discussão do subdesenvolvimento econômico brasileiro. 


\section{SUBDESENVOLVIMENTO ECONÔMICO BRASILEIRO NO PERÍODO 1930-1980: UMA DISCUSSÃO BASEADA NA ABORDAGEM DA COMPLEXIDADE}

Nesse capítulo, busca-se realizar uma discussão da economia brasileira no período 1930-1980 por meio da aplicação de alguns dos elementos e discussões de caráter teórico, metodológico e histórico, apresentados no decorrer dos capítulos precedentes. E, assim como os capítulos anteriores, este também é de caráter estritamente teórico. Não se pretende desenvolver aqui novas estatísticas, muito menos novas interpretações gerais, mas apenas discussões e ilações teóricas, tendo sempre em mente a Abordagem da Complexidade.

Conforme discussão iniciada no capítulo 2, a emergência da Economia do Desenvolvimento no pós II Guerra Mundial se deveu à percepção de diversos pensadores, aos quais foi atribuída a alcunha de pioneiros do desenvolvimento, de que o tratamento teórico das nações que não faziam parte do centro desenvolvido deveria ser diferenciado. $\mathrm{O}$ tratamento teórico diferenciado englobava, por sua vez, a necessidade de alterações não apenas de foco, mas de contestação, em alguma medida ou direção, da própria Teoria Econômica então disponível.

Com esse objetivo em mente, de discutir a própria base teórica, se procurou, nos capítulos anteriores, resgatar a contribuição de alguns autores que realizaram essa contestação e que formaram interpretações alternativas ao mainstream, supostamente mais adequadas ao contexto específico dos países subdesenvolvidos. A discussão aqui empreendida foi iniciada no capítulo 3, sob a ótica de alguns pioneiros anglo-saxões, que compuseram uma visão mais geral de certas especificidades do contexto de subdesenvolvimento. Passou-se à discussão de um grupo específico de nações subdesenvolvidas, a América Latina, sob a ótica de dois pioneiros latino-americanos. Por fim, dedicou-se um capítulo à discussão de um país específico, o Brasil, a partir da perspectiva de um único autor.

O intuito desse capítulo continua sendo a discussão de um caso específico, mas a partir da perspectiva de todos os autores até então discutidos, cuja seleção e investigação esteve pautada pelos paralelismos possíveis com o que seria um tratamento da temática desenvolvimento econômico compatível com a Abordagem da Complexidade, tal como apresentado no capítulo 2. A seguir, tendo essa base teórica como pano de fundo, discutem-se, sob a ótica da Abordagem da Complexidade, alguns dos motivos pelos quais o Brasil, mesmo tendo transformado e desenvolvido sua base produtiva, bem como alcançado consideráveis 
taxas de crescimento, por longos períodos na chamada fase desenvolvimentista, não teria conseguido escapar da armadilha do subdesenvolvimento.

O presente capítulo está dividido em duas seções. Na primeira delas, à semelhança do realizado no capítulo 5, constrói-se uma narrativa direcionada da história econômica brasileira no período 1930-1980, enfatizando algumas questões consideradas cruciais para a discussão da armadilha do subdesenvolvimento, por meio da aplicação de algumas das ideias e modelos teóricos dos pioneiros do desenvolvimento. Na segunda seção, retoma-se a discussão iniciada na subseção 2.2.3 do capítulo 2, sugerindo alguns caminhos pelos quais a Abordagem da Complexidade poderia contribuir para alargar o horizonte de compreensão de algumas questões relacionadas à emergência e perpetuação do subdesenvolvimento econômico brasileiro no seu período desenvolvimentista.

\subsection{O retorno dos pioneiros: discutindo alguns aspectos da emergência e da perpetuação do subdesenvolvimento econômico brasileiro no período 1930-1980}

Nessa primeira seção, retomam-se algumas das discussões teóricas realizadas anteriormente com base nos pioneiros do desenvolvimento econômico. O intuito aqui é a realização de um exercício teórico, com o seguinte roteiro: a partir da seleção, realizada nos capítulos anteriores, de certas discussões e elementos teóricos, compatíveis com a Abordagem da Complexidade e derivados dos pioneiros do desenvolvimento, aplicam-se algumas dessas discussões e elementos à investigação do caso brasileiro no período 1930-1980.

Essa discussão, por sua vez, está norteada pelo seguinte questionamento: por que o Brasil não conseguiu escapar da armadilha do subdesenvolvimento, mesmo, aparentemente, tendo apresentado condições para tal? Importante ressaltar, ademais, que não se pretende realizar uma narrativa detalhada e minuciosa dessas cinco décadas de história econômica brasileira. Assim como no capítulo 5, busca-se desenhar um panorama geral, concedendo maior profundidade a alguns assuntos considerados centrais, os quais, em larga medida, ajudariam a compor um fio condutor analítico desse período desenvolvimentista.

Nesse sentido, retomando discussão sobre o papel do Estado como potencial redirecionador da tendência de perpetuação do subdesenvolvimento, tal como iniciada no capítulo 2, a ênfase da discussão norteia-se especialmente pelos planos de governo implementados ao longo desse meio século de economia brasileira. Passemos à narrativa, que 
se inicia com a crise de 1929 e se encerra com a crise da dívida no início dos anos 1980.

Dentre as consequências mais profundas da crise de 1929 para o grupo de países periféricos, nos quais se inclui o Brasil, figura a imposição de um contexto altamente restritivo em termos de intercâmbio internacional. Para as economias exportadoras dependentes, pouco desenvolvidas e com limitada autossuficiência produtiva, a imposição dessa restrição colocou em xeque a sustentabilidade do próprio modelo primário-exportador, nos quais se baseavam desde o período colonial.

Referindo-se à América Latina, Tavares (1972) explica que nas suas economias dependentes primário-exportadoras, as exportações representavam o único componente autônomo do crescimento, sendo o setor exportador o centro dinâmico do sistema econômico. Como implicações, observavam-se limites à diversificação da capacidade produtiva e a dependência da natureza da produção primário-exportadora no que diz respeito às possibilidades de irradiação interna, bem como de seu efeito multiplicador e distribuidor de renda. Embora o desenvolvimento do setor exportador tenha levado a um processo de urbanização, ao longo do qual se estabeleceram indústrias tradicionais, de baixa complexidade, essa atividade industrial em conjunto com as atividades de subsistência seriam insuficientes para imprimir um dinamismo endógeno e autônomo às atividades econômicas internas.

Conforme demonstrara a tese Singer-Prebisch (Singer, 1950; Prebisch, 1949), as nações periféricas, cujo modelo de crescimento baseava-se predominantemente na exportação de bens primários, estavam sujeitas a efeitos perniciosos no longo prazo, relacionados à deterioração dos termos de troca dos bens primários, que exportavam, relativamente aos bens manufaturados, que importavam. Tavares chama a atenção para o fato de que o núcleo da problemática do crescimento "para fora" vinculava-se à divisão internacional do trabalho. No caso dos países centrais, não haveria uma separação nítida entre a capacidade produtiva destinada a suprir o mercado interno e o externo. Já no caso do Brasil, por exemplo, havia uma divisão clara, com um setor exportador bem definido e de alta rentabilidade econômica, especializado em poucos produtos (e pouco consumidos internamente) vis-à-vis um setor interno de baixa produtividade, basicamente de subsistência e ainda insuficiente para satisfazer a demanda interna.

Segundo caracterização do pioneiro Lewis $(1954,1955)$, que parte da hipótese de oferta de mão-de-obra (não qualificada) ilimitada, nesses setores, era possível observar produtividade marginal do trabalho zero ou quase zero. Além disso, a alta concentração de propriedade (de terra e de capital) originou uma significativa desigualdade de renda e riqueza. 
Nesse sentido, o pioneiro também argumentara que o que causava uma diminuição da parcela dos lucros era a parcela de renda da terra, e não a parcela de salários, do que decorria sua ênfase na crucialidade da distribuição funcional da renda e da riqueza para o processo de crescimento e desenvolvimento.

Assim, como resultado da dualidade estrutural, teria sido gerado um mercado interno restrito, com classes altas com padrões de consumo similares aos dos países desenvolvidos, em grande parte atendido por importações. Essa questão do perfil de demanda emulador dos padrões de consumo das nações centrais foi objeto de discussão dos pioneiros latinoamericanos, $^{229}$ e também do pioneiro Nurkse $(1952,1953)$, que transplantara o efeito demonstração da Teoria de Duesenberry para explicar o comportamento emulador das nações periféricas vis-à-vis as centrais. No caso brasileiro, conforme discutido no capítulo anterior e retomado a seguir, essa tendência emuladora, em grande medida, implicou uma relativa insistência numa suposta capacidade de dinamizar, de maneira sustentável, a economia por meio de impulsos provenientes predominantemente do setor produtor de bens de consumo duráveis. Na combinação de uma estrutura produtiva dual e de uma acentuada desigualdade distributiva de renda e riqueza residia, para Tavares, a base do que seria a principal característica do modelo primário-exportador: a disparidade entre a estrutura produtiva e a composição da demanda interna, cujo ajuste se realizava pelo setor externo.

Frente à restrição externa que se colocou com a Grande Depressão, naquele momento praticamente intransponível, a solução implicava uma mudança de rota, qual seja, o rompimento com o modelo primário-exportador. Essa era uma observação comum a todos os pioneiros, que indicaram e fundamentaram a necessidade de recorrer à industrialização para que as nações periféricas tivessem ao menos chances de romper com a armadilha do subdesenvolvimento. Só assim, conforme destacara Prebisch (1949), seria possível às nações periféricas extrair as vantagens das interações internacionais - comerciais e tecnológicas - e escapar da armadilha da tendência à deterioração dos termos de troca. No caso brasileiro, como resultado de uma política industrial intencionada ou não, a partir da década de 1930, o setor industrial passou a desempenhar um papel crescentemente importante na determinação da dinâmica da economia brasileira, tendo o centro dinâmico da economia brasileira se deslocado para o mercado interno, assim como delimitado por Furtado (1954a, 1959).

Conforme elucida Tavares, com a crise, estava desfeita aquela possibilidade de ajuste ex ante via comércio exterior entre a estrutura produtiva e a demanda interna. $\mathrm{O}$ reajuste ex

\footnotetext{
${ }^{229}$ Essa discussão é realizada pelos autores em diversos momentos de suas obras. Vide capítulo 4.
} 
post se produziu por meio de um aumento dos preços relativos das importações, o qual estimulou a produção interna substitutiva. Conforme já salientara Furtado (1959), o processo se deu inicialmente por meio da utilização da capacidade produtiva ociosa já instalada e, posteriormente, o processo prosseguiu por meio da redistribuição de fatores e administração de divisas, permitindo a instalação de novas unidades produtivas.

Tavares apresenta a definição do novo modelo de desenvolvimento brasileiro - e latino-americano, em sua maioria -, o Processo Substitutivo de Importações (PSI), cuja vigência delimita o que se considera nessa tese como período desenvolvimentista brasileiro. Como características do novo modelo de desenvolvimento, observou-se que a importância das exportações fora substituída pela variável endógena investimento. O papel do setor externo continuou a ser relevante, mas agora como decisivo no processo de diversificação da estrutura produtiva mediante importações de bens de capital e bens de investimento. No entanto, segundo a autora, as transformações no sistema econômico observadas foram de caráter parcial, na medida em que se limitaram ao setor industrial e atividades conexas, sem modificar de forma significativa o setor primário, inclusive aquele voltado à exportação.

A perpetuação da dualidade estrutural, característica dos países subdesenvolvidos, seguindo a conceituação de Kalecki (1960), possui consequências dinâmicas fundamentais para entender as particularidades dos países subdesenvolvidos, uma vez que o desemprego e o subemprego nos países subdesenvolvidos resultariam mais da limitação de capacidade produtiva do que da insuficiência de demanda efetiva. Para incrementar o volume de investimento, por sua vez, além de resolver questões relativas à oferta e demanda de capital, havia, para o autor, um problema que, se não fosse resolvido, criaria dificuldades crescentes ao processo de desenvolvimento, qual seja, o gargalo na oferta de bens de alimentos. A não resolução desse problema implicava, necessariamente, uma resposta inflacionária do preço desses bens em virtude do próprio crescimento da economia, dificultando, em tese, o prosseguimento do próprio crescimento. Porém, para garantir uma produção adequada de alimentos, segundo observara Kalecki (1968), sem que se observassem mudanças institucionais, principalmente àquelas relativas à propriedade de terras, não seria possível acelerar o desenvolvimento agrícola.

Segundo Tavares, os novos setores dinâmicos apareceram e se expandiram no âmbito mais restrito do mercado nacional, conferindo um caráter mais fechado a esse modelo de desenvolvimento baseado no PSI. Assim, conclui a autora que a transformação da base produtiva possibilitada pela industrialização não fora acompanhada por uma transformação equivalente na divisão internacional do trabalho. Em suas palavras: 
Em suma, o "processo de substituição das importações" pode ser entendido como um processo de desenvolvimento "parcial" e "fechado" que, respondendo às restrições do comércio exterior, procurou repetir aceleradamente, em condições históricas distintas, a experiência da industrialização dos países desenvolvidos. (TAVARES, 1972, p. 35).

O Golpe ou Revolução de 1930, em alguma medida, representou uma diluição do poder político das elites cafeeiras, o que, supostamente teria aberto espaço para a participação de outros grupos de interesse na discussão das diretrizes a serem tomadas pelo Estado brasileiro. O movimento golpista, ou revolucionário, iniciara-se no início de outubro, culminando com a transferência do poder para Vargas em novembro de 1930.

De acordo com Fausto (1986), a Revolução de 1930 não foi expressão da ascensão da dominação política da burguesia industrial, mesmo porque, ao menos no caso de São Paulo, não haveria nenhum indício de mudança de atitude da grande indústria quando da preparação do levante revolucionário. O próprio episódio revolucionário de 1932 revelaria, pelo contrário, o alinhamento da indústria paulista ao lado das demais forças que se opuseram à Revolução de 1930. No entanto, o autor pondera que, mesmo não tendo sido a Revolução de 1930 impulsionada pelo interesse da burguesia industrial, isso não significaria, por outro lado, que o governo Vargas tivesse adotado uma linha de políticas contrária à indústria.

Weffort (1979) destaca que, após a Revolução de 1930, instalou-se um compromisso entre os vários grupos que compunham o cenário político-econômico brasileiro, formando o que o autor definiu como Estado de Compromisso, pois teria desencadeado uma crise do sistema oligárquico de poder, ao mesmo tempo em que ampliou institucionalmente as bases sociais do Estado, englobando as classes médias e industriais, bem como as classes populares. $\mathrm{Na}$ prática, os grupos ligados à indústria é que teriam sido os maiores beneficiários das mudanças políticas. Diz o autor sobre a instabilidade do Estado de Compromisso:

O novo Governo terá, portanto, que mover-se sempre dentro de uma complicada faixa de compromissos e conciliações entre interesses diferentes e por vezes contraditórios. De nenhum dos grupos participantes - as classes médias, os grupos menos vinculados à exportação e os setores vinculados à agricultura do café - se poderia dizer que teria assegurado para si as funções de hegemonia política. Por outro lado, nenhum desses grupos tem condições para oferecer as bases da legitimidade do novo Estado, para apresentar seus próprios interesses particulares como expressão dos interesses gerais da Nação. (WEFFORT, 1979, p. 69).

Segundo Weffort, esse equilíbrio instável entre os grupos dominantes constituiu um traço marcante da política brasileira. Nessas condições, teria sua gênese a personalização de poder, a imagem da soberania do Estado sobre o conjunto da sociedade e a necessidade da participação das massas populares urbanas. O chefe de Estado assumira, então, a posição de árbitro. Por outro lado, na condição de árbitro, sua pessoa tendeu a se confundir com o próprio Estado. Nesse sentido, o autor argumenta que a ditadura teria sido uma solução para a 
consolidação do poder pessoal de Vargas e para a estabilização do Estado de Compromisso, pois a representação das massas populares, fonte de legitimidade para o Estado, estava controlada pelo próprio chefe de Estado. Essas seriam as bases, por sua vez, do populismo, outra característica considerada marcante do período desenvolvimentista brasileiro. Nas palavras do autor:

Em realidade, o populismo é algo mais complicado que a mera manipulação e sua complexidade política não faz mais que ressaltar a complexidade das condições históricas em que se forma. $\mathrm{O}$ populismo foi um modo determinado e concreto de manipulação das classes populares mas foi também um modo de expressão das suas insatisfações. (Ibid., p. 62-63).

De acordo com Fausto, a concretização do Estado de Compromisso foi permitida pela inexistência de oposições radicais no interior das classes economicamente dominantes. Até 1937, a burguesia do café fora alijada do poder central. A instituição que teria garantido a existência do Estado de Compromisso foi o Exército. Além disso, o Estado manteve o papel fundamental de desorganizador político da classe operária, embora abordasse a questão social, também com o intuito de controle. ${ }^{230}$ Exemplo disso, conforme destaca Weffort, é que Vargas "doou" às massas urbanas uma nova legislação trabalhista - a Consolidação das Leis Trabalhistas (CLT) -, publicada em 1943.

Não obstante, vale notar que essa nova legislação estava limitada aos setores urbanos, justamente aqueles com maior capacidade de pressão política, e, também por isso, não se chocava com os interesses dos grandes proprietários de terras. Ainda segundo Fausto, esse Estado de Compromisso correspondia a uma nova forma de Estado mais centralizador, intervencionista e, em certa medida, nacionalista. Do ponto de vista ideológico, estabelecia-se uma tendência ao abandono de fórmulas e políticas liberais, conferindo uma maior dose de intervencionismo ao Estado, considerado como uma condição básica para a expansão das atividades industriais, como bem ressaltado pelos próprios pioneiros do desenvolvimento econômico.

Sobre a relação entre a nova forma de Estado inaugurada com a Revolução de 1930 e o desenvolvimento industrial, Dean (1971) argumenta que a crescente intervenção governamental observada não propunha explicitamente acelerar o processo de industrialização. Segundo ao autor, durante as fases provisória e constitucional do governo de Vargas, ainda estaria presente uma crença de que o mundo de 1913 pudesse voltar a

\footnotetext{
${ }^{230}$ Segundo Malloy (1977), a organização das relações econômicas, com o Estado regulando e definindo tanto a forma quanto o conteúdo das relações entre trabalhadores e empresários, era central aos esforços de Vargas. O Ministério do Trabalho foi criado em 1930. O sistema de cooptação e controle acabou neutralizando o trabalho como fonte de sustentação de grupos de oposição, despolitizando as organizações trabalhistas. Desenvolveu-se um elaborado corpo de legislação regulatória relacionada às relações trabalhistas. Assim, na Era Vargas, o sistema de seguridade social teria se tornado parte integrante de uma atuação estatal consciente e estratégica.
} 
reorganizar-se. Nesse sentido, "Os controles impostos à economia eram medidas ditadas pelo desespero, constante ação de retaguarda que mais visava salvar o sistema existente do que a tentar criar um sistema novo" (DEAN, 1971, p. 220-221). Teriam sido a redução da entrada de capital e as dificuldades de aumento das exportações os fatores que levaram à busca de novos caminhos, e não uma suposta opção intencionada, desde o princípio, em prol do desenvolvimento industrial.

Essa observação remete novamente à questão da intencionalidade da escolha pela industrialização do governo brasileiro, discutida e retomada por Furtado em vários momentos de sua obra. Conforme discutido anteriormente, a industrialização parece ter sido uma resposta mais às restrições externas que se colocaram com a Grande Depressão, inviabilizando a insistência no modelo de crescimento primário-exportador, do que propriamente um resultado de uma elevada consciência, naquele momento, de que a industrialização era crucial para superar o subdesenvolvimento e conquistar uma trajetória de desenvolvimento autônomo. Rosenstein-Rodan (1943, 1944), por exemplo, ressaltara que a industrialização das regiões atrasadas não ocorreria espontaneamente, por conta de mecanismos cumulativos existentes entre nível de renda e industrialização, requerendo a formação de um grande impulso, que pressupunha a promoção de investimentos em bloco baseados numa industrialização planejada pelo Estado. Por outro lado, mesmo antes de 1930, o Brasil já possuiria indústrias, ${ }^{231}$ embora pouco complexas. Provavelmente, o aproveitamento dessa capacidade produtiva já instalada ${ }^{232}$ teria sido um dos facilitadores do aumento da produção industrial na década referida, fazendo frente à demanda deslocada das importações.

Naquele contexto enfrentado pelo Brasil no início da década de 1930, de grandes restrições às importações e com a garantia da manutenção da renda por meio da política de defesa de preços do café, mesmo na ausência de uma política industrial intencional, foi possível desenvolver a produção industrial, embora predominantemente de bens de consumo não duráveis. No entanto, isso não quer dizer que a industrialização tenha acontecido espontaneamente: se as condições adversas decorrentes da Grande Depressão não tivessem se colocado, o mais provável é que a economia brasileira não tivesse deslocado o seu centro dinâmico para o mercado interno. Essa não intencionalidade de política industrial teria sido superada, em alguma medida, no decorrer das próximas décadas, quando passaram a surgir preocupações relativas à necessidade de desenvolvimento de setores básicos e/ou

\footnotetext{
${ }^{231}$ Vide, por exemplo, Fishlow (1972).

${ }^{232}$ Vide, por exemplo, Furtado (1959).
} 
considerados estratégicos, e na tentativa de incentivar o desenvolvimento de setores produtores de bens de consumo, de capital ou intermediários, por meio de políticas cambial, creditícia e fiscal.

Fruto ou não de intencionalidade política, o setor industrial passou a ter peso crescente como centro dinâmico da economia brasileira, provocando transformações profundas na composição socioeconômica brasileira. Por outro lado, a ausência de programação e de planejamento de longo prazo, que seriam possíveis reflexos da não intencionalidade, teve efeitos nada negligenciáveis. Os modelos teóricos dos pioneiros do desenvolvimento, de uma forma ou de outra, traziam implícita a necessidade de planejamento estatal para que se superassem os círculos viciosos representativos do subdesenvolvimento. Mesmo Hirschman (1958), que salientara, com razão, que o processo de aprendizado se realizava especialmente no decorrer do processo, não podendo, portanto, ser um pressuposto, indicava a importância estratégica de concentrar esforços, dada a escassez de recursos disponíveis, em setores com maior capacidade de geração de encadeamentos pelo sistema econômico. Em poucas palavras, de alguma forma o planejamento e programação tinham que estar presentes.

Assim sendo, em alguma medida, seria possível já afirmar que algumas das distorções e desequilíbrios que se colocaram à economia brasileira conforme se avançava na industrialização podem ter decorrido desse caráter relativamente improvisado com que se efetivaram os investimentos no setor industrial. Embora, vale ponderar, conforme discutido adiante, esse caráter de improvisação tenha diminuído no decorrer dos cinquenta anos do período desenvolvimentista, algo que, ao menos em teoria, é possível visualizar na elaboração dos planos de governo, que vão se tornando crescentemente complexos.

Segundo Dean, em 1937, diante da iminente redução da quantidade de divisas necessárias para as importações vitais e para manter os pagamentos da dívida, o governo adotou o monopólio cambial. O autor destaca que, dez dias depois de assumir poderes ditatoriais, instaurando o Estado Novo (1937-1945), Vargas decretou a suspensão do pagamento da dívida externa. No mês seguinte, o governo estabeleceu o monopólio de venda de divisas e impôs uma taxa sobre todas as operações cambiais. Desse modo, de acordo com o autor, o Estado Novo abandonara o liberalismo, tanto econômico quanto político. Observada a tendência à deterioração dos termos de troca, mostrava-se patente a necessidade de substituição de importações para desenvolver a indústria e dinamizar a economia brasileira. $\mathrm{O}$ equilíbrio das forças políticas também se modificara: restituiu-se o poder aos membros do Partido Republicano Paulista e, com eles, aos industriais. A Constituição criou um organismo legislativo separado, o Conselho Econômico Nacional, com representação funcional, ao estilo 
do corporativismo italiano. As greves e os bloqueios foram declarados antissociais e nocivos ao trabalho e ao capital. Nas palavras do autor:

[...] a atitude dos industriais [...] era cada vez mais favorável à ditadura. Esta não somente lhes proporcionava toda uma nova série de incentivos e favores, mas também lhes assegurava um dócil pool de mão-de-obra barata e lhes abria considerável esfera de influência na formação da política econômica. (DEAN, 1971, p. 241).

Dean afirma que no início de 1938 já era possível perceber que o monopólio do câmbio estava surtindo efeitos, tendo aumentado os fluxos de importações de metais, máquinas e combustíveis. No fim do mesmo ano, o governo estabeleceu uma escala de prioridades das importações, favorecendo o influxo de bens de capital. Foram abertas novas e extensas fontes de financiamento público, tal como o "Departamento de Crédito Agrícola e Industrial" vinculado ao Banco do Brasil. Entretanto, segundo o autor, o ato mais importante do governo de Vargas teria sido a construção da usina siderúrgica integrada em Volta Redonda, ${ }^{233}$ o que potencialmente permitiria reduzir a dependência de importações de ferro e aço. Além disso, no contexto de crescente apreensão com relação ao encaminhamento à guerra das potências europeias, foram assegurados empréstimos, subsídios e incentivos aos industriais que se dispuseram a aliviar a escassez de importações produzindo similares nacionais. Concomitantemente, desencorajava-se, por meio de controle de preços e pelas cotas de exportação, o investimento na produção café e de outras mercadorias básicas de exportação.

Segundo Abreu (1990a), no contexto da II Guerra Mundial, em vistas da escassez de importações, alcançaram-se saldos positivos na balança comercial. Com relação à referida escassez, o autor destaca a importância de notar seu efeito dúbio: por um lado, um efeito protecionista para alguns setores produtivos e, por outro lado, um efeito retardatário ao desenvolvimento de outros setores. $\mathrm{O}$ autor indica, com base em dados sobre o crescimento industrial no período, que teriam predominado as benesses do efeito protecionista ao setor industrial.

Abreu detalha que, antes de 1942, as autoridades brasileiras não pareciam tão preocupadas com o controle das importações. ${ }^{234}$ No entanto, no final de 1943, estabeleceu-se

\footnotetext{
${ }^{233}$ Abreu (1990a) ressalta que o caso de Volta Redonda, cuja consecução contou com créditos e materiais estadunidenses, seria paradigmático dos objetivos estratégicos dos Estados Unidos na América Latina. Ademais, do lado brasileiro, há que se considerar as crescentes dificuldades observadas no seu comércio de compensação com a Alemanha, bem como da perda de importância relativa das relações anglo-brasileiras. Em troca dos recursos dos Estados Unidos, o Brasil forneceu garantias genéricas de fornecimento de materiais estratégicos.

${ }^{234}$ Segundo Abreu (1990a, p. 95), "Em mais de um sentido, 1942 corresponde a um ponto de inflexão do ponto de vista econômico no Brasil: acelerou-se o crescimento industrial; pela primeira vez desde a década de 20 começaram a acumular-se reservas cambiais; observa-se a entrada de capitais privados norte-americanos após longo período de desinteresse."
} 
um novo arranjo de controle de importações feito pela Carteira de Importações e Exportações (CEXIM), em conjunto com a embaixada dos Estados Unidos. No entanto, as metas de fornecimento dos Estados Unidos ao Brasil não foram cumpridas. $\mathrm{O}$ autor observa que, na medida em que se configurava o fim da guerra, tentou-se reorientar a política externa de forma a promover uma reaproximação comercial com a Inglaterra, o que permitiria fazer um contrapeso à dependência comercial crescente com os Estados Unidos. No entanto, segundo o autor, o apelo estadunidense teria sido mais forte. Importante notar desde já que, aos Estados Unidos passarem a apoiar uma guinada de caráter liberal no Brasil, esse fato teria composto um fator significativo no processo de desestabilização da ditadura varguista.

Ainda sobre o período de guerra, segundo Malloy (1977), além da turbulência externa, estabeleceu-se um conflito interno no Brasil, relacionado às questões trabalhistas. Assim como após a I Guerra Mundial, após a II Guerra Mundial, os países centrais passaram a se direcionar em prol de políticas sociais reformistas. No Brasil, estavam colocadas três novas metas reformistas: a universalização da cobertura da seguridade social, a uniformização dos benefícios e a unificação da administração dos sistemas de seguridade social, lembrando que a CLT fora estabelecida em 1943. Todavia, naquele momento já não haveria mais margem de manobra para sustentar a centralização política. Com a queda de Vargas, a batalha pela reforma da seguridade social se transferiu, pela primeira vez, para a esfera legislativa.

Para Lessa e Fiori (1991), o governo Dutra (1946-1951) tinha implícita a esperança de que, no pós-guerra, a divisão internacional do trabalho voltaria ao seu funcionamento tradicional, e que, portanto, o Brasil poderia retomar sua identidade predominantemente agroexportadora. Em 1946, o mercado livre de câmbio foi restaurado, inclusive para a conta de capital, optando-se, por conseguinte, por uma política liberal de importações. O Decreto Lei $\mathrm{n}^{\circ} 9.025$ de fevereiro de 1946 marcou o retorno da liberalização cambial após o fim da II Guerra Mundial. Acreditava-se no diagnóstico de que a situação das reservas inspirava tranquilidade, de que, se necessário, os Estados Unidos prestariam assistência ao governo brasileiro e de que o influxo de investimentos estrangeiros também aumentaria. Com essas expectativas em mente, a restauração do mercado livre de câmbio permitiria, simultaneamente, atender à demanda reprimida de bens de capital e de insumos importados, reduzir as pressões inflacionárias internas e atrair capital externo. No entanto, as reservas acumuladas na guerra eram, em sua maioria, inconversíveis. Para complicar o quadro, a maior parte dos déficits do Brasil continuava sendo com a área conversível. Assim sendo, apesar da expansão das exportações, o clima de euforia importadora acabou durando pouco.

Vale ressaltar que essa guinada liberal do governo Dutra seria mais um exemplo da 
ausência de planejamento de longo prazo do governo brasileiro e, inclusive, do contexto internacional em que se enquadrava, caraterizado, segundo os pioneiros do desenvolvimento, pela tendência das nações subdesenvolvidas a permanecerem como tais na ausência de políticas deliberadas de desenvolvimento, que incluíam necessariamente o intervencionismo estatal e o desenvolvimento da indústria. Era como se, retiradas, mesmo que aparentemente, as restrições externas, a nostalgia dos períodos de liberalismo econômico se fizesse sempre presente, incitando um retorno a políticas e modelos econômicos de outrora.

Segundo Vianna (1990a), em virtude das restrições externas e do reconhecimento das dificuldades e implicações da manutenção de políticas liberais, o retorno aos controles cambiais e de importações ocorreu já em meados de 1947. Institui-se o regime de câmbio por cooperação, cuja regra implicava que os bancos autorizados a realizar operações cambiais tinham que vender $30 \%$ de suas cambiais ao Banco do Brasil, à taxa oficial de compra. O Banco do Brasil, por sua vez, distribuía essas cambiais de acordo com critérios de essencialidade das importações. Mesmo diante dessas medidas, de acordo o autor, o controle instituído não teria sido rigoroso, o que sugeriria que "[...] as restrições ao comércio exterior eram apresentadas como passageiras e destinadas a serem abandonadas assim que os mercados mundiais se recuperassem.” (VIANNA, 1990a, p. 111). Apenas no início de 1948 foi adotado um controle mais estrito, com o contingenciamento de importações via concessão de licenças prévias. ${ }^{235}$

Lessa e Fiori destacam que, como agência administradora desse regime, a CEXIM constituiu-se em arena privilegiada de jogo de interesses. Nesse espaço burocrático, decidiase, em larga medida, o desempenho relativo das empresas. O regime de licenças prévias privilegiou as importações de bens intermediários e de capital, tendo o setor industrial se beneficiado de tal esquema. Vale notar, igualmente, que a decisão de manter a taxa de câmbio constante estava relacionada ao temor de uma realimentação inflacionária - em virtude do incremento dos custos de produção - e de que se verificassem manobras baixistas no preço internacional do café. Os autores chamam a atenção para o fato de que, como o esquema de licenças prévias manteve-se por cinco anos, isso seria um indicativo de uma relativa comunhão de interesses, uma vez que se mostrava conveniente para o capital industrial, o capital comercial e o capital cafeeiro. ${ }^{236}$

\footnotetext{
${ }^{235}$ Segundo Vianna (1990a, p. 111), esse sistema de controle permaneceu, na prática, até a liberalização ocorrida no início do Governo Vargas e, em termos de legislação, até outubro de 1953, sendo substituído pela Instrução 70 da SUMOC - Superintendência da Moeda e do Crédito.

${ }^{236}$ Os únicos que não teriam se beneficiado teriam sido os exportadores de produtos "gravosos", ou seja, aqueles produtos sem condições de colocação no mercado exterior à taxa oficial de câmbio (VIANNA, 1990a, p. 113).
} 
Lessa e Fiori ressaltam que, assim como a CEXIM, o Banco do Brasil também se constituiu em arena privilegiada de disputa de interesses. Como não existia um mercado de capitais que possibilitasse operações de valorização financeira, e sendo o sistema bancário privado relativamente pouco desenvolvido - porquanto operava apenas linhas de desconto e de crédito pessoal -, o Banco do Brasil desempenhava papel crucial. O padrão de financiamento do conjunto de empresas requeria contínua expansão creditícia e apresentava alta vulnerabilidade a variações negativas da taxa de expansão de crédito.

No início da década de 1950, a base técnico-produtiva industrial brasileira persistia criticamente dependente das importações de bens intermediários e de capital. Lessa e Fiori enfatizam que a matriz industrial nacional apresentava descontinuidades profundas. A superação dos pontos de estrangulamento - ou gargalos produtivos - teria sido, para os autores, a preocupação central das orientações governamentais na década de 1950. O segundo governo Vargas (1951-1954) apresentava como prioridade a ampliação da infraestrutura de transportes e energia. De acordo com os autores, o desinteresse e a incapacidade do setor privado em assumir a solução desses pontos de estrangulamento implicaram a necessidade de atuação estatal direta. Como exemplos dessa fase, observaram-se a criação da Petrobras, em 1953, e a proposta de criação da Eletrobras, em 1954, embora tenha sido efetivada apenas em 1962.

Essa observação é importante, pois os setores de infraestrutura podem se constituir em sérios obstáculos para o desenvolvimento satisfatório de outros setores, tal como salientara explicitamente o pioneiro Rosenstein-Rodan (1943, 1944), ao argumentar que, inicialmente, os investimentos deveriam se concentrar na formação de indústrias básicas e nos serviços públicos, não somente porque ambos possuíam alto potencial de fazer surgir novos canais de investimento, por meio da geração de economias externas, mas principalmente porque a sua não disponibilidade poderia ser impeditiva do estabelecimento de outras atividades produtivas, bloqueando o processo de desenvolvimento. Também nesse sentido, são elucidativos os conceitos de encadeamentos para frente e para trás de Hirschman (1958), pois seria justamente a falta de interdependência e de encadeamentos entre os setores que compõem o sistema econômico nacional uma das características típicas das nações subdesenvolvidas. Dito de outro modo, o não enfrentamento direto dos gargalos na estrutura produtiva da economia brasileira tenderia a enfraquecer os impulsos pela cadeia produtiva, como bem ressaltara Myrdal (1957).

No entanto, apesar das supostas preocupações estratégicas, Lessa e Fiori não identificam no segundo governo Vargas a existência de um pacote integrado de investimentos 
que promoveria a industrialização pesada, tampouco um caráter nacionalista de seu programa de desenvolvimento. Além disso, não teria havido uma política industrial explícita, pois, mesmo levando em consideração o regime de licenças cambiais, teria prevalecido o atendimento a demandas do parque industrial já existente. A superação dos pontos de estrangulamento implicava também a necessidade de um aumento da base fiscal e financeira do setor público. Porém, nesse caso, as soluções teriam respondido igualmente aos interesses e às articulações existentes.

No início de 1953, observou-se um acúmulo de problemas. Segundo Lessa e Fiori, a política de estocagem de importações - relacionada ao contexto da Guerra da Coréia - fora executada sem levar em conta os riscos relacionados à queda da disponibilidade de reservas cambiais, bem como ao acúmulo de atrasados comerciais. Foram promovidos cortes fiscais, contenção creditícia e controle seletivo de importações. Em outubro, foi estabelecida a Instrução 70 da SUMOC, ${ }^{237}$ que englobava um complexo sistema de administração cambial, composto por diversos mercados cambiais com taxas múltiplas de câmbio, definidos a partir da combinação de critérios de proteção e essencialidade. Dentro de cada grupo, a partir de patamares, foram leiloadas as licenças. No caso das exportações, conforme indica Vianna (1990b) foi estabelecida uma escala de bonificações variáveis - uma para o café e outra para os demais produtos - criando-se, na prática, duas taxas de câmbio para as exportações.

Apesar das medidas intervencionistas e da atuação direta do Estado em alguns setores considerados estratégicos, sobre o segundo governo Vargas, Lessa e Fiori concluem que não se estabeleceu de fato uma política de cunho nacionalista; o que se observou foi o desenho progressivo de uma política de desenvolvimento capitalista associado ao capital estrangeiro e ao capital privado nacional no longo prazo, combinada a uma política econômica conservadora condizente com os interesses de curto prazo. Sob a perspectiva dos autores, não haveria, então, descontinuidades entre o projeto de desenvolvimento dos governos Getúlio Vargas e Juscelino Kubitscheck.

Como bem observa Villela (2005), na sua campanha presidencial em 1955, Juscelino Kubitscheck divulgou um documento intitulado "Diretrizes Gerais de um Plano Nacional de Desenvolvimento". Esse documento foi uma declaração de intenções, indicando a implementação de um programa de desenvolvimento econômico acelerado, com o intuito de transformar o país estruturalmente. A base do Plano de Metas, lançado em 1956, consistiu nos estudos da Comissão Mista Brasil-Estados Unidos (CMBEU) e do Grupo Misto CEPAL-

\footnotetext{
${ }^{237}$ No final de 1953, extinguiu-se a CEXIM e instituiu-se a CACEX - Carteira de Comércio Exterior - como administradora do novo sistema de controle e administração de divisas.
} 
BNDE. O Conselho de Desenvolvimento, criado por decreto em 1956, foi o responsável pela elaboração do Plano de Metas. Estabeleceram-se cinco áreas de investimento, relacionadas à energia, ao transporte, à alimentação, à indústria de base ${ }^{238}$ e à educação, além de uma meta extra, a construção de Brasília - cujos gastos não estavam orçados no Plano. Na prática, os setores prioritários eram os de energia elétrica, de produção de carvão, de petróleo, de siderurgia, de cimento, de indústria automobilística, de mecânica, de material elétrico pesado e naval. Previu-se que 50\% dos gastos seriam provenientes do setor púbico, $35 \%$ de fundos privados e os restantes $15 \%$ de agências públicas. Porém, mesmo diante da previsão do aumento dos investimentos e gastos públicos, não foi proposta nenhuma reforma tributária.

De acordo com Lessa (1982), o Plano de Metas “[...] constitui a mais sólida decisão consciente em prol da industrialização na história econômica do país.” (LESSA, 1982, p. 27). Teria sido concedida prioridade absoluta à construção dos estágios superiores da pirâmide industrial verticalmente integrada. $\mathrm{O}$ autor explica que a política econômica implícita ao Plano previa um tratamento preferencial ao capital estrangeiro, o financiamento dos gastos públicos e privados via expansão monetária e creditícia, a ampliação do setor público na formação bruta de capital fixo e o estímulo à iniciativa privada, via a concessão de uma gama de subsídios e incentivos, dos quais se destacavam: a Instrução 113 da SUMOC de 1955; o financiamento de importações a "câmbio de custo"; as quotas de câmbio para peças importadas; as isenções fiscais, de diversas naturezas; e o crédito subsidiado às indústrias de base, de modo que as empresas desses setores passaram a ter acesso ao crédito e às garantias financeiras do BNDE. Vejamos em mais detalhes algumas dessas medidas.

Até meados de 1957, a política cambial continuou sendo ditada pela Instrução 70 da SUMOC, com duas modificações importantes durante o breve governo Café-Filho. A primeira delas, a Instrução 112 da SUMOC, de janeiro de 1955, ampliou as categorias de exportação do sistema de bonificações fixas iniciado com a Instrução 109, de novembro de 1954. A segunda mudança referiu-se à Instrução 113 da SUMOC, também de janeiro de 1955, que simplificou o licenciamento de importações, via CACEX, que seriam realizadas sem cobertura cambial para máquinas e equipamentos destinados à instalação ou ampliação da base produtiva das empresas. A CACEX também ficava autorizada a licenciar, a favor das empresas nacionais, a importação de equipamentos financiados no exterior em prazo não inferior a cinco anos. Como bem observa Pinho Neto (1990), esses equipamentos seriam incorporados aos ativos das empresas sem implicar uma contrapartida no passivo exigível.

\footnotetext{
${ }^{238}$ No Plano de Metas, o conceito de indústria de base abrangia: a siderurgia, a automobilística, a de material elétrico, a de máquinas e equipamentos e a naval.
} 
Ainda segundo o autor, na verdade o que se pretendia com a Instrução 113 era a consolidação de legislação anterior ${ }^{239}$, porém facilitando o processo, uma vez que a aprovação das importações sem cobertura cambial passava a depender apenas da deliberação da CACEX. Na prática, segundo Villela, a Instrução 113 da SUMOC se mostrou um instrumento eficaz de atração de capital estrangeiro, na medida em que a esse era concedido um subsídio implícito. Assim, os objetivos da Instrução foram permitir a elevação das importações - necessárias aos planos de investimentos do Plano de Metas -, sem que isso implicasse uma contrapartida de pressão sobre as divisas, ${ }^{240}$ bem como estimular a entrada de capital estrangeiro.

De acordo com Villela, a Instrução 70 da SUMOC foi substituída em agosto de 1957, pela Lei de Tarifas, $\mathrm{n}^{\mathrm{o}} 3.244^{241}$. Manteve-se o sistema de leilão cambial, mas as categorias foram alteradas. Duas categorias continuariam sujeitas ao sistema de leilão e uma não. As categorias que continuariam sob o sistema de leilão eram a categoria geral, compreendendo as matérias-primas, os equipamentos e os produtos em geral que apresentassem um abastecimento doméstico insuficiente, e a categoria especial, que englobava os bens de luxo e outros bens que apresentassem um abastecimento interno considerado suficiente. A categoria preferencial, que não estava sujeita ao sistema de leilão cambial, englobava bens considerados essenciais, que seriam importados a câmbio de custo.

No que se refere às exportações, segundo Orenstein e Sochaczewski (1990), a reforma cambial promovida em 1957, que vigorou até 1961, sofreu mudanças importantes ao longo desses quatro anos, referentes à passagem gradual das exportações para o mercado livre. Os autores destacam: a Instrução 167 da SUMOC, de janeiro de 1959, que liberara as exportações de manufaturados para o mercado livre; a Instrução 192 da SUMOC, de dezembro de 1959, que transferira todas as exportações para o mercado livre, à exceção do café e de alguns outros poucos produtos; e a Instrução 181 da SUMOC, de abril de 1959, que

\footnotetext{
${ }^{239}$ Segundo Pinho Neto (1990, p. 167, nr. 13), essa legislação anterior correspondia à: Lei no 1.807 de janeiro de 1953, que criara o mercado livre de câmbio e transferira para ele o movimento de capitais; Instrução 81 da SUMOC de dezembro de 1953; e Lei no 1.145 também de dezembro de 1953 . Todas elas isentaram determinadas importações consideradas essenciais da licitação de divisas. Com essas medidas anteriores em mente, Pinho Neto realiza uma observação semelhante àquela de Lessa e Fiori (1991), em que os autores indicavam que o Governo Vargas não teria sido, de fato, um governo nacionalista. Diz o autor: "[...] é importante enfatizar que não houve qualquer "ruptura", no que tange ao tratamento concedido ao capital estrangeiro, que tenha sido introduzida pela Instrução, já que o Governo Vargas, apesar da retórica nacionalista, vinha progressivamente liberalizando a legislação aplicável aos fluxos de capitais privados." (PINHO NETO, 1990, p. 155).

240 Conforme observa Villela (2005), a restrição de divisas estava agravada pelo desempenho ruim das exportações de café. Segundo o autor, "Após uma relativa estabilidade no triênio 1955-1957, os preços internacionais do café dão início a uma trajetória de queda, refletindo a expansão da oferta mundial do produto [...] As exportações do produto reduziram-se em mais de US\$ 150 milhões em relação ao ano anterior, o mesmo ocorrendo com as exportações totais, que atingiram em 1958 o nível mais baixo da década [...]" (VILLELA, 1990, p. 54).

${ }^{241}$ Como bem destaca Villela (2005, p. 66, nr. 11), a referida lei modificou a política tarifária, introduzindo a cobrança de impostos ad valorem.
} 
liberara os fretes. Vale notar que as mudanças no regime cambial e no seu sistema de proteção contribuíram, temporariamente, para aumentar as exportações e reduzir as importações.

Quanto ao capital estrangeiro, o novo regime, como argumentado acima, especialmente com relação à Instrução 113 da SUMOC, estimulara o seu ingresso. Entretanto há que se ressaltar que a atração de capital externo tinha uma contrapartida importante: as remessas de recursos referentes a lucros, dividendos e amortizações, que acabaram contribuindo para a persistência do desequilíbrio externo brasileiro. ${ }^{242}$ Assim como ressaltara Singer (1950), tendo em mente a tese Singer-Prebisch, havia uma tendência à acumulação de vantagens por parte das nações desenvolvidas em detrimento das nações subdesenvolvidas. No que se refere às consequências do fluxo de capital, o autor destacou os seus efeitos cumulativos perniciosos às nações subdesenvolvidas - por conta do direcionamento de recursos de investimento a setores específicos, que expressariam o interesse dos investidores estrangeiros, e não necessariamente da economia nacional - e a necessidade de atuação planejada para reverter essa tendência.

Já para o pioneiro Nurkse $(1952,1953)$, a entrada de capital externo por si só não resolveria a questão do círculo vicioso da pobreza, por conta do chamado efeito demonstração, que fazia com que as nações mais pobres, ao terem renda disponível, tendessem a emular o padrão de consumo das nações mais ricas. Um meio de coibir os efeitos perniciosos do efeito demonstração seria própria restrição de importações, especialmente a de bens de luxo, algo realizado de maneira crescente pelo modelo substitutivo de importações. Entretanto, segundo o autor, essa política de restrição de importações não seria suficiente, pois o efeito demonstração tende a atuar na função de consumo geral, e não apenas na pauta de importação, resultando na concentração de capital em indústrias produtoras desses bens de luxo.

De modo que, a combinação da observação de Singer (1950) com a de Nurkse (1952, 1953), destacadas nos dos parágrafos anteriores, constituiria uma boa explicação para a tendência ao sobreinvestimento em setores produtores de bens de consumo duráveis, tal como destacara Furtado, em variados momentos de sua obra, conforme discutido no capítulo anterior. Também nesse sentido, Kalecki e Sachs (1966) advertiram sobre o risco do influxo de recursos externos se dissiparem em consumo adicional de bens de luxo. Essa foi uma tendência identificável no modelo de desenvolvimento brasileiro que, embora tenha permitido o desenvolvimento de toda a sua base industrial, teve sua dinâmica pautada, especialmente a

\footnotetext{
${ }^{242}$ Conforme discutido mais à frente, essa questão ganhou dimensão ainda mais importante a partir da década de 1960, no período do "milagre" e da implementação do II PND.
} 
partir do Plano de Metas, pelo setor produtor de bens de consumo duráveis, que além de concentrar boa parte do volume de capital captado, à sua produção tinham acesso apenas os grupos de alta renda.

Lessa observa que outra orientação implícita do Plano de Metas teria sido uma relativa negligência quanto aos investimentos na infraestrutura social, apesar de apresentar a educação como uma das suas cinco metas. Mesmo diante de altos índices de analfabetismo, vale notar que a meta de educação referia-se apenas ao ensino técnico, e previa apenas 2,8\% do total dos gastos do Plano. Com relação à qualificação da mão-de-obra, no caso brasileiro, seria possível inferir que a acomodação com a tecnologia teria contribuído para diminuir o estímulo ou a preocupação com a formação de uma base de pesquisa científico-tecnológica própria, seja na esfera pública, seja na esfera privada. A forma de especialização de mão-deobra exigida pela indústria brasileira não requeria, ou não estimulava, inversões significativas de recursos. Além de a tecnologia ser importada, vale destacar que, em sendo considerável o peso das empresas estrangeiras, especialmente nos setores relativamente mais intensivos em tecnologia, a demanda por mão-de-obra qualificada acabava sendo provavelmente satisfeita pelos próprios técnicos estrangeiros.

Outro exemplo que ajudaria a corroborar a observação sobre a despreocupação com a qualificação de mão-de-obra seria o próprio setor agrícola: a liberação de mão-de-obra da agricultura não se realizou preponderantemente em virtude de melhorias nas técnicas produtivas e nos incrementos de produtividade, mas porque os salários urbanos representavam um atrativo quando comparados com as baixas condições de vida rural. Assim, além da pouca relevância direcionada à questão educacional, nenhuma atenção concreta foi concedida pelo Plano de Metas à transformação estrutural do setor agropecuário. O setor agrícola brasileiro, mesmo com o desenvolvimento da base industrial, continuava caracterizado, em geral, por baixa produtividade e, por conseguinte, pelo emprego de mão-de-obra não especializada, mantendo os problemas cruciais do subdesenvolvimento destacados por Kalecki (1960) e a dualidade estrutural explicada por Lewis $(1954,1955)$; e no setor industrial, a tecnologia da qual se dispunha era importada e, também por isso, inadequada à disponibilidade de recursos local: abundância de mão-de-obra e escassez de capital. Além disso, no setor industrial, os requisitos de qualificação da mão-de-obra que atuava na indústria eram muito mais técnicooperacionais do que propriamente tecnológicos ou científicos.

Tampouco o Plano de Metas teria demonstrado grande preocupação com o nível de 
desigualdade da distribuição de renda, entre classes ou entre regiões ${ }^{243}$. Especificamente sobre a questão da concentração regional, vale destacar da observação de Rosenstein-Rodan (1943, 1944) sobre os mecanismos cumulativos entre industrialização e renda, que, no caso brasileiro, essa cumulatividade teria se traduzido em uma tendência à concentração regional na região Sul-Sudeste, especialmente em São Paulo. Essa concentração, em boa medida, seria explicável pelo fato de ser essa região a que apresentava maior dinamismo prévio, em termos de produção e de mercado consumidor.

A industrialização, no decorrer dos cinquenta anos da fase desenvolvimentista, no entanto, continuou concentrada nessa região. A falta de integração nacional, conforme argumentara Myrdal (1957), explicaria e seria explicada pelos efeitos propulsores fracos característicos das nações subdesenvolvidas. Assim sendo, sem uma interferência planejada, o resultado seria a geração ou ampliação de desigualdades regionais, dificultando a integração nacional, sendo as próprias disparidades regionais, portanto, um obstáculo ao progresso nacional. Para tal, retomando Rosenstein-Rodan, mostrar-se-ia uma boa medida a criação de um novo ambiente institucional que viabilizasse uma industrialização planejada em larga escala, envolvendo o treinamento planejado de mão-de-obra e a promoção dos investimentos em bloco. No caso brasileiro, a interferência planejada englobaria, além do desenvolvimento industrial em outras regiões, a própria racionalização da produção agrícola, conforme argumentara Furtado. ${ }^{244}$

Frente às prioridades do Plano de Metas, Lessa destaca que também teriam ficado em segundo plano as preocupações com o equilíbrio de preços, a situação da balança de pagamentos e o comportamento sadio dos setores monetário, fiscal e cambial. $\mathrm{O}$ financiamento do Plano implicou ainda uma intensificação dos desequilíbrios já existentes, uma vez que não se contava, internamente, nem com recursos, nem com canais financeiros suficientes e adequados às necessidades de investimento que se apresentavam, além do setor público continuar desprovido de instrumentos eficazes de captação de recursos. E o Plano, nesse quesito, não previa quaisquer mudanças institucionais e instrumentais.

Por outro lado, segundo Lessa, quando o Plano de Metas foi lançado, a economia brasileira encontrava-se em um contexto de perda de dinamismo do crescimento e, por isso, não estaria disponível uma margem de manobra política para tentar a alternativa de drenar e de captar recursos do setor privado. O esquema de financiamento inflacionário adotado,

\footnotetext{
${ }^{243}$ Sobre a desigualdade regional, e especialmente com relação ao Nordeste do país, conforme destacado no capítulo anterior, a SUDENE foi criada apenas em 1959, já no final do governo Juscelino Kubitscheck.

${ }^{244}$ Vide, por exemplo, Furtado (1989), em que o autor detalha discussões relativas à SUDENE.
} 
ademais, facilitava a atuação da classe empresarial, por meio da captação de poupanças forçadas, por conta das altas taxas de lucro possíveis - porquanto o crescimento econômico na década de 1950 fora acompanhado por uma redistribuição da renda da indústria em favor dos lucros - e do fácil acesso ao crédito, possíveis de serem conseguidas devido ao alto crescimento do produto promovido pelo Plano.

Em termos qualitativos, segundo Lessa, o Brasil adentrou a década de 1960 com um perfil industrial relativamente maduro. No entanto, não maduro o suficiente para atestar que havia se estabelecido de fato uma economia desenvolvida. Pelo contrário, a evolução observada até então teria acentuado os desníveis e desigualdades setoriais, regionais e sociais pré-existentes. Por outro lado, teria disposto as pré-condições necessárias para a correção dessas disparidades, ao montar uma estrutura industrial mais integrada. Além disso, estava evidenciado o esgotamento das possibilidades de financiar, via inflação, o processo de formação de capital, bem como a necessidade de resolver o problema instrumentalinstitucional do qual padecia o Estado brasileiro.

Em linhas gerais, o Plano de Metas constituiu um exemplo conveniente do que seria uma relativa falta de compreensão, por parte do governo brasileiro, da dimensão da complexidade que envolvia a configuração do processo de desenvolvimento de uma nação subdesenvolvida. O Plano, apesar de conter uma série de metas que abarcavam a busca de soluções para pontos de estrangulamento da base produtiva brasileira, além de ter negligenciado áreas importantes, como a educação e/ou qualificação de mão-de-obra e a produção agrícola, não previa quaisquer mudanças institucionais para lidar com a grande necessidade de recursos que demandava para a sua consecução. Assim, mesmo que a industrialização tenha passado a ser uma meta explícita e principal do Estado, há que se observar que os meios disponíveis para o desempenho do papel de planejador e investidor por parte do governo não sofreram mudanças significativas, o que, ao fim e ao cabo, acabou por dificultar o próprio planejamento, algo considerado central por todos os pioneiros do desenvolvimento econômico.

A década de 1960, como bem salienta Abreu (1990b), foi um período de intensa conturbação política. Em meados de 1961, Jânio Quadros renunciou à presidência. Foi adotado o regime parlamentarista em setembro de 1961, assumindo João Goulart como primeiro ministro. O presidencialismo foi restaurado, no início de 1963, com a eleição de João Goulart, apoiado no Plano Trienal. Embora o Plano Trienal tenha fracassado definitivamente ao final de 1963, na prática, tinha sido abandonado em maio do mesmo ano. Em $1^{\circ}$ de abril de 1964, foi instaurada a ditadura militar, que permaneceu até o início da 
década de 1980. A seguir, alguns detalhamentos sobre a década de 1960, repleta de conturbações e de importantes mudanças para os rumos da economia brasileira.

Ainda de acordo com Abreu, as dificuldades econômicas herdadas do governo Juscelino Kubitscheck, relativas à aceleração inflacionária, à indisciplina fiscal e à deterioração do balanço de pagamentos, foram ressaltadas pelo recém-eleito presidente Jânio Quadros. Em março de 1961, a Instrução 204 da SUMOC determinou a desvalorização da taxa de câmbio e a unificação do mercado cambial. Ademais, foi adotado um sistema de Letras de Importação, cuja implicação era que, ao comprarem suas divisas, os importadores eram obrigados a depositar o valor em cruzeiros referente à importação por 150 dias no Banco do Brasil. Pouco tempo depois, foi extinto o "câmbio de custo", antes aplicável às importações ditas preferenciais. Como bem observa o autor, outra medida de impacto do breve governo Quadros foi a recorrência a novos empréstimos e ao reescalonamento da dívida externa, cujos estoque e serviços derivados haviam aumentado durante o governo Kubitschek. Com a renúncia de Quadros em agosto de 1961, a crise política que então se instaurou ajudou a intensificar o descontrole monetário, fiscal e creditício. Até a eleição presidencial de 1963, segundo o autor, instalou-se um contexto de indefinição política e de dificuldades na tomada de decisões econômicas.

O sistema parlamentarista foi implantado através de emenda constitucional, e apresentava, segundo Abreu, um programa de governo extremamente genérico, com o indicativo de que o principal problema a ser enfrentado era a insuficiente taxa de crescimento. O governou parlamentarista estabeleceu medidas de emergência e de reforma institucional no que se referia ao escopo das políticas monetária, bancária e financeira. No terreno monetário e bancário, as medidas emergenciais abrangiam controles quantitativos de crédito. Já as reformas institucionais, incluíam menção à criação do Banco Central e do Banco Rural, a reforma da legislação bancária e medidas de estímulo ao mercado de capitais. No que se refere à política financeira, a proposta era a aplicação de um plano de economia de gastos e o financiamento do déficit de maneira não inflacionária. No campo das reformas institucionais, indicava-se a necessidade de promover uma reforma administrativa e uma reforma fiscal que estimulasse a formação bruta de capital fixo. A política cambial, por sua vez, deveria se basear em taxa única, fixada em um nível considerado realista, introduzindo tarifas ad valorem de importação. Entretanto, continuava sendo necessário manter o controle quantitativo das importações consideradas não essenciais. Como destaca o autor, João Goulart comprometeu-se ainda com a realização de uma Reforma Agrária.

Abreu destaca que João Goulart apresentou o Plano Trienal de Desenvolvimento 
Econômico e Social, elaborado sob a coordenação de Celso Furtado. As condições políticas para a implementação do Plano pareciam garantidas por conta do apoio ao presidencialismo manifestado no plebiscito. O Plano pretendia corrigir os desequilíbrios internos e externos, cujas medidas estariam embutidas numa política que assegurasse o crescimento da economia e, ao mesmo tempo, estimulasse as transformações estruturais necessárias para diminuir o custo social do crescimento, por meio de reformas de base relativas às áreas administrativa, bancária, fiscal e agrária.

O receituário de correção inflacionária do Plano Trienal, segundo Abreu, embora gradualista, seria semelhante ao de outros programas de estabilização adotados anteriormente: correção de preços defasados, redução do déficit público e controle da expansão creditícia. ${ }^{245}$ Foram estabelecidas metas inflacionárias e metas de crescimento, além da meta de redução do déficit público. Diante de diversos problemas que persistiram e se intensificaram com a implementação do Plano, já no final de abril de 1963, Goulart passou a sinalizar sua desistência com relação à tentativa de conciliar as reformas de base e a estabilização econômica. Foram reintroduzidos os subsídios às importações de trigo e de derivados de petróleo - logo após o anúncio do Plano Trienal, os preços desses dois produtos haviam sofrido ajustes e seus subsídios haviam sido retirados -, iniciaram-se as negociações com o funcionalismo público, sendo concedidos $60 \%$ de aumento salarial, e o salário mínimo foi reajustado em $56,25 \% .{ }^{246}$ Em maio, Goulart explicitou novamente o compromisso oficial de seu governo com a Reforma Agrária.

Embora o Plano Trienal não tenha sido implementado em sua totalidade, especialmente no que se refere às reformas de base, vale tecer algumas considerações sobre a sua diferenciada percepção de planejamento relativamente aos planos de governo anteriores. A adoção de reformas de base seria a tradução, na prática, das discussões teóricas realizadas pelos estruturalistas, tal como Prebisch e Furtado, ${ }^{247}$ a respeito da necessidade de promover transformações estruturais para viabilizar o desenvolvimento no contexto do

\footnotetext{
${ }^{245}$ Abreu (1990b, p. 206) sugere que apesar de elaborado por um estruturalista-Cepalino, o diagnóstico da aceleração inflacionária do Plano Trienal seria ortodoxo, pois apontaria para o excesso de demanda via gasto público como principal causador. No entanto, como bem destacara o próprio autor do Plano Trienal, o seu diagnóstico da inflação referia-se especialmente aos efeitos da emissão monetária provocada pelo déficit público. Vide explicação de Furtado (1989), conforme apresentado na subseção 5.3.4 do capítulo 5.

${ }^{246}$ Sobre a questão trabalhista, de acordo com Malloy (1977), entre 1960 e 1964, a Previdência Social se torna ainda mais um ponto de embate político, com os institutos ainda mais politizados do que antes. Passam a ser controlados por líderes trabalhistas nacionalistas mais radicais, formando a base de poder da coalizão populista do governo Jango. Com o golpe militar em 1964, o novo regime busca despolitizar as questões sociais, desmobilizar o trabalho e eliminar o trabalho organizado como uma força política significante. Passou a dominar o princípio do controle tecnocrático administrativo anti-político.

${ }^{247}$ Vide discussões realizadas com base nos dois autores nos capítulos 4 e 5 .
} 
subdesenvolvimento, pois, conforme salientara Prebisch (1963), sem uma mudança profunda na estrutura social, as transformações produtivas não podem ser satisfatoriamente realizadas, resultando na persistência dos desequilíbrios.

Conforme adiantado no capítulo 5, as reformas de base do Plano Trienal ${ }^{248}$ referiam-se às esferas administrativa, bancária, fiscal e agrária. A reforma administrativa visava incrementar a racionalidade da ação governamental, tanto no que concernia ao funcionamento dos seus centros decisórios, quanto à atuação efetiva dos seus órgãos executivos. A reforma bancária partia do princípio de que a formação de um mercado de capitais amplo e eficiente era crucial para o bom andamento dos programas de desenvolvimento; para tal, fazia-se necessário o aperfeiçoamento da legislação que regulava a atuação das instituições financeiras, criando inclusive bancos especializados para financiar o setor agrícola, o setor exportador e o setor de produção de equipamentos. A reforma fiscal destacava a necessidade de atualizar o sistema tributário, tornando-o compatível com a estrutura da economia brasileira, permitindo uma distribuição mais equitativa da carga fiscal e uma maior eficiência na arrecadação e fiscalização, além de fazer da tributação um instrumento eficaz da política de desenvolvimento econômico e de justiça social. Por fim, a reforma agrária, provavelmente ainda mais polêmica do que a reforma fiscal, partia da análise de que a rigidez da oferta de alimentos era um fator de desequilíbrio no sistema econômico. Indicava-se, inclusive, um desperdício de fatores em virtude da irracionalidade organizacional da economia agrícola brasileira, ainda pautada pelas regras organizacionais que serviram à produção para a exportação. Assim, a reforma agrária prevista pelo Plano Trienal deveria enfrentar, especialmente, a erradicação do latifúndio econômico ${ }^{249}$ e do latifúndio social ${ }^{250}$.

Tavares (2011) ressalta que, embora o primeiro Estatuto da Terra tenha sido aprovado no governo Jango, em 1963, a sua regulamentação deveria ter sido feita pelo governo Castello Branco, que a engavetou. No que se refere à reforma fiscal, embora o objetivo fosse criar uma estrutura fiscal progressiva e uma fiscalização para evitar favorecimentos indevidos, na prática, manteve-se apenas a tônica da fiscalização, com o intuito de aumentar a arrecadação. Como bem destaca a autora, uma reforma fiscal mais abrangente foi realizada já na ditadura militar, embora com caráter mais conservador do que se pretendia pelo Plano Trienal. Quanto à reforma administrativa, foram feitas algumas minirreformas, contudo, as maiores mudanças,

\footnotetext{
${ }^{248}$ Vide "Plano Trienal do Desenvolvimento Econômico e Social" apud Furtado, 2011.

249 Caracterizado pela concentração de propriedade e má exploração da terra ("Plano Trienal do Desenvolvimento Econômico e Social” apud Furtado, 2011, p. 437).

${ }^{250}$ Também caracterizado pela concentração de propriedade, porém a sua forma de exploração seria ainda mais perniciosa do que a do latifúndio econômico, pois o proprietário, sempre ausente, extrairia a sua renda por meio de diversas formas de aluguel da terra (Ibid., p. 437).
} 
segundo a autora, vieram com a ditadura, imprimindo um caráter elitista à política de pessoal. Por fim, quanto à reforma bancária, a autora afirma que, de todas as propostas, só a criação de fundos especializados em bancos oficiais fora implantada, sendo que a reforma bancária também acabou sendo objeto de política da ditadura militar.

Desse modo, pelo menos do ponto de vista da intenção, o Plano Trienal elucidava uma visão ampla das mudanças profundas que precisavam ser empreendidas pelo governo brasileiro para alcançar uma trajetória sustentável de desenvolvimento econômico. Não por acaso, fora idealizada pelo Cepalino Celso Furtado, que se debruçara sobre o estudo do subdesenvolvimento e da experiência brasileira desde o início da década de 1950. Embora não haja como afirmar, com qualquer grau de certeza, quais teriam sido as consequências para a trajetória econômica brasileira, a partir de então, se as reformas de base previstas pelo Plano Trienal tivessem sido efetivamente realizadas, é possível conjecturar que, em elas não tendo sido nunca implementadas, poderia residir justamente na não observação delas boa parte da explicação de porque o Brasil não rompeu definitivamente com a armadilha do subdesenvolvimento no seu período desenvolvimentista. Retomando conclusão geral dos Cepalinos Prebisch e Furtado, as reformas de base seriam condição necessária, embora não suficiente, para que os efeitos do crescimento industrial se traduzissem em desenvolvimento econômico de fato.

A questão da necessidade de reformas foi retomada com a ditadura, porém, conforme destaque de Tavares, sob uma roupagem marcadamente conservadora. A política econômica do novo regime militar, sob o comando inicial de Castello Branco, após a deposição do governo Goulart em abril de 1964, foi ditada pelo Programa de Ação Econômica do Governo (PAEG), vigente no triênio 1964-1966. O PAEG foi lançado como um plano de curto prazo emergencial, com o objetivo de enfrentar os desequilíbrios econômicos e a crise decorrente dos anos anteriores. Resende (1990) destaca que os objetivos do PAEG eram: acelerar o ritmo de desenvolvimento econômico, conter o processo inflacionário, atenuar os desníveis econômicos setoriais e regionais, assegurar oportunidades de emprego produtivo à mão-deobra e corrigir a tendência aos déficits do balanço de pagamentos, especialmente em vistas das dificuldades que imprimiam à capacidade de importar, dificultando a continuidade do processo substitutivo de importações. Segundo o autor, o programa acentuava a importância da recuperação das taxas de crescimento da economia, estando o combate à inflação condicionado a não ameaçar o ritmo da atividade produtiva.

O diagnóstico básico do PAEG relacionou a crise que enfrentava a economia brasileira com o descontrole da inflação, a qual teria distorcido as relações econômicas básicas, 
relacionadas ao cálculo de custos, às expectativas de investimento, à taxa de câmbio e ao crédito. $^{251}$ Conforme indica Resende, segundo o PAEG, as causas imediatas da inflação brasileira eram os déficits públicos, a expansão creditícia às empresas e a concessão de aumentos salariais acima dos incrementos de produtividade. Com base nessa análise, como diretrizes gerais de combate à inflação, portanto, o PAEG indicava a necessidade de: conter o déficit público, por meio do corte de despesas não consideradas essenciais e da promoção de uma maior racionalização do sistema tributário; promover uma política de crédito às empresas que evitasse inflamar a inflação de demanda, mas que se adaptasse suficientemente à inflação de custos; e de equivaler os incrementos dos salários aos de produtividade.

Conforme explicitado anteriormente, a política de controle inflacionário proposta pelo PAEG estava qualificada para não paralisar o ritmo da atividade produtiva. A variável-chave do processo de substituição de importações, que compunha o modelo de desenvolvimento brasileiro desde a década de 1930, era a capacidade de importação. Por isso a necessidade de combater a restrição do balanço de pagamentos. A proposta do PAEG para solucionar essa questão explicitava, segundo Resende, além da necessidade de promover incentivos à exportação, “[...] uma opção pela internacionalização da economia, abrindo-a ao capital estrangeiro, promovendo a integração com os centros econômicos internacionais e o explícito alinhamento com o sistema norte-americano da Aliança para o Progresso.” (RESENDE, 1990, p. 215).

Para atingir seus objetivos de contenção da inflação e de promoção do crescimento, o PAEG previa a realização de diversas reformas estruturais, nas áreas fiscal, financeira, cambial e salarial, por meio de instrumentos de ação, relativos à política financeira, à política econômica internacional e à política de produtividade social. De acordo com Hermann (2005), essas reformas tinham como foco principal as estruturas tributária e financeira. ${ }^{252}$ A seguir, uma breve descrição de cada uma desses instrumentos de ação e das suas reformas relacionadas.

A política financeira do PAEG englobava cinco dimensões: política de redução do déficit de caixa governamental, política tributária, política monetária, política bancária e

\footnotetext{
${ }^{251}$ A literatura apresenta interpretações diferentes sobre o diagnóstico da natureza da inflação contido no PAEG. Um grupo de autores tende a ver o diagnóstico da inflação no início dos anos 1960 como sendo de demanda (vide, por exemplo, Macarini, 2006). Para Resende (1990, p. 215), o diagnóstico foi de conflito distributivo, manifestado via orçamento fiscal e salários, sendo a expansão monetária só meio de transmissão, e não causa autônoma de inflação.

${ }^{252}$ Hermann destaca também a criação do Fundo de Garantia por Tempo de Serviço (FGTS), em substituição ao regime de estabilidade de emprego vigente até então, " [...] entendido como um entrave institucional ao aumento do emprego e, por conseguinte, ao crescimento econômico." (2005, p. 74).
} 
política de investimentos. A reforma fiscal levou à criação de novos tributos ${ }^{253}$ e objetivava a redução do consumo governamental, o incremento da poupança pública e a liberação de recursos para o consumo e para o investimento privados. Especificamente sobre a reforma tributária, Hermann sugere que apesar de ter sido exitosa em seu propósito de aumentar a carga tributária, acabou significando mais um impacto distributivo que ajudaria a reforçar a desigualdade de renda. Em suas palavras:

Esse conjunto de medidas resultou em uma significativa elevação da carga tributária do país, que passou de $16 \%$ do PIB em 1963 para $21 \%$ em 1967. Do ponto de vista distributivo, a reforma tributária do governo Castello Branco foi regressiva, beneficiando as classes de renda mais alta (os poupadores), com os incentivos e isenções sobre o imposto de renda. Assim, a maior parte do aumento de arrecadação foi obtida através dos impostos indiretos, que, em termos relativos, penalizam mais as classes de baixa renda. (HERMANN, 2005, p. 75).

No que se refere à reforma financeira, segundo Hermann, as sua medidas objetivavam complementar o sistema financeiro brasileiro, que até então estava constituído basicamente pelas seguintes instituições: bancos comerciais privados e financeiras; caixas econômicas federais e estaduais; e bancos públicos (Banco do Brasil e BNDE), os únicos que atuavam em intermediações de mais longo prazo. Observavam-se também instituições não bancárias, contudo, segundo a autora, não tinham papel relevante até então. Em linhas gerais, a reforma financeira pretendia: disciplinar a operação do sistema bancário e financeiro; criar uma estrutura especializada de agentes; atenuar os efeitos da inflação; e conectar intermediários domésticos ao mercado externo.

Como bem destaca Hermann, o objetivo central da reforma era então disponibilizar ao sistema financeiro brasileiro mecanismos de financiamento que pudessem fazer frente às necessidades do processo de industrialização sem que isso provocasse novas pressões inflacionárias. Nesse sentido, foram criados o Banco Central do Brasil (Bacen) e o Conselho Monetário Nacional (CMN), a fim de reorganizar o funcionamento do mercado monetário. Com respeito ao modelo de financiamento sugerido, esse pretendia que as instituições financeiras atuassem em diferentes segmentos do mercado. Para a viabilização desse modelo, segundo a autora, era necessário: estabelecer regras claras de funcionamento do mercado de capitais, o que foi realizado por meio de uma série de Leis e Resoluções; e dotar as instituições financeiras de condições de acesso a recursos de longo prazo, o que seria

\footnotetext{
${ }^{253}$ Segundo Hermann (2005, p. 74): criação do Imposto sobre Serviços (ISS), a ser arrecadado pelos municípios; substituição do imposto estadual sobre vendas, incidente sobre o faturamento das empresas, pelo Imposto sobre Circulação de Mercadorias (ICM), que incidiria apenas sobre o valor adicionado a cada etapa de comercialização do produto. Além disso, como bem observa a autora, fora ampliada a base de incidência do imposto sobre a renda de pessoas físicas, estabelecera-se uma série de mecanismos de isenção e incentivos a atividades consideradas prioritárias pelo governo e criara-se o Fundo de Participação dos Estados e Municípios (FPEM), por meio do qual o governo federal repassaria parte de seus impostos arrecadados às demais esferas de governo.
} 
supostamente solucionado se fosse incrementado o retorno real dos ativos, requerendo, para tal, medidas de contenção do processo inflacionário e/ou proteção do retorno real dos ativos. $^{254}$

A política econômica internacional do PAEG, por sua vez, compreendia: uma política cambial e de comércio exterior, buscando diversificar as fontes de suprimento e incentivar as exportações; uma política de consolidação da dívida externa e de restauração do crédito externo; e uma política de estímulos ao ingresso de capitais estrangeiros e de cooperação técnica e financeira com agências internacionais. Especificamente com relação ao ingresso de capitais estrangeiros, segundo Hermann, as reformas vinculadas ao PAEG buscaram ampliar o grau de abertura da economia brasileira ao capital externo, de risco e de empréstimo. Para a atração dos recursos externos, foram tomadas, por exemplo, medidas para permitir a captação direta de recursos externos por empresas privadas nacionais e para facilitar as remessas de lucro ao exterior.

Por fim, a política de produtividade social envolvia uma política salarial, uma política agrária, uma política habitacional e uma política educacional. Destacando a política salarial por conta de suas implicações diretas sobre o processo inflacionário -, genericamente, o intuito dessa era conciliar uma maior participação dos trabalhadores nos benefícios do desenvolvimento, sem que os reajustamentos salariais implicassem retroalimentações inflacionárias. Conforme destaca Resende, a Circular nº10 de 1965, do então ministro extraordinário para Assuntos do Gabinete Civil, determinou como deveria ser realizado o reajuste salarial da Administração Pública Federal. ${ }^{255}$ Na prática, consistiu numa forma de intervenção direta na determinação dos reajustes para todos os salários dos setores público e privado. Diz o autor: "Com as atividades sindicais severamente reprimidas e as greves em atividades "essenciais" proibidas - e ao governo competia o julgamento da "essencialidade" o poder de barganha dos sindicatos tornou-se praticamente nulo.” (RESENDE, 1990, p. 217). Como resultado, observaram-se quedas no nível de salário real médio e, consequentemente, uma intensificação da concentração de renda, a qual, segundo observação de Hermann destacada anteriormente, já sofrera um impacto, no mesmo sentido, por conta da reforma tributária.

\footnotetext{
${ }^{254}$ Com vistas a esse objetivo, por exemplo, foram criadas as Obrigações Reajustáveis do Tesouro Nacional (ORTNs), que instituiu a correção monetária da dívida pública.

${ }^{255}$ Em 1966, as normas estabelecidas pela circular referida foram estendidas aos casos de dissídio do setor privado. As normas referiam-se a: deveria ser restabelecida a média salarial real dos 24 meses precedentes; uma taxa de produtividade incidiria sobre o salário real médio; seria acrescida a metade da inflação prevista pelo governo para o ano subsequente, chamado de resíduo inflacionário; e seriam feitos reajustes anuais. Essas normas só viriam a ser alteradas em junho de 1968. (RESENDE, 1990, p. 216-217).
} 
As mudanças e reformas promovidas pelo PAEG, ao menos em tese, buscaram sanar algumas fontes de desequilíbrios da economia brasileira, tendo em vista, especialmente, a forma de financiamento dos investimentos. Nesse sentido, era como se o PAEG tivesse ajudado a preparar o cenário para o "milagre" a ser discutido a seguir.

O governo Costa e Silva (1967-1969) trouxe mudanças significativas à condução da política econômica. Delfim Netto, o novo ministro da Fazenda, teria avaliado de maneira crítica o rigor e a orientação do ajuste promovido durante o governo Castello Branco. Macarini (2006), inclusive, sugere que foi esse novo momento um período marcado pela heterodoxia na condução da política econômica, porém com um intervalo ortodoxo entre dezembro de 1968 e agosto de 1969. O diagnóstico de Delfim indicava que a política adotada entre 1964 e o início de 1967 falhara em combater a inflação e, além disso, causara forte declínio da produção e do emprego, por conta do foco equivocado de que a inflação era exclusivamente de demanda, fazendo com que a política macroeconômica do PAEG impedisse a retomada dos investimentos e, por conseguinte, do crescimento e do desenvolvimento econômicos.

Lago (1990) indica que essa mudança de ênfase foi demonstrada nas "Diretrizes de Governo", documento lançado em julho de 1967. Novamente, os objetivos explícitos da política econômica eram acelerar o desenvolvimento econômico e conter o processo inflacionário. Sinteticamente, as "Diretrizes do Governo" indicavam que, num primeiro momento, previa-se que a aceleração do crescimento seria possibilitada pela melhor utilização da capacidade produtiva já instalada e, posteriormente, pela expansão dessa capacidade por meio de investimentos em setores considerados prioritários, em melhorias nos métodos de produção e nos recursos humanos. Os investimentos públicos, por sua vez, deveriam se concentrar em infraestrutura - energia, transportes e comunicação -, siderurgia, habitação, saúde, educação e agricultura. No que se refere à contenção da inflação, a nova estratégia explicitava a necessidade de concentrar os esforços no combate dos focos de inflação de custos, embora sem descuidar dos focos tradicionais de inflação de procura.

Ainda segundo Lago, todas essas estratégias de política econômica explicitadas nas "Diretrizes do Governo" foram retomadas pelo Plano Estratégico de Desenvolvimento (PED) publicado no final de 1967. As diretrizes de política econômica apresentadas a partir do diagnóstico expresso em meados de 1967 foram complementadas ainda, segundo o autor, por diversas manifestações públicas de autoridades econômicas e, no governo Médici, pelo documento "Metas e Bases para a ação do Governo", publicado em setembro de 1970, e o I Plano Nacional de Desenvolvimento (I PND), publicado em 1972, referindo-se ao triênio 
1972-1974. Essas diretrizes de política econômica formaram o pano de fundo em que se desenrolou o chamado período do "milagre" brasileiro (1967-1973).

Já em 1967, a demanda foi estimulada, de acordo com Lago, por meio de políticas monetária, creditícia e fiscal mais flexíveis. Por outro lado, em vistas da preocupação com a inflação de custos, manteve-se a política salarial anterior, apesar de seus efeitos negativos sobre o nível de demanda agregada via consumo. Outras medidas tomadas para a atenuação da inflação de custos foram a contenção da taxa de juros pagas pelos tomadores de empréstimo e o controle de preços dos insumos e de produtos selecionados. Como bem observado por Hermann, esse controle de preços iniciou-se com a Comissão Nacional de Estabilização de Preços (CONEP), com caráter voluntário, mas, no final de 1967, passou a ser compulsório via Comissão Interministerial de Preços (CIP).

Macarini (2006) sustenta que, do final de 1968 até agosto de 1969, o governo alterou sua rota em direção a uma política deflacionária clássica, promovendo um controle estrito da oferta monetária. Para o autor, as razões para essa mudança foram: o Ato Institucional $\mathrm{n}^{\circ} 5$ (AI-5) de dezembro de 1968, que concedera maior margem de manobra à gestão econômica; e o aumento da insegurança do governo com relação aos resultados econômicos já alcançados, bem como aos futuros. Formou-se a ideia de que, dada a retomada do crescimento observada, seria possível combater novamente a inflação sem colocar em risco o desenvolvimento.

Em outubro de 1969, com o novo governo Médici, Delfim Netto permaneceu no Ministério da Fazenda, porém passou a defender uma nova reorientação da política econômica. A estratégia de crescimento voltou-se especialmente ao incentivo à agricultura e às exportações, encaradas como vias importantes para dinamizar o mercado interno e para promover o crescimento econômico. Embora o prosseguimento do processo de substituição de importações continuasse a ser defendido, passou-se a criticar a exclusiva dependência do crescimento da economia brasileira com relação ao desempenho do setor industrial.

Em linhas gerais, conforme destaca Lago, os resultados em termos de crescimento econômico do período do "milagre" foram bastante significativos, especialmente no setor industrial, mas também no setor agrícola. Os investimentos do governo em infraestrutura de transportes, comunicação e energia contribuíram para a consolidação do setor de bens de capital. Outro destaque no período foi o aumento da produção de bens de consumo durável, o qual seria devido, segundo o autor, não apenas ao processo de concentração de renda pessoal observado, mas também à expansão do crédito ao consumidor iniciada em 1966. Ademais, conforme destaca Fishlow (1986), o período do "milagre" beneficiou-se de uma capacidade ociosa acumulada, o que não implicou a necessidade de altas taxas de investimento para 
atingir e sustentar as altas taxas de crescimento observadas.

Lago destaca ainda o papel importante, para o alcance desses resultados ditos "milagrosos", da política industrial iniciada em 1964 e coordenada pelo Conselho de Desenvolvimento Industrial $(\mathrm{CDI})^{256}$. A política consistiu na concessão indiscriminada de incentivos, uma vez que a CDI teria aprovado, entre 1968 e 1973, a maioria dos projetos submetidos à análise, o que também ocasionou efeitos negativos, especialmente em termos de critérios de essencialidade e da eficiência dos projetos industriais que foram sendo aprovados indiscriminadamente.

Outra questão importante do período do "milagre" refere-se ao papel do endividamento externo. De acordo com Fishlow (1981), entre 1967 e 1973, o Brasil foi um caso de crescimento liderado por endividamento externo, cuja funcionalidade foi financiar altos níveis de importações requeridas para prosseguir na formação da matriz industrial, assim como para permitir a realização de investimentos sem implicar reduções do nível consumo. Essa noção de crescimento liderado por endividamento externo é, porém, criticada por parte da literatura. Lago, por exemplo, conclui, com base em evidências similares às de Fishlow, que a formação bruta de capital fixo fora financiada majoritariamente por recursos internos, enquanto o endividamento levara ao acúmulo de reservas. Na mesma linha argumentativa de Lago, Cruz (1984) afirma, a partir de uma reagregação das contas do balanço de pagamentos $^{257}$, que entre 1969-1973, a balança comercial encontrava-se equilibrada, com entradas de capital de risco e financiamentos que superaram as remessas de lucros, dividendos, amortizações e juros. Teria sido promovida, dessa forma, uma acumulação de reservas. Assim, no ciclo expansivo de 1969-1973, não teria havido uma real necessidade de recorrer aos recursos externos para promover os investimentos internos, por isso a dívida acumulada no período teria apresentado caráter predominantemente financeiro.

Sobre o período do "milagre", ressaltem-se as altas taxas de crescimento alcançadas, bem como o dinamismo industrial que lhe basearam. No entanto, mesmo tendo em vista as mudanças e reformas vinculadas ao PAEG, notava-se a persistência de antigos problemas característicos da economia brasileira, notadamente os de disparidade distributiva - para a resolução da qual as reformas institucionais referidas não tinham se voltado, pelo contrário, teriam inclusive ajudado a intensificá-las - e inclusive de problemas relativos ao financiamento - foco das mudanças institucionais então empreendidas.

\footnotetext{
${ }^{256}$ Antes, a CDI era a Comissão de Desenvolvimento Industrial.

${ }^{257}$ Vale notar que a reagregação de Cruz (1984) define a agregação de capital de risco como investimentos diretos, saldos de lucros e dividendos; e a agregação de capital de empréstimo como empréstimos, saldos de juros e amortizações.
} 
Carneiro (1990) salienta que o ano de 1973 teria sido notável sob diversos aspectos. O contexto prévio ao primeiro choque do petróleo incluía uma economia mundial bastante aquecida e uma série de inovações financeiras associadas ao surgimento do mercado de euromoedas, que permitiu o aprofundamento dos fluxos comerciais e financeiros entre as nações centrais e periféricas. As consequências para a economia brasileira da quadruplicação dos preços do petróleo no final de 1973 foram notáveis, já que, além do impacto direto sobre os custos de importação, anteriormente, o país havia absorvido uma grande quantidade de capitais de empréstimo, com consideráveis contrapartidas em termos de juros e serviços a serem pagos.

Internamente, desenhava-se um contexto também turbulento, pois, segundo Carneiro, "O fim do milagre econômico encerraria também um ciclo festivo de exercício de poder sem limites e sem prestação de contas, sem oposição, sem incômodos da livre imprensa e sem compromissos políticos a criar embaraços ao voluntarismo da política econômica." (CARNEIRO, 1990, p. 297). Em poucas palavras, a margem de manobra do governo militar havia se reduzido consideravelmente, o que, para diversos autores, seria um fator importante para explicar a opção do governo Geisel de prosseguir e de intensificar o processo de crescimento baseado na substituição de importações, colocando a economia brasileira "em marcha forçada".

Em 1974, foi lançado o II Plano de Desenvolvimento Nacional (II PND). Em linhas gerais, o II PND pretendia combinar altas taxas de crescimento com uma mudança na natureza do desenvolvimento econômico brasileiro. Foi elaborado como um programa de ajuste à crise internacional de 1973 e de superação definitiva do subdesenvolvimento. $\mathrm{O}$ alto crescimento industrial previsto seria coordenado pelo Estado, com participação ativa da empresa nacional, seguida pelas empresas estatais e estrangeiras. Pretendia-se, ademais, combinar a industrialização substitutiva de importações com o incentivo às exportações.

A interpretação clássica, e possivelmente a mais aceita pela literatura, do II PND é a apresentada por Castro e Souza (1985). Os autores sugerem que o Plano tinha como intuito atacar os problemas da economia brasileira pela raiz, e, naquele momento, não haveria opção senão recorrer ao endividamento externo e ao redirecionamento forçado dos investimentos. Conforme destacado no capítulo anterior, Furtado (1981) não compartilhava dessa visão, indicando que o II PND acabou perpetuando e intensificando os problemas e desequilíbrios herdados dos períodos de crescimento anteriores.

Fishlow (1986), por sua vez, sugere que haveria duas inconsistências básicas na formulação do II PND. Primeiramente, como não havia uma ampla margem de capacidade 
ociosa na indústria e nem uma capacidade de resposta rápida das exportações, não seria possível que o programa de industrialização substitutiva de importações funcionasse, no curto prazo, como meio de ajustar o balanço de pagamentos. Segundo o autor, o peso excessivo dado à substituição de importações como o principal meio de aliviar a restrição de divisas impediu que essa estratégia funcionasse como uma política efetiva no curto prazo. Além disso, o peso das importações era ainda mais exacerbado por conta da complexidade e da grande escala de investimentos e importações necessárias para avançar nos setores privilegiados pelo II PND. Para o autor, um aumento vigoroso das exportações era um componente fundamental para que a estratégia de ajustamento do balanço de pagamentos tivesse sido bem sucedida.

Em segundo lugar, para Fishlow, o II PND teria pressuposto a existência de um setor público forte e de relações construtivas deste com o setor privado nacional. Entretanto, a base fiscal do governo não teria sido fundamentalmente alterada - e, por isso, derivou-se a necessidade de recorrência ao financiamento externo - e, ademais, o setor privado resistia ao aumento da tributação e exigia, por outro lado, cada vez mais subsídios e transferências do setor público. Além disso, vale destacar que o governo não demandava como contrapartida dos subsídios concedidos ao setor privado provas de práticas produtivas eficientes e competitivas por parte deste. Ou seja, apesar de o Estado ter se ampliado, teria se tornado economicamente mais fraco e por isso teria recorrido à concessão de subsídios e incentivos crescentes ao empresariado nacional como meio de manter seu apoio ao governo militar. Ainda segundo o autor, havia uma miríade de interesses econômicos e políticos envolvidos na estratégia do endividamento externo, conforme discutido adiante.

Dessa forma, contrariamente ao argumento derivado da interpretação de Castro e Souza de que o II PND teria uma alta dose de racionalidade econômica, seria perfeitamente possível encarar o Plano também como uma resposta econômica à insatisfação civil ou como uma forma de legitimar o regime militar instaurado na década anterior. Segundo Lessa (1978), o plano teria sido uma peça central de um projeto "Brasil Potência", o qual teria sido formulado à revelia da sociedade. Já para Fonseca e Monteiro (2007), o II PND teria sido determinado tanto econômica quanto politicamente, pois almejava alcançar, por meios econômicos, a legitimidade e a estabilidade políticas do regime militar. Nesse mesmo sentido, Fishlow argumenta que o momento político não era propício para a imposição de medidas impopulares, como políticas de austeridade monetária e fiscal ou de contenção do crescimento econômico.

Outra questão que se coloca a partir da argumentação de Castro e Souza é se os setores 
estratégicos-alvo do II PND - indústria (bens de capital e insumos básicos) e infraestrutura (energia e transportes) - permitiriam, por si só, a superação do subdesenvolvimento. Com relação a essa questão, a primeira dúvida que surge é se a promoção do desenvolvimento industrial seria condição suficiente para promover e sustentar o desenvolvimento econômico. Conforme derivado dos próprios pioneiros, embora, obviamente, o desenvolvimento de sua base industrial - e, consequentemente, o alcance da autossuficiência em setores produtivos mais complexos - fosse uma condição necessária para um país atingir um estado mais satisfatório em termos de desenvolvimento econômico, e inclusive social, estaria longe de ser uma condição suficiente. Nesse sentido, o enfoque estruturalista indicaria a necessidade de promoção de algumas reformas de base que permitissem solucionar as fontes de disparidades observadas na economia brasileira. Por exemplo, a questão distributiva, que implicaria, dentre outras questões, a promoção de uma reforma tributária de efeito progressivo, a promoção de reforma agrária e uma política salarial que permitisse um maior repasse relativo dos ganhos de produtividade aos trabalhadores. Condições essas que não foram satisfeitas, e tampouco discutidas, nem pelo II PND, nem pelos demais planos de governo efetivamente implementados no decorrer do período desenvolvimentista.

Quanto ao endividamento externo relacionado ao II PND, para Fishlow (1981), o período após 1973 é definido como de "ajuste financiado pelo endividamento". E, como bem destaca Fishlow (1986), o governo facilitou as condições para a entrada de capitais, via redução dos prazos mínimos de vencimento e dos impostos domésticos. O endividamento externo tornara-se, de maneira crescente, um instrumento altamente desejável na medida em que cumpria múltiplos objetivos: amortecia pressões inflacionárias; o relativo barateamento das importações facilitava a manutenção de altas taxas de investimento; e, dado o contexto de alto grau de utilização da capacidade produtiva, o endividamento externo fazia frente à necessidade de financiamento para sustentar as altas taxas de investimento requeridas para cumprir as metas de crescimento. ${ }^{258}$ Ainda segundo o autor, os novos mercados de capitais cuja preferência era o setor público, tendo inclusive as estatais se transformado em agentes do Estado, tanto do ponto de vista do setor produtivo quanto da cobertura de déficits orçamentários e do balanço de pagamentos - foram muito bem quistos, especialmente por conta das baixas taxas reais de juros (que chegaram até a serem negativas), embora, vale enfatizar, contratadas como flutuantes. Assim, o autor conclui que o ajuste da economia brasileira teria passado a depender quase que integralmente do endividamento externo

\footnotetext{
${ }^{258}$ E também, na linha de argumentação de Castro e Souza, de superação do subdesenvolvimento econômico.
} 
comandado pelo crescimento.

Já de acordo com Cruz, no triênio 1974-76, a acumulação de reservas teria sido apenas marginal, sugerindo que o endividamento estaria associado aos níveis elevados de investimento, não sendo de natureza financeira. Já no biênio 1977-78, a acumulação de reservas teria voltado a ser dominante, tendo o endividamento externo assumido, assim como no período do "milagre", um caráter financeiro, retroalimentado pelo peso crescente da dívida acumulada. Por fim, no biênio 1979-80, com o $2^{\circ}$ choque do petróleo e o choque dos juros decorrente da alteração de política monetária dos Estados Unidos, a dívida externa brasileira teria adquirido autonomia em termos financeiros, na medida em que influxo de recursos se tornara insuficiente, inclusive para o pagamento dos juros da dívida.

Dessa dinâmica observada no caso brasileiro, não se segue que o endividamento externo por si só seria um problema, pois, observadas certas condições, poderia pagar-se de forma consistente. Como bem salientaram os pioneiros, entre as funcionalidades do endividamento externo estariam a possibilidade de financiar altos níveis de importação e atenuar as restrições de recursos necessários à realização de investimentos. Em se tratando de economias subdesenvolvidas, como a brasileira, a pobreza, como condição inicial, implicava a perpetuação da própria pobreza, compondo o que Nurkse $(1952,1953)$ denominara de círculo vicioso da pobreza. A recorrência a recursos externos poderia funcionar, então, como uma fonte para impulsionar o rompimento desse círculo vicioso. Os problemas do endividamento surgem especialmente quando há a exigência de pagar a dívida no curto prazo e em divisas estrangeiras, o que exigiria um bom desempenho do setor exportador, o que não necessariamente se verificava. Problemas esses potencializados no caso de se assumir mais dívida do que realmente seria necessário, e ainda mais nas condições de incerteza como as de meados da década de 1970 e com contratos baseados em taxas de juros flutuantes.

Outra observação importante que merece ser aqui retomada refere-se à maneira como foram utilizados esses recursos decorrentes do endividamento externo. Como destacado por Furtado (1981), a reconfiguração do sistema produtivo brasileiro implicava a necessidade de elevar a sua capacidade de autofinanciamento. No entanto, a promoção da capacidade de autofinanciamento parecia ser conflitante com a própria diretriz geral do modelo de desenvolvimento, pautada pelo crescimento rápido do mercado de bens de consumo duráveis. A insistência nessa forma de desenvolvimento, conforme também advertiram outros pioneiros, como Prebisch (1952), Nurkse $\left(1952\right.$, 1953) e Kalecki ${ }^{259}$, teria esterilizado os

\footnotetext{
${ }^{259}$ Vide Kalecki e Sachs (1966).
} 
recursos para fins que não contribuíram significativamente para a superação do subdesenvolvimento.

Uma ponderação de fundamental importância que precisa ser feita, e que se contrapõe à opção pelo endividamento, é a de que se os efeitos sobre a dívida externa foram secundários, ou, em outras palavras, se não foram importantes o suficiente para invalidar a suposta funcionalidade do próprio endividamento externo. Sobre esse questionamento, Fishlow também contribui com uma interessante observação. Mesmo que o endividamento em si não seja um problema e, de fato, tenha funcionalidade em determinados contextos, trata-se de um mecanismo que transfere a necessidade de ajustamento para o futuro e, portanto, não a resolve definitivamente. Dessa forma, independentemente das mudanças nas condições econômicas observadas no fim da década de 1970, o problema do endividamento já estava colocado na pauta de problemas brasileiros. Dado o nível de endividamento assumido, para o qual o II PND contribuiu sobremaneira, o país havia se colocado numa situação bastante vulnerável a qualquer mudança nas condições vigentes, seja do lado das exportações, das importações, das condições de oferta, de demanda ou de financiamento.

A argumentação de Castro e Souza, embora sujeita a diversas ponderações e críticas, evidencia um aspecto importante da que alcunham "estratégia de 1974", qual seja, a opção ousada por seguir no avanço da matriz industrial para setores altamente complexos, o que, conforme argumentado acima, de fato é uma condição importante a ser cumprida por nações que buscam a superação do subdesenvolvimento econômico. Tendo essa hipótese em consideração, os autores não estariam equivocados em apontar que se tratava sim de uma estratégia que estava na direção da superação do subdesenvolvimento econômico. No entanto, os autores teriam enfatizado demasiadamente a infalibilidade e a suficiência da estratégia, o que se evidencia pela pouca importância que eles direcionam às consequências e aos efeitos negativos, de curto ou de longo prazo, tanto da natureza da industrialização substitutiva de importações promovida pelo II PND, quanto do financiamento em que se baseou.

A recorrência ao endividamento externo, embora não fosse um fato inédito, ganhou proporções significativas especialmente a partir do período do "milagre", e intensificou-se no período do II PND. Mesmo considerando o contexto de escassez relativa de recursos internos para prosseguir no processo de industrialização substitutiva de importações, é válido ponderar que a estratégia de endividamento foi uma escolha e, portanto, não resultou de uma imposição ou de uma ausência de alternativas. Conforme observam Wells e Sampaio (1973), havia uma restrição financeira interna à economia brasileira que dificultava a manutenção de altas taxas de crescimento do consumo e do investimento. O sistema financeiro interno não teria 
desenvolvido, naquele contexto (décadas de 1960 e 1970), a capacidade de suprir a demanda de recursos de médio e de longo prazos exigidos por investimentos em setores produtivos mais complexos do sistema econômico. Essa deficiência do sistema privado foi historicamente compensada pelo governo (seja via promoção de incentivos, seja via captação de poupanças involuntárias) e pela captação de recursos externos (também estimulada pela política governamental). Embora os dois meios estivessem disponíveis, o que se observou com maior frequência foi especialmente a recorrência a recursos externos.

Essa preferência, segundo Wells e Sampaio, explicar-se-ia pela opção do governo por uma relativa inércia institucional e por uma determinada seletividade na alocação do crédito, a qual, por sua vez, teve importantes efeitos distributivos, como a concentração de recursos nos setores mais modernos, produtores de bens de luxo, e o aumento da dívida pública. Portanto, para os autores, a opção pelo estímulo à captação de recursos externos seria, aos olhos do governo, a menos sujeita a resistências e problemas, tanto do ponto de vista econômico, quanto político. Por outro lado, há que se considerar o efeito pernicioso de que, ao recorrer a recursos externos para solucionar os problemas internos de financiamento, diminuiu-se o próprio incentivo ao desenvolvimento de um sistema financeiro interno. Ou seja, parafraseando Castro e Souza, não se atingiu o problema (do financiamento) em sua raiz e, ademais, criou-se outro, relativo ao custo crescente do serviço da dívida.

Diante de choques externos - como o primeiro choque do petróleo em 1973 -, poderiam ser elencadas ao menos quatro alternativas de políticas colocadas aos países menos desenvolvidos ${ }^{260}:$ a adoção de políticas deflacionárias, reduzindo a absorção doméstica e, por conseguinte, as importações; a promoção das exportações; a substituição de importações; e a captação de novos recursos externos. As duas últimas alternativas eram justamente aquelas que teriam apresentado menor resistência, seja do ponto de vista político-social, seja da conjuntura econômica internacional que se verificava na época. E foram elas que caracterizaram o caso brasileiro e, para parte da literatura, teriam sido as causas básicas da profundidade da crise que se inicia na década de 1980.

Conforme discutido anteriormente, a recorrência ao endividamento externo, especialmente como realizada nos governos Médici e Geisel, não teve efeitos negligenciáveis sobre a crise que se observou na década de 1980. Resta analisar em que a medida o modelo de desenvolvimento baseado na substituição de importações, por si só, influiu na crise que inaugurou uma sucessão de "décadas perdidas".

\footnotetext{
${ }^{260}$ Vide, por exemplo, Fishlow (1981) e Balassa (1989).
} 
Para a realização de uma avaliação geral do modelo de desenvolvimento baseado na substituição de importações, que norteou a economia brasileira por todo o seu período desenvolvimentista e que teve como fundamentação teórica, em grande medida, a obra dos pioneiros do desenvolvimento econômico, vale partir da consideração de Thorp (1998), que ressalta que a história econômica da América Latina mostra uma realidade por demais complexa para ser sintetizada apenas por uma avaliação totalmente positiva ou totalmente negativa. Por um lado, sem dúvida, foram observadas diversas distorções, medidas inadequadas e ineficiências. Todavia, por outro lado, não se pode negar que grandes avanços foram realizados, seja do ponto de vista infraestrutural, tecnológico, institucional e até social. Inclusive a própria recorrência ao endividamento externo precisa ser relativizada, conforme discutido anteriormente, pois os maiores problemas parecem ter decorrido não da estratégia de financiamento em si, mas da intensidade em que foi realizada.

Em linhas gerais, a crítica mais ortodoxa sustenta que a estratégia de industrialização substitutiva de importações teria sido a principal causa da crise na América Latina após 1979. Implícita a essa crítica está a hipótese de que as falhas do governo teriam sido cruciais para esse resultado. O exemplo concreto a que mais se recorre para destacar a invalidade estratégica do PSI seria a experiência dos países do Leste Asiático, que optaram por um modelo de crescimento baseado na exportação de manufaturas e, por conta disso, os asiáticos teriam sido mais bem sucedidos do que as nações latino-americanas, que insistiram na industrialização substitutiva de importações, planejada e com participação do Estado.

Segundo Balassa (1989), diante do baixo dinamismo da industrialização substitutiva de importações, uma vez que o período fácil de substituição havia sido superado, as alternativas que se colocavam aos países ainda não desenvolvidos eram, conforme já adiantado anteriormente: exportação de manufaturados, opção preferida por Coréia e Taiwan; ou o aprofundamento da industrialização substitutiva de importações, opção preferida por Argentina, México e Brasil. De acordo com o autor, o avanço da industrialização substitutiva de importações não teria compensado o baixo desempenho das exportações, gerando crises externas recorrentes.

Uma boa maneira de ponderar se a industrialização promovida no Brasil no período 1930-1980 foi de atestada qualidade é questionar, conforme fazem Teitel e Toumi (1986), quais foram os determinantes básicos das exportações de manufaturas, se os subsídios do governo ou a eficiência produtiva das empresas. Conforme demonstram alguns estudos, haveria indícios de crescente eficiência produtiva e de indústrias específicas competitivas 
internacionalmente. $^{261}$ Por outro lado, verificaram-se sérias deficiências e, especialmente, desempenhos heterogêneos, o que, em certa medida, é uma característica esperada do crescimento industrial. ${ }^{262}$ Entretanto, segundo Colistete (2009), o caso brasileiro parece ter apresentado heterogeneidade tecnológica e de produtividade mais acentuada do que a média. Observou-se um grupo de empresas altamente eficientes convivendo com outras altamente ineficientes. Como bem demonstra o autor, isto contraria a visão corrente de que a industrialização substitutiva de importações teve como resultado a formação de um setor industrial caracterizado somente por estagnação tecnológica e por baixa produtividade.

Parte da explicação para a relativa ausência de competitividade das empresas brasileiras pode ser encontrada na reduzida pressão por modernização observada em ao menos duas frentes, quais sejam, alto protecionismo comercial e baixos salários reais relativamente aos ganhos de produtividade, o que teria provocado uma distribuição regressiva da renda gerada no setor industrial. Ademais, há que se considerar em que medida as condições desfavoráveis, relativas à educação, aos direitos trabalhistas, à saúde e à habitação, influíram em termos de aprendizagem e desenvolvimento tecnológico por parte da força de trabalho. Por outro lado, na ausência desse protecionismo à indústria nascente promovido pela industrialização substitutiva de importações, dificilmente a industrialização brasileira teria atingido os níveis que atingiu.

Ainda sobre a questão tecnológica, além de a tecnologia ser importada, em geral, seria também defasada. A adoção dessa tecnologia, desenvolvida para o contexto dos países avançados, em que a mão-de-obra não é um fator ilimitado, e inadequada às condições brasileiras, teve papel importante na implicação de resultados negativos na distribuição de renda, o que, ao diminuir o potencial de demanda efetiva, teria colocado limites ao crescimento sustentado. Como implicação de Lewis $(1954,1955)$, a oferta ilimitada de mãode-obra não qualificada implicava uma tendência baixista aos salários, nas apenas nos setores de baixa produtividade, mas inclusive nos setores mais modernos. Assim, a industrialização substitutiva de importações ao invés de atenuar, ao ajudar a perpetuar a condição de excedente de mão-de-obra, teria agravado a própria condição de vulnerabilidade externa da economia brasileira. Além disso, a industrialização substitutiva de importações teria sido marcada, em grande medida, por um protecionismo indiscriminado, o que acabou contribuindo para a geração de distorções profundas, seja do ponto de vista alocativo, seja do ponto de vista distributivo. Sobre essa questão do protecionismo, importante também ponderar as

\footnotetext{
${ }^{261}$ Vide, por exemplo, Colistete (2009).

${ }^{262}$ Vide, por exemplo, Baumol (1967).
} 
considerações teóricas que decorreram dos pioneiros do desenvolvimento. Embora os pioneiros recorressem, em maior ou menor medida, ao argumento da indústria nascente, indicando a necessidade de adoção de políticas protecionistas, em nenhum momento, os pioneiros implicaram que esse protecionismo deveria ser indiscriminado e indefinido temporalmente.

Fishlow (1972) parece ter razão quando critica o caráter parcial da industrialização substitutiva de importações, além de destacar os mecanismos inadequados que teriam levado a uma excessiva concentração de investimentos em indústrias mais simples. De fato, o caráter seriado implicou uma dependência continuada - e cada vez mais sofisticada, conforme se avançava na matriz industrial - da importação de tecnologia externa, o que por sua vez levou a distorções, como as explicitadas por autores estruturalistas, como Prebisch e Furtado. Por outro lado, dadas as condições em que se encontrava o Brasil naquele momento, talvez não estivesse posta uma alternativa distinta para avançar na industrialização. Sobre esse ponto, há que se destacar, entretanto, que escolhas em outros níveis - por exemplo, questão educacional, tributária e agrária - estavam postas. E, novamente, conforme discutido com base no Plano Trienal, provavelmente, na ausência dessas discussões residiria parte das explicações para a estratégia de desenvolvimento adotada pelo Brasil não ter levado à emergência do desenvolvimento econômico, e sim à perpetuação da sua condição de subdesenvolvimento.

Desse modo, especificamente sobre a desaceleração observada na década de 1980, essa parece ter sido consequência, em larga medida, do endividamento externo exagerado observado especialmente nos governos Médici e Geisel, e, em menor medida, do processo substitutivo de importações, no que se refere especialmente à promoção de indústrias ineficientes e na excessiva concentração de recursos nos setores produtores de bens de luxo. Por outro lado, há que se ponderar se os efeitos negativos do endividamento e das distorções da industrialização substitutiva de importações teriam tido uma sobrevida tão longa, atingindo as próximas duas décadas, se as políticas econômicas adotadas a partir de então tivessem mantido a mesma linha desenvolvimentista daquela observada no período 1930-1980 discussão que extrapola o escopo dessa tese.

Assim, sobre o período desenvolvimentista, em linhas gerais, com base na contribuição dos pioneiros do desenvolvimento, sugere-se que na ausência de conquista de um nível suficientemente adequado de autonomia econômica, em diversas esferas, encontrase uma parte da explicação para a não superação do subdesenvolvimento econômico brasileiro. Até 1930, a dependência econômica referia-se inclusive à satisfação do consumo além de produtiva, tecnológica e financeira -, na medida em que a maioria dos bens 
consumidos internamente era de importados. Mesmo com o deslocamento do centro dinâmico para o mercado interno, iniciando uma série de desenvolvimentos e transformações produtivas importantes a partir da década de 1930, essas mudanças não foram suficientes para desencadear outra série de mudanças, especialmente certas modificações estruturais, que resultassem na superação definitiva do subdesenvolvimento. Essas mudanças derivadas não ocorreram porque não poderiam ser geradas espontaneamente, devendo ter sido objeto de políticas governamentais intencionadas e direcionadas, as quais não se verificaram com a profundidade requerida no decorrer dos cinquenta anos de período desenvolvimentista.

A ausência de mudanças estruturais, discutidas especialmente por Kalecki, Furtado e Prebisch - embora ao menos citadas, mesmo que genericamente, pelos demais pioneiros -, relacionadas à estrutura agrária, à estrutura tributária, à estrutura fiscal, à educação e à tecnologia, teria contribuído para a perpetuação e acentuação da diversidade de desequilíbrios perniciosos à sustentação do processo de desenvolvimento econômico enfrentados pela economia brasileira no decorrer do período. Por isso, a não verificação de certas mudanças estruturais teria funcionado como um meio importante de perpetuação dos diversos círculos viciosos de pobreza de Nurkse, da causação circular cumulativa perniciosa ao desenvolvimento de Myrdal, da inviabilização do grande impulso de Rosenstein-Rodan, do enfraquecimento da potencialidade transformadora dos efeitos de encadeamento para frente e para trás de Hirschman, da não superação da dualidade estrutural definida por Lewis, do não enfrentamento satisfatório da restrição externa explicada pela tese Singer-Prebisch e, por fim, da perpetuação da condição de periferia, definida por Prebisch, e de capitalismo periférico, conceituado por Furtado, da economia brasileira.

Na próxima seção, essa linha de raciocínio é retomada, recolocando explicitamente as discussões sobre subdesenvolvimento com base na Abordagem da Complexidade, tal como apresentadas no capítulo 2.

\subsection{Alguns caminhos abertos pela Abordagem da Complexidade para a discussão da emergência e da perpetuação do subdesenvolvimento econômico brasileiro no período} 1930-1980

Nessa subseção, retoma-se o roteiro da subseção 2.2.3, discutindo-se alguns caminhos pelos quais a Abordagem da Complexidade pode contribuir para a compreensão de alguns 
aspectos e elementos relativos à emergência e à perpetuação do subdesenvolvimento econômico brasileiro, observado como resultado do seu período desenvolvimentista. Para tal, retoma-se aqui a $2^{\mathrm{a}}$ Lei da Termodinâmica $\left(2^{\mathrm{a}} \mathrm{L}\right.$. T.) e algumas de suas consequências para a discussão da dinâmica dos sistemas econômicos nacionais, caraterizados como sistemas complexos adaptativos, e a cujo grau de complexidade, retomando Beinhocker (2006), estaria relacionada a sua capacidade de gerar riqueza e de se desenvolver.

Conforme discutido no capítulo 2 - ao final da subseção 2.2 .2 e retomado na subseção 2.2.3, com base especialmente em Rihani e Geyer (2001) -, da observação da composição do sistema político-econômico mundial seria possível conjecturar que a emergência do subdesenvolvimento em algumas nações poderia estar organicamente interligada à emergência do desenvolvimento em outras. $\mathrm{O}$ enfrentamento da desordem teria permitido o desenvolvimento em algumas nações, porém, teria acarretado a desordem e a perpetuação do subdesenvolvimento em outras nações, porquanto a entropia do sistema global é sempre crescente, segundo a $2^{\text {a }}$ L.T. Trata-se, em certo sentido, da relação centro-periferia de Prebisch (1949) traduzida em termos da Abordagem da Complexidade. Nesse sentido, o reflexo da desordem nas nações periféricas poderia estar, por sua vez, na sua incapacidade de apreender satisfatoriamente o potencial do seu efeito multiplicador interno, bem como na própria perpetuação de desigualdades e disparidades internas, em diversos níveis.

Com essa definição termodinâmica e adaptativo-complexa em mente, inferiu-se na subseção 2.2.3 do capítulo 2 que, para uma nação periférica ter chances de promover seu desenvolvimento, ela precisaria estar capacitada, de alguma forma, a se adaptar às mutantes e instáveis condições internas e externas. Como as condições externas estariam, por definição, fora do controle das nações periféricas, para que um sistema econômico nacional periférico pudesse se desenvolver, ele deveria apresentar, como pré-requisito, ao menos elementos internos adequados, cuja combinação lhes possibilitasse um melhor tratamento dos efeitos provocados pelos fatores externos, bem como da interação deles com os próprios fatores internos. No caso brasileiro, a transferência de desordem proveniente dos países centrais foi observada, no período desenvolvimentista, especialmente por meio da transferência de tecnologia, via importação de máquinas e equipamentos, ${ }^{263}$ geralmente já obsoletos nos países de origem, e de capital externo, em condições nunca muito favoráveis ou seguras aos

\footnotetext{
263 Para algumas das consequências da absorção de tecnologia importada, ressaltem-se novamente as contribuições de Prebisch e Furtado.
} 
tomadores de empréstimo. ${ }^{264}$

Como conclusão, apresentou-se que, por conta do efeito das retroalimentações positivas observadas em sistemas complexos e adaptativos, se não fosse observada uma intervenção e redirecionamento, de modo a quebrar a lógica própria desses efeitos cumulativos, a tendência é que as desiguldades e disparidades internas à nação periférica, e as desigualdades externas entre o centro e a periferia, aumentassem. $O$ papel de redirecionamento caberia aos governos das nações, pois só o Estado possuiria, ao menos potencialmente, os meios e ferramentas adequados para provocar mudanças sistêmicas de grande alcance, observação corroborada, guardadas as suas especificidades, pelos pioneiros do desenvolvimento econômico discutidos por essa tese.

Realizada essa breve retomada de argumentos apresentados ao final do capítulo 2, vejamos, a seguir, se, e em que medida, essas considerações podem ser elucidativas para a discussão de algumas questões relativas ao período desenvolvimentista brasileiro, retomando o raciocínio apresentado na seção anterior, em que se atribuiu à ausência de reformas estruturais parte da explicação para a não superação do subdesenvolvimento econômico brasileiro.

O processo de desenvolvimento das nações envolveria uma cadeia de mudanças, que resultariam numa maior complexidade sistêmica e, por conseguinte, numa maior capacidade de continuar gerando riqueza e desenvolvimento. Alcançado determinado nível de complexidade, o processo possivelmente se tornaria autossustentável, não mais requerendo, para sua perpetuação e sua sustentabilidade, a observação de mudanças radicais. Retomando discussão derivada do conceito de mudanças revolucionárias de Schumpeter (1912), a necessidade de ocorrência de mudanças radicais para resultar em desenvolvimento ganha ainda mais sentido no contexto das nações subdesenvolvidas. Dito de outro modo, mudanças gradativas e/ou esparsas seriam suficientes para sustentar o processo de desenvolvimento no contexto de nações já desenvolvidas. No caso das nações subdesenvolvidas, essas mudanças precisariam ser revolucionárias o suficiente - o grande impulso à la Rosenstein-Rodan - para superar definitivamente a condição inicial de atraso. Historicamente, esse quesito foi satisfeito pelas nações centrais. Para as nações periféricas, permanecera o problema de atingir esse nível mínimo de complexidade que lhes permitisse romper definitivamente com o subdesenvolvimento.

No período 1930-1980, apesar da inegável evolução da estrutura produtiva brasileira,

\footnotetext{
${ }^{264}$ Sobre alguns dos efeitos perniciosos do capital externo, vale destacar novamente a contribuição de Singer
} (1950). 
especialmente no que diz respeito ao desenvolvimento da sua matriz industrial, foram observados, não apenas o já esperado aparecimento de desequilíbrios, distorções e disparidades, mas principalmente a perpetuação e recrudescimento deles. Dito de outro modo, partindo da condição de subdesenvolvimento e compondo o grupo de nações periféricas, mesmo que, desde sempre, tivessem sido elaborados programas de desenvolvimento que buscassem, de antemão, resolver problemas potenciais, seria inevitável que distorções aparecessem, pois nenhum planejamento pode ser perfeito em condições intrínsecas de incerteza e, em se tratando de mudanças revolucionárias que se relacionam ao desenvolvimento no contexto do subdesenvolvimento, essa incerteza é ainda mais pronunciada. Como bem destacara Hirschman (1958), o processo de desenvolvimento, no contexto do subdesenvolvimento, era necessariamente desequilibrado. E na emergência desses desequilíbrios deveriam ser buscados impulsos adicionais para o prosseguimento do próprio processo de desenvolvimento. Ressalte-se, novamente, que mesmo para a consecução desses impulsos adicionais pressupunha-se, segundo o pioneiro, uma ação intencionada e coordenada.

Por outro lado, pelo menos até a década de 1960, mesmo diante do aparecimento e do recrudescimento de disparidades produtivas, com excessiva concentração de recursos em determinados setores industriais, de disparidades regionais, de disparidades entre classes sociais e de desequilíbrios internos e externos, os planos de governo não buscaram combater, mesmo em teoria, a origem de boa parte desses problemas em sua raiz. Em outras palavras, os planos de governo não indicaram certas medidas de transformação estrutural e institucional do sistema econômico brasileiro que teriam sido importantes para evitar o aparecimento ou o recrudescimento daqueles problemas. De certo modo, parecia prevalecer uma crença de que o dinamismo permitido pelo desenvolvimento industrial, seja por qual meio e via quais recursos fossem, acabaria gerando condições para a resolução encadeada e/ou espontânea dessas disparidades e desequilíbrios.

O Plano Trienal elaborado pelo Cepalino Celso Furtado parece ter sido a primeira demonstração concreta do reconhecimento, por parte do Estado brasileiro, da necessidade de promover reformas de base, eliminando alguns dos entraves presentes no sistema econômico brasileiro que dificultavam uma distribuição mais equitativa dos benefícios da industrialização, ao diminuírem - e até conterem - os seus efeitos de encadeamento e/ou multiplicadores por todo o sistema econômico. Até então, mesmo com a crescente e importante atuação estatal, essa se verificara sob a forma de incremento de participação do Estado como planejador e investidor propriamente dito. $\mathrm{O}$ foco estava sobre $\mathrm{o}$ 
desenvolvimento da estrutura produtiva industrial, não tendo sido promovidas mudanças significativas para o aparelhamento do Estado para fazer frente a essas funções. Tampouco se demonstravam grandes preocupações com as disparidades crescentes de renda e riqueza entre as classes e as regiões.

Conforme discutido na seção anterior e na subseção 5.3.4 do capítulo 5, os pontos focais do Plano Trienal, em termos de longo prazo, eram: ampliar a base fiscal do Estado, permitindo-lhe fazer frente ao seu papel de planejador e investidor, sem implicar pressões inflacionárias internas e uma grande necessidade de captação de recursos externos; promover uma reforma agrária que permitisse uma maior racionalização da produção agrícola, diminuindo a pressão inflacionária do mercado de alimentos, bem como possibilitando um maior acesso a esses bens; uma reforma tributária, que além de permitir ampliar a base fiscal do Estado, teria o papel de redistribuir a renda o que, em conjunto com a reforma agrária, potencialmente ajudaria a atenuar as grandes disparidades de renda sociais e regionais. No entanto, como a maioria das medidas do Plano Trienal não foram implementadas, o que teriam sido seus efeitos reais são apenas conjecturas. Por outro lado, à exceção dos pontos relativos às reformas tributária e financeira especialmente, as demais reformas de base não foram ponto de discussão dos planos de governos seguintes, já sob a ditadura militar.

Alguns dos pontos de reforma do Plano Trienal foram retomados pelo PAEG, mas com um foco distinto em diversos sentidos. Buscava-se igualmente uma ampliação da base fiscal do Estado e uma racionalização do mercado financeiro; porém, no que se refere aos pontos mais polêmicos da reforma tributária, da reforma agrária e da discussão de distribuição de renda e riqueza que delas derivava, o período da ditadura, como um todo, se mostrou bastante conservador sobre essas questões. Nesse sentido, vale destacar novamente a política salarial, que resultou numa diminuição do salário real médio, bem como os efeitos regressivos da reforma tributária então empreendida, intensificando ainda mais a desigualdade distributiva.

Como resultado dos cinquenta anos do período desenvolvimentista, mesmo diante das grandes taxas de crescimento e do inegável avanço na matriz industrial, do período do "milagre" e da implementação do II PND, assim como nos períodos de crescimento anteriores, desde a década de 1930, a resolução dos nós que bloqueavam a superação do subdesenvolvimento econômico brasileiro não surgiu espontaneamente. Um desses entraves, o referente à dependência de recursos externos, adquiriu tal dimensão que teria inviabilizado prematuramente a continuidade do modelo de desenvolvimento baseado na substituição de importações, culminando com a crise da década de 1980. 
No entanto, há que se questionar porque o nó do endividamento externo adquiriu tal dimensão. Para isso, faz-se necessário discutir alguns dos outros entraves que compuseram a armadilha do subdesenvolvimento econômico brasileiro. Dentre eles: a perpetuação e os incrementos de desigualdades sociais e disparidades regionais; a ineficiência dos investimentos, com concentração em setores produtores de bens de luxo; e a inadequação tecnológica, reflexo não apenas da dependência tecnológica, mas principalmente da não efetividade de uma política científico-tecnológica. Vejamos, a seguir, algumas maneiras pelas quais esses entraves se influenciaram mutuamente.

Em certo sentido, esses nós e entraves, destacados por Prebisch e especialmente por Furtado, estavam imbricados entre si. Em outras palavras, influenciavam e recebiam influência uns dos outros, gerando efeitos cumulativos e de retroalimentação que resultavam na manutenção e recrudescimento deles mesmos. Em termos da Abordagem da Complexidade, esses nós e entraves seriam representativos das formas de perpetuação, no caso brasileiro, da desordem que seria característica dos países subdesenvolvidos e que dificultaria o seu processo de auto-organização que poderia resultar em seu desenvolvimento. Vale notar novamente que a desordem, também tinha, geralmente, origem externa; contudo, a maneira como se colocavam os fatores internos, no caso brasileiro, não apenas teriam dificultado o seu enfrentamento, mas inclusive o teriam intensificado. Retomando a definição de sistemas abertos contemplada pela Abordagem da Complexidade, ${ }^{265}$ os sistemas abertos recebem fluxo de matéria e energia externos; e seria justamente esse fluxo renovado que funcionaria como fonte adicional de recursos para fazer frente à entropia que permanecia no sistema. Ou seja, se por outro lado eles acarretariam desordem, por outro poderiam constituirse em meio para enfrentar a própria desordem. E para eles se constituírem em meio de enfrentamento seria necessário, então, que as condições internas favorecessem esse redirecionamento dos efeitos desordenadores em prol da evolução do sistema.

Desde a sua fase colonial, a grande desigualdade distributiva era característica do território brasileiro, cuja base produtiva e dinâmica, seguindo a conceituação Pradiana, ${ }^{266}$ era ditada por grandes propriedades, trabalho escravo e monocultura de exportação. Conforme destacara Furtado (1959), a economia cafeeira baseada em trabalho assalariado imprimiu uma série de mudanças ao sistema econômico brasileiro, relacionadas à formação de um mercado interno e, consequentemente, da possibilidade de apreender, em alguma medida, os efeitos multiplicadores da renda dentro do território nacional. Quanto mais os efeitos multiplicadores

\footnotetext{
${ }^{265}$ Vide Beinhocker (2006), tal como abordado na subseção 2.2.1 do capítulo 2.

${ }^{266}$ Vide seção 5.2 do capítulo 5.
} 
funcionassem internamente, maiores seriam os efeitos em termos de autopropulsão da economia.

Ainda sob a perspectiva de Furtado, o deslocamento do centro dinâmico na década de 1930 constitui outro momento crucial, na medida em que, a partir de então, coube ao mercado interno responsabilidade crescente na determinação da dinâmica da economia brasileira. Embora as desigualdades sociais e as disparidades regionais continuassem presentes, esperava-se que, com a industrialização, essas questões fossem sendo internamente amenizadas. No entanto, isso não teria ocorrido; pelo contrário, teria se intensificado.

Retomando Lewis $(1954,1955)$, ao invés de ter se buscado o incremento da parcela de lucros por meio da diminuição da parcela de renda da terra, no caso brasileiro, teria se buscado o incremento daquela por meio da diminuição da parcela de salários, mantendo-se a grande concentração de terras. E, em virtude também da grande concentração de renda e riqueza, reduzia-se o próprio potencial impulsionador do mercado interno. A ausência de uma reforma agrária, por sua vez, teria tido como implicação a não racionalização da produção agrícola brasileira, o que teria impedido a modernização de regiões mais dependentes dessa produção, como a região Nordeste - perpetuando as disparidades regionais -, bem como mantido uma pressão constante sobre o preço dos alimentos, conforme advertira Kalecki (1960), o que impactava diretamente sobre o padrão de vida das classes mais baixas. Além de, por outro lado, conforme advertido por Lewis (1954, 1955), a manutenção de uma oferta ilimitada de mão-de-obra se constituir numa pressão baixista sobre os salários e, conforme discutido por Furtado (1975), mesmo que se capitalizasse a agricultura, sem que se disponibilizasse uma ocupação a essa mão-de-obra excedente, os efeitos de uma racionalização na produção agrícola não atenuaria a tendência baixista sobre os salários.

Embora a manutenção e a intensificação da concentração de renda e riqueza tenham sido aparentemente funcionais por determinado período de tempo - na medida em que teria ajudado a sustentar a demanda de bens de luxo dos grupos de alta renda, da qual o sistema econômico brasileiro teria derivado boa parte de seu dinamismo no período desenvolvimentista -, a insistência no crescimento baseado nessa forma de demanda encontraria limites e implicaria outros problemas. Dentre esses problemas se destaca outro nó de difícil solução naquele contexto, qual seja, a excessiva concentração de investimentos em setores que produziam bens de luxo, os bens de consumo duráveis, tendência intensificada a partir do Plano de Metas. É como se a concentração de renda e riqueza tivesse funcionado, ela mesma, como uma forma de aprisionamento na dependência do modelo brasileiro com relação ao dinamismo da demanda de bens de consumo duráveis. 
Também relacionada ao setor de bens de consumo duráveis estava a importante atuação de empresas estrangeiras, como bem salientara Furtado em várias de suas obras. ${ }^{267}$ Dessa identificação, derivavam-se ao menos duas consequências importantes, explicadas a seguir.

Os setores mais dinâmicos - e que, portanto, concentravam uma parte considerável dos efeitos multiplicadores da economia brasileira - estariam especialmente sob o comando de empresas que remeteriam outra boa parte desses efeitos multiplicadores para o exterior. Outra consequência relacionar-se-ia à questão tecnológica. A atuação das empresas estrangeiras nos setores mais dinâmicos não apenas facilitaria, mas inclusive estimularia a importação de tecnologia de seus países de origem, o que se constituía tanto em mais uma fonte potencial de dispersão dos efeitos multiplicadores internos para alhures, quanto numa possível forma de desestímulo do desenvolvimento de tecnologia própria. Conforme discutido por Prebisch e Furtado, ${ }^{268}$ em variadas de suas obras, as consequências da inadequação tecnológica das máquinas e equipamentos importados não eram nada negligenciáveis, especialmente levandose em consideração a dotação de fatores nacional e a dotação de fatores vigente no contexto em que a tecnologia importada fora desenvolvida. Assim, mesmo que a importação de tecnologia tivesse sido funcional por determinado tempo ou em determinado contexto, a insistência na dependência tecnológica pode ter ajudado a perpetuar determinados problemas, relativos pelo menos ao desemprego de mão-de-obra e à falta de incentivo para o desenvolvimento de tecnologia própria, bem como para o investimento em educação e em pesquisas científicas, visando especialmente à formação de mão-de-obra qualificada.

Os parágrafos anteriores buscaram discutir alguns dos nós e entraves, bem como suas interligações, que teriam ajudado a compor a armadilha do subdesenvolvimento econômico brasileiro no período 1930-1980, da qual o Brasil não conseguiu se desvencilhar, mesmo tendo apresentado importantes transformações produtivas e sustentado grandes altas taxas de crescimento no período. Esses problemas podem ter contribuído para a perpetuação e a intensificação da desordem que provinha das nações centrais, cuja transferência pode ter se efetuado, dentre outras formas, sob a forma de fluxos comerciais - traduzida na deterioração a longo prazo dos termos de troca dos bens primários -, sob a forma de fluxos de máquinas, equipamentos e tecnologia, e sob a forma de fluxo de capitais.

Além disso, seria possível conjecturar que esses nós e entraves, relativos à tecnologia, ao modelo de crescimento e as disparidades regionais e de distribuição de renda, bem como às

\footnotetext{
${ }^{267}$ Vide especialmente discussão realizada nas subseções 5.3.4 e 5.3.5 do capítulo 5 .

${ }^{268}$ Vide novamente capítulo 4.
} 
suas inter-relações, teriam ajudado a implicar, ao final da década de 1970, a grande desordem interna traduzida sob a forma de uma grande dívida externa. Pois, a recorrência ao endividamento seria reflexo, em boa medida, da tentativa de resolver a própria situação de desordem interna. Só que ao invés de ajudar a resolver a desordem interna, em virtude das próprias condições internas, acabou por acentuar as disparidades e os desequilíbrios iniciais, jogando a solução do problema para adiante. Só que esse adiante teve um limite, a crise da dívida externa e o engavetamento posterior das políticas desenvolvimentistas.

O desatar dos nós, ou a resolução dos problemas, conforme se buscou argumentar no evolver dessa tese, apresentaria como condições necessárias uma série de mudanças estruturais que não poderiam ter ocorrido de maneira espontânea, mesmo porque a direção dos efeitos cumulativos e das causações circulares tendia a perpetuar e a intensificar a presença daqueles problemas. Retomando os pioneiros, uma das condições necessárias seria o próprio desenvolvimento da indústria, por conta de seu maior potencial transformador, relativo à sua maior capacidade germinativa (Furtado, 1973; 1975), ao seu potencial de geração de efeitos de encadeamento (Hirschman, 1958) ou à sua geração de economias externas (Rosenstein-Rodan, 1943; 1944). Ao longo dos cinquenta anos da fase desenvolvimentista, apesar da concentração de recursos em determinados setores industriais tais como o de bens de consumo duráveis -, não haveria como negar que o Brasil transformara profundamente a sua base produtiva. No entanto, os efeitos dessa transformação não foram suficientes para colocar o país numa trajetória sustentada de desenvolvimento.

Ter transformado a base produtiva, em prol da industrialização, era, portanto, uma condição necessária, porém longe de ser suficiente para que o Brasil se libertasse da armadilha do subdesenvolvimento. Observação que, se por um lado, ajudaria a corroborar o fato de o desenvolvimento necessariamente extrapolar o escopo da Economia, por outro lado, colocaria em destaque que, mesmo aquelas reformas estruturais que teriam motivação e racionalidade econômicas implícitas, acabaram não sendo satisfatoriamente promovidas. Como inferido, por exemplo, de Prebisch e Furtado, também as reformas estruturais não seriam uma condição suficiente para garantir o resultado de desenvolvimento. Por outro lado, na ausência delas, se perpetuariam as fontes de desequilíbrios, disparidades, problemas e desordem que faziam com que os efeitos propulsores das transformações da estrutura produtiva se dispersassem.

Assim sendo, a perpetuação do subdesenvolvimento econômico brasileiro no período desenvolvimentista pode ter sido um resultado emergente da combinação da internalização pelo Brasil de parte da desordem decorrente das nações centrais com a ausência de fatores 
internos adequados para o seu enfrentamento, na medida em que, apesar do desenvolvimento produtivo e das altas taxas de crescimento, não teriam sido promovidas mudanças institucionais consideradas importantes para que o país tivesse ao menos chances de superar a sua condição de subdesenvolvimento.

Vale ressaltar que essa conclusão seria apenas uma conjectura possível, também resultado emergente da trajetória investigativa proposta por essa tese. Mesmo porque o mais interessante a derivar da Abordagem da Complexidade não seria a indicação de um resultado ou de uma explicação fechada, e sim o alargamento do horizonte de compreensão permitido por seu método mais sistêmico ${ }^{269}$, porquanto especialmente escapa a determinismos. E seria justamente por conta desse potencial de enriquecimento explicativo que a recorrência à perspectiva analítica da Abordagem da Complexidade se mostrou interessante para a discussão dos temas relativos ao desenvolvimento econômico, os quais, conforme algumas discussões e determinados elementos derivados dos próprios pioneiros fazem referência à: (i) heterogeneidade das nações; (ii) mecanismos cumulativos ou relações de retroalimentação; e (iii) a resultados em aberto. Questões essas que, de partida, não seriam passíveis de tratamento adequado pelo método mais tradicional pautado por análises de equilíbrio que pressupõe: (i)' agente representativo; (ii)' existência de mecanismos de estabilização automática; e (iii)' resultados, em geral, de equilíbrio ótimo.

Conforme algumas críticas apresentadas com base nos diversos autores aqui discutidos, essa base teórica mais ortodoxa implicara aos países em subdesenvolvimento uma série de indicações de políticas econômicas que seriam funcionais ao contexto dos países desenvolvidos, os quais não mais requereriam a consecução de mudanças revolucionárias. Para tentar sanar esse problema teórico, os autores que compuseram a gênese da Economia do Desenvolvimento no pós II Guerra Mundial buscaram se debruçar sobre determinadas especificidades das nações subdesenvolvidas, objetivando um alargamento de sua compreensão sobre essas questões, das quais buscaram derivar indicações de políticas que seriam potencialmente mais eficazes para promover algumas das mudanças revolucionárias necessárias nas nações subdesenvolvidas, para que essas pudessem ter chances de superar o subdesenvolvimento.

Nesse sentido, o potencial alargamento do horizonte de compreensão possibilitado pela Abordagem da Complexidade faria frente, em certa medida e em determinados sentidos, a algumas daquelas queixas teóricas elencadas pelos pioneiros. Inclusive sobre a necessidade

\footnotetext{
${ }^{269}$ Para uma discussão do conceito de método sistêmico e de método reducionista, vide Prado (2006).
} 
de intervenção estatal, questão bastante enfatizada desde o final do capítulo 2, essa não seria incompatível com a referida abordagem; de outro modo, da identificação de mecanismos cumulativos que implicariam a tendência de perpetuação das desigualdades entre as nações, inferiu-se a necessidade de impor uma contra-tendência, a qual, ao menos potencialmente, só poderia ser realizada pelo Estado. Retomando novamente discussão iniciada com base especialmente em Beinhocker (2006), Arthur (2009) e Geyer e Rihani (2010), ${ }^{270}$ em termos de desenvolvimento, a questão não se resumiria a quem deveria predominar, a intervenção do Estado ou a lógica do mercado, e sim a como combinar essas duas esferas de modo a criar um sistema evolucionário efetivo. No caso das nações subdesenvolvidas, buscou-se argumentar que essa combinação, ao menos incialmente, implicaria a necessidade de uma maior intervenção estatal.

Por fim, a discussão particular do caso brasileiro buscou exemplificar, por meio de um exemplo concreto e específico, se e por quais caminhos a Abordagem da Complexidade poderia de fato cumprir aquele propósito. Face às discussões propostas por essa tese, e levando em consideração que a Abordagem da Complexidade é de aplicação recente à Economia - e ainda mais recente no que se refere à discussão de políticas públicas e de questões relativas ao desenvolvimento -, sugerindo-se com isso que o porvir resguardaria ainda uma série de desenvolvimentos futuros, manteve-se a intuição inicial de que a referida abordagem pode contribuir, em diversas direções, para a compreensão de assuntos e temas concernentes à Economia do Desenvolvimento.

\footnotetext{
${ }^{270}$ Vide subseção 2.2.2, capítulo 2.
} 


\section{CONSIDERAÇÕES FINAIS}

Tendo como pergunta norteadora porque o Brasil não conseguiu escapar da armadilha do subdesenvolvimento no seu período desenvolvimentista, e com base na sugestão de discutir o tema a partir de uma diferente perspectiva, essa tese buscou apresentar algumas ilações teóricas relativas à questão que seriam possivelmente inspiradas pela Abordagem da Complexidade e por alguns dos pioneiros do desenvolvimento econômico.

A recorrência aos pioneiros teve como intuito a identificação de algumas das particularidades e especificidades das nações subdesenvolvidas que seriam potencialmente compatíveis e/ou complementares ao que seria uma discussão possível de subdesenvolvimento com base na Abordagem da Complexidade. Nesse sentido, a retomada dos pioneiros foi intencionalmente seletiva; o objetivo era coletar elementos teóricos e analíticos que permitissem adensar a concepção do subdesenvolvimento como um fenômeno cuja compreensão poderia se beneficiar da perspectiva analítica da Abordagem da Complexidade.

Igualmente não se pretendia propor uma síntese geral dessas várias contribuições, seja entre os próprios pioneiros do desenvolvimento, seja entre eles e a Abordagem da Complexidade. O intuito era montar uma estrutura analítica, coerente e consistente, a partir de alguns dos elementos recolhidos em cada um deles, que permitiria contribuir, em alguma medida, para uma melhor compreensão de certos aspectos e dimensões do caso brasileiro de subdesenvolvimento.

Nos dois últimos capítulos, passou-se à discussão explícita do caso brasileiro. Primeiramente sob a perspectiva de um autor específico e, em seguida, trazendo novamente à baila os pioneiros do desenvolvimento. Buscou-se avançar na discussão de algumas questões e fatos característicos do subdesenvolvimento econômico brasileiro, para a qual a perspectiva da Abordagem da Complexidade poderia possivelmente contribuir.

Por possibilitar uma perspectiva e um tratamento teórico mais sistêmico, a Abordagem da Complexidade fornece alguns elementos que permitiriam, ao menos em potencial, uma apreensão mais fidedigna das particularidades relativas ao subdesenvolvimento, seja numa perspectiva mais geral, seja relacionada a casos particulares, como o brasileiro. As discussões promovidas por essa tese buscaram, então, ressaltar alguns dos caminhos pelos quais essa abordagem recentemente aplicada à Economia poderia contribuir para alargar o horizonte de 
compreensão de um fenômeno específico, o subdesenvolvimento econômico brasileiro.

Nesse mesmo sentido, importante ressaltar que não se pretendia resolver controvérsias relativas ao tema, tampouco indicar novas interpretações gerais. O objetivo, bem mais modesto, era a realização de algumas discussões e ilações teóricas relativas à experiência brasileira no período, tendo sempre em mente a Abordagem da Complexidade e sua potencial contribuição para o alargamento do escopo de compreensão do tema.

Com base em algumas das discussões teóricas a partir da investigação seletiva dos pioneiros e, buscando manter-se a perspectiva analítica da Abordagem da Complexidade como diretriz investigativa, como conclusão possível relativa à pergunta norteadora apresentou-se que o subdesenvolvimento econômico brasileiro no período 1930-1980 teria sido possivelmente um resultado emergente da combinação da internalização da desordem proveniente das nações centrais com a ausência de determinadores fatores internos adequados ao seu enfrentamento, na medida em que, apesar do desenvolvimento produtivo e das altas taxas de crescimento verificados no período, não teriam sido promovidas mudanças institucionais consideradas também como condições necessárias para que as tentativas de retirar o país da armadilha do subdesenvolvimento pudessem ter reais chances de sucesso.

No entanto, o mais interessante a derivar da Abordagem da Complexidade não seria a indicação de um resultado ou de uma explicação fechada, e sim o alargamento do horizonte de compreensão permitido por seu método, porquanto especialmente escapa a determinismos. E seria justamente por conta desse potencial de enriquecimento explicativo que a recorrência à perspectiva analítica da Abordagem da Complexidade se mostrou interessante para a discussão dos temas relativos ao desenvolvimento econômico. A discussão do caso brasileiro buscou refletir, por meio de um exemplo concreto e específico, se e por quais caminhos a Abordagem da Complexidade poderia de fato cumprir aquele propósito.

Face às discussões propostas por essa tese, e levando em consideração que a Abordagem da Complexidade é de aplicação recente à Economia - e ainda mais recente no que se refere à discussão de políticas públicas e de questões relativas ao desenvolvimento manteve-se e confirmou-se a intuição inicial de que a referida abordagem pode contribuir, em diversas direções, para a compreensão de assuntos e temas concernentes à Economia do Desenvolvimento. 


\section{REFERÊNCIAS}

Abreu, Marcelo de Paiva. "Crise, crescimento e modernização autoritária: 1930-1945” em Abreu, Marcelo de Paiva (org.), A ordem do progresso - cem anos de política econômica republicana, 1889-1989. Rio de Janeiro: Campus, 1990a.

Abreu, Marcelo de Paiva. "Inflação, estagnação e ruptura: 1961-1964”, em Abreu, Marcelo de Paiva (org.), A ordem do progresso - cem anos de política econômica republicana, 18891989. Rio de Janeiro: Campus, 1990b.

Arndt, Heinz Wolfgang. Economic Development - the History of an Idea. Chicago/London: The University of Chicago Press, 1987.

Arthur, William Brian. "Complexity and the Economy" in Rosser Jr., John Barkley (ed.), Handbook of Research on Complexity, Cheltenham: Edward Elgar, 2009.

Arthur, William Brian; Durlauf, Steven; e Lane, David. "Introduction" in Arthur, William Brian; Durlauf, Steven; and Lane, David (eds.), The Economy as an Evolving Complex System II, Reading MA: Addison Wesley, 1997.

Badcock, Abbie. "Can Complexity Save Development Theory?" in Bogg, Jan and Geyer, Robert (eds.), Complexity, Science and Society, New York: Radcliffe Publishing, 2007.

Balassa, Bela. "Adjustment policies in East Asia", World Bank Working Papers, $\mathrm{n}^{\circ} 280$, September, 1989.

Baumol, William. "Macroeconomics of Unbalanced Growth: the Anatomy of Urban Crisis". American Economic Review, v. 57, p. 415-426, 1967.

Beinhocker, Eric. The Origin of Wealth - Evolution, Complexity, and the Radical Remaking of Economics, Harvard Business School Press, 2006.

Bielschowsky, Ricardo (ed.). Cinqüenta anos de pensamento da CEPAL, Rio de Janeiro: Record, vol. 1, 2000.

Brunner, Hans-Petter e Allen, Peter. "Complex Systems Modeling and International Development" in Rosser Jr., John Barkley (ed.), Handbook of Research on Complexity, Cheltenham: Edward Elgar, 2009.

Bourdieu, Pierre. "L'illusion biographique". Actes de la Recherche en Sciences Sociales (62/63), p. 69-72, junho de 1986.

Buescu, Mircea. "Rodrigues de Brito: um libelo contra o colonialismo" em Buescu, Mircea. História econômica do Brasil: pesquisas e análises. Rio de Janeiro: APEC, p. 230-238, 1970.

Cardoso, Ciro Flamarion. "A brecha camponesa no sistema escravista" em Cardoso, Ciro Flamarion, Agricultura, escravidão e capitalismo. Petrópolis: Vozes, 1979.

Cardoso, Fernanda Graziella. Elementos para a integração analítica da micro e da macroeconomia. Rio de Janeiro: IE/UFRJ, dissertação de mestrado, 2008. 
Cardoso, Fernanda Graziella e Lima, Gilberto Tadeu. "A visão de Keynes do sistema econômico como um todo orgânico complexo" em Economia e Sociedade (Unicamp), vol. 17 (4), p. 359-381, 2008.

Carneiro, Dionísio Dias. “Crise e esperança: 1974-1980”, em Abreu, Marcelo de Paiva (org.), A ordem do progresso - cem anos de política econômica republicana, 1889-1989. Rio de Janeiro: Campus, 1990.

Castro, Antonio Barros de. "As mãos e os pés do senhor de engenho: a dinâmica do escravismo colonial" em Pinheiro, Paulo Sérgio (coord.). Trabalho escravo, economia e sociedade. Rio de Janeiro: Paz e Terra, p. 41-87, 1984.

Castro, Antonio Barros de e Souza, Francisco Pires de. A economia brasileira em marcha forçada. São Paulo: Paz e Terra, 1985.

Cechin, Andrei. D. A natureza como limite da economia, São Paulo: Edusp, Editora Senac, 2010 .

Cepêda, Vera Alves. "Celso Furtado e a interpretação do subdesenvolvimento" em Lima, Marcos Costa e David, Maurício Dias (orgs.), A atualidade do pensamento econômico de Celso Furtado, São Paulo: Verbena Editora, 2008.

Chang, Ha-Joon. "Breaking the Mould - an Institutionalist Political Economy Alternative to the Neoliberal Theory of the Market and the State", Social Policy and Development Programme, paper number 6, May/2001.

Chang, Ha-Joon. Chutando a escada: a estratégia do desenvolvimento em perspectiva histórica. São Paulo: Editora Unesp, 2002.

Cruz, Paulo Davidoff. Dívida Externa e Política Econômica - a experiência brasileira nos anos setenta. São Paulo: Editora Brasiliense, 1984.

Colistete, Renato Perim. "Salários, produtividade e lucros na indústria brasileira, 1945-1978". Revista de Economia Politica, no 29 (4), p. 386-405, 2009.

Costa, Iraci del Nero da. Arraia-miúda: um estudo sobre os não-proprietários de escravos no Brasil. São Paulo: MGSP, 1992.

Costa, Iraci del Nero da. Repensando o modelo interpretativo de Caio Prado Júnior, São Paulo: NEHD-FEA/USP, Cadernos NEHD, n³, 1995.

Costa, Iraci del Nero da e Nozoe, Nelson Hideiki. "Elementos da estrutura da posse de escravos em Lorena no alvorecer do século XIX". Estudos Econômicos, v.17, n 2, p. 319345, maio/agosto de 1989.

Coutinho, Maurício. "A teoria econômica de Celso Furtado: Formação Econômica do Brasil" em Lima, Marcos Costa e David, Maurício Dias (orgs.), A atualidade do pensamento econômico de Celso Furtado, São Paulo: Verbena Editora, 2008.

Dean, Warren. A industrialização de São Paulo, 1880-1945. $3^{\text {a }}$ ed., São Paulo: Difel, 1971.

Dutt, Amitava. "Kalecki e os kaleckianos: a relevância atual de Kalecki” em Pomeranz, 
Lenina; Miglioli, Jorge; e Lima, Gilberto Tadeu (orgs.), Dinâmica Econômica do Capitalismo Contemporâneo: Homenagem a M. Kalecki, São Paulo: Edusp, 2001.

Dweck, Esther. Uma Análise da Interação Micro-Macro com base em um Modelo Dinâmico Multissetorial de Simulação. Rio de Janeiro: IE/UFRJ, tese de doutorado, 2006.

Fausto, Boris. A Revolução de 1930. 10ª ed., São Paulo: Brasiliense, 1986.

Fiori, José Luis. "De volta à questão da riqueza de algumas nações" em Fiori, José Luis (org.), Estados e moedas no desenvolvimento das nações, Petrópolis: Editora Vozes, 1999.

Fishlow, Albert. "Origens e consequências da substituição de importações no Brasil”, Estudos Econômicos, vol. 2 (6), p. 7-75, dezembro de 1972.

Fishlow, Albert. "A dívida externa latino-americana: um caso de desenvolvimento com incerteza", Pesquisa e Planejamento Econômico, vol. 11 (2), p. 283-322, agosto de 1981.

Fishlow, Albert. "A economia política do ajustamento brasileiro aos choques do petróleo: uma nota sobre o período 1974/84", Pesquisa e Planejamento Econômico, vol. 16 (3), p. 507550, dezembro de 1986.

Foley, Duncan. Unholy Trinity - Labor, Capital, and Land in the New Economy, London: Routledge, 2003.

Fonseca, Pedro Cezar Dutra e Monteiro, Sérgio Marley Modesto. "O Estado e suas razões: o II PND”. Revista de Economia Política, vol. 28 (1), 2008.

Fragoso, João e Florentino, Manolo. O arcaísmo como projeto: mercado atlântico, sociedade agrária e elite mercantil em uma economia colonial tardia: Rio de Janeiro, c.1790-c.1840. Rio de Janeiro: Civilização Brasileira, 2001.

Freeman, Chris e Soete, Luc. The Economics of Industrial Innovation. Cambridge, Mass.: MIT Press, $3^{\text {a }}$ ed., 1997.

Furtado, Celso. A Economia Brasileira, Rio de Janeiro: Editora A Noite, 1954a.

Furtado, Celso. "Formação de Capital e Desenvolvimento Econômico" em Agarwala, A. e Singh, S. P. (eds.), A Economia do Subdesenvolvimento, Rio de Janeiro: Cia Editora Forense, ([1954b] 1969).

Furtado, Celso. Perspectivas da Economia Brasileira, Ministério da Educação e da Cultura, Instituto Superior de Estudos Brasileiros, Textos Brasileiros de Economia, Rio de Janeiro, 1958.

Furtado, Celso. Formação Econômica do Brasil, São Paulo: Companhia Editora Nacional, ([1959] 2001).

Furtado, Celso. Desenvolvimento e Subdesenvolvimento, Rio de Janeiro: Editora Contraponto ([1961] 2009].

Furtado, Celso. A Pré-Revolução Brasileira, Rio de Janeiro: Editora Fundo de Cultura, 1962. 
Furtado, Celso. A dialética do desenvolvimento, Rio de Janeiro: Editora Fundo de Cultura, 1964.

Furtado, Celso. Teoria e Política do Desenvolvimento Econômico, São Paulo: Companhia Editora Nacional, ([1967] 1977).

Furtado, Celso. Um projeto para o Brasil, Rio de Janeiro: Editora Saga, $5^{\text {a }}$ ed., 1969.

Furtado, Celso. Raízes do subdesenvolvimento. Rio de Janeiro: Civilização Brasileira, ([1973] 2011).

Furtado, Celso. Economia do Desenvolvimento - curso ministrado na PUC-SP em 1975. Arquivos Celso Furtado 2. Rio de Janeiro: Editora Contraponto; Centro Internacional Celso Furtado de Políticas para o Desenvolvimento, ([1975] 2008).

Furtado, Celso. A economia latino-americana, São Paulo: Companhia das Letras, ([1976] 2007).

Furtado, Celso. O Brasil Pós-“Milagre”, São Paulo: Paz e Terra, 1981.

Furtado, Celso. A Fantasia Organizada, São Paulo: Paz e Terra, 1985.

Furtado, Celso. A Fantasia Desfeita, São Paulo: Paz e Terra, 1989.

Furtado, Celso. Brasil - a construção interrompida, São Paulo: Paz e Terra, 1992.

Furtado, Rosa Freire D’Aguiar (org.). O Plano Trienal e o Ministério do Planejamento. Arquivos Celso Furtado 4. Rio de Janeiro: Editora Contraponto; Centro Internacional Celso Furtado de Políticas para o Desenvolvimento, 2011.

Georgescu-Roegen, Nicholas. The Entropy Law and the Economic Process, Cambridge: Harvard University Press, 1971.

Georgescu-Roegen, Nicholas. "Métodos em ciência econômica" em Edições Multiplic, 1 (2), dezembro de 1980. Texto originariamente publicado em 1979, em inglês, no Journal of Economic Issues.

Gerschenkron, Alexander. Economic Backwardness in Historical Perspective: a Book of Essays, Cambridge, Massachussets: The Belknap Press of Harvard University Press, 1962.

Geyer, Robert e Rihani, Samir. Complexity and Public Policy - a New Approach to 21st Century Politics, Policy and Society. London/New York: Routledge, 2010.

Gleiser, Ilan. Caos e complexidade - a evolução do pensamento econômico. Rio de Janeiro: Editora Campus, 2002.

Goodwin, Craufurd. "The Patrons of Economics in a Time of Transformation". In: Morgan, M. e Rutherford, M. (eds.). From Interwar Pluralism to Postwar Neoclassicism. Suplemento annual, HOPE 30: 53-81, 1998.

Gorender, Jacob. O escravismo colonial. $4^{\mathrm{a}}$ ed. São Paulo: Editora Ática, 1985.

Hamilton, Alexander. "Report on Manufactures", in Mckee, S. (ed.), Papers on Public Credit, 
Commerce and Finance, New York: Columbia University Press, ([1791] 1934).

Hermann, Jennifer. "Reformas, endividamento externo e o "milagre" econômico (19641973)", em Giambiagi, Fabio; Villela, André; Castro, Lavínia Barros de; e Hermann, Jennifer. (orgs.). Economia brasileira contemporânea. Rio de Janeiro: Campus, 2005.

Higgins, Jean Downing. "The Reluctant Planner: An Overview" in Cook, W. D. e Kuhn, T. E. (eds.), Planning and Development Processes in the Third World, TIMS Studies in Manegement Science, New York: North Holland, 1980.

Hirschman, Albert Otto. The Strategy of Economic Development, New Haven: Yale University Press, 1958.

Hirschman, Albert Otto. "The Rise and Decline of Development Economics", in Essays in Trespassing - Economics to Politics and Beyond, Cambridge: Cambridge University Press, 1981.

Hirschman, Albert Otto. “A Dissenter's Confession: The Strategy of Economic Development Revisited", in Meier, Gerald e Seers, Dudley (eds.). Pioneers in Development, publicado pelo Banco Mundial, Oxford University Press, 1984.

Iglésias, Francisco. Situação da história econômica no Brasil. Anais de História. Assis: FFCL de Assis, ano II, p. 9-64, 1970.

Kalecki, Michal. Teoria da Dinâmica Econômica, Coleção Os Economistas, São Paulo: Editora Nova Cultural, ([1954a] 1985).

Kalecki, Michal. "The Problem of Financing Economic Development" in Essays on Developing Economics, The Harvester Press Limited, ([1954b] 1976).

Kalecki, Michal. "Unemployment in Underdeveloped Countries" in Essays on Developing Economics, The Harvester Press Limited, ([1960] 1976).

Kalecki, Michal. "The Difference between Perspective Planning in Socialist and Mixed Economies" in Essays on Developing Economics, The Harvester Press Limited, ([1963] 1976).

Kalecki, Michal. "Observations on Social and Economic Aspects of 'Intermediate Regimes"” in Essays on Developing Economics, The Harvester Press Limited, ([1967] 1976).

Kalecki, Michal. "The Difference between Crucial Problems of Developed and Underdeveloped Non-Socialist Economies" in Essays on Developing Economics, The Harvester Press Limited, ([1968] 1976).

Kalecki, Michal. "Problems of Financing Economic Development in a Mixed Economy" in Essays on Developing Economics, The Harvester Press Limited, ([1970] 1976).

Kalecki, Michal e Sachs, Ignacy. "Forms of Foreign Aid: an Economic Analysis" in Essays on Developing Economics, The Harvester Press Limited, ([1966] 1976).

Keynes, John Maynard. A teoria geral do emprego, do juro e da moeda, Coleção Os Economistas, São Paulo: Editora Nova Cultural, ([1936] 1985). 
Keynes, John Maynard. “A Teoria Geral do Emprego” em Szmrecsányi, Tamás (org.), John Maynard Keynes, Editora Ática, ([1937] 1984).

Kirman, Alan. "Complexity and Aggregation" in Rosser Jr., John Barkley (ed.), Handbook of Research on Complexity, Cheltenham: Edward Elgar, 2009.

Kuhn, Thomas. A estrutura das revoluções científicas, São Paulo: Perspectiva, 1972.

Lago, Luiz Aranha Corrêa do. "A retomada do crescimento e as distorções do 'Milagre': 1967-1973”, em Abreu, Marcelo de Paiva (org.), A ordem do progresso - cem anos de política econômica republicana, 1889-1989. Rio de Janeiro: Campus, 1990.

Lessa, Carlos. Estratégia de desenvolvimento 1974-1976: sonho e fracasso. Tese de Professor Titular, UFRJ, 1978.

Lessa, Carlos. Quinze anos de política econômica. $3^{\mathrm{a}}$ ed., São Paulo: Brasiliense, 1982.

Lessa, Carlos e Fiori, José Luis. "E houve uma política econômica nacional-populista?”. Textos para Discussão. IE-UFRJ, nº 251, janeiro de 1991.

Lewis, Arthur. "O desenvolvimento econômico com oferta ilimitada de mão-de-obra" em Agarwala, A. N. e Singh, S. P. (eds.), A Economia do Subdesenvolvimento, Rio de Janeiro: Cia Editora Forense, ([1954] 1969).

Lewis, Arthur. A Teoria do Desenvolvimento Econômico, Rio de Janeiro: Zahar Editores, ([1955] 1960).

Lewis, Arthur. "Development Economics in the 1950s" in Meier, Gerald e Seers, Dudley (eds.). Pioneers in Development, publicado pelo Banco Mundial, Oxford University Press, 1984.

List, Friedrich. The National System of Political Economy, Philadelphia: J. B. Lippincott, 1856.

Macarini, José Pedro. “A política econômica do governo Costa e Silva, 1967-1969”. Revista de Economia Contemporânea, vol. 10 (3), p. 453-489, setembro/dezembro, 2006.

Malloy, James. "Social Security Policy and the Working Class in Twentieth-Century Brazil". Journal of Interamerican Studies and World Affairs, v. 19, p. 35-60, feb/1977.

Marx, Karl e Engels, Friedrich. O Manifesto Comunista, São Paulo: Editora Paz e Terra, ([1848] 2001).

Meier, Gerald. "Preface" em Meier, Gerald e Seers, Dudley (eds.), Pioneers in Development, publicado pelo Banco Mundial, Oxford University Press, 1984.

Myrdal, Gunnar. "International Inequality and Foreign Aid in Retrospect" em Meier, Gerald e Seers, Dudley (eds.), Pioneers in Development, publicado pelo Banco Mundial, Oxford University Press, 1984.

Myrdal, Gunnar. Teoria Econômica e Regiões Subdesenvolvidas, Rio de Janeiro: Editora 
Saga, 2a ed., ([1957] 1968).

Nelson, Richard. "Economic Development from the Perspective of Evolutionary Economic Theory", Oxford Development Studies, vol. 36 (1), p. 9-21, 2008.

Novais, Fernando Antônio. Estrutura e dinâmica do antigo sistema colonial (séculos XVIXVIII). $5^{\text {a }}$ ed. São Paulo: Brasiliense, 1990.

Nurkse, Ragnar. "Alguns Aspectos Internacionais do Desenvolvimento Econômico" em Agarwala, A. N. e Singh, S. P. (eds.) A Economia do Subdesenvolvimento, Rio de Janeiro: Cia Editora Forense, ([1952] 1969).

Nurkse, Ragnar. Problemas da Formação de Capital em Países Subdesenvolvidos, Rio de Janeiro: Editora Civilização Brasileira, ([1953] 1957).

Oliveira, Francisco de. "Formação Econômica do Brasil: gênese, importância e influências teóricas" em Oliveira, Francisco de (org.), A navegação venturosa - ensaios sobre Celso Furtado, São Paulo: Editora Boitempo, 2003.

Orenstein, Luiz e Sochaczewski, Antonio Claudio. "Democracia com desenvolvimento: 19561961", em Abreu, Marcelo de Paiva (org.), A ordem do progresso - cem anos de política econômica republicana, 1889-1989. Rio de Janeiro: Campus, 1990.

Patnaik, Prabhat. "Why 'Development Economics'?" in Jomo, Kwame Sundaram (ed.), The Pioneers of Development Economics - Great Economists on Development, New Delhi: Tulika Books, 2005.

Pinho Neto, Demósthenes Madureira de. "O interregno Café Filho: 1954-1955”, em Abreu, Marcelo de Paiva (org.), A ordem do progresso - cem anos de política econômica republicana, 1889-1989. Rio de Janeiro: Campus, 1990.

Possas, Mario Luiz. A Dinâmica da Economia Capitalista: uma abordagem teórica. São Paulo: Brasiliense, 1987.

Possas, Mario Luiz e Baltar, Paulo. "Demanda efetiva e dinâmica em Kalecki", Pesquisa e Planejamento Econômico, vol. 11(1), abril, 1981.

Possas, Mario Luiz; Dweck, Esther; e Reif, Ana Cristina. "Um Modelo Macrodinâmico Multissetorial”. IE/UFRJ, Textos para Discussão, 2004.

Prado, Eleutério Fernando da Silva. "Microeconomia reducionista e microeconomia sistêmica”, Revista Nova Economia, 16 (2), p. 302-322, maio-agosto de 2006.

Prado, Eleutério Fernando da Silva. Economia, Complexidade e Dialética. São Paulo: Editora Plêiade, 2009.

Prado Júnior, Caio. Formação do Brasil Contemporâneo, São Paulo: Brasiliense, ([1942] 2000).

Prebisch, Raúl. "O desenvolvimento econômico latino-americano e alguns de seus principais problemas" em Bielschowsky, Ricardo (org.), Cinqüenta anos de pensamento da CEPAL, Rio de Janeiro: Record, vol. 1, ([1949] 2000). 
Prebisch, Raúl. "Problemas teóricos e práticos do crescimento econômico" em Bielschowsky, Ricardo (org.), Cinqüenta anos de pensamento da CEPAL, Rio de Janeiro: Record, vol. 1, ([1952] 2000).

Prebisch, Raúl. "Por uma dinâmica do desenvolvimento latino-americano" em Bielschowsky, Ricardo (org.), Cinqüenta anos de pensamento da CEPAL, Rio de Janeiro: Record, vol. 1, ([1963] 2000).

Prebisch, Raúl. "Por uma nova política comercial em prol do desenvolvimento" em Bielschowsky, Ricardo (org.), Cinqüenta anos de pensamento da CEPAL, Rio de Janeiro: Record, vol. 1, ([1964] 2000).

Prebisch, Raúl. "Five Stages in my Thinking on Development" em Meier, Gerald e Seers, Dudley (eds.), Pioneers in Development, publicado pelo Banco Mundial, Oxford University Press, 1984.

Reis, Cristina Fróes de Borja e Cardoso, Fernanda Graziella. “A crucialidade dos condicionantes internos: o desenvolvimento comparado das colônias temperadas inglesas entre 1850 e 1930", Revista Estudos Econômicos, v. 39 (2), p. 329-357, 2009a.

Reis, Cristina Fróes de Borja e Cardoso, Fernanda Graziella. "Outra vez a crucialidade dos condicionantes internos: o contraste das trajetórias de desenvolvimento econômico de Brasil, Argentina e Canadá entre 1850 e 1930”, Revista EconomiA, v. 10 (3), p. 635-664, 2009b.

Reis, Cristina Fróes de Borja e Cardoso, Fernanda Graziella. “A incompatibilidade entre o mito da globalização e o desenvolvimento dos países periféricos diante do sistema de poder mundial", Revista de Economia Contemporânea, vol. 14 (3), p. 551-574, 2010.

Resende, André Lara. "Estabilização e Reforma: 1964-1967” em Abreu, Marcelo de Paiva (org.), A ordem do progresso - cem anos de política econômica republicana, 1889-1989. Rio de Janeiro: Campus, 1990.

Ricupero, Bernardo. Caio Prado Jr e a nacionalização do marxismo no Brasil. São Paulo: Departamento de Ciência Política da Universidade de São Paulo; FAPESP; Editora 34, 2000.

Rihani, Samir. "Implications of adopting a complexity framework for development", Progress in Development Studies, vol. 2, n² 2, p. 133-143, 2002.

Rihani, Samir e Geyer, Robert. "Complexity: an appropriate framework for development?", Progress in Development Studies, vol. 1, n 3, p. 237-245, 2001.

Robinson, Joan. "Introduction" in Essays on Developing Economics, The Harvester Press Limited, ([1974] 1976).

Rosenstein-Rodan, Paul. "Problemas de Industrialização da Europa Oriental e Sul-Oriental" em Agarwala, A. N. e Singh, S. P. (eds.), A Economia do Subdesenvolvimento, Rio de Janeiro: Cia Editora Forense, ([1943] 1969).

Rosenstein-Rodan, Paul. "The International Development of Economically Backward Areas", International Affairs (Royal Institute of International Affairs), vol. 20, nº 2, p. 157-165, 1944.

Rosenstein-Rodan, Paul. "Natura Facit Saltum: Analysis of the Disequilibrium" in Meier, 
Gerald e Seers, Dudley (eds.), Pioneers in Development, publicado pelo Banco Mundial, Oxford University Press, 1984.

Rosser Jr., John Barkley. "Introduction" in Rosser Jr., John Barkley (ed.), Handbook of Research on Complexity, Cheltenham: Edward Elgar, 2009.

Schumpeter, Joseph. A Teoria do Desenvolvimento Econômico, Coleção Os Economistas, São Paulo: Abril Cultural, ([1912] 1985).

Schumpeter, Joseph. Capitalismo, Socialismo e Democracia, Rio de Janeiro: Editora Fundo de Cultura, ([1943] 1961).

Schwartz, Stuart. Escravos, roceiros e rebeldes. Bauru, SP: EDUSC, 2001.

Schwartz, Stuart. Segredos Internos: engenhos e escravos na sociedade colonial. São Paulo: Cia das Letras, ([1988] 2005).

Silva, Eduardo e Reis, João José. Negociação e conflito: a resistência negra no Brasil escravista. São Paulo: Cia das Letras, 1989.

Simon, Herbert. "A behavioral model of rational choice" in The Quarterly Journal of Economics, vol. 69, nº 1, p. 99-118, 1955.

Simon, Herbert. "From substantive to procedural rationality" in Philosophy and Economic Theory, Hahn, F. e Hollis, M. (eds.), New York: Oxford University Press, 1979.

Singer, Hans Wolfgang. "The Distribution of Gains between Investing and Borrowing Countries", The American Economic Review, vol. 40, n 2, p. 473-485, 1950.

Singer, Hans Wolfgang. "O mecanismo do desenvolvimento econômico" em Agarwala, A. N. e Singh, S. P. (eds.), A Economia do Subdesenvolvimento, Rio de Janeiro: Cia Editora Forense, ([1952] 1969).

Singer, Hans Wolfgang. "The Terms of Trade Controversy and the Evolution of Soft Financing: Early Years in the U. N." in Meier, Gerald e Seers, Dudley (eds.), Pioneers in Development, publicado pelo Banco Mundial, Oxford University Press, 1984.

Singer, Hans Wolfgang. "The Relevance of Keynes for Developing Countries" in Wattel, H. (ed.), The Policy Consequences of JMK, 1985.

Tavares, Maria da Conceição. "Auge e declínio do processo de substituição de importações no Brasil" em Tavares, Maria da Conceição, Da substituição de importações ao capitalismo financeiro. Rio de Janeiro: Zahar, 1972.

Tavares, Maria da Conceição. "Uma releitura das reformas" em Furtado, Rosa Freire D’Aguiar (org.). O Plano Trienal e o Ministério do Planejamento. Arquivos Celso Furtado 4. Rio de Janeiro: Editora Contraponto; Centro Internacional Celso Furtado de Políticas para o Desenvolvimento, 2011.

Teitel, Simon e Thoumi, Francisco. "From import substitution to exports: the manufacturing exports experience of Argentina and Brazil", Economic Development and Cultural Change, vol. 34 (3), p. 455-490, April/1986. 
Thorp, Rosemary. Progress, poverty and exclusion. An economic history of Latin America in the 20th century. New York: IDB, 1998.

Veblen, Thorstein. A teoria da classe ociosa, Coleção Os Economistas, São Paulo: Abril Cultural, ([1899] 1983).

Vianna, Sérgio Besserman. "Política econômica externa e industrialização: 1946-1951", em Abreu, Marcelo de Paiva (org.), A ordem do progresso - cem anos de política econômica republicana, 1889-1989. Rio de Janeiro: Campus, 1990a.

Vianna, Sérgio Besserman. "Duas tentativas de estabilização: 1951-1954”, em Abreu, Marcelo de Paiva (org.), A ordem do progresso - cem anos de política econômica republicana, 1889-1989. Rio de Janeiro: Campus, 1990b.

Villela, André. "Dos 'anos dourados' de JK à crise não resolvida", em Giambiagi, Fabio; Villela, André; Castro, Lavínia Barros de; e Hermann, Jennifer (orgs.). Economia brasileira contemporânea. Rio de Janeiro: Campus, 2005.

Wallerstein, Immanuel. The Modern World System, Nova York: Academic Press, 1974.

Weffort, Francisco. O populismo na política brasileira. Rio de Janeiro: Paz e Terra, 1979.

Wells, John e Sampaio, J. "Endividamento externo, etc. - uma nota para discussão". Estudos CEBRAP, (6), p. 36-55, outubro-dezembro 1973. 